\title{
Student migrant, refugee or both?
}

Citation for published version (APA):

Bonfiglio, A. E. (2020). Student migrant, refugee or both? Exploring refugee agency and mobility through tertiary education in Kenya, South Africa and Uganda. [Doctoral Thesis, Maastricht University].

ProefschriftMaken Maastricht. https://doi.org/10.26481/dis.20200220ab

Document status and date:

Published: 01/01/2020

DOI:

10.26481/dis.20200220ab

Document Version:

Publisher's PDF, also known as Version of record

\section{Please check the document version of this publication:}

- A submitted manuscript is the version of the article upon submission and before peer-review. There can be important differences between the submitted version and the official published version of record.

People interested in the research are advised to contact the author for the final version of the publication, or visit the DOI to the publisher's website.

- The final author version and the galley proof are versions of the publication after peer review.

- The final published version features the final layout of the paper including the volume, issue and page numbers.

Link to publication

\footnotetext{
General rights rights.

- You may freely distribute the URL identifying the publication in the public portal. please follow below link for the End User Agreement:

www.umlib.nl/taverne-license

Take down policy

If you believe that this document breaches copyright please contact us at:

repository@maastrichtuniversity.nl

providing details and we will investigate your claim.
}

Copyright and moral rights for the publications made accessible in the public portal are retained by the authors and/or other copyright owners and it is a condition of accessing publications that users recognise and abide by the legal requirements associated with these

- Users may download and print one copy of any publication from the public portal for the purpose of private study or research.

- You may not further distribute the material or use it for any profit-making activity or commercial gain

If the publication is distributed under the terms of Article $25 \mathrm{fa}$ of the Dutch Copyright Act, indicated by the "Taverne" license above, 

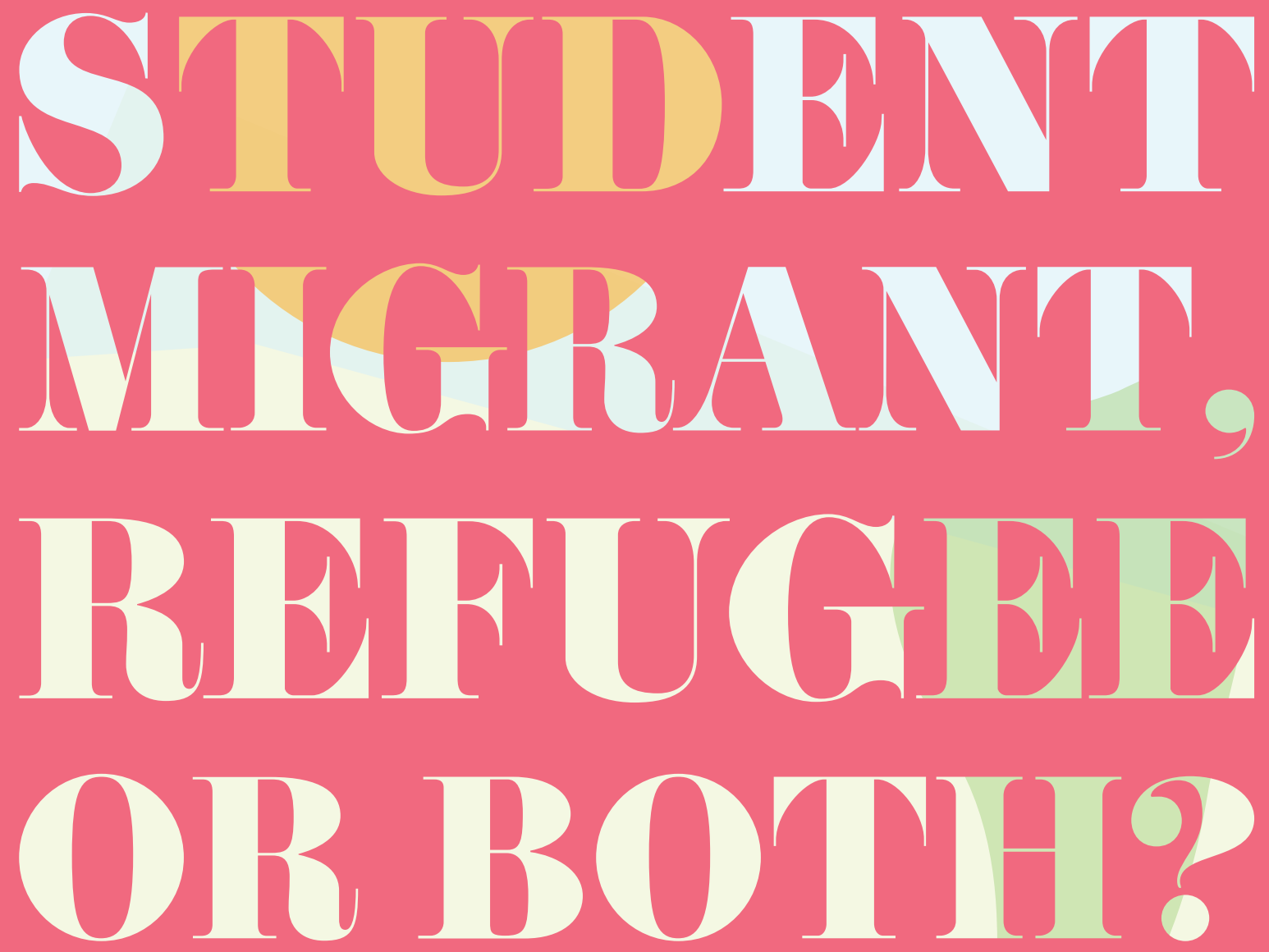

Exploring Refugee Agency and Mobility through Tertiary Education in Kemya, South Africa and Uganda

\section{Ayla E. Bonfiglio}





\section{STUDENT MIGRANT, REFUGEE OR BOTH?}

Exploring Refugee Agency and Mobility through Tertiary Education in Kenya, South Africa and Uganda 
() copyright Ayla E. Bonfiglio, Maastricht 2020

Printing: ProefschriftMaken II www.proefschriftmaken.nl

Cover Design and Maps: The Very Little Agency II www.theverylittleagency.com

ISBN 978-94-6380-701-2

All rights reserved. No part of this publication may be reproduced, stored in a retrieval system or transmitted, in any form or by any means, electronic, mechanical, photocopying, recording or otherwise, without prior permission of the author or the copyright-owning journals for previous published chapters. 


\title{
STUDENT MIGRANT, REFUGEE OR BOTH? \\ Exploring Refugee Agency and Mobility through Tertiary Education in Kenya, South Africa and Uganda
}

\author{
DISSERTATION \\ to obtain the degree of Doctor at Maastricht University, \\ on the authority of the Rector Magnificus Prof. Dr. Rianne M. Letschert, \\ in accordance with the decision of the Board of Deans, \\ to be defended in public on Thursday, February 20, 2020, at 12:00 hours
}

by

AYLA E. BONFIGLIO 
SUPERVISOR

Prof. Dr. Ronald Skeldon

CO-SUPERVISOR

Prof. Dr. Roger Zetter, University of Oxford

ASSESSMENT COMMITTEE

Prof. Dr. Jozef Ritzen (Chair)

Prof. Dr. Elena Fiddian-Qasmiyeh, University College London

Prof. Dr. Loren B. Landau, University of Witwatersrand

Prof. Dr. Hildegard Schneider 


\section{Acknowledgements}

This research would not have been possible without the time, assistance, and patience of members of the Congolese and Somali refugee and migrant communities living in Cape Town, Johannesburg, Kampala, Nairobi, and Kakuma Refugee Settlement. Special mention must be made to the Somali Students Association of South Africa, the Somali community in Mayfair, Johannesburg; the Congolese Students Society of South Africa; and the entire team at the Young African Refugees for Integral Development in Uganda (YARID), particularly Robert Hakiza and Elvis Wanume. Special thanks to my supervisors Prof. Ronald Skeldon and Prof. Roger Zetter for their guidance and trust from the very moment I sent them my initial research ideas.

In collecting and transcribing the interviews for this study, I benefited from the help of several outstanding research assistants, including Ekky Cecil, Fortune Kahigwa, Michael Stewart-Evans, Caroline Bullen, Madeline Leibin, Olivia Seifert, Charlotte Mueller, Jonathan Anketell, Mwansa Phiri, Zachary Strain, and Karissa Atienza.

I would like to express my gratitude to all of the institutions that hosted me while I was carrying out data collection: Makerere University in Kampala; the African Migration and Development Policy Centre in Nairobi; the African Centre for Migration and Society at the University of the Witwatersrand in Johannesburg; and the University of the Western Cape in Cape Town. Thank you in particular to Prof. Charlotte Mafumbo who provided invaluable orientation and support, the late Prof. John Oucho and Dr. Linda Oucho, Prof. Loren Landau, and Prof. Gabriel Tati.

Thank you to the members of my Assessment Committee for their time and feedback: Prof. Jozef Ritzen, Prof. Elena Fiddian-Qasmiyeh, Prof. Loren Landau, and Prof. Hildegard Schneider. At UNU-MERIT, several individuals deserve special mention for their guidance and wisdom, including Ms. Eveline in de Braek, Prof. Lonneke Nillesen, Prof. Jozef Ritzen, and Prof. Melissa Siegel. It was a pleasure to be your colleague. Thank you also to Susan Roggen and Marc Vleugels who managed the grants for this research. Outside of UNU-MERIT, thank you dear friends Nicolás Domínguez, Katherine Kominis, and Mea Verhoef. This research would also not have been possible without generous support from the Porticus Foundation, whose commitment to refugee higher education is making a difference, and the Limburg University Fund/SWOL.

Lastly, and most importantly, I would like to acknowledge the unconditional support of my family. This endeavor would not have been possible without you. To Aurora-Zehra Rizvi, Clara-Zehra Rizvi, and Atif Rizvi and to my parents Patricia and Nicholas Bonfiglio. 


\section{Table of Contents}

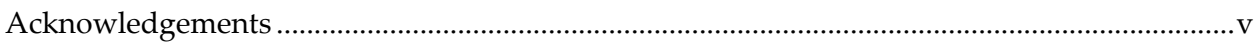

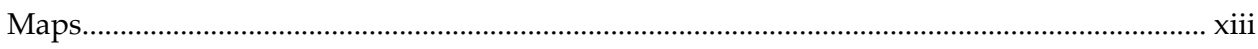

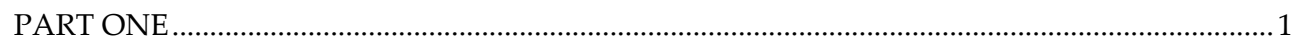

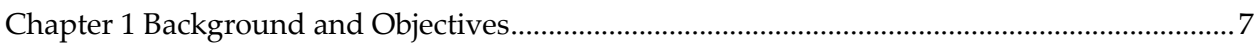

1.1 Shifting International Attention towards Refugee Tertiary Education? ............................... 8

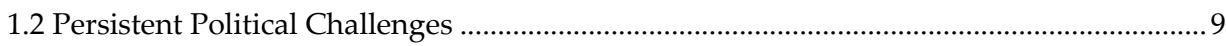

1.3 The Importance of Tertiary Education for Refugee Development...................................... 10

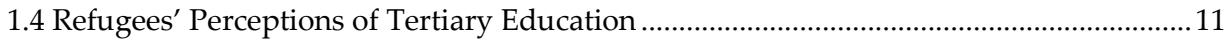

1.5 The Unmet Demand for Tertiary Education ......................................................................... 13

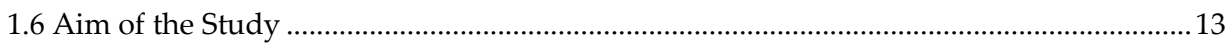

1.7 Implications for Complementary Protection and Refugee Mobility ...................................15

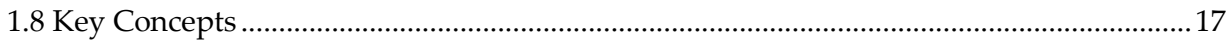

Chapter 2 Literature Review and Conceptual Framework ......................................................... 23

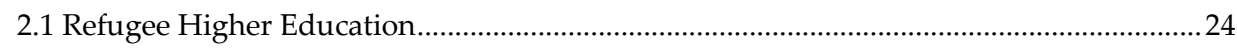

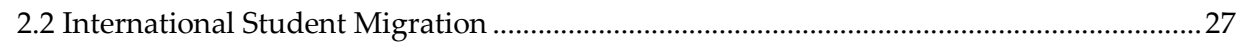

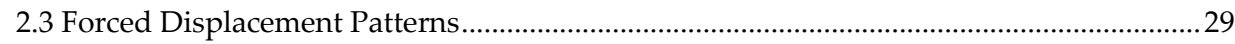

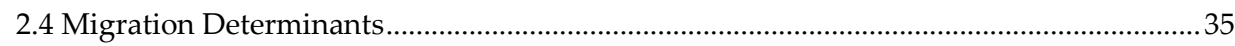

2.5 Conceptual Framework on Agency and Mobility within Forced Displacement...............39

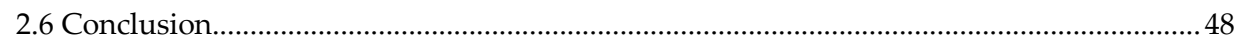

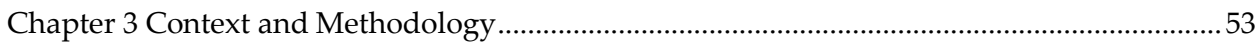

3.1 Site Selection: Kenya, South Africa and Uganda .................................................................. 54

3.2 Gaining Access to Refugee and Migrant Communities and Institutions.............................58

3.3 Data: Quantitative Data on Migration and Forced Displacement Stocks ...........................61

3.4 Data: Narratives of Refugees and Migrants Pursuing Higher Education .......................... 64

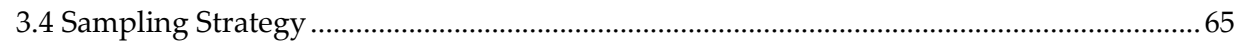

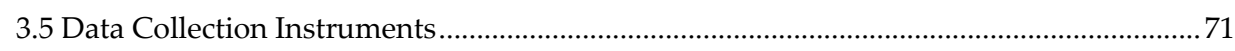

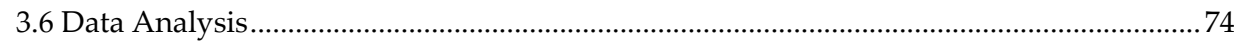




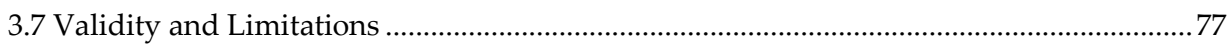

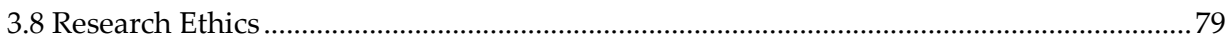

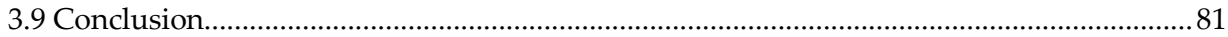

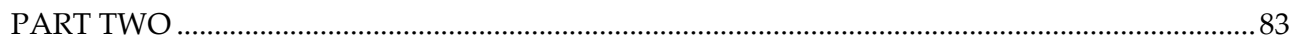

Chapter 4 Framing Movement: Drivers of Forced Displacement and Migration........................ 87

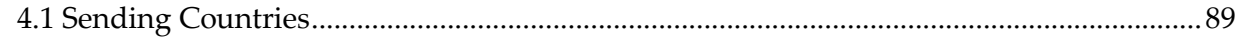

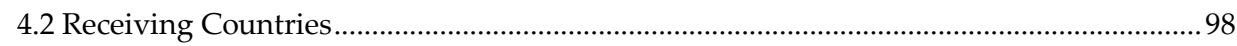

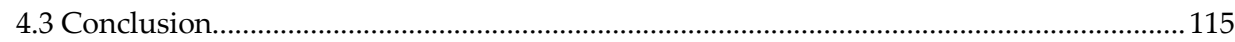

Chapter 5 Framing Movement: Patterns of Forced Displacement and Migration ................... 119

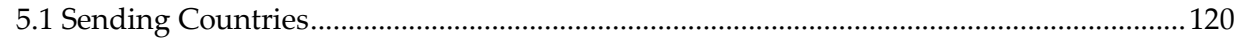

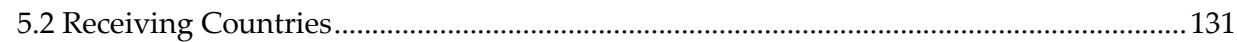

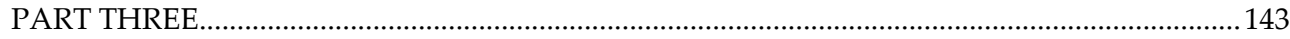

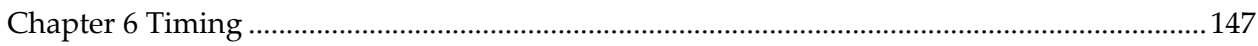

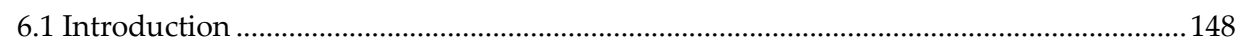

6.2 Defining the Timing of Displacement or Exit ................................................................. 148

6.3 Findings: Key Timing Patterns Related to Higher Education ............................................ 149

6.4 Putting Findings into Context: Non-Exhibitors and Never Enrolled ................................. 169

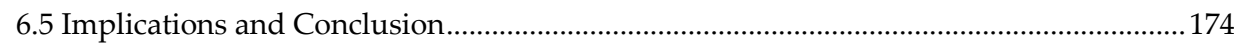

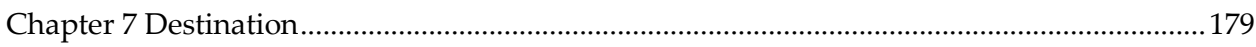

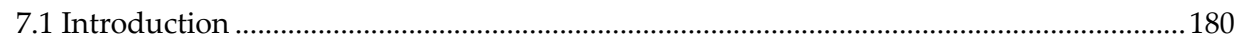

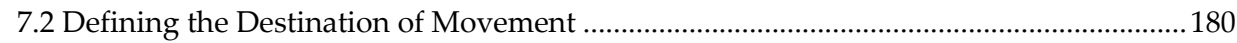

7.3 Findings: Key Destination Patterns Related to Higher Education..................................... 181

7.4 Putting Findings into Context: Non-Exhibitors and Never Enrolled ................................. 201

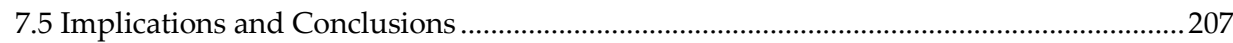

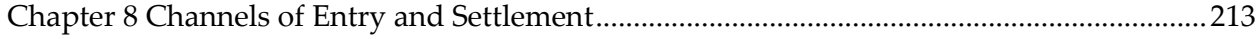

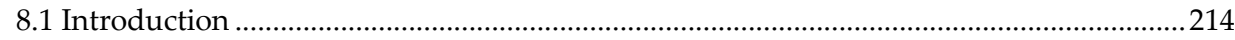

8.2 Defining the Channels of Entry and Settlement .................................................................2. 214

8.3 Findings: Key Channel Patterns Related to Higher Education ..........................................2. 215

8.4 Putting Findings into Context: Non-Exhibitors and Never Enrolled ................................ 232 


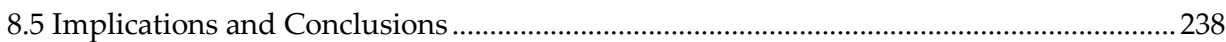

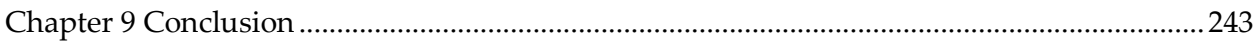

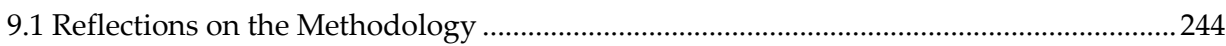

9.2 Synthesis of Key Findings on Timing, Destination and Channel .....................................2. 249

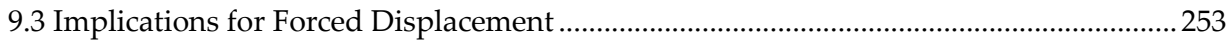

9.4 Implications for Complementary Protection Pathways through Higher Education ..... 255

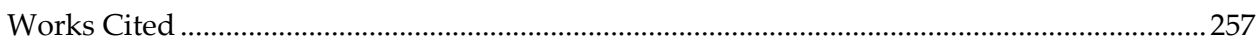

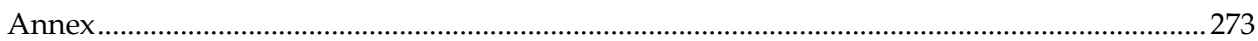

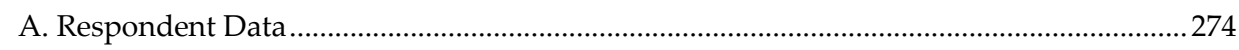

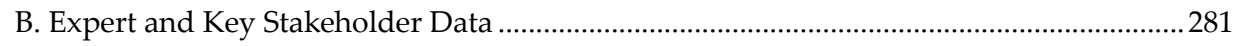

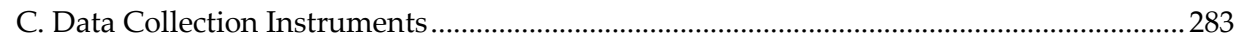

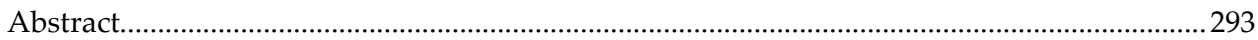

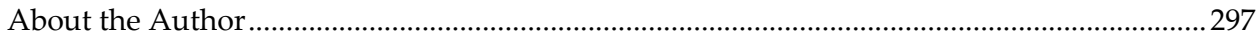




\section{Tables of Figures}

Figure 1: Map of the Democratic Republic of Congo.................................................................... xiii

Figure 2: Map of Somalia ...........................................................................................................

Figure 3: Map of Sub-Saharan Africa .............................................................................................

Figure 4: Refugees and Migrants in Kenya, South Africa and Uganda in 2015 ..............................54

Figure 5: Summary of Context in Kenya, South Africa and Uganda .............................................58

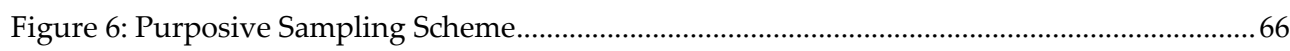

Figure 7: Congolese and Somali Migrants and Refugees in each Research Country in 2015 .......67

Figure 8: Projected Purposive Sampling Scheme per Destination Country .....................................68

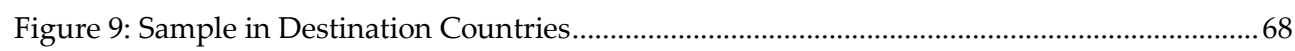

Figure 10: Sample Breakdown by Origin Country ........................................................................6

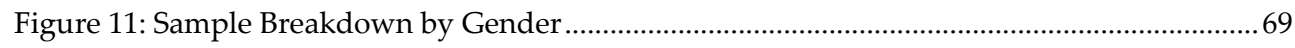

Figure 12: Sample Breakdown by Tertiary Education Level ..........................................................70

Figure 13: Sample Breakdown by Relationship to Tertiary Education ............................................ 70

Figure 14: Expert Interviews per Destination Country ................................................................... 73

Figure 15: DRC GDP per capita PPP Compared to Regional Averages in 2015 .............................91

Figure 16: Human Development Levels of Sending and Receiving Countries in 2015 .................92

Figure 17: Life Expectancy at Birth in Sending and Receiving Countries in 2015 .........................92

Figure 18: Uganda GDP per capita PPP Compared to Regional Averages in 2015......................101

Figure 19: Kenya Life Expectancy at Birth Relative to Regional Averages in 2015 ......................107

Figure 20: South Africa GDP per capita PPP Compared to Regional Averages in 2015..............112

Figure 21: Summary of Development and Human Security Indicators.......................................115

Figure 22: Congolese and Somali Emigrant and Refugee Populations in 2015.............................121

Figure 23: Congolese Migrants and Refugees by Regional Destination ....................................... 122

Figure 24: Congolese Refugees and Asylum Seekers by Regional Destination ............................122

Figure 25: Congolese Migrants and Refugees by African Regional Destination ...........................123

Figure 26: Congolese Refugees and Asylum Seekers by African Regional Destination...............123

Figure 27: Top African Destinations for Congolese Migrants and Refugees ................................. 125

Figure 28: Top African Destinations for Congolese Refugees and Asylum Seekers .....................125

Figure 29: Somali Migrants and Refugees by Regional Destination............................................127

Figure 30: Somali Refugees and Asylum Seekers by Regional Destination .................................127

Figure 31: Somali Migrants and Refugees by African Regional Destination ................................ 128

Figure 32: Somali Refugees and Asylum Seekers by African Regional Destination .....................129

Figure 33: Top African Destinations plus Uganda for Somali Migrants and Refugees ................130

Figure 34: Top African Destinations for Somali Refugees and Asylum Seekers ..........................130

Figure 35: Refugees and Migrants in Kenya, South Africa and Uganda in 2015 ..........................132 
Figure 36: Top Migrant and Refugee Populations in Uganda plus Somalia 133

Figure 37: Top Refugee and Asylum Seeker Populations in Uganda .133

Figure 38: Top Migrant and Refugee Populations in Kenya plus the DRC 135

Figure 39: Top Refugee and Asylum Seeker Populations in Kenya 135

Figure 40: Largest Planned/Managed Refugee Camps Worldwide in 2015. 136

Figure 41: Top Migrant and Refugee Populations in South Africa plus Somalia and DRC........138

Figure 42: Top Refugee and Asylum Seeker Populations in South Africa ..... 138

Figure 43: Top Student Migrant Populations in South Africa plus Somalia 140

Figure 44: Timing Patterns of Respondents who Never Enrolled in Higher Education 173

Figure 45: Destination Patterns of Respondents who Never Enrolled in Higher Education...... 205

Figure 46: Respondent Profiles: Entering Channels......................................................................219

Figure 47: Respondent Profiles: Avoiding Humanitarian Channels .............................................. 224

Figure 48: Entry and Exit Channels of Respondents who cited Switching Channels ...................228

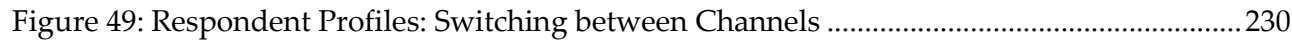

Figure 50: Entry and Exit Channels of Non-Exhibitor Respondents ............................................ 235

Figure 51: Channel Patterns of Respondents who Never Enrolled in Higher Education ............ 237 


\section{Maps}

Figure 1: Map of the Democratic Republic of Congo

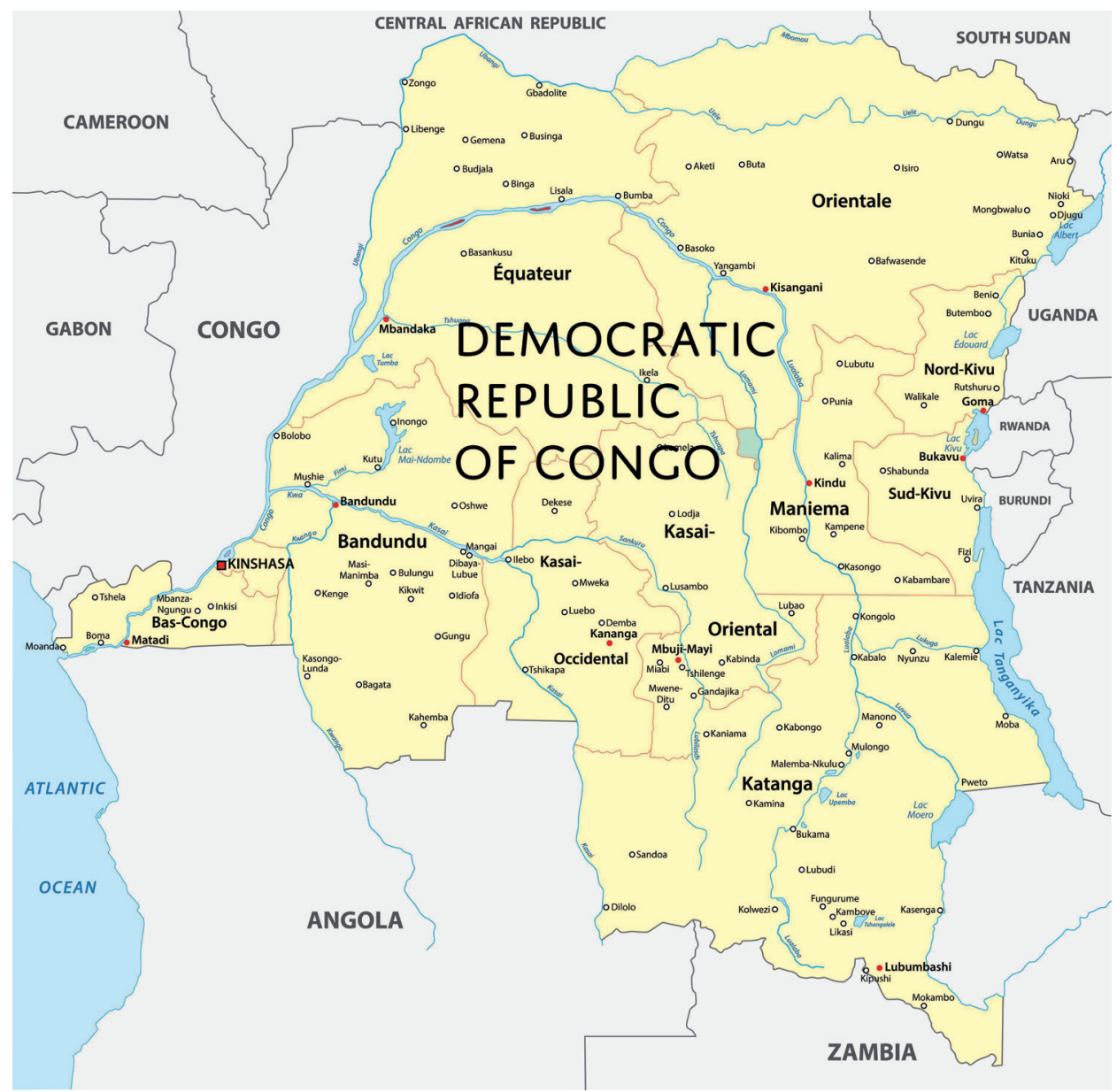


Figure 2: Map of Somalia

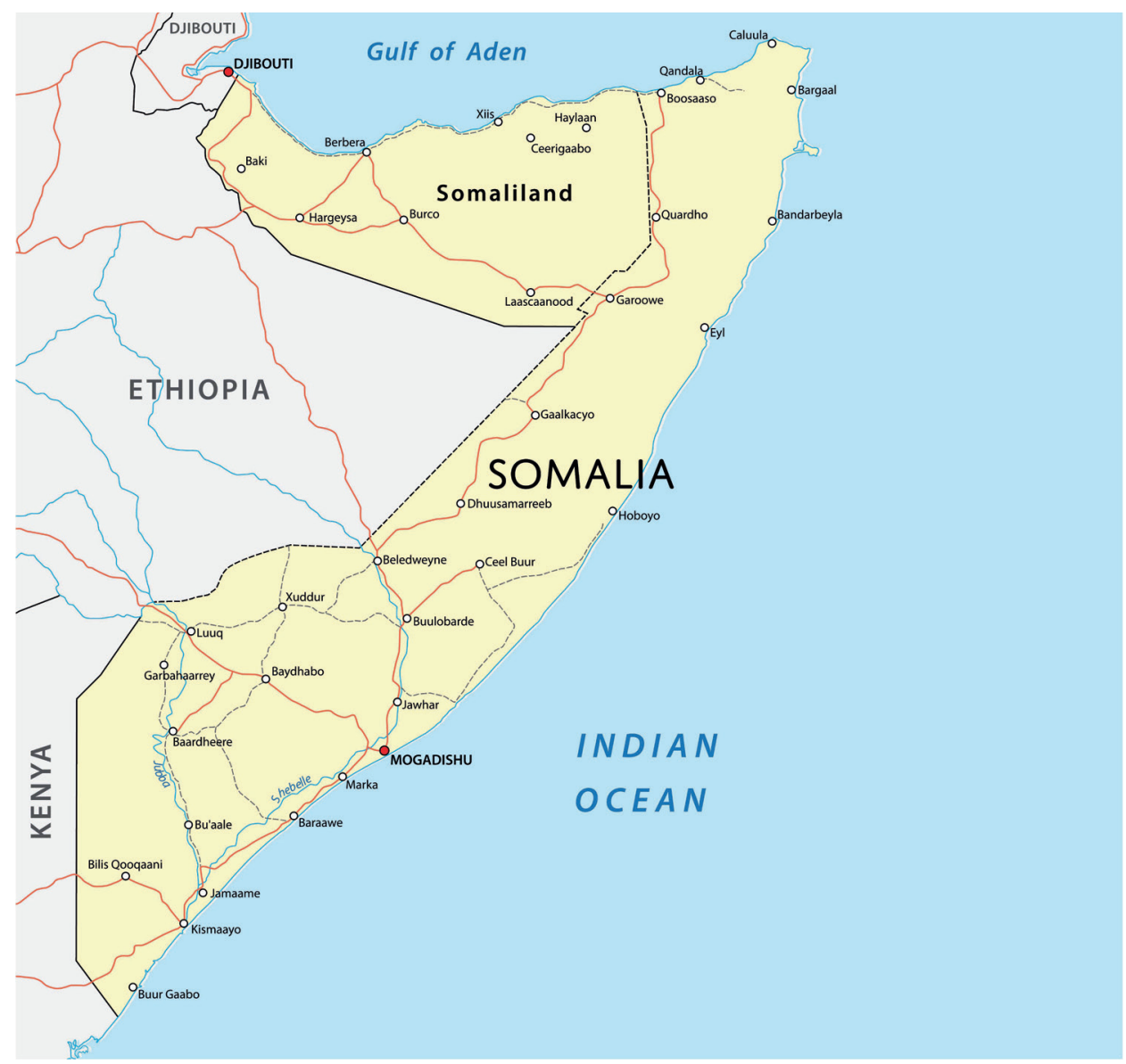


Figure 3: Map of Sub-Saharan Africa

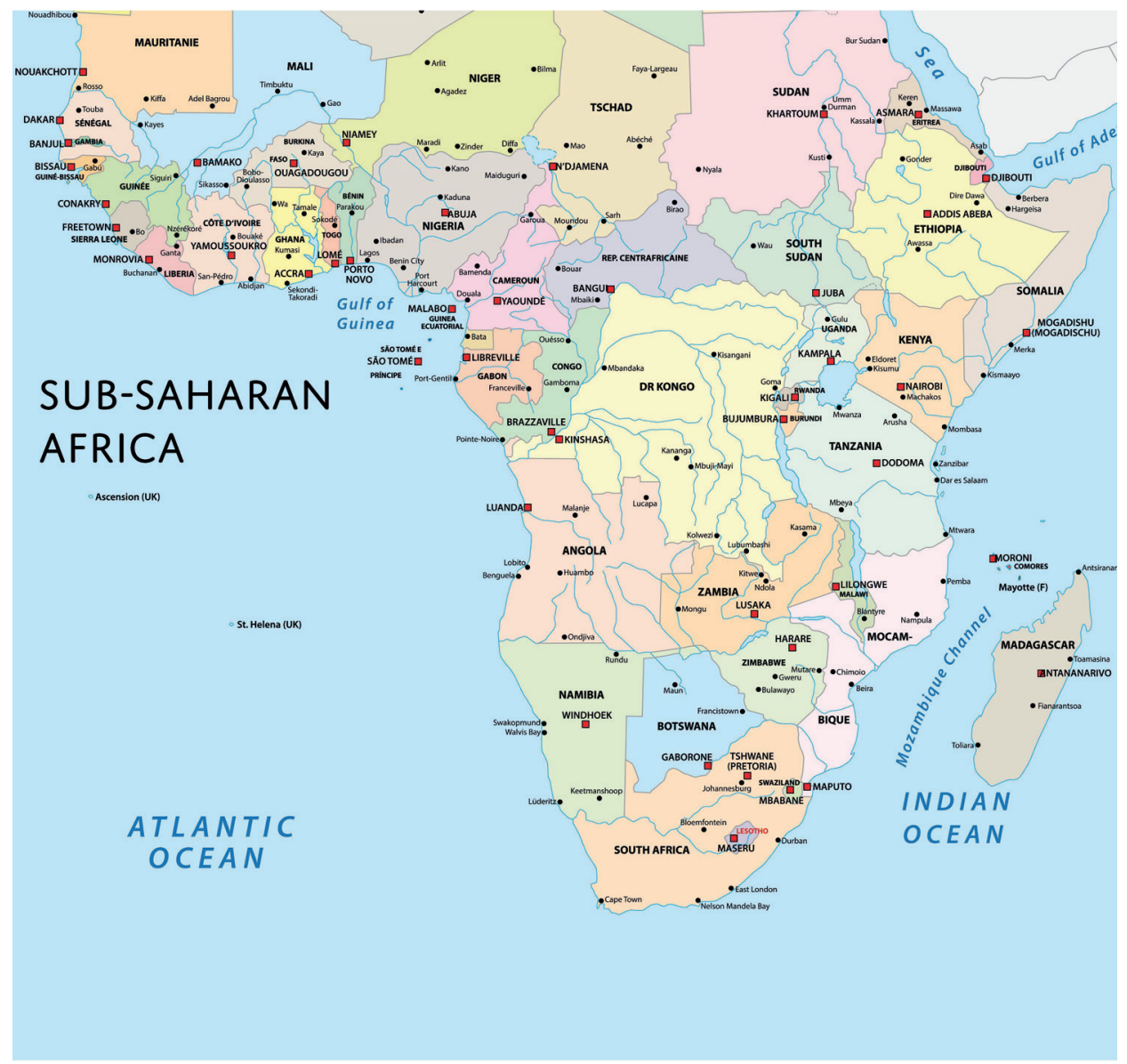





\section{PART ONE}


I began studying issues of forced displacement in January 2008 in Uganda. At the time, the country was host to refugees from the Democratic Republic of Congo (DRC), Rwanda, South Sudan, Sudan, Burundi, and Kenya, amongst others. Over the course of the year, I visited and carried out research at the Kyangwali and Oruchinga Refugee Settlements as well as in Kampala in urban refugee communities. Back then, I was examining refugee self-reliance. I wanted to learn why refugees living in Kampala had greater levels of selfreliance despite having waived their rights to aid or assistance. It was based on this research, involving approximately 100 interviews with refugees in all three locations, that I first learned of the importance of education, particularly higher education, for refugee development. My results revealed that higher education was not only the strongest indicator of self-reliance, but also the strongest indicator in determining self-settlement in Kampala. In other words, my respondents living in Kampala seemed more self-reliant because they were a more highly educated group and higher education appeared to be the most important factor in determining their ability to provide for their livelihoods. These individuals had chosen not to live in the settlements, which were located in marginalized rural communities, but to live in Kampala, where they could apply their skills and knowledge and participate in a more diverse labor market.

In light of these insights, I focused my studies and research on refugee education as well as displacement and mobility while at the Refugee Studies Centre and the International Migration Institute at the University of Oxford in the succeeding years. In 2013, I came to the United Nations University in Maastricht to pursue my doctoral studies with the intention to delve deeper into how higher education impacts refugees' forced displacement patterns. Rather than center my research on refugees who had gained higher education prior to their displacement, I aimed to study refugees who had pursued or were pursuing higher education in host countries, and to learn how this pursuit impacted where and how they sought asylum. For instance, if a person's higher education was interrupted, prevented, or was not an option in his or her home country because of conflict, crisis, or persecution, how might the prospect of higher education elsewhere play a role in that person's displacement decision-making?

Such a question may help us to understand the extent to which higher education may offer a complementary form of protection for refugees, outside the settlement and perhaps outside the humanitarian sphere. Higher education institutions in resettlement and asylum countries across the world are asking what role can and should they play in responding to today's forced displacement crises. Exploring and better understanding opportunities within higher education for complementary protection should be a priority. More generally, understanding how the pursuit of higher education by refugees impacts their forced displacement patterns invites us to re-examine the limited ways in which we think about forced displacement patterns and refugee mobility. 
The fieldwork for this study brought me back to Uganda as well as to Kenya and South Africa. Sub-Saharan Africa is one of the largest refugee hosting regions in the world. In 2015 it hosted 25.7 percent of the world's refugee population, behind Asia and the Pacific at 26.8 percent and ahead of both Europe and North Africa and the Middle East, which each hosted close to 21 percent (UNHCR 2014c). The share of the world's refugees in SubSaharan Africa has remained relatively stable until the present. Most African countries are subject to the same international and regional norms and many of the same refugee populations can be studied in multiple countries. Moreover, Sub-Saharan Africa has relatively porous borders, which means that the movements of migrants and refugees are not fully constrained by highly enforced visa regimes and legal migration channels that would structure and pre-determine their movements. Additionally, the data on international migration reveal that most cross-border movements take place within rather than between world regions. Bakewell (2009: 6-7) showed that in Africa, Asia, and Europe, the majority of migrants moved to countries within the same region. For all of these reasons, the continent is an apt place to study processes of forced displacement, to observe how different groups of people move based on their aspirations, norms, and capabilities, as well as structural factors like levels of development, geography, migration and refugee policies, and higher education policies.

Kenya, South Africa, and Uganda are among the top hosts for refugees and migrants in Africa, have some of the most developed higher education sectors, and have different refugee hosting policies. To provide some context on the migration and forced displacement patterns of these countries, at the time of this study's fieldwork in 2015, South Africa ranked first in Africa for hosting international migrants (more than 3.1 million) and second for hosting refugees and asylum seekers (more than 1.2 million). Kenya ranked fourth for hosting international migrants (just under 1.1 million) and third for hosting refugees and asylum seekers $(593,881)$. Despite being low on the human development scale, Uganda ranked eighth for hosting international migrants $(704,676)$ and fourth for hosting refugees and asylum seekers $(512,966) \cdot{ }^{1}$ Just two other countries ranked in the top ten for both categories, Ethiopia and the Democratic Republic of Congo.

Part One of this book is comprised of three chapters, which lay out the scope and design of this study. Chapter One outlines this study's central research question that relates to how the pursuit of tertiary education by refugees shapes their forced movements and explores its implications for research and policy. The chapter also sets out the political and practical context within which the study sits, the importance of higher education for

\footnotetext{
${ }^{1}$ These figures do not reflect the large numbers of refugees and asylum seekers from South Sudan (more than one million), who have since entered Uganda and caused the country to become the second largest host for refugees, after Turkey and tied with Pakistan, in the world (UNHCR 2018c).
} 
refugees, the high value that refugees place on higher education, as well as the high unmet demand that exists among refugees for such education.

Chapter Two brings together several disparate bodies of literature, including studies on refugee higher education, international student migration, forced displacement patterns, and migration determinants to examine how the movements of refugees pursuing higher education are conceptualized. Moreover, it sets forth this study's theoretical framework developed by Bakewell and Bonfiglio (2013) on agency and mobility. This framework enables this study to identify the various dimensions of refugee agency related to tertiary education which play a role in shaping refugees' forced displacement patterns.

Chapter Three sets out the context of this study in Kenya, South Africa, and Uganda as main destinations for refugees and migrants and hubs for higher education on the continent. This chapter also outlines this study's qualitative and interpretive methodology and use of refugee and migrant narratives of their forced displacement and higher education trajectories. These narratives were collected at various research sites in the selected destination countries. Strategies for data collection and analysis, validity and limitations, and ethical considerations are also outlined in the chapter.

Chapters Four and Five, comprising Part Two, seek to situate respondents' expressions of agency within time and space, by understanding the macro-level factors related to higher education, mobility, and asylum that structure and set the boundaries for refugee and migrant agency in Kenya, South Africa, and Uganda. Chapter Four examines key drivers of forced displacement and migration across the research sites, including factors related to human security and political stability, human and economic development, and education. Chapter Five explores key patterns of displacement and migration to situate respondents' movements within broader movement trends over space and time and to assess the extent to which the observed movements may be part of a larger migration system or systems.

Chapters Six, Seven, and Eight, comprising Part Three, is dedicated to the analysis of 149 interviews with Congolese and Somali migrants and refugees living in Kenya, South Africa, and Uganda. These chapters argue that respondents expressed their agency in relation to tertiary education to shape their movement patterns along three main dimensions: timing, destination, and channel of entry and settlement. "Timing" refers to when respondents initiated their movement. "Destination" refers to where they moved and whether respondents engaged in single vector or multiple vector movements. "Channel" refers to which legal or irregular status and associated procedures that they adopted when entering and settling in an asylum country, such as student migrant, refugee, or undocumented migrant. Each of these chapters identifies and examines different movement patterns related to tertiary education within a particular dimension, 
how respondents expressed their agency in negotiating each pattern, and the profiles of respondents expressing each pattern. Each chapter also considers the different ways respondents shaped each dimension where higher education appeared not to play a role and also examines the movement patterns of respondents who never enrolled in any form of higher education to understand the extent to which the observed patterns are unique to respondents pursuing higher education.

Chapter Nine concludes by exploring the implications of how respondents shape their movement patterns in relation to tertiary education for how we conceptualize forced displacement and international protection. 
CHAPTER 1

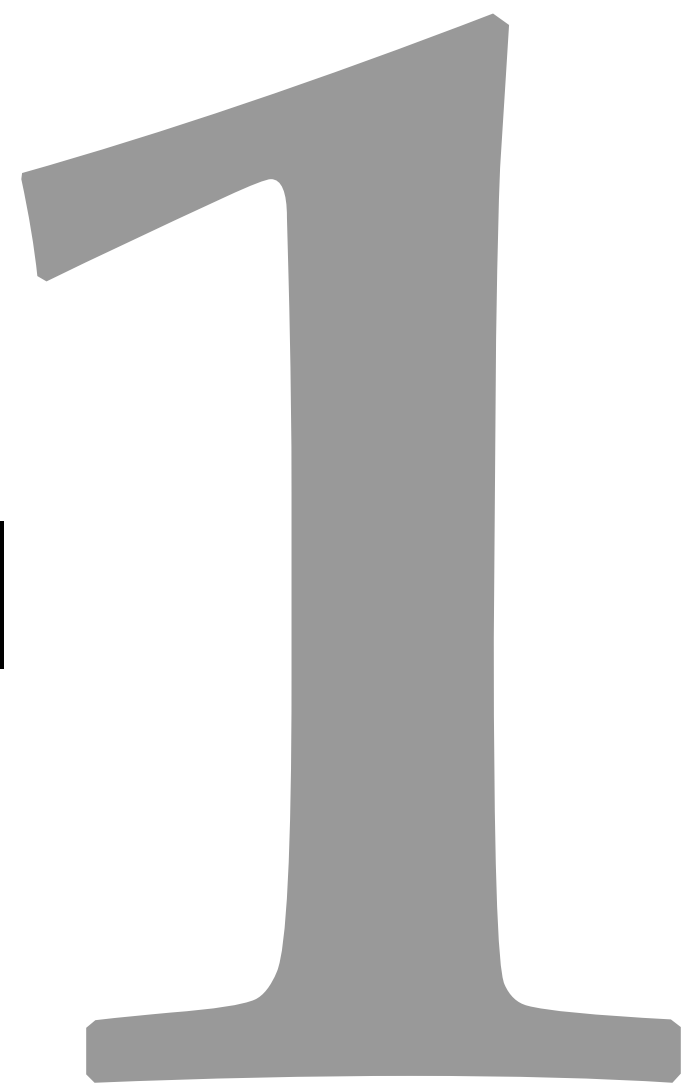




\section{Background and Objectives}


This study seeks to understand: How does refugees' pursuit of tertiary education impact their forced displacement patterns to asylum countries? In other words, how does the pursuit of tertiary education by refugees impact the when, where, and how of their forced displacements to asylum countries? This question has important implications for identifying and examining refugee mobility as well as understanding the potential of higher education to provide complementary protection pathways in asylum countries.

Before delving further into this study's overarching question and its implications, this chapter sets out the political and practical context within which the study sits, including the importance of higher education for refugees, the high value that refugees place on higher education, and the high unmet demand that exists among refugees for such education. Taken together, these issues provide insight into why higher education might feature in the forced displacement patterns of select refugees and why higher education is increasingly featured in discussions on refugee protection and development.

\subsection{Shifting International Attention towards Refugee Tertiary Education?}

More than 40 years after the adoption of the 1951 Convention Relating to the Status of Refugees, in the 1990s and early 2000s, and coinciding with the launches of Education for All and the Millennium Development Goals, education began to be considered a part of refugee development. In 2005, UNHCR published its Development Assistance for Refugees (DAR) Programmes handbook, which made a direct link between development assistance and education, but focused on primary and secondary education. In 2003, just 3 percent of all UNHCR education programs were at either the tertiary or vocational level (UNHCR 2003: 27). Nine years later, in its 2012-2016 Global Education Strategy, UNHCR pledged to make education a part of all emergency responses and to increase tertiary education enrollment (UNHCR 2012). This explicit reference to higher education within a strategic plan for refugee development may signal a shift in thinking.

On September 19 $9^{\text {th }}, 2016$, the United Nations General Assembly adopted the New York Declaration for Refugees and Migrants, which not only referenced education as a crucial part of refugee protection and development throughout its 90 paragraphs, but also highlighted the importance of tertiary education for refugees. It stated:

"In conflict and crisis situations, higher education serves as a powerful driver for change, shelters and protects a critical group of young men and women by maintaining their hopes for the future, fosters inclusion and nondiscrimination and acts as a catalyst for the recovery and rebuilding of postconflict countries" (NYDMR Nations 2016: para 82). 
Moreover, in 2017, nine institutions, including UNHCR, publicly launched the Connected Learning Consortium, which aims to promote higher education "in contexts of conflict, crisis and displacement" (Connected Learning Consortium 2017). While the international and institutional actions of the past six years suggest that international actors are recognizing the value of higher education, with primary and secondary education, to refugee development, future support for tertiary education remains uncertain. UNHCR's Strategic Directions 2017-2021 does not appear to reflect this shift or carry the same momentum. The strategy document references tertiary education once alongside other forms of education, and does so parenthetically (UNHCR 2017b: 23).

\subsection{Persistent Political Challenges}

Despite the apparent shifting of international attention towards refugee higher education and the New York Declaration's recognition of refugees pursuing higher education as a "critical group," as of 2010, education at all levels received less than 4 percent of humanitarian funding in conflict-affected countries. Moreover, education is among the first items to be cut from budgets when funding is constrained (Shakya et al. 2010: 66). Refugee education is largely financed by emergency funds, which means that any longerterm strategy for education receives little support. Aside from issues of budgets and time, UNHCR lacks sufficient education data, for it rarely tracks refugees' educational access and attainment, causing the educational needs and gaps of refugees to remain "invisible" (UNHCR 2016b: 5).

Furthermore, Zeus (2010: 261) argued that UNHCR perceives providing higher education as undesirable because tertiary educated refugees are better able to access information on resettlement opportunities and resettlement negates educated refugees' potential contributions to refugee communities in asylum countries. To avoid a so-called brain drain, she argued that the policy preference has been to rely on resettlement countries, rather than asylum countries, to provide higher education opportunities. It should be noted that Zeus (2010) was writing prior to the passing of the New York Declaration and, thus, one would expect this alleged policy preference to no longer apply.

Turning from the example of UNHCR, the policies of many host governments related to protection, shelter, and employment treat refugee situations as temporary phenomena (Bradley 2019). Focusing on the longer-term education needs at the tertiary level is often overlooked. This policy preference appears out of touch with the present realities of displacement, with the majority of the world's refugees being in protracted exile (more than five years) and with the average duration of exile being approximately 20 years (UNHCR 2015). Additionally, amongst donors, higher education has been and continues to be a low priority, "often perceived as a 'luxury' for an elite few, especially in refugee 
situations where access to primary and secondary education is far from universal" (Dryden-Peterson 2010: 4).

\subsection{The Importance of Tertiary Education for Refugee Development}

While the amount of aid that donors provide for refugee education may be a fixed sum, necessitating a trade-off, and while refugees' access to primary and secondary education is lacking, this does not mean that global support should be solely directed at filling the basic education deficit. In fact, such a narrow focus risks stunting the growth of basic education development, particularly in an era when the average years of protracted displacement supersede the years of primary and secondary education. Dryden-Peterson (2010) maintained that this is because education functions as a system, in which expanding opportunities for higher education also have a positive impact on the higher education pipeline. For instance, with fewer opportunities for higher education, some refugees might be deterred from completing secondary schooling.

Additionally, higher education attainment has positive externalities for a society, or what are referred to as civic or social returns. Moretti (2004) argued that, in the United States, an increase in the share of university graduates has a positive impact on the wages of not only higher skilled workers, but also lower skilled workers, and finds evidence of positive spillover effects. Additionally, higher education enables refugees to be active in the rebuilding of the social, political, and economic institutions of their origin countries, assuming they return. Hence, post-genocide, the Rwandan government targeted higher education as the primary mechanism of development, dedicating one-third of its education budget (Dryden-Peterson 2010: 11). Moreover, in Afghanistan, Morlang and Stolte (2008) found that higher education contributed to reconstruction and repatriation.

At the individual level higher education is important for refugees because it imparts employable skills and knowledge, increases their social capital, and expands their labor market and socio-economic integration opportunities in different host societies (Crea 2016; Taylor and Sidhu 2012; Wright and Plasterer 2010). For this reason, many households sponsor youth to obtain higher education abroad or in nearby urban centers, with the hope that they will obtain jobs and remit funds back to their families. Based on interviews with refugee students in South Africa, Lanzi Mazzocchini (2008) argued that many refugees learn skills they know are in high demand in the local labor market. Moreover, those unable to find work matching their qualifications are more employable with local degrees than their counterparts with foreign diplomas. In a similar vein, Dodds and Inquai (1983) maintained that higher education, more so than other education levels, promotes refugees' self-reliance and integration and inclusion into host societies and, in turn, reduces their potential "burden" on host communities. Indeed, this advantage 
forms part of UNHCR's current rationale to provide tertiary education scholarships for refugees through the Albert Einstein German Academic Refugee Initiative Fund (DAFI) (Zeus 2010: 258 citing UNHCR 2007: 2). UNHCR (2017a) positioned higher education as integral to refugee protection and durable solutions, which include repatriation, resettlement, and local integration and which mark the so-called end of refugeehood.

Higher education is also important for refugees and migrants for the same reasons as other levels of education, in that it imparts knowledge and fosters abilities that could mean the difference between surviving and thriving in a new society. According to Nussbaum (2001: 78) in her discussion of "central human capabilities," education is integral to the development of "senses, imagination, and thought," which allow a person to reason and make choices, express oneself, and seek positive experiences and avoid unnecessary negative ones. In this way, education can assist refugees and migrants coming from countries affected by conflict to overcome the physical and psychological obstacles specific to displacement. For instance, it promotes psycho-social wellbeing and cognitive development and may help refugees deal with trauma; aids refugees in regaining a sense of security, independence, and dignity; decreases their risk of being recruited by armed groups; and decreases the chances of young women and girls entering into early marriages or engaging in so-called "survival sex" (Bonfiglio 2010: 1 citing Sommers 2003 and UNHCR 2009).

\subsection{Refugees' Perceptions of Tertiary Education}

Perhaps just as important as acknowledging the real benefits of higher education for refugees, is understanding refugees' perceptions of higher education, for they ultimately play a role in shaping refugees' strategies and actions. The literatures on refugee education and education in emergency settings reveal that refugees and migrants coming from areas affected by conflict place a high value on higher education (Alzaroo and Hunt 2003; Donald 2014; Shakya et al. 2010). Sommers (2003) held that as soon as a conflict or emergency begins to subside and refugees secure their basic needs of food, water, and shelter, they will look for educational opportunities for their children and youth. Others have argued that education is sought alongside basic needs, while others still have argued that education should be considered a basic need (UNHCR 2016b). This is because "refugees recognize the importance of education to improve their livelihoods, particularly in the context of forced displacement" (Bonfiglio 2010: 3).

In her study on the schooling of Congolese refugees in Uganda, Clark-Kazak (2010: 57) found that all the respondents in her 400-person sample had aspirations for further study, irrespective of whether they had already completed tertiary-level studies or had not received any formal schooling. Her respondents reasoned that higher education was 
important to secure a better future, that not having higher education meant having a bad future, and that higher education would help them contribute to home country reconstruction (Clark-Kazak 2010: 60).

Overall, three predominant perceptions of higher education emerge from the refugee education literature and are of particular relevance to this study: refugees perceive higher education as key to rebuild their lives in host countries, to attain future goals, and to rebuild home countries and improve the lives of their countrymen and women. Indeed, in terms of providing for one's livelihood and the livelihood of one's family, one respondent from this study explained, "from university [you] will find a good job, so that you can take care of your family and yourself" (Congolese woman who completed college, Nairobi 2015). Expressing a similar sentiment and associating higher education with "being somebody," another respondent said,

"Going to university is the best because once I go to university... I will get a good job. That is why [I am pushing myself] and making me to be somebody in the future. By working this and this, 'small jobs,' one day I will end up like that, so it is better to go to university and focus on education" (Congolese man who never enrolled in university, Kakuma Refugee Settlement 2015).

Another respondent framed higher education in terms of gaining opportunities and transcending boundaries, "[A]s you go further studying, then you get all the opportunities, because when you study, the world comes to you....the more you get experience and the more you study, you won't collapse, you will go forward, you will be a success in life" (Somali man who was enrolled in college, Cape Town 2016). Such statements reveal that these respondents perceived higher education as a crucial ingredient (or the crucial ingredient) to life success. In terms of respondents perceiving higher education as key to rebuilding their home countries, yet another respondent stated,

"I wish that one day I may go and found my own NGO in my country....in order to fight against women abuses, violence, war. They need people to understand what a war can create inside a human man and spirit.... That was my inner motivation for me to move and to come [to South Africa] for education" (Congolese woman who completed college, Johannesburg 2016).

While the real benefits of higher education for refugees have been established, as has the importance that refugees, themselves, place on higher education, the question becomes whether these benefits and positive perceptions translate into a real demand for higher education. Moreover, it is important to learn who comprises this "critical group of young men and women," which is seeking out higher education, as not every refugee qualifies for, or can gain access to, higher education. 


\subsection{The Unmet Demand for Tertiary Education}

A significant, unmet demand amongst refugees for tertiary education exists. Just 1 percent of all refugees attend university, compared to more than one-third of universityage youth worldwide and 3 percent of university-age youth in developing countries (UNHCR 2016b). ${ }^{2}$ This low figure is in part the result of a small proportion of refugees qualifying for higher education, given their challenges completing primary and secondary education. However, it is also the result of challenges related to access, including the inability to finance higher education studies and the limited number of scholarships available. For every refugee the United Nations High Commissioner for Refugees (UNHCR) sponsors for a university or college degree, it rejects between ten and 30 applicants, and in some countries, as many as 50 applicants; from 1992 to 2007, it funded approximately 5,000 refugees (Dryden-Peterson 2011: 52).

Aside from UNHCR, a number of national and international organizations help refugees attain higher education. The Danish Refugee Council in Kenya and South Africa and the Windle Trust in Kenya and Uganda estimate that they fund roughly ten percent of the applications they receive for higher education scholarships. ${ }^{3}$ In terms of nongovernmental organizations, in South Africa, the United Tertiary Refugee Students had provided support to 1,300 refugees seeking higher education (CEI 2014). These figures cover people with official refugee status, who are receiving official support and largely enrolling at universities. More support themselves and enroll in colleges and technical schools. More still leave their studies or do not enroll owing to financial constraints (Lanzi Mazzocchini 2008). These figures suggest that there is indeed a segment of refugees that meets the standards for enrollment and actively seeks out higher education opportunities. They also show that there are more refugees attempting to pursue higher education than there is support for their enrollment.

\subsection{Aim of the Study}

The importance of higher education is relatively well-understood from a livelihoods or development perspective despite a persistent gap in international support for refugee higher education. The academic and policy literatures acknowledge the positive impact of higher education on refugees' wellbeing, their socio-economic integration into host societies, and their contributions to their home countries. What is less understood is the impact of higher education on forced displacement patterns. By displacement patterns, I

\footnotetext{
2 There is no figure for the percentage of refugees in developing countries who attend university; presumably, the figure is much lower than 1 percent.

${ }^{3}$ This figure was cited in interviews with Windle Trust Uganda (2015), Windle Trust Kenya (2015), Danish Refugee Council Kenya (2015), and Danish Refugee Council South Africa (2016).
} 
refer to the spatial and temporal patterns of movement that refugees undertake, including the what, when, where, and how of refugees' forced displacement.

Zolberg, Suhrke and Aguayo (1986) argued that violence and conflict alone do not explain the dynamics of forced displacement; rather they point to the grounds for claiming the legal status of refugee. The more ethnographic literature on migration in conflict settings reveals that factors related to conflict and crisis interact with and are mediated by a range of socio-cultural and economic factors and processes (Bakewell and Bonfiglio 2013; Hansen 1981; Lindley 2010; Lubkemann 2000; Monsutti 2008). Further, we know from the education migration literature that "education is the major factor influencing migration in most societies" (Ayiemba and Oucho 2007: 11). Given that many refugees perceive higher education as being key to rebuilding their lives in displacement and, of those, a select group actively seeks enrollment in hosting countries, it is reasonable to assume that for some members of this select group, the prospect of higher education has impacted upon their forced displacement patterns.

Therefore, this study seeks to understand: How does refugees' pursuit of tertiary education impact their forced displacement patterns to asylum countries? For instance, if a person's higher education was interrupted, prevented, or not possible in his or her home country because of conflict or persecution, how might the prospect of tertiary education elsewhere play a role in that person's decision-making about where and how to seek asylum?

To be clear, this study does not assume or allege that all refugees who pursue tertiary education in asylum countries shape their forced displacement patterns in some way in relation to higher education. To investigate this study's overarching research question, I shall assess cases in which higher education appears to play no role in the forced displacement patterns of respondents who went on to obtain tertiary degrees; and to examine whether and how the prospect of higher education in asylum countries might also impact respondents who ultimately did not enroll in any form of tertiary studies. I shall also investigate the dimensions of forced displacement patterns which appear most apt to being shaped in relation to higher education.

This question centers on how refugees negotiate or shape their displacement patterns in pursuit of higher education. Hence, at its core, this study seeks to examine refugees' agency within their displacement patterns, and how this agency is expressed through the pursuit of tertiary education, amid the great constraints presented by conflict and crisis and asylum and migration regimes. Briefly, agency is a process by which actors engage with different structural environments, based on what they have experienced in the past, what they perceive as possibilities for the future, and how they evaluate the past and future within the contingencies of the present (Emirbayer and Mische 1998: 970). In other 
words, we can understand where and how some refugees seek asylum and protection, based on their experiences, abilities, and thinking related to higher education. Re-framing this study's research question to make explicit the link between higher education and refugee agency, it asks: How does refugees' agency expressed through the pursuit of tertiary education shape their forced displacement patterns to asylum countries?

Monsutti (2008: 67) argued that asking "how" and not "why" people move is most effective in understanding the strategies of refugees and migrants and their mobility patterns. He critiqued the work of Connor (1987), who examined the motivations of people departing Afghanistan, and who identified a range of responses such as "livelihoods" or "fear for life." Such "reasons" for movement reveal little about the nuances and dynamics of movement, and lack sensitivity to overlapping motivations or the multi-scalar nature of migration determinants. Hence, it is crucial one that one examine what people do in addition to what they say (Monsutti 2008: 63).

Lastly, this question focuses on refugees who have pursued or are pursuing tertiary education in asylum countries. This group may include individuals with previous higher education experience from their origin countries who are looking either to complete their studies, which were interrupted by conflict or persecution, or to further their studies by pursuing graduate education in asylum countries. It is possible that the previous higher education experience of these individuals is partly to blame for their forced displacement, if they were persecuted for their political activities and student organizing at higher education institutions. We saw examples of this in Burundi in 2015, when the government shut down universities and targeted students protesting President Nkurunziza's unconstitutional bid for a third term in office.

\subsection{Implications for Complementary Protection and Refugee Mobility}

Understanding how refugees' pursuit of tertiary education impacts their displacement patterns has important implications for complementary protection pathways and refugee mobility. Complementary protection pathways are "safe and regulated avenues by which refugees may live in a country and have their international protection needs met, while also being able to support themselves and reach sustainable and lasting solutions" (UNHCR 2018a). In the context of tertiary education, complementary pathways might take shape through international student channels or exceptional skills channels. UNHCR and its educational partners have recognized the value of higher education in providing complementary protection options in third countries. For instance, UNHCR supports the "Japanese initiative for the future of Syrian refugees," which provides 100 Syrian refugee students the opportunity to pursue MA degrees and remain in Japan for at least five years (UNHCR 2018a). Additionally, through the World University Service 
of Canada (WUSC), refugees living in asylum countries are provided scholarships to pursue university education in Canada and gain resettlement.

In UNHCR's current framing of higher education and complementary protection, refugees from countries of asylum move to "third" countries to pursue higher education and gain protection. This research explores the rights and protection that refugees seek out in asylum countries and the strategies that certain individuals undertake to avoid contact or sever ties with the asylum and refugee regimes. Tertiary education institutions in resettlement and asylum countries across the world are asking what role can and should they play in responding to today's forced displacement crises. Exploring and better understanding opportunities within higher education for complementary protection should be a priority.

In terms of implications for refugee mobility, understanding how refugee's pursuit of higher education impacts how they negotiate their forced displacement patterns invites us to re-examine the limited ways in which we think about forced displacement with respect to refugee agency. Malkki (1995: 508) argued that "the refugee experience" is too often generalized and that refugee movements are portrayed as aberrant and entail the loss of one's agency at an international border. Conceptualizations of forced displacement patterns are often dominated by the initial exit or flight from the home country; it is often taken for granted that entrance into an asylum country will be the closest, peaceful neighboring country. Additionally, Zetter (2018) maintained that the widespread use of the terms "forced migrant" and "forcibly displaced person" has grown out the desire for (broader) definitions of "refugee" and "refugee movements," which reflect "the complex drivers, processes, impacts and consequences, and the multiplicity of categories...[characterizing] contemporary and emerging forced displacement dynamics. Indeed, contemporary studies on forced displacement patterns reveal the ways in which refugees negotiate whether, when, where, and how they move to asylum countries, and, at times, the overlapping or "mixed" nature of forced displacement and migration dynamics.

An example of the limited ways in which policy perceives refugee mobility lies in UNHCR's framing of the "secondary movement" of refugees and asylum seekers as a problem to be solved and prevented. The term "secondary movement" refers to the onward movement of people from countries of first asylum through "independentlymade arrangements - often using irregular methods to reach their destination" (Lindley and Van Hear 2007: 2). In the context of tertiary education, refugees pursuing higher education outside of their country of first asylum or outside of their region of origin might be unfairly branded as "disingenuous" and trying to access education markets. Another example of the limited recognition of refugees' mobility strategies within policy and practice is the lack of freedom of movement granted to refugees in host countries that 
have encampment policies. This limits refugees' ability to seek out educational opportunities outside of settlements and in urban centers. Integrating a more nuanced concept of agency into the refugee movement discourse, particularly with respect to the pursuit of higher education and skills, and hence employment, has the potential to impact the way policy and practice conceptualize and seek to manage refugee mobility.

\subsection{Key Concepts}

Before moving to examine the theories and literature underpinning this research, this section outlines how this study defines tertiary or higher education, refugees and other migrant groups included in this study, as well as how this study delineates what is a forced migration pattern.

\subsubsection{Tertiary or higher education}

Tertiary or higher education refers to graduate and undergraduate degree programs at universities; associate degree and diploma programs at colleges; as well as professional diploma and certificate programs at vocational or technical schools. Tertiary education does not include secondary-level vocational programs; and enrollment requires a certain minimum of secondary education to meet the standards of admission. Technical programs within higher education can be distinguished from non-formal education programs focused on skills training because the former is accredited by a tertiary institution, which in turn receives an accreditation charter from a country's government, and contributes directly to the attainment of a tertiary degree or certificate.

\subsubsection{Who is a refugee and who is a respondent?}

According to the 1951 Refugee Convention, a refugee is:

"[A person who] ...owing to a well-founded fear of being persecuted for reasons of race, religion, nationality, membership of a particular social group, or political opinion, is outside the country of their nationality, and is unable to or, owing to such fear, is unwilling to avail him/herself of the protection of that country" (UNGA 1951: Article 1A, Section 2).

In 1969, in response to large numbers of Africans fleeing anti-colonialist struggles taking place across the continent, (Okello 2014b: 70) maintained that the Organization of African Unity (OAU) enacted the OAU Convention Governing the Specific Aspects of Refugee Problems in Africa to expand the definition of refugee to include: 
"[E]very person who, owing to external aggression, occupation, foreign domination or events seriously disturbing public order in either part or the whole of his country of origin or nationality, is compelled to leave his place of habitual residence in order to seek refuge in another place outside his country of origin or nationality" (OAU 1969: Article 1, Section 1).

This definition departs from individualized persecution as the sole basis of status, by recognizing acts and conditions in the country of origin. In this vein, Okello (2014: 72) argued that the prima facie mechanism is intrinsic to the OAU Convention. By virtue of being from the same affected area within an origin country or the same affected origin country, people may be experiencing the same or similar impositions to flee.

Following this same logic, this research recognizes refugees as people who have obtained the legal definition of refugee under the 1969 OAU Convention as well as those who are sometimes (interchangeably) referred to as "unregistered refugees," "de facto refugees," or what UNHCR terms "people in refugee-like situations" and who are from the same communities of origin that are marked by conflict. Unregistered refugees are people who have chosen not to claim asylum and remain in a host country without any authorized status, but who identify themselves as refugees and often find themselves living under the same conditions as refugees. The reasons for refugees not to register themselves in countries of asylum include their deeming legal status unnecessary, not knowing how to register, fearing threats to their security from revealing their identities, or finding the registration process too arduous (Bailey 2004: 7, 26; Jacobsen 2006: 274).

Many scholars carrying out, particularly qualitative, research on refugees within Africa have opted to include unregistered refugees in their samples not only for the aforementioned reasons, but also because they represent such a large population relative to the registered population (Clark 2006; Hovil 2007; Macchiavello 2003). For example, in 2003, Uganda's Office of the Prime Minister had estimated there were approximately 15,000 refugees living in Kampala, while the Head of Research at the Refugee Law Project estimated that there were more than 50,000 if one considered registered, unregistered refugees, as well as registered refugees who did receive permission to settle in Kampala (Okello, personal interview, July 16, 2008).

In addition to registered and unregistered refugees, this study includes asylum seekers as respondents given the considerable backlog of pending asylum applications found in many African countries, and in particular in this study's countries of research. Indeed, in Kenya the author collected the stories of refugees who had been asylum seekers for up to ten years. Moreover, South Africa is among the top countries in the world for pending asylum applications; however, there is controversy and disagreement over the number of South Africa's pending cases. Conservative estimates put the number at fewer than 
400,000 (Stupart 2016). The reason for South Africa's high ranking is not because it receives among the highest numbers of asylum seekers, rather it is because its status determination system is slow to process applications, which means people wait years before they receive an answer to their petition (Stupart 2016). In her study on urban refugees in Kampala, Machiavello (2003) included asylum seekers in her sample and explains that while refugee status determination takes an average of six months, in some cases it can take years.

Lastly, this study includes in its sample migrants who have arrived at this study's destination countries through legal and so-called "voluntary" migration channels, and who are from the same origin communities marked by conflict as refugee respondents. Had these individuals applied for refugee status, they would have received it, given that they did originate from the same communities of origin as those who obtained status, according to the 1969 OAU Convention. Moreover, some of these respondents identified themselves as refugees, despite not having refugee status. This study therefore felt it crucial to include this group of co-nationals to learn their less-constrained movement patterns and how they moved through alternative movement channels, to create a more complete picture of displacement.

In sum, based on the political and practical realities that refugees face, this research amasses a broad respondent pool, which includes individuals with and without legal refugee status who identify themselves as refugees, asylum seekers, as well as individuals coming from the same conflict-afflicted communities as refugees, but who have entered this study's destination countries using other legal migration channels, such as student channels. To reflect the diverse landscape of respondents, this study will hereafter refer to respondents as "refugees and migrants."

\subsubsection{Delimiting forced migration patterns}

As mentioned previously, displacement patterns refer to the physical movement that refugees and migrants undertake, including the when, where, why, and how of forced migration. In examining forced migration patterns and the factors which shape them, it is necessary to set out the limits of where such processes "begin" and "end" (Benezer and Zetter 2014). Displacement may start with the anticipation of exile or with the actual planning of movement, rather than the action of movement (Benezer and Zetter 2014: 305; Kunz 1973). Additionally, refugees and migrants, particularly those coming from areas of protracted conflict, often experience multiple displacements, including internal displacement; thus, it is possible that forced migration processes begin with the earliest instances of constrained movement. In many protracted refugee situations, people are born in countries of asylum, meaning that displacement can begin at the very start of 
one's life. Indeed, this was the case for a number of respondents included in this study. For these reasons, I decided to collect data on respondents' movement (and education) from the very beginning of their lives, in an effort to create a more complete picture of their forced migration patterns.

In terms of the end of displacement, Black and Koser (1999) questioned the conventional "ends" of the "refugee cycle" - the durable solutions of repatriation, local integration, and resettlement. They argued that arrivals to safe countries could instead represent continuations of the cycle or the beginnings of new cycles. Moreover, their work suggested that the end of displacement could differ for each individual, depending on how he or she experiences forced displacement. In reference to development-induced displacement, rather than refugee displacement, Cernea (2003: 24) held that the end depends on the cause, content and type or category of displaced person, and requires a policy solution; while Mooney (2005) set aside policy and maintained that the end of displacement should be assessed against the needs of displaced persons.

This research identifies respondents in asylum countries. Hence, they are still in the midst of their forced migration "journeys" or patterns and have yet to reach their "ends." For this reason, it can be said that this research largely examines forced migration patterns from origin to asylum countries. On the other hand, given that this research focuses on refugees and migrants coming from areas of protracted or cyclical conflict taking place over decades, it is possible to question how useful the concept of "end" is in its current form, given that protracted refugee situations now make up the majority of refugee situations. Persisting in limbo is also an end and it could be said that this research therefore explores the full process of forced migration for people in protracted refugee situations. A select number of respondents in this study did achieve citizenship or permanent residence in their asylum country, and in these instances, a more conventional "refugee cycle" process may be observed. Also, one respondent did resettle to the United States and then returned to South Africa to finish her studies. 
CHAPTER 2

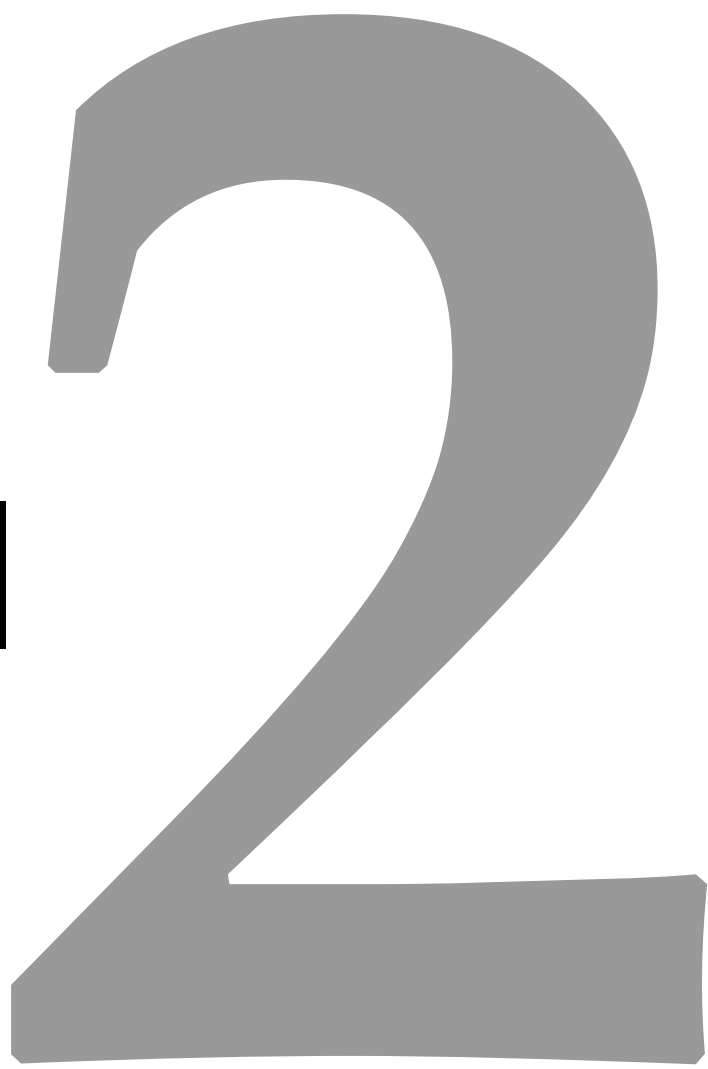




\section{Literature Review and Conceptual Framework}


To understand how refugees and migrants pursuing higher education express their agency and shape their movement patterns in relation to higher education, this research explores and integrates several complementary bodies of academic and policy-oriented literature. First, it looks to the literature on refugee tertiary education, to find evidence of higher education decision-making affecting forced displacement and to learn whether refugees in higher education engage in unique or specific types of forced displacement. Second, it looks to the education migration literature to understand features of educational mobility, particularly in conflict settings. Third, this chapter examines the literature on forced displacement patterns, to understand how such movements are conceptualized, particularly with respect to refugee agency. Finally, it looks to the migration determinants literature to create a broader picture of how people shape their movement patterns within the boundaries of macro-level constraints and opportunities. In drawing upon the literatures on international student migration and migration determinants, this review seeks to gain insight into migrant agency with respect to tertiary education and to consider how such insights might be cautiously extrapolated to inform conceptualizations of refugee agency. This chapter concludes by putting forward an agency and mobility framework, developed by Bakewell and Bonfiglio (2013) to study mobility in conflict settings, to examine how refugees and migrants pursuing higher education shape their movements.

\subsection{Refugee Higher Education}

The literature on refugee higher education is dominated by program evaluations, most often of universities within developed, resettlement country contexts, particularly in Australia, Canada, the United States, and the United Kingdom (Donald 2014; Prokop 2013; Shakya et al. 2010; Stevenson and Willott 2007). These evaluations have assessed how well universities integrate refugees into student bodies and classroom environments, best practices for teachers, and the factors that impede and promote enrollment and graduation, to name a few (Ben-Moshe et al. 2008; Earnest et al. 2010; Lee 1997). Fewer evaluations have been carried out in developing, asylum contexts. These studies have centered on tertiary education programs provided by non-governmental organizations (NGOs) in refugee settlements and accredited by foreign or domestic higher education institutions. Such studies have examined best practices in education delivery (MacLaren 2010), barriers to educational access (Lanzi Mazzocchini 2008; Zeus 2011), and the impact of higher education on refugee livelihoods (Crea 2016; Dippo, Orgocka and Giles 2012; Morlang and Watson 2007).

While the policy and academic literatures largely focus on the institutions and governments providing education, there is a growing body of literature that examines 
the experiences of refugees who attempt to access and pursue tertiary education. These studies have explored how higher education acts as a mechanism for nation-building and/or shapes refugees' socio-political identities, challenges conventional gender dynamics, and enhances refugees' agency or capacities (Ben-Moshe et al. 2008; Donald 2014; Dryden-Peterson 2011; El Jack 2010; Farah 2010; Fiddian-Qasmiyeh 2009; FiddianQasmiyeh 2011; Oh and van der Stouwe 2008; Zeus 2011). These studies have also explored refugees' perceptions of and aspirations for higher education (Alzaroo and Hunt 2003; Chelpi-den Hamer 2009; Clark-Kazak 2010; Shakya et al. 2010).

The literature on refugee tertiary education does not expressly consider how education, or the pursuit of it, shapes forced migration processes; however, some studies reveal distinct education-displacement patterns. First, they document refugees being sponsored by organizations and governments to move temporarily from asylum countries to third countries to gain higher education (Farah 2010; Fiddian-Qasmiyeh 2010; FiddianQasmiyeh 2011). Refugees are engaging explicitly in educational mobility and are being assisted by an external actor to do so. In this way, this pattern reveals higher education impacting the destination and legal channel of refugee movements and whether refugees engage in single-vector versus multiple-vector moves over the course of their displacement trajectories. Fiddian-Qasmiyeh (2011) examined refugees from the Middle East and North Africa who were sponsored by the Cuban government to pursue medical, dentistry, and nursing degrees in Cuba. The effects that this "study abroad" program had on students' further mobility were two-fold: students decided whether to return to their communities of origin to contribute their newly acquired skills or to move onward to a European country with the hope of securing a job that would allow them to remit funds to their families and communities of origin.

The second education-displacement pattern depicts refugees accessing tertiary education after being resettled to more developed countries because of increased aspirations resulting from increased educational opportunities (Hannah 2000); while the third reveals refugees receiving tertiary education in asylum countries based on support from organizations, universities, and fellow refugees (Chelpi-den Hamer 2009; Lanzi Mazzocchini 2008; Zeus 2011). These latter patterns show refugees accessing higher education in situ, after arriving in countries of resettlement and asylum. The authors of these studies make the link between obtaining higher education and the enhancement of refugees' integration prospects. Moreover, UNHCR observed that refugees who gain higher education in asylum countries are more likely and equipped to seek out information on, and take full advantage of, resettlement opportunities (Zeus 2011: 261). In this way, the third pattern suggests that higher education can shape the destination and, ultimately, the legal channel of movement if refugees get resettled. 
Additionally, while not the focus of her study, Donald (2014: 9) observed during her fieldwork in Dzaleka Refugee Camp in Malawi that the country is "a site of second or third asylum for refugees, with education anecdotally described as a contributing 'pullfactor' for seeking asylum there." Based on interview and oral history data, she argued that some Burundian respondents chose Malawi as a site of further displacement over repatriating to Burundi, given a lack of capacity in Burundi's education system and expanded capacities in Malawi. She noted, citing an interview with a World University Service of Canada (WUSC) senior staff member, that the highly desirable and competitive WUSC Student Refugee Program, which is a scholarship program for refugees to gain higher education in Canada and is linked to resettlement, is present in Malawi and draws refugees from neighboring countries not offering the program (Donald 2014: 75). Hence, greater higher education capacity as well as the possibility of accessing higher education shapes the destination, directness, and channel of displacement patterns.

Lastly, in terms of education-displacement patterns, the historical literature on refugees in higher education reveals that youth enrolled in universities and colleges have been targeted and persecuted during the early stages of a conflict or crisis, given that they have often represented new intellectual elites who might challenge the political status quo. Buckland (2005: 18) wrote, "[s]tudents are often involved, especially at the tertiary level, as activists in the political struggles that precede conflict, and so universities and postsecondary colleges tend to be targeted more often." Consequently, students and intellectuals can represent the first arrivals of refugees from a country and may often attempt to continue their studies and activism in asylum countries. This echoes the work of Kunz (1973) who conceptualized the first cohorts of refugees to arrive in a destination country as "anticipatory refugees," who have high levels of education, which enables them to anticipate conflict and better plan the conditions of flight. Thus, the flight of more highly educated individuals might signal the onset of greater forced displacement. Further, this pattern reveals that higher education can shape the timing of refugees' displacement patterns, or when they exit their origin country.

In sum, while not dealing directly with patterns of forced migration, the literature on refugee higher education does reveal that higher education can be linked to the timing of flight, to the destination of the movement, to educational mobility and multiple-vector moves during displacement, to the legal migration channels that refugees move within, to access to resettlement and other durable solutions, as well as to greater wellbeing and integration during displacement. This literature also links the attainment of higher education to refugees' increased agency or their capacity to express their agency. This means that examining refugees who are pursuing or who have pursued higher education in countries of origin and asylum perhaps offers this study an "ideal case" to understand the extent to which refugees may shape their forced migration patterns. 


\subsection{International Student Migration}

The literature on international student migration ${ }^{4}$ (sometimes referred to as the education migration literature) may offer insights on how refugees make decisions about their displacement based on higher education considerations. A multitude of drivers and patterns of student migration and mobility are conceptualized within this literature, related to the degree being pursued, level of study, and subject, amongst others (Findlay et al. 2012). The sub-literature on tertiary degree migration is likely the most applicable and relevant to the respondents in this study, although the full spectrum of international student migration is considered here to establish in the broadest sense how higher education considerations might shape forced migration patterns.

Carlson (2013) argued that international student migration is contingent, dynamic, and shaped by a wide range of factors. At the macro level, inadequate access to education in origin societies and the presence of opportunities abroad (Tati 2010), labor market and student visa policies in the destination (Rafi and Lewis 2013), and the political situation in home countries (Hazen and Alberts 2006) are factors that impact education migration decisions. Kritz (2015) found that some 6 percent of tertiary students study abroad in Africa and found that in African countries with more developed higher education sectors, rates of outbound education mobility were lower (see also UNECA 2017: 10).

At the micro-individual level, sociological and ethnographic studies have highlighted the socio-cultural values that people attach to education and migration (Moore 2001; Punch 2002; Punch 2007a) and the part education plays in cultural rites of passage (Punch 2007b). From a development perspective, education migration decisions have been shaped by greater rates of return and employability from foreign degrees (Rafi and Lewis 2013) and have formed part of individual and household survival strategies (Black, Hilker and Pooley 2004; Helgesson 2006). Hazen and Alberts (2006) argued that for some, student migration is a pathway to longer-term or permanent residence in a desirable country, and therefore forms part of a larger migration strategy. Finally, on a microinstitutional level, King and Raghuram (2013) and Tati (2009) highlighted the recruitment function of higher education institutions and the role they play in structuring migration processes.

Thinking about these drivers in the context of forced migration, we would anticipate that conflict or crisis would strain local or national education systems, prompting students

\footnotetext{
${ }^{4}$ It should be noted, that while this study adopts the terms "international student migration" and "tertiary degree migration" in this review, this does not suggest that achieving a tertiary degree is the sole driver of movement, as migration is a complex and multidimensional process of transformation, driven by a range of direct and indirect factors related to education, but also, for instance, employment, political factors, and socio-cultural factors.
} 
with sufficient resources to look further afield. Moreover, local and national education institutions would likely be targets for violence and persecution. One might also see refugees and migrants who have previous education migration experiences return to the places abroad where they studied because they are familiar and contain existing support networks. For instance, a Congolese woman who received secondary education in Kenya might flee to Kenya rather than Uganda, since the location is familiar to her. Further, people may engage in education migration as a survival strategy, using student migration channels as a vehicle to legally and temporarily access other countries during upheavals in conflict and crisis, in lieu of seeking asylum, which might be seen as a more permanent and political act. More generally, as explored by Bakewell and Bonfiglio (2013), understanding education migration drivers is important because any of the aforementioned education migration drivers might overlay and interact with conflict and crisis dynamics to produce diverse forced migration patterns.

Also, in terms of drivers, aspirations for education and employment are often inextricably linked, meaning that their "drivers" are aligned and people are likely to study in the same environments in which they desire to work (Bakewell and Bonfiglio 2013; Blunch 2009; Hashim 2007; Tati 2009). Tati (2009) argued that working and studying may occur simultaneously, as this legitimizes a student's decision to migrate by signaling success, or as students need to work to fund themselves while abroad. In some cases, students must first gain employment upon arriving in destination countries, to earn funds to enroll in higher education programs later on (Tati 2009). On the supply side, a strong link exists between labor markets and the types of education and skills offered at higher education institutions (Bakewell and Bonfiglio 2013; Sabot 1972); in other words, the labor market structures educational offerings, which in turn attracts students. In the context of this study, this means that refugees and migrants may choose their destinations based on where they think they will have the best opportunities to build their lives and/or where they may want to live and work.

Aside from drivers, international student migration yields distinct patterns, depending on the type of education. Migration for higher education tends to be directed towards urban and economically prosperous areas where such education institutions are often located (Porter et al. 2010; UNDESA 2003). It also is more likely to be international and independent (single person) than migration for primary or secondary education and intersects with socio-cultural drivers of migration such as the transition to adulthood. Within Africa, Black et al. (2006) and Black, Hilker and Pooley (2004) found that students often go abroad to other countries on the continent for university education. In particular, anglophone countries are especially attractive to international students as learning English and obtaining English degrees are perceived as being beneficial to tapping into international labor markets (Baláž and Williams 2004). Additionally, migration within 
Africa for higher education is increasingly undertaken by youth to obtain the best education and employment opportunities (UNDESA 2003; Tati 2009). This might suggest that refugees and migrants forgo asylum migration channels in favor of student migration channels if studying abroad was planned before or at the time conflict or crisis reached an untenable threshold in their origin countries.

In contrast, migration for primary and secondary education is more likely than tertiary education to be internal and involve family members, given the age of students at this level and the greater proximity of primary and secondary schools to communities of origin. Studies on so-called "fostering" migration within Africa show children moving to live with relatives who live in areas with better primary and secondary schools or who can provide them with an education on their family's cultural traditions (Black et al. 2006; Black, Hilker and Pooley 2004). Aside from relatives, it is not uncommon for children from higher socio-economic backgrounds to be sent to boarding schools, based on the perception that they provide higher quality education than public schools and better discipline. While this form of educational mobility may not have direct implications for international displacement, it might be relevant to any internal displacement respondents might have experienced prior to seeking asylum. On the other hand, it is possible that conflict or crisis might internationalize these otherwise internal educational mobility patterns, for those with financial means. For instance, a Congolese family might decide to send its child to boarding school in Uganda, if the Congo is deemed unsafe or if the schools are closing too frequently because of outbreaks of conflict or crisis.

The international student migration literature provides some insight into how the pursuit of higher education may factor into forced displacement patterns, both at a structural level, in terms of educational constraints and opportunities present across the continent, and at the micro level, in terms of refugee and migrant education aspirations, norms, and capabilities interacting with conflict and crisis dynamics. Based on this brief exploration of the literature, it appears that higher education has the potential to shape the timing, distance, destination, and mode of forced displacement - mode referring to whether refugees travel alone or with family and/or use their social networks. The following section turns to the literature on forced displacement patterns to understand more broadly how refugees negotiate their forced movements.

\subsection{Forced Displacement Patterns}

The literature on forced displacement patterns provides further insight on how the pursuit of higher education by refugees shapes their movement to asylum countries, by highlighting how refugees express their agency in negotiating their forced movements. I 
examine this literature in two parts. The first part consists of the more historical literature on conceptualizing forced movements. Beginning in the 1950s, such studies attempted to create typologies of forced displacement patterns and to distinguish forced displacement from so-called voluntary migration. As these typologies became further refined, we see a greater recognition of refugee agency emerge. The second part of this literature appears to leave behind the quest for a typology or unifying theory of forced displacement and takes a more critical view on how refugee movements and refugee agency are depicted. Within this domain, we see the proliferation of contemporary studies that incorporate or reflect highly nuanced analyses of refugee movements and agency and a growing body of work that blurs the line between migration and forced displacement dynamics.

One of the earliest attempts to conceptualize forced displacement patterns, and perhaps one that has had lasting impacts on the field, is Petersen's (1958) typology of migration, which included two categories of forced migration: forced displacement and impelled flight. Forced migration occurs when a person exercises no agency in moving and is physically moved by another, for instance, those who have been trafficked or abducted. Impelled flight occurs when people can exercise some choice, in terms of their destination or in the decision to remain and face potentially dire consequences. Refugees, as defined by the 1951 Convention, fall into this latter category. Importantly, Petersen (1958) recognized that impelled fleers exercise some degree of choice with respect to their destinations. However, both of Peterson's (1958) forced migration types described single vector moves and impelled flight encompassed such a wide range a forced movement that it falls short of being theoretically useful.

A number of field-defining studies have since been carried out which have created typologies of refugee movements (Giddens 1991; Hansen 1981; Keller 1975; Koser 1996; Kunz 1981; Kunz 1973; Richmond 1993; Stein 1981; Van Hear 1998). Kunz (1973, 1981) radically expanded upon Peterson's (1958) work more than a decade after its publication, by interrogating the category of impelled fleers and conceptualizing refugees as "anticipatory" versus "acute" in his "Refugee Kinetics" model. He argued that anticipatory refugees have higher levels of education, resources, and evaluative skills and can anticipate conflict or crisis and move directly to a country of their choosing that would accept them. Implicitly, such refugees more directly access durable solutions and avoid limbo in countries of first asylum. By contrast, acute refugees have few resources and little education and therefore face greater constraints. Acute refugees are forced to flee to asylum countries until they experience "pressures" to move onward, locally integrate, repatriate, or resettle. Kunz (1973) framed the timing of an individual's movement as his or her ability to anticipate threats or not and this ability is based on resources, skills, and education, particularly higher education (see also (see also Otunnu 1994 on Sudanese refugee movements). Kunz (1973) classified all refugees who must first 
flee to asylum countries as acute and therefore, by definition, did not recognize any agency they may exert over their choice of destination, mode of movement, and timing of displacement, or that they might indeed be educated. In this way, this study's respondents, who are pursuing higher education in asylum countries, have no place in Kunz's (1973) framework.

Like Peterson, Kunz (1973) distinguished forced movers based on the greater or lesser choices they have. Kunz (1973) suggested these choices are based on something we might equate with financial and human capital. What is absent from such a concept of choice is the presence of aspirations or socio-cultural norms. Moreover, Kunz's (1973) model is built upon a simplistic push-push framework, which drastically diminishes refugee agency once you look beyond the ability to mobilize resources. In fact, in his paper and in an earlier book he compares refugees to billiard balls and maintains that for people to be refugees, they must have no "self-propelling" dynamics in relation to movement (Kunz 1969: 225). In other words, in the absence of persecution, such individuals would have had no cause to move.

Further, Kunz's model allows for two-vector moves, by considering the move to the asylum country - what he calls the 'midway-to-nowhere' stage. In attempting to abstract a large and widely-applicable model of forced migration, he conceptualizes all movement to countries of asylum as the same. Kunz differentiates how refugees leave their origin countries, and the different durable solutions they assume when displacement "ends," but there is little exploration of what happens in between.

Hansen (1981) critiqued the agency-lacking model of Kunz and further contributed to the conceptualization of forced migration processes by highlighting the importance of refugee hosting (or settlement) policies on their movements. As evidence of their agency, Hansen's study revealed how refugees opt to settle themselves outside of UNHCRassisted settlements and waive their rights to assistance. While agency is at the center of his critique, Hansen provided little indication what agency means in the context of forced displacement and how it is exercised.

In the late 1980s and early 1990s, Richmond $(1988,1993)$ put agency at the center of his framework on refugee movement. He saw refugee movements as existing on a continuum of agency; on one extreme, there are refugees who engage in proactive movement and exhibit a high degree of agency and at the other extreme, there are refugees who engage in reactive movement and whose agency is highly constrained. He held that most refugees fall somewhere in between, although largely on the reactive end of the continuum. In an effort to link refugee agency with structural forces, Richmond's framework included a continuum of structures, ranging from constraints to 
opportunities, which proactive and reactive refugees interact with in different ways. While this framework significantly advanced notions of refugee agency and linked it with macro-structural forces, agency itself remained a hollow concept. Once again, agency seems to be defined as more-or-less choice.

Van Hear (1998) assumed the approach of his predecessor by integrating the proactivereactive continuum into his voluntary-involuntary migration framework, and with it, a notion of agency as more-or-less choice. However, Van Hear (1998) departed significantly in his spatial-temporal conception of movement as "outward, inward, return, onward, or staying put." This framework positioned refugees in terms of their geography and, implicitly, their own forced migration trajectories. Further, it maintained that refugee movements are multi-vector and spatially oriented, meaning that how we think about their movements depends on whether they are arriving or leaving. Fundamentally, this framework and refinements to it by Van Hear, Brubaker and Bessa (2009) showed that despite outward movements, the concomitant inward movement entails choices. It also acknowledged the case of refugees "staying put," which is one examined by Lubkemann (2008) when he wrote of involuntary immobility. Therefore, while not opening up what agency means, Van Hear (1998) revealed the diversity within refugee movements and the broad scope of refugee agency.

Moving away from early attempts to create typologies or a unifying theory of forced displacement, the more contemporary literature on forced displacement patterns critiques notions of refugee agency and takes a micro-level approach to depicting refugee movements. Malkki (1995: 508) argued against functionalist models of forced displacement, citing the approaches of Keller (1975) and Stein (1981), which described displacement in terms of "stages" from the initial perception of threat to acculturation and change of behavior in the destination. She maintained that such approaches depicted all movement associated with displacement as aberrant and they associated the forced crossing of an international border with the complete loss or rupture of one's norms and aspirations (Malkki 1995: 509). Indeed, based on his research on Ethiopian and Eritrean refugee movements to the Sudan, Kibreab (1996: 132) held that refugees negotiate their choice of destination based on their aspirations, norms, past experiences of living in a rural versus urban area, means, and capabilities. In this way, he found that refugees coming from urban backgrounds were more likely to have higher levels of education, occupational skills, and ambitions and settle in urban locations in the Sudan. Further, he argued that pre-existing mobility strategies linked to economic deprivation and political oppression shape forced displacement patterns.

Kibreab (1996: 149) also found that earlier cohorts of Ethiopian and Eritrean refugees coming to the Sudan were from centers of political opposition in urban areas and moved as individuals or in small groups, while later cohorts came from rural areas and moved 
as whole communities. He argued that respondents who were part of these earlier cohorts made decisions about their exact urban destinations at the time of their departure and not after they crossed the border into the Sudan. These findings underscore the different ways in which refugees express their agency in shaping their movements and interacting with structural constraints and opportunities. In the context of this study on refugees who shape their forced displacement patterns in relation to higher education, the work of Kibreab (1996) suggests that respondents pursuing higher education may come from higher socio-economic and urban backgrounds, hold high aspirations and positive norms for higher education, and choose an asylum destination at the time of their departure based on opportunities for enrollment in higher education.

Following these influential critiques on forced migration patterns, numerous studies have explored refugee agency and mobility and have recognized the, at times, overlapping dynamics of forced displacement and migration (Knudsen 2018; Koser 1997; Lindley 2010; Lindley 2011; Long 2009; Lubkemann 2008; Monsutti 2008; Shum 2014; Steele 2009). Examining the relationship between forced displacement and organized crime in the Northern Triangle of Central America and Mexico, Cantor (2014) argued that

"[A]gency...often manifests itself in the decision by inhabitants to flee their homes....Such agency is shown not only in the decision to flee, and how to leave, but also in the choice of where to go and what to do....such decisions are hedged by wider sets of opportunities and constraints that reflect not only the distinct forms of displacement identified above but also empirical differences between the affected populations in terms of social position and identity."

Cantor (2014) also argued that patterns of forced displacement overlap with patterns of movement linked to family reunification and employment. In his work on Palestinian and Syrian refugees in Lebanon, Knudsen (2018) similarly maintained that movement followed different and complex migration routes, through official and unofficial border posts. Moreover, he argued that refugees choose their destinations based on proximity to the origin country, kindship ties, previous knowledge of the destination country, and shared language and culture (see also Conner 1987). Writing on the experience of Somali refugees in Kenya, Lindley (2011) held that mobility often continues after arrival to the asylum country, when refugees face considerable economic marginalization in settlements and seek out better access to education and health facilities, employment opportunities, and information and communication technologies that allow them to contact relatives abroad. She also highlighted how Somalis living in conflict-affected areas express their agency in avoiding or delaying international displacement and how displacement may be selective, when used as a household strategy to protect its more vulnerable members (Lindley 2011: 24). These authors revealed that refugees negotiate 
not only their destination choice, but also the timing of their movement and their mobility after arrival to the asylum country.

Building upon research on overlapping mobility and displacement patterns, Long (2013); Long (n.d.) argued that migrant and refugee statuses can overlap or be blurred. In her research from Uganda, Long (n.d.) maintained that refugees and migrants from countries impacted by conflict and crisis can acquire and move between multiple legal statuses "to maximize their capacity to move freely in search of goods, services and opportunities with which they can build a 'good life' in exile." In the context of this study, this suggests that refugees and migrants may shape the legal channels of their movements in relation to tertiary education.

Within the narrow empirical literature on forced displacement patterns, Czaika and KisKatos (2007) and Engel and Ibáñez (2007) found that economic opportunities and livelihood considerations feature alongside conflict in forced displacement decisionmaking in Indonesia and Colombia, respectively. Moreover, livelihood considerations play a role not only in determining the destination, but also in the propensity to leave an area of origin. Additionally, it is possible that conflict or crisis acts as a constraining force, impeding the movement of the socio-economically vulnerable (see also Carling 2002; Lubkemann 2008).

Lastly, writing on the movement of Afghans to Pakistan and Iran, Monsutti (2008) put forward an approach that focuses on "strategies," or exploring how people move rather than why they move. Such an approach examined the spatial mobility of Afghans, their transfers of goods and money, and the circulation of information. He argued that Afghans identifying as refugees and those identifying as migrants engage in similar mobility strategies, involving continual back-and-forth movements and belonging to networks that span countries and continents. Further, he held that any durable solutions for refugees should acknowledge mobility as a key livelihood strategy.

In sum, the more historical literature on forced displacement patterns sought to theorize and create typologies of how refugees move. Such studies played a crucial role in prompting researchers to examine what is unique about forced displacement and in understanding what shapes the timing and destination of forced displacement. While refugee agency occupied a space within these frameworks, underscoring its importance, its conceptualization and the conceptualization of refugee mobility remained thin. By contrast, many contemporary studies on forced displacement patterns have highlighted the numerous ways in which refugees express their agency to shape their movements. Moreover, they have argued that refugees might have moved without the presence of persecution or conflict, as people often have mobility-related norms, aspirations, and practices that pre-exist or co-exist with conflict (Bakewell and Bonfiglio 2013). 
Blurring the lines between forced displacement and migration or applying concepts from migration studies to understand refugee mobility does not detract from the unique experiences that refugees face linked to persecution, violence, and conflict, nor does it detract from the legal claim of refugees to international protection. Rather, applying methodological and theoretical concepts from migration studies:

"[S]tems from the concern that refugees are not mere victims but people adapting to the world system, using their social and cultural resource. Refugees and other types of migrants share a number of social features, and individuals may belong to several categories at a time or successively" (Monsutti 2008: 65).

With this in mind, the following section shall look to the migration determinants literature to build upon the insights provided by studies of forced displacement patterns on how refugees negotiate whether they move, where they move, when they move, and whether and how they move onwards, locally integrate, or return. In particular, the following section seeks to understand how notions of migrant agency are conceptualized and applied to learn how such notions might be (cautiously) operationalized to examine how refugees shape their forced displacements in relation to higher education.

\subsection{Migration Determinants}

Up until the last few decades, the migration determinants field featured few explorations of migrant agency and was dominated by neoclassical theories. At the macro-level, functionalist and historical-structuralist theories and models were largely deterministic in their conceptualization of movement (de Haas 2014: 1, 4; Massey et al. 1993: 432). They depicted migrants moving between countries with development disparities to maximize their income or wellbeing, in the case of functionalist theories, or in response to exploitive systems which force lower wage workers from peripheral countries to move to core countries to support their economies, in the case of historical-structuralist theories (Castles, De Haas and Miller 2013; de Haas 2014; Massey et al. 1993). At the micro-level, neoclassical micro-level approaches depicted migrants as rational actors who migrate because of perceived financial gains and increases to their productivity, despite the social, economic, and other costs associated with movement. Such approaches conceptualized migration as an investment in human capital (Massey et al. 1993; Todaro 1976). ${ }^{5}$

\footnotetext{
${ }^{5}$ Based on their assumptions and propositions, neither functionalist nor historical-structuralist theories can adequately account for migrants moving between countries with similar levels of development (which is largely the case for the refugees and migrants within this study), situations of return migration, or middle-income countries having higher rates of emigration than low-income countries. They also cannot account for migrants moving for the sake of moving
} 
Against this context of determinism, scholars like Bakewell (2014); Bakewell, de Haas and Kubal (2011); de Haas (2010); de Haas (2011); Mabogunje (1970); Massey (1990); and Stark and Levhari (1982) put forward critiques which, either directly or indirectly, highlighted the lack of recognition of migrant agency, and put forward migration theories or frameworks which integrated aspects of agency. De Haas (2014: 22) argued, "[t]o move migration theory (and social theories more generally) forward, theories should simultaneously account for agency and structure and their interplay."

At the meso level, migration systems theory examined how migration is embedded in broader development or transformation processes by showing how exchanges of goods and information (for instance) can shape aspirations related to migration as well as peoples' capabilities to migrate through altering their contextual environments (see Lee 1966 on "stream and counterstream"; Mabogunje 1970: 4-5). Extrapolating the basic features of migration systems to the context of forced migration, albeit cautiously, we might observe that when insecurity reaches an untenable threshold, for instance in Somalia, residents living in affected areas of Mogadishu join their families in the wellestablished Somali community of Eastleigh in Nairobi, Kenya, rather than a location to which they have no connection. This move would be supported by remittances sent and information shared by kin in Eastleigh to help their journey; brokers, ICT companies, and travel agencies that facilitate movement through this specific corridor; as well as possible previous travel to Nairobi undertaken by newly displaced Somalis. Bakewell (2014) argued for a relaunching of migration systems theory, which gives greater attention to migrant agency through the recognition of internal feedback mechanisms alongside the original model's recognition of external feedback mechanisms.

Drawing on the work of sociologists Emirbayer and Mische (1998), who put forward a theory of agency, Bakewell and Bonfiglio (2013) and Bakewell, de Haas and Kubal (2011) maintained that social actors - in both conflict and non-conflict settings - can demonstrate different aspects of agency, related to their socio-cultural norms, routines, and aspirations and can shape the emergence of a migration system as well as its development. In the previous example of Somali displacement, an example of an external feedback mechanism would be the larger structures that arise to change the costs related to migration, such as improved ICT or transportation networks. An internal feedback mechanism would be the steps taken by Somali migrants in Nairobi to support the movement of their displaced kin, based on cultural norms or more routine practices.

\footnotetext{
- i.e., the desire to have a migration experience - or feedback effects - i.e., migrants' roles in reducing or increasing migration costs for other migrants (de Haas 2014: 16-17). Further, and of particular relevance to the context of forced migration, determinist theories which rely on push-pull models provide insights on the "average" movers or "representative agents," and obscure the experiences of marginalized or persecuted groups and the salient differences between them and the larger population of movers (de Haas 2014: 8 citing Piketty 2014: 16).
} 
After initial emigration from a community, migration systems theory as well as migration network and cumulative causation theories describe how further flows of ideas, goods, money, and people between origin and destination communities can create feedback effects and perpetuate migration. Migration network theory describes the ties that arise between migrants and non-migrants in origin and destination countries over time, which can facilitate migration by reducing the costs and risks associated with movement and enhancing its attractiveness (Massey 1990). In this same example of Somali displacement, these theories might explain how information sent to kin in Mogadishu could prompt continued or increased asylum migration to Nairobi, by helping their navigation of the Kenyan asylum system, securing their employment, or transforming their lifestyle preferences and aspirations to be more in line with a Nairobi urbanite.

At the micro level, Stark and Levhari (1982) developed the New Economics of Labor Migration (NELM), which understood movement as a household strategy to spread risk by securing a household's income abroad in the face of unemployment in its domestic labor market or an economic shock constraining its ability to obtain basic needs. In this way, NELM allowed for a collective expression of agency. Adepoju (2000: 385) argued that many migration patterns in Africa follow the principles of NELM. As part of their investment strategies for the future, families sponsor one of their members to pursue education abroad with the hope that this will enable him/her to secure a job and contribute to household income. Adapting NELM to situations of forced migration, a household might sponsor one of its members to seek asylum in a country farther afield that offers favorable education and employment opportunities, either to remit funds back to the family or to prepare the way for their eventual (forced) migration.

De Haas (2014: 22) maintained that while many, particularly postmodern, qualitative (interpretivist) scholars have recognized the importance of recognizing migrant agency, ideas on how to incorporate structure and agency have remained vague (see also Bakewell 2014: 306). To overcome this conceptual obstacle, and in departing from previous conceptions of migrant agency as more-or-less choice, de Haas (2011, 2014) conceptualized migration at the micro-level as a function of people's "capabilities" and "aspirations." Drawing upon the work of Sen (1999), capabilities refer to the ability to do and to be in the face of constraints, and they refer to whether migrants are able to bear the costs and risks of migration. Capabilities are determined, in part, by the local development context. Aspirations refer to notions of the "good life" and were mediated by people's perceptions of opportunity differentials. They determine whether migrants desire to move or see movement as key to reaching their desires. Aspirations may be shaped by media and popular culture, former migrants who might be role models, improved education and access to information, and the intrinsic value attached to migration, to name a few (de Haas 2014: 23-24). Potential migrants must both have the 
ability and desire to migrate, to carry out migration successfully; having only the former would result in voluntary immobility or non-migration while having only the latter would result in involuntary immobility (see also Carling 2002, Lubkemann 2008).

Aspirations and capabilities are also both shaped by structural factors, which are conceptualized in terms of positive liberties (or freedoms), which enable the expression of a person's capabilities, and negative liberties (or freedoms), which are structures that constrain or pose obstacles to a person's aspirations and capabilities (de Haas 2014: 2627; Sen 1999). Innovatively, conceptualizing structures as positive and negative freedoms allowed de Haas (2014) to link structures to behaviors. Applying the aspirationscapabilities framework to this study, while recognizing the limits of extrapolation to a forced displacement context, factors such as education and employment aspirations, life aspirations, knowledge of education and employment opportunities abroad, on the one hand, and education levels, financial resources, and social capital and networks, on the other, would play a role in respondents' forced movements. Structural factors relating to conflict and crisis as well as migration and asylum regimes would constrain or enable refugees' and migrants' capabilities.

While conceptually distinct, capabilities and aspirations are at times overlapping and interdependent concepts. For instance, education can enhance a person's capabilities by enhancing his/her skills and earning potential as well as his/her aspirations by increasing his/her knowledge about opportunities abroad. More generally, enhanced capabilities may result in increased aspirations (de Haas 2014: 24) and, I would argue, vice versa, as high aspirations may inspire a person to increase his/her capabilities. Additionally, sociocultural norms and values appear subsumed within de Haas' (2014) concept of aspirations. Norms refer to collective or socially-determined values about migration, which may be different from individually-held aspirations. Without explicit reference, including social values and norms within aspirations could have the unintended effect of marginalizing or underserving them.

The literature on migration determinants lends insight into how refugees and migrants may shape their forced migration patterns by revealing different ways in which agency is expressed, as an external or internal feedback mechanism that alters the structural environment, as a collective or household behavior, or as a function of migrants' aspirations and capabilities. Furthermore, migration systems theory and the aspirationscapabilities framework emphasize the interplay between agency and larger structures. This interplay takes the form of feedback effects, forces which constrain or promote the conditions for migration, and embeddedness, respectively. Importantly, these various approaches to agency complement and inform one another, such that one could recognize household-level capabilities or see aspirations arising out of a larger migration system. 
However, while they may be sensitive to such spatial forces, insofar as we can consider structural factors to be spatially oriented, these more agency-rich migration approaches lack temporal sensitivity. De Haas' (2014) aspirations-capabilities framework, which is perhaps the framework that most concretely operationalizes migrant agency, can be considered present-oriented through the capabilities dimension and future-oriented through the aspirations-dimension, yet a dimension which considers the weight or impact of past actions or traditions on present behavior is absent. Additionally, the dimensions of the aspirations-capabilities framework do not fully reinforce each other, as a uni-directional relationship is drawn between capabilities and aspirations. This simplifies the dynamism within agency and its expression. For these reasons, this study adopts a framework developed by Bakewell and Bonfiglio (2013) of a three-dimensional concept of agency to study mobility within conflict settings. The following section shall outline this framework and its advantages.

\subsection{Conceptual Framework on Agency and Mobility within Forced Displacement}

The forced displacement literature depicts agency as: the capacity to exercise control over the direction of one's life and escape from "passivity and dependency" (Alzaroo and Hunt 2003: 175), self-realization and self-determination (Crea 2016; Donald 2014), political participation and voice (Dryden-Peterson 2010), and self-authoring in the arena of development (Zeus 2010). While these conceptions highlight the primary and underlying principle of agency, which is one of action and self-determination, they are so broad that they fail to be useful. According to sociologists Hitlin and Elder (2007: 170171), such definitions "use 'agency' as a placeholder for some vague sense of human freedom or individual volition within a broader model." No single dimension, such as "routine," "purpose," or "judgement" can describe agency because it would fail to reflect "the dynamic interplay among these dimensions and how this interplay varies within different structural contexts of action" (Emirbayer and Mische 1998: 963).

Emirbayer and Mische (1998: 970) conceptualized agency as a process by which actors engage with different structural environments based on what they have experienced in the past (iteration), what they perceive as possibilities for the future (projection), and how they evaluate the past and future within the contingencies of the present (practical evaluation) (see also Bakewell et al. 2012: 23). De Haas (2014: 21) similarly argued that agency "reflects the limited but real ability of human beings (or social groups) to make independent choices and to impose these on the world and, hence, to alter the structures that shape people's opportunities or freedoms." The ability of individuals to interact with and transform structures is a key element of a more meaningful concept of agency, as it provides insight into how agency is expressed and how we might study it. 
To examine how refugees and migrants express their agency in relation to higher agency to shape their forced displacement patterns, this study adopts a framework on agency and mobility developed by Bakewell and Bonfiglio (2013) based on sociological theories of agency (Emirbayer and Mische 1998) and migrants' understandings and pursuit of a "normal" life (Galasińska and Kozlowska 2009; Lopez Rodriguez 2010; Rabikowska 2010). This framework conceptualized agency along three dimensions: aspirations, norms, and practices. We developed this framework in response to a tendency in the migration and forced displacement literature to put conflict and crisis at the center of explanatory frameworks on movement in areas affected by conflict, obscuring the existence of any mobility strategies, and furthering the conceptual divide between migration and forced displacement. In our paper, we argued that the majority of studies of mobility in the African Great Lakes over the last two decades have positioned conflict and crisis as the primary drivers of movement, as solely determining how or the ways in which people move, and as wholly shaping the impacts of movement. This is despite evidence from the sociological literature that "even in the most extreme of circumstances, social life is patterned, regular, and endowed with a logic and meaning amenable to analytic elucidation" (Wacquant 1997: 349). Wacquant (1997) maintained that rather than define a process or place by its most extreme elements, one should uncover the "order" or meaning within the "chaos" and reveal the more "normal" features of life. Following this logic, this study examines respondents' aspirations, norms, and practices related to higher education to better understand both the conflict and non-conflict-related factors that play a role in displacement. The following sections explore in more detail the framework's three dimensions to demonstrate how they are operationalized in this study.

\subsubsection{Aspirations}

The framework adapted aspirations from Emirbayer and Mische's (1998: 971) "projective" dimension, which they defined as "the imaginative generation...of possible future trajectories of action" stemming from actors' "hopes, fears, and desires for the future." Aspirations are shaped by a person's notion of the "good life" and his or her future goals. Bakewell and Bonfiglio (2013: 11) held that "[i]n the context of migration, aspirations can describe one's ambitions to move as well as ambitions that require movement to be fulfilled." Similarly, higher education aspirations may describe one's motivations to gain higher education or motivations that require higher education to be achieved, such as working in a particular profession.

The literature on aspirations and, in particular, migration aspirations, is varied. Much of this literature associates aspirations with preferences and desires and, at times, willingness, intentions, and motivations (Carling 2014; Frye 2012; Schewel 2015). While a 
helpful shorthand, preferences and desires are one-dimensional and fail to be useful in understanding how aspirations feature in a larger migration process or how aspirations compare with one another or across different persons. Willingness or motivations conflate migration aspirations with "reasons" for migration, which is in itself an inadequate descriptor of migration determinants (Monsutti 2008). Moreover, reasons are much broader than aspirations and take us away from the more individual, creative, and future-oriented aspects, which aspirations uniquely represent.

Nuanced accounts of migration aspirations certainly exist. The following is a brief overview of different ways in which aspirations have been operationalized, with reference to the context of forced migration and higher education. This overview is by no means exhaustive. Carling (2014: 2) argued that with respect to migration aspirations, the act of migration, itself, is desirable and has intrinsic value. Conversely, aspirations that require migration see it as a means to an end and as having more instrumental value (Carling 2014: 2). Distinguishing migration aspirations as means versus ends is not clearcut, as aspirations may be complex and multidimensional. For instance, one's aspiration to attend a top-ranked university in South Africa may stem from his or her aspiration to achieve educational excellence and take part in the intellectual setting that the university and its city might provide.

In addition to providing more nuanced definitions and types of migration aspirations, Carling (2014) conceptualized migration aspirations as existing on a continuum, ranging from the aspiration to stay to the aspiration to move. The aspirations nearer the extremes are more deeply held and more readily carried out in situations in which people have the necessary capabilities. The aspirations closer to the midpoint require additional inputs to be introduced to activate migration. This would indicate that it is not enough to ask a respondent whether they had an aspiration to move or gain higher education. Instead, one must delve into the meaning of respondents' aspirations relative to other life goals and desires.

Frye (2012: 1567) argued that aspirations are more fundamental to the self than desires; they are "assertions of identity shaped by cultural schemas and shared standards of morality." One's future desires are intertwined with whom one desires to be-an idealized version of oneself. This more intrinsic notion of aspirations may be, in part, why I and other researchers have found that some refugees find it challenging to talk about their future aspirations, because they are in states of extreme uncertainty and their futures are in limbo. On the other hand, Frye (2012) found that a more intrinsic notion of aspirations was why her respondents in Malawi had unrealistic educational ambitions given their individual constraints and the lack of opportunities present in the country. Their high aspirations were more a projection of their identities and principles, of how 
they saw themselves, and of how they wanted to be seen, than an indicator of possible future actions based on desires. This calls into question the degree to which aspirations are impacted by a person's contextual environment. It may therefore be the case that some of this study's respondents will have had tertiary education aspirations in their formative years, not as achievable goals or signs of taking steps towards said goals, but because such aspirations were associated with being a "good" and successful person.

A stream within the migration aspirations literature examines how aspirations arise, which may provide insight on how they are expressed. Emirbayer and Mische (1998: 985) held that aspirations can vary according to the "periods, cultures, theoretical traditions, or even individuals" in which they take shape. This echoes Ferro (2006) who argued that aspirations are formed out of market and immigration conditions, social and family pressures, as well as individual traits; as well as de Haas (2014) who maintained that one's aspirations are impacted by one's capabilities. These authors have embedded and interdependent views of aspirations. In the context of this research, such views might reveal, for instance, that a respondent's aspirations for higher education are related to the high level of basic education he or she received and his or her parents' placing a high value on education. Providing a more place-oriented notion of aspirations, Schewel (2015) argued that aspirations are formed from factors associated with origins and destinations as well as internal constraints. Hence, opportunities for higher education in South Africa might influence the formation of a respondent's educational aspirations.

This brief review has shown that both migration and higher education aspirations may be seen as either means or ends, or as inextricably linked to respondents' identities. Moreover, aspirations may be location-specific, if one's notion of the good life is tied to a specific place, higher education sector, or higher education institution. They may also be migration channel-specific, if one has goals related to being an international student or to adopting an international student lifestyle and identity.

\subsubsection{Norms ${ }^{6}$}

The norms dimension of the agency and mobility framework is adapted from Emirbayer and Mische's (1998: 971) "iterational" element, which they defined as "the selective reactivation... of past patterns of thought and action...thereby giving stability and order to social universes and helping to sustain identities, interactions, and institutions over time." This aspect of agency highlights the power of past action, routinized behaviors, social structures, identities, and institutions on present actions, which are all aspects of

\footnotetext{
${ }^{6}$ Much of this section's review of the migration norms literature comes from an earlier, draft version of the Bakewell and Bonfiglio (2013) working paper, which was solely written by the author of this thesis.
} 
or related to socio-cultural norms. Easthope and Gabriel (2008) defined norms as a set of socially sanctioned rules, customs, and values. In the context of this research, customs and values would relate to movement and the attainment of higher education. Ali (2007: 39) described migration norms as "ideas, practices and cultural artefacts that reinforce the celebration of migration as well as migrants." This could be extended to ideas and cultural artifacts which reinforce the celebration of education and educated persons.

Norms are culturally constructed and widely understood; consequently, both migrants and non-migrants, educated and non-educated persons, from a given society will understand and (possibly) value norms related to movement and higher education attainment (Åkesson 2004). In this way, norms offer a more collective aspect of agency, whereas aspirations have a greater capacity to highlight individual aspects. Of course, while someone may be aware of the norms of his or her society, he or she may act against them. Thus, norms do not wholly determine behaviors.

In addition, migration norms do not treat everyone living within a society equally and can differ according to class, generation, and gender. It is therefore necessary to qualify norms and "tease out the differences and inequalities that are often hidden by them" (Ní Laoire 2000: 239). For instance, in Morocco, Heering et al. (2004) found that migration norms differed for men and women from more conservative backgrounds. Emigration was very acceptable and common for men, but not for women, reflecting the different positions and roles that men and women played in society. Similarly, Hampshire and Randall (1999) found that different Fulani groups in northern Burkina Faso had vastly different migration norms, which varied according the groups' agricultural or pastoral modes of production and wealth.

The Moroccan and Fulani cases highlight a link that exists between norms and the external environment. While this link may play a role in prompting and influencing norms, norms are ultimately characterized by their ability to assume a self-sustaining and reproducing dynamic (Boyle and Halfacree 1998; Jones and Kittisuksathit 2003; Kandel and Massey 2002; Ní Laoire 2000). For instance, in Hyderabad, migration norms have remained salient and further intensified despite the growth of capital and investment in the city and the increase in employment opportunities, which might have otherwise reduced migration incentives (Ali 2007).

Migration and education norms may arise from repeated practices over an extended time period; from the occurrence of a large-scale movement or shift in the education sector; from repeated and extended contact with educated persons, immigrants, or return migrants; or from having family and community members abroad, gaining higher education, and engaging in transnational relationships (Asis, Huang and Yeoh 2004; 
Duval 2004; Easthope and Gabriel 2008; Kandel and Massey 2002). To explain why migration sustains itself over time, the theory of "cumulative causation" holds that each act of migration builds off of the previous and changes the context in which future migration practices are carried out (Massey et al. 1998). In Mexico, Kandel and Massey (2002) argued that children from families involved in migration to the United States have a higher probability of wanting to migrate and engage in behaviors that further increase their likelihood of migrating.

Much of the existing literature on migration norms and cultures can be conceptualized into three broad groups, which differ by degrees of embeddedness. While this literature centers on migration norms, one could extend this categorization to other types of norms, including those related to higher education. The first and least embedded group describes norms as a society's or culture's accepting, positive, or idealized beliefs about migration. For instance, Ali (2007) argued that the act of migration in India has come to enhance social mobility and prestige and to make one a more desirable spouse, prompting men to spend time abroad to improve their marriage prospects at home (Ali 2007). In Morocco, migration to Western Europe is not only accepted, but also deemed a desirable method for increasing one's socio-economic status, through increased incomes and better lifestyles (Heering et al. 2004). In the context of this study, this means that a respondent might come from a society that values tertiary education and holds those who attain it in high esteem.

The second group positions migration as an important feature of life-course transitions, most notably, the transition to adulthood in a society or culture. Easthope and Gabriel (2008: 173) described emigration norms in Tasmania as a "legitimate and unremarkable step in the process of growing up." They maintained that youth respondents believed it was "expected" and "natural" that they would leave Tasmania (Easthope and Gabriel 2008). Similarly, in Romania in the 1980s and early 1990s, the out-migration of youth seeking employment in the "world" market was perceived as a part of the transition between finishing school and becoming an adult and establishing a family. The norm has since shifted, and tertiary education is the stage at which international migration takes place (Horváth 2008).

Lastly, the third and most embedded group understands migration to be an integral part of daily life and a defining feature of culture. Despite inconsistencies with regard to the term's use, this group most nearly resembles the literature on "cultures of migration." In addition to describing migration as entrenched in everyday lives, cultures of migration perceive migration as an "ideology" that "concerns collective experiences of...history, political economy, ecology, and geography" and "notions about the life of the person" (Åkesson 2004: 6-7). Two distinct types of cultures of migration may be found in 
transnational and nomadic communities. Cape Verde provides an apt example of transnational cultures, as most Cape Verdeans have a close relative living abroad. The transnational relationships between those at home and those away - and the resources, ideas, and projects that are actively exchanged and carried out through those relationships - shape the lives and identities of Cape Verdeans (Åkesson 2004). Pastoral Fulani groups in Burkina Faso (Hampshire and Randall 1999), pastoral Hawaweer in Sudan (Haug 2002), and hunter-gathering Mbuti in the Congo region (Kelly 1983) are apt examples of nomadic cultures of migration. Such cultures practice both "logistical mobility," in which a select number of people depart from the community for temporary periods of time to carry out economic or cultural tasks, and "residential mobility," in which an entire society episodically moves its location, as it fulfils the economic and cultural tasks integral to livelihoods maintenance (Kelly 1983).

This brief review has shown that norms related to migration and higher education are collectively held and can range in intensity, from values and beliefs to ideology and identity. This study will therefore seek to create a picture of the different norms related to migration and higher education of respondents from the DRC and Somalia, which could shape their displacement patterns. Given that norms can be highly differentiated, this study will also seek to be sensitive to variation according to gender, ethnicity, community, and class, to name a few.

\subsubsection{Practices $^{7}$}

Finally, the practices dimension of the agency and mobility framework is adapted from Emirbayer and Mische's (1998: 971) "practical-evaluative" element, which referred to "the capacity of actors to make practical...judgements among alternative possible trajectories of action, in response to the emerging demands, dilemmas, and ambiguities of presently evolving situations." Practices (also referred to herein as "practical considerations") describe how people behave in the aggregate and reflect how people actually move when faced with constraints or opportunities, which may overlap with or stand in contrast to social norms and personal ideals. Factors which may determine practices in the context of mobility and higher education are related to individual and household capabilities as well as structural conditions that can serve to constrain, shape, or facilitate mobility and higher education attainment. In this sense, practices are similar to de Haas' (2014) notion of capabilities, which are individually experienced, but are shaped by one's larger household as well as structural forces, including but not limited to labor markets, insecurity, education sectors, and policies.

\footnotetext{
${ }^{7}$ Much of this section's review of the practices literature comes from an earlier, unpublished version of the working paper published by Bakewell and Bonfiglio (2013), which was solely written by the author of this thesis.
} 
De Haas (2010, 2014) observed a strong, positive relationship between capabilities characterized by economic and human development - and emigration in developing countries, as improvements in individual and household capabilities release people from economic constraints and enable them to move to places with perceived opportunities. Similarly, Carling (2002) argued that 'involuntary immobility' results from people having insufficient abilities to migrate, despite wanting or needing to as part of a survival strategy. Hence, respondents in this study may have aspirations for higher education and strong positive norms related to higher education, but whether they pursue higher education will also depend on more practical conditions related to whether they qualify for higher education, can speak the language of instruction, gain admission to a higher education institution, and can pay tuition fees. These are all factors which can link to larger structural constraints and opportunities and which comprise practices.

Macro-level or structural factors refer to organizations and patterns of behavior that "arise from complicated arrangements of social relations" and "take on a significance which is greater than the sum of its parts" (Bakewell 2010: 7). Such factors include states, policies, labor markets, status hierarchies, power inequalities, security, and social services at home versus the destination, amongst others (de Haas 2011: 10, 17; Kureková 2011). In his work on Afghan migrants in Pakistan and Iran, Monsutti (2008) argued that migration is driven by a complex combination of structural forces, including conflict and insecurity as well as poverty and expectations of economic opportunities at destinations. Further, social status and extensive migration networks mediate who participates in mobile livelihood strategies. In this study, key structural factors are likely to include levels of conflict and insecurity in origin communities, labor market structures, migration and asylum policies, refugee hosting policies, opportunities within the higher education sector, educational equivalence, and levels of development, to name a few.

Monsutti's (2008) work also highlighted that both structures and the perception of structures impact migration (see also Kureková 2011). In exploring the migration outcomes of positive versus negative expectations for future economic prospects, Czaika (2015) maintained that negative economic prospects for origin societies elicit a stronger migratory response than positive prospects in destination societies and, in particular, that expectations about labor markets prompt a stronger response than general economic prospects. These findings are particularly poignant for the respondents in this study who come from areas of conflict and crisis in the DRC and Somalia. Increased insecurity, increased constraints on the labor market and education sector, the closure of higher education institutions as a result of conflict, and the perception and anticipation of these life and livelihood threats, may all be factors that shaped respondents' forced displacement patterns. 
While capabilities and structures are defined separately and conceptualized on different scales, they are closely linked (even endogenously related) and interact in varying combinations to yield different migration practices. For instance, in the Sahel, Hampshire and Randall (1999) maintained that despite one Fulani group having cultural objections to migration - finding it to be a public display of one's poverty - some members must engage in the practice if economic conditions at home are too dire and local coping strategies do not exist. For other Fulani groups, seasonal migration is perceived positively as a livelihood-optimizing strategy, engaged in by those with a greater amount of wealth who anticipate insufficient yields from agropastoralism. In Somalia, Lindley (2010: 12) argued that it was the confluence of macro-level political and economic factors, such as outbreaks in violence in Mogadishu, persecution, chronic political uncertainty, a lack of economic opportunities, and the steep decline in individual and household socioeconomic and political capabilities that prompted a sharp increase in mobility between 2007 and 2008.

This brief review has shown that practices related to migration, forced displacement, and higher education stem from people's capabilities as well as real and perceived constraints and opportunities at the macro and micro-levels. Practices represent the third dimension of agency - distinct from individual, future aspirations and collective, past-oriented norms - because they are steeped in the realities of the present. Practices might therefore explain why some respondents act in ways that are ill-aligned with their goals and beliefs. Based on the extreme constraints they often face, practices are a particularly important dimension of agency for forced migrants.

The preceding sections have sought to elaborate and operationalize the three dimensions of Bakewell and Bonfiglio's (2013) agency and mobility framework to understand how refugees pursuing higher education shape their forced migration patterns and express their agency with respect to higher education considerations. The final section of this chapter will explore how these dimensions interact.

\subsubsection{Framework Dynamics}

Aspirations, norms, and practices are not mutually exclusive and can shape each other. For instance, norms that depict education as being a key component of life-success may shape an individual's aspirations for higher education. These dimensions are useful to distinguish analytically because they serve as different lenses for viewing the agency of forced migrants. Solely focusing on a respondents' capabilities might reveal his or her high level of basic education and funds to pay for higher education; however, it would 
not reveal whether the respondent had a desire to gain a tertiary degree and if so, the type of degree.

Additionally, using this framework, it would be possible to see whether a person's agency was expressed more as a function of individual aspirations versus socio-cultural norms, or whether practices were constrained to an extent that dominated all other aspects of agency. In other words, the framework is able to reflect the varied ways in which people express agency. Relatedly, the three dimensions do not fall into a hierarchy, with one dimension being more prominent than the other two. Each dimension shapes and is shaped by the other two. This balance is important because it is also sensitive to respondents' different expressions of agency.

Further, these dimensions depict a concept of agency which is sensitive to time. including changes over time. Aspirations are future-oriented, norms are embedded in the past, and practices are based on evaluations of the present (Bakewell and Bonfiglio 2013: 10-11). Such temporal considerations accommodate the varied life course experiences and key transitional events that impact a person's agency and mobility. Moreover, such considerations contextualize a forced migration behavior or action, and - combined with the dimension of practices, which are sensitive to macro-level factors impacting a forced migrant's capabilities - help to identify patterns of behavior and the role of larger forces in structuring movement. This connection to larger forces is often overlooked in microlevel analyses of movement. Hitlin and Elder (2007: 171 citing Flaherty 2003) argued that a temporal orientation is critical to the study of agency because time is "a fundamental aspect of social interaction." These authors maintained that actors employ different social psychological processes and exhibit different forms of agency depending on the perceived time space or time horizon.

\subsection{Conclusion}

This chapter examined and integrated several complementary bodies of academic and policy-oriented literature to understand how refugees pursuing higher education express their agency and shape their forced displacement patterns to countries of asylum. First, this chapter looked to the literature on refugee tertiary education, and while this literature did not directly examine the forced displacement patterns of tertiary educated refugees or of refugees seeking tertiary education, it revealed that higher education can be linked to the timing of flight, destination and directness of movement, educational mobility during displacement, access to resettlement and other durable solutions, and greater wellbeing and integration during displacement. This literature also links higher education attainment to the enhancement of refugee agency. 
Second, this chapter examined the international student migration literature to gain insight on how higher education may shape forced migration drivers and patterns, both at a structural level, in terms of educational constraints and opportunities, and the micro (agent) level, in terms of refugees' and migrants' educational aspirations, norms, and capabilities interacting with conflict and crisis dynamics. Based on this brief exploration, it appears higher education has the potential to shape the timing, distance, destination, and mode of forced displacement - referring to whether refugees travel alone or with family and/or using social networks.

Third, this chapter examined the literature on forced migration patterns, to understand how such movements are conceptualized, particularly with respect to refugee agency and mobility. While the more historical literature on forced displacement patterns sought to theorize and create typologies of how refugees move and revealed different patterns of refugee movement related to timing and directness, its conceptualization of refugee agency and mobility remained thin. By contrast, more contemporary studies on forced displacement patterns revealed that refugees often have mobility-related norms, aspirations, and practices that pre-exist or co-exist with conflict and that shape whether, when, where, and how refugees move.

Fourth, while recognizing the limits of extrapolating insights from the migration literature to understand forced displacement processes, this chapter examined studies on migration determinants to learn how refugee agency, expressed through the pursuit of higher education, might shape movements to asylum countries. Briefly, it found that agency may be expressed as an external or internal feedback mechanism that alters the structural environment, as a collective or household behavior, or as a function of migrants' aspirations and capabilities. While de Haas' (2014) aspirations-capabilities framework put migrant agency at its center, it lacked sensitivity to norms and past actions as well as the full range of dynamic interactions between different aspects of agency. It should be noted that applying concepts from migration studies to understand refugee mobility does not detract from the unique experiences that refugees face linked to persecution, violence, and conflict, nor does it detract from the legal claim of refugees to international protection. Rather, it underscores the fact that refugees are not passive victims and they are able to use their capabilities and sociocultural resources.

Lastly, this chapter put forward its conceptual framework on agency and mobility, developed by Bakewell and Bonfiglio (2013) to study mobility in conflict settings. This framework moves beyond notions of agency as choice and operationalizes agency as existing on three dimensions: aspirations, norms, and practical considerations. These dimensions are dynamic, interact with and shape one another, and are sensitive to time and space, making this framework apt to study how refugees and migrants express their 
Chapter 2

agency related to higher education in highly complex contexts of conflict and crisis. Reimagining this study's central research question using this framework, it asks: How do refugees and migrants who are pursuing higher education in asylum countries shape their movement patterns by expressing their aspirations, norms, and practices related to higher education? The next chapter shall outline the context, methodological approach, and research design of this study. 
CHAPTER 3

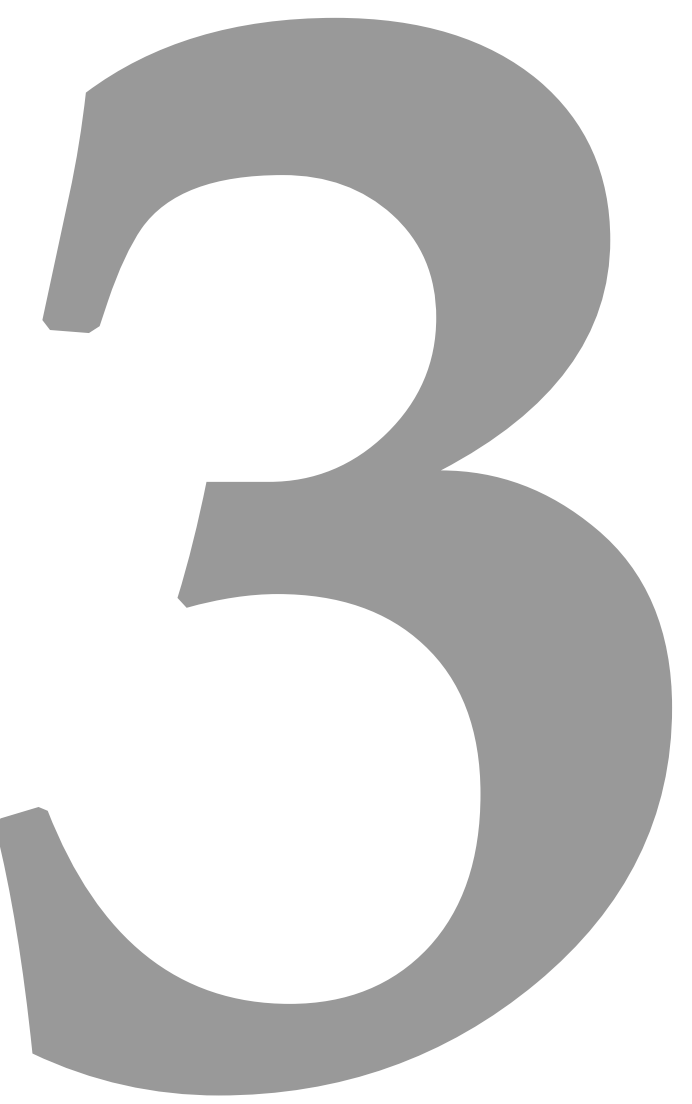




\section{Context and Methodology}


This study examines how refugees, who pursue tertiary education in the asylum countries of Kenya, South Africa, and Uganda, shape their forced displacement patterns based on their agency related to tertiary education. In so doing, this study employs a qualitative and interpretive research design which, at its core, relies on the first-hand accounts of refugees and migrants of their aspirations, norms, and practices related to higher education and mobility. This chapter begins by setting out the context and rationale for this study being set in Kenya, South Africa, and Uganda. It then discusses the decisions made and steps taken to access refugee and migrant communities, employ narrative data on the mobility and higher education trajectories of refugees and migrants, sample respondents, select data collection instruments, devise an interpretive strategy for data analysis, ensure validity and identify limitations, and examine the ethical considerations underpinning this study.

\subsection{Site Selection: Kenya, South Africa and Uganda}

This study is set in Kenya, South Africa, and Uganda because these countries are main asylum and migration destinations (Figure 4) as well as tertiary education hubs on the continent. The three countries also represent different hosting environments, proximities to conflict, and levels of development (Figure 5). These factors combined seek to draw out the greatest diversity of forced movements and agency related to tertiary education and seek to generate findings that are applicable to multiple hosting environments. This section discusses each of these factors in turn. It should be noted that all data and statistics cited in this section and elsewhere in the thesis describe the years 2015 and/or 2016 to correspond to when I carried out the fieldwork for this study.

Figure 4: Refugees and Migrants in Kenya, South Africa and Uganda in 2015

\begin{tabular}{lrrrr}
\hline Country & $\begin{array}{c}\text { Refugees, People in } \\
\text { Refugee-like } \\
\text { Situations, Asylum } \\
\text { Seekers }\end{array}$ & $\begin{array}{c}\text { Rank within } \\
\text { Africa }\end{array}$ & $\begin{array}{c}\text { International } \\
\text { Migrants (Foreign } \\
\text { Born, including } \\
\text { Refugees) }\end{array}$ & $\begin{array}{c}\text { Rank within } \\
\text { Africa }\end{array}$ \\
\hline Kenya & 593,881 & 3 & $1,084,357$ & 4 \\
South Africa & $1,217,708$ & 1 & $3,142,511$ & 1 \\
Uganda & 512,966 & 4 & 704,676 & 8 \\
\hline
\end{tabular}

Sources: UNHCR 2017 Population Statistics and UNDESA 2015 Revision

In terms of being a destination for both migration and forced displacement, South Africa ranks first on the continent for hosting international migrants and refugees, people in refugee-like situations, and asylum seekers. Kenya closely follows South Africa as a main African destination, ranking fourth for hosting international migrants and third for 
hosting refugees, people in refugee-like situations, and asylum seekers. Despite being low on the human development scale, Uganda ranks eighth on the continent for hosting international migrants, and fourth for hosting refugees. Only two other countries ranked in the top ten for both categories, Ethiopia and the Democratic Republic of Congo. Ethiopia was not selected as a research site because it did not have the same diversity of refugee populations as Kenya, South Africa, and Uganda. Also, Ethiopia, which has an encampment refugee-hosting policy similar to Kenya, does not have the same level of support as Kenya for refugee higher education in the form of in-camp programs or scholarships to attend national tertiary education institutions. The Democratic Republic of Congo was not selected as a research site because it ranked the lowest of all the countries in the top ten for hosting refugees and international migrants and because the DRC is one of this study's origin countries in the sampling scheme for respondents.

In terms of refugee policy, South Africa espouses a self-settlement policy - refugees live among nationals, mostly in urban centers, and are largely responsible for their subsistence. By contrast, Kenya requires all refugees to reside in UNHCR-administered settlements, although exemptions are given to refugees pursuing higher education or refugees with specific security or health concerns (Campbell, Crisp and Kiragu 2011: 6). Uganda represents a hybrid case, allowing self-settlement and hosting UNHCRadministered settlements (Okello 2014a: 71). If refugees in Uganda meet certain criteria concerning security, health, or education, or are deemed self-sufficient, the government grants them explicit permission to reside in urban locations (Lyytinen 2015; Mulumba and Olema 2009). In return, refugees must waive their rights to humanitarian assistance (including basic construction materials, food, free education, etc.). It should be noted that many individuals simply leave rural settlements without providing any such proof and doing so does not hinder their access to education or health services (Bonfiglio 2009; Dryden-Peterson 2003). From my past research in Uganda, I observed that refugees with higher levels of education, particularly tertiary education, settled themselves in Kampala rather than one of the country's rural settlements.

According to Mason (2000: 245), the majority of work in refugee studies is single-sited and micro-level, creating a need for comparative work, which generates insights that are applicable to different refugee settings. Chatty (2007: 266) similarly argued that comparative qualitative research in forced migration "in general, is very limited... [given] the hesitation among social scientists and others to engage in comparisons built upon qualitative data which is firmly embedded in the particular social, political and cultural context of the society under study." This study seeks to contribute to filling this gap by including research sites that are embedded within each of the main types of refugee hosting policies. In so doing, it is hoped that this study's findings on refugee mobility and agency can be relevant to a wider set of forced displacement contexts. 
In terms of proximities to conflict, Kenya and Uganda are near or adjacent to protracted or cyclical conflicts in the DRC and Somalia, while South Africa is a greater distance away. This diversity was carefully chosen to capture both movements which are more acutely affected by conflict and undertaken with little resources and preparation, which in this case would be to Kenya and Uganda, as well as movements which may be less acute and may be undertaken with relatively more resources and greater consideration for what the destination country might offer, which in this case would be South Africa. According to migration theory, countries that are a farther distance away require greater capabilities and aspirations to reach. The results of this study will allow the researcher to closely examine this theory and determine whether respondents in South Africa indeed enjoy a greater share of high aspirations and capabilities.

In terms of levels of development, in 2015 and 2016, South Africa was among the top ten countries with the highest levels of human development on the continent, and had an index rating of Medium Human Development, whereas Kenya and Uganda both had ratings of Low Human Development (UNDP 2016). Despite its low rating, Kenya had the highest level of human development of the Low Human Development countries in Africa, positioning it between South Africa and Uganda on the human development scale. Kenya remains the economic and communications hub of East Africa. Its ports in Mombasa and Lamu, amongst others, and the fact that the country is home to a major oil pipeline, make Kenya a key site for trade from the East as well as within the continent. Uganda, on the other hand, had one of the lowest urbanization and highest fertility rates on the continent in 2015 and 2016 (UNDESA 2017a). This development diversity across the research sites was intended to yield a greater variety of refugee research participants, and hence a greater variety of migration trajectories, as the migration determinants literature reveals that people coming from different socio-economic backgrounds engage in different migration strategies. For instance, families unable to support their entire migration may sponsor an individual member to move; or a person unable to fund his or her ideal migration is likely to engage in step-wise movement (Schapendonk 2009; Stark and Levhari 1982). On the other hand, individuals with greater resources to migrate are more likely to engage in direct movement (Kunz 1973).

In terms of tertiary education, all three countries have universities, colleges, and vocational schools and are higher education hubs in their sub-regions. This was key because different education levels afford different opportunities, fee structures, and acceptance criteria more likely to accommodate refugees' diverse needs and capabilities. For this criterion, rather than look for diversity among countries, it was important that I chose research countries with a sufficient level of diversity, to capture the full spectrum of potential respondents. 
Within each country, I conducted data collection in key locations for refugee and migrant settlement as well as tertiary education attainment: Cape Town and Johannesburg in South Africa, Kampala in Uganda, and Nairobi in Kenya. Despite having a strict encampment policy, Kenya allows refugees to self-settle in Nairobi if they are pursuing higher education or have specific security or health concerns. UNHCR collects data on where refugees settle in Kenya and Uganda, and Nairobi and Kampala were the only locations outside of refugee settlements with reported populations totaling 47,249 and 51,397, respectively, in 2015 (UNHCR 2016a). While UNHCR does not have data on the locations where refugees settle in South Africa, Johannesburg is the city which houses the greatest number of foreign nationals (Meny-Gibert and Chiumia 2016; Peberdy 2013). This is not surprising as Gauteng is the economic hub of the country. The Western Cape, where Cape Town is located, houses the second-largest population of foreign nationals.

This study also carried out data collection in Kakuma Refugee Settlement in Kenya, which, at the time, was among the largest refugee settlements in the world (UNHCR 2016a). Over the course of conducting semi-structured interviews in Nairobi, I encountered many respondents who had lived in Kakuma Refugee Settlement and most had lived in one of the country's refugee settlements at some point in their lives. This was likely the result of Kenya's encampment refugee hosting policy. Numerous opportunities for higher education at the technical level are available within the settlement through online distance and blended learning programs. Blended learning programs, as the name suggests, are hybrid programs that combine online learning with more traditional, classroom learning. Hence, a student might receive the majority of his or her learning materials and instructions online, but also have an instructor who is physically present to assist in the learning process. While not the focus of this study, I interviewed a number of refugees who had received such online education, for they had gone on to enroll in more conventional college and university education programs. 
Figure 5: Summary of Context in Kenya, South Africa and Uganda

\begin{tabular}{|c|c|c|c|c|c|c|c|}
\hline Country & $\begin{array}{l}\text { Rank in } \\
\text { Africa: } \\
\text { refugees, } \\
\text { persons in } \\
\text { refugee- } \\
\text { situations, } \\
\text { asylum } \\
\text { seekers }\end{array}$ & $\begin{array}{c}\text { Rank in } \\
\text { Africa: } \\
\text { migrants } \\
\text { (foreign } \\
\text { born, } \\
\text { refugees) }\end{array}$ & $\begin{array}{c}\text { Refugee } \\
\text { hosting } \\
\text { policy }\end{array}$ & $\begin{array}{l}\text { Conflict } \\
\text { proximity }\end{array}$ & $\begin{array}{l}\text { HDI } \\
\text { level }\end{array}$ & $\begin{array}{c}\text { Higher } \\
\text { education } \\
\text { sector }\end{array}$ & $\begin{array}{l}\text { Main sites: } \\
\text { refugee } \\
\text { settlement } \\
\text { and higher } \\
\text { education } \\
\text { attainment }\end{array}$ \\
\hline Kenya & 3 & 4 & Camp & Borders & Low & Differentiated & $\begin{array}{r}\text {-Nairobi } \\
\text {-Kakuma } \\
\text { Settlement }\end{array}$ \\
\hline $\begin{array}{l}\text { South } \\
\text { Africa }\end{array}$ & 1 & 1 & $\begin{array}{l}\text { Self- } \\
\text { Settle }\end{array}$ & $\begin{array}{r}\text { Does Not } \\
\text { Border }\end{array}$ & Med & Differentiated & $\begin{array}{r}\text {-Johannesburg } \\
\text {-Cape Town }\end{array}$ \\
\hline Uganda & 4 & 8 & Hybrid & Borders & Low & Differentiated & -Kampala \\
\hline
\end{tabular}

Sources: UNHCR 2017 Population Statistics, UNDESA 2015 Revision, Human Development Index 2016, UNDP

This section discussed the rationale for situating this study in Kenya, South Africa and Uganda, based on factors that seek to draw out the greatest diversity of respondents and their forced displacement trajectories. Further, it stated how this study selected the locations within each country to carry out data collection, based on their being main sites for refugee settlement and higher education attainment. The next section discusses the design and process of data collection within each country.

\subsection{Gaining Access to Refugee and Migrant Communities and Institutions}

To obtain information on the first-hand experiences of refugees and migrants pursuing higher education in Kenya, South Africa, and Uganda, I had to gain two forms of access, institutional and individual. Institutional refers to the access granted by refugee and migrant-assisting organizations and higher education institutions, which required that I follow specific bureaucratic procedures and hierarchies of approval. Individual refers to the access granted by refugees and migrants themselves, which required multiple points of entry and a great degree of trust.

To gain institutional access, I had to obtain research permits from Uganda's National Council for Science and Technology and Kenya's National Commission for Science, Technology and Innovation. For South Africa, it was sufficient to obtain research clearance from Maastricht University's Ethical Review Committee. I also affiliated with a local academic or research institution in all three countries and had my research proposal 
and instruments reviewed by each institution. I affiliated with the African Migration and Development Policy Centre in Nairobi, the African Centre for Migration and Society at the University of the Witwatersrand in Johannesburg, the University of the Western Cape in Cape Town, and Makerere University in Kampala. In Kakuma Refugee Settlement, I was hosted by, and my point of initiation was with, the Jesuit Refugee Service, which is an international organization that is a main provider of higher education and non-formal education in the settlement.

In all three countries where data collection was carried out, it is not possible to conduct refugee and migrant interviews, or interview experts at public universities, nongovernmental organization, or international organizations without first showing that you have received the necessary clearance, and copies of such documentation are regularly requested and reviewed. A reason for this institutional requirement is that refugees and migrants are considered to be a security concern by national authorities. Refugees have been recruited to work for rebel movements based in their countries of origin or have been threatened and targeted by parties in home conflicts. A number of respondents described experiences with insecurity and violence. Consequently, host governments must screen anyone wishing to conduct research at a refugee organization or among refugee and migrant populations to ensure that he or she will not put people at risk.

The second form of access I had to gain was to the refugees and migrants themselves. In the urban areas of Cape Town, Johannesburg, Kampala, and Nairobi, where the majority of this research took place, gaining access was a challenge as refugees and migrants are dispersed throughout cities, often living in neighborhoods with co-nationals. Further, I had to establish a degree of trust and understanding with potential respondents for them to agree to speak with me, especially those who did not have official status and wanted to avoid identification by the authorities.

To identify refugee and migrant respondents with a connection to university education, the primary point of initiation at each research site was the local university or research institution where I gained a visiting researcher status. Becoming embedded within higher education institutions afforded a more collegial and equitable relationship with research participants and helped to access and negotiate refugee student communities (Maxwell 2004: 84). Moreover, the institutions where I was affiliated had vast experience with each country's refugee and migration issues, and researchers and staff members extended invaluable contacts to key experts and stakeholders.

Within universities, international student organizations and other student associations provided invaluable support in reaching out to potential respondents, including students who never enrolled or had graduated, and organizing interviews, as often the social networks of such organizations were very broad. In contacting each student organization, 
I first met its leadership and presented an outline of my study, consent form, semistructured interview guide, and ethical review documentation. I also met respondents by simply being present at universities and talking to students, whether at the cafeteria or in seminars. Further, I met with staff and leadership at the international student offices and registrar offices of universities, colleges, and technical schools. Staff provided an important perspective for expert interviews and, on a few occasions, provided introductions to potential student respondents.

To identify respondents with certain characteristics who were more difficult to locate, for instance individuals who had dropped out of higher education programs, I hired a small number of research assistants, who were a combination of national as well as refugee and migrant students and who had different relationships to higher education. I call these individuals research assistants as they were not affiliated with particular organizations and they helped me to cover the wide geographies of each city and make appointments with potential respondents. These assistants were fully briefed on the objectives of my research, the interview guide, and the interview consent form; received basic methodological training, particularly as it related to fieldwork; and could help to answer the basic questions of potential respondents.

Subsequent points of initiation with refugee and migrant communities included refugee and migrant community-based organizations, community leaders, churches, nongovernmental organizations, and international organizations. As with speaking to the leaders of student organizations, I found that it was important to speak with community leaders to introduce myself as the researcher and to outline the research project and research instruments, as they were often gatekeepers to speaking with refugees and migrants. Such leaders could also help me to communicate my position as a researcher and communicate that there were no "right" answers to the questions that I was asking. Refugees and migrants trusted the judgement of community leaders, so if such leaders understood the research and trusted me as the researcher, potential respondents were more likely to be open to being interviewed and less likely to tell me what they perceived I wanted to hear.

The importance of building trust with points of contact and gatekeepers extended beyond leaders of student organizations and communities to refugee and migrant assistance organizations, churches, and educational institutions. In addition to presenting my research and ethical clearance to these entities and spending time with their staff, I also provided research expertise, when requested and only on a voluntary basis, based on my experiences working in the field of refugee education. Bloch (2007: 236) argued that, "the premise of trust, the development of good relations and adherence to good ethical practice are basic requirements of refugee research" (see also Hynes 2003). 
Aside from issues of "making contact" and building trust, a final issue of gaining access to refugee and migrant communities relates to the challenges presented by using specific contact points, gatekeepers, and research assistants, and the potential consequences for this study. I attempted to have a wide range of points of initiation, and hence a diverse set of gatekeepers, to tap into different social networks, to ensure a varied sample and reduce possibilities for selection bias (Bloch 2007; Jacobsen and Landau 2003). No single point of initiation was used more than others in an attempt to reduce potentials for selection bias and homogeneous interview data. Moreover, only a select number of respondents were identified through each point of initiation or gatekeeper. This was to ensure that my sample did not reflect a particular social network or limited set of networks (Atkinson and Flint 2001). Where possible, I tried to locate individuals not actively connected to assistance organizations, in an effort to identify more marginalized groups and a greater variety of refugee and migrant experiences (Bloch 2007; Castles et al. 2002; Jacobsen and Landau 2003). Further, my purposive sampling scheme (detailed in Section 3.4), was another way to overcome potential selection biases introduced by gatekeepers and research assistants, since the scheme required that I interview specific numbers of respondents with particular sets of criteria.

In sum, I had to obtain two forms of access to carry out research with refugees and migrants in Kenya, South Africa, and Uganda - institutional and individual. Individual refers to the access granted by refugees and migrants themselves, which required multiple points of entry and a great degree of trust, while institutional refers to the access granted by refugee and migrant-assisting organizations and higher education institutions, which required following specific bureaucratic procedures and hierarchies of approval. Gaining research clearance and undergoing ethical review were crucial to obtain both forms of access.

\subsection{Data: Quantitative Data on Migration and Forced Displacement Stocks}

No complete discussion can be had of refugee agency without an examination of the context within which agency is expressed. Hence, in Chapter Five, this study examines the patterns of forced displacement and migration from, to, and between the selected sending and receiving countries to situate respondents' movements within broader movement trends taking place over time and space. To identify patterns of movement at the macro-level, this study obtained quantitative data on migrant and forced migrant stocks from the United Nations Department of Economic and Social Affairs (UNDESA), data on the population sizes of refugee camps from the United Nations High Commissioner for Refugees (UNHCR), and data on international student migrant stocks from the statistics branch of the United Nations Economic, Social and Cultural Organization (UNESCO). The following is an in-depth discussion of these data and their 
limitations. All data discussed in this section and elsewhere in the thesis describe the years 2015 and/or 2016 to correspond with when I conducted the fieldwork for this study.

For all developing countries, UNDESA includes data on refugees and persons in refugeelike situations in its estimates of international migrants. This is because these countries tend to host greater numbers of refugees, experience rapid influxes, and restrict refugees' freedom of movement and settlement and, hence, tend not to include refugees in their national census data (UNDESA 2015; UNDESA 2017b). For the years up to and including 2015, the stock data for developing countries do not include asylum seekers. ${ }^{8}$ Hence, I use the term "migrants and refugees" when referencing such data in Chapter Five. This study carried out a separate examination of the stock data on refugees, persons in refugee-like situations, and asylum seekers to see whether trends for international forced migrants mirrored those of international migrants. I refer to such data using the term "refugees and asylum seekers." This study included asylum seekers in exploring the international forced migrant stock data because in countries with lower capacities to process asylum claims and/or large numbers of asylum seekers, asylum caseloads represent a significant share of the total forced migrant population. For instance, in 2015 there were approximately 121,000 refugees (from all origin countries) in South Africa as compared to more than one million asylum seekers awaiting refugee status determination (UNHCRc Population Statistics 2018). Moreover, in such countries, many asylum seekers have been awaiting refugee status determination for years rather than months. It is because of this issue of long waiting times that there is a less of a risk that in a given year a person will be double-counted as an asylum seeker and refugee. Further, it is unlikely that the number of people double-counted would exceed the number of undocumented migrants and refugees in a country.

To provide some definitions for these forced migrant categories, according to UNHCR (2014), "persons in refugee-like situations" is not a legal, but a descriptive category which includes "groups of persons who are outside their country or territory of origin and who face protection risks similar to those of refugees, but for whom refugee status has, for practical or other reasons, not been ascertained." This suggests that some "undocumented" or "unregistered" refugees are included in these estimates. Asylum seekers are "[p]ersons whose application for asylum or refugee status is pending at any stage in the asylum procedure" (UNHCRc 2014). Individuals going through the bureaucratic process of becoming asylum seekers and who have yet to obtain their papers are included in these estimates. This is an important distinction because asylum countries have different caseloads and capacities and, hence, different waiting periods for people

\footnotetext{
${ }^{8}$ Based on an interview with Pablo Lattes at the Population Division of UNDESA, the 2017 Revision includes asylum seekers in its migration stock estimates after 2015.
} 
to be recognized as asylum seekers and refugees. Hence, some of these people may become frustrated and drop out of the registration process, while others might receive a negative determination and decide to continue living in the host country. While, undocumented or unregistered refugees are nearly impossible to count, given that some choose to hide their status and have no contact with organizations, the flexibility of these two categories provides a sense of the relative differences in both registered and unregistered refugee populations among this study's sending and receiving countries. Including such persons within this study is crucial because they highlight, along with student migrants, the range of different movement trajectories that people who have been impacted by conflict and crisis take.

Although undocumented refugees and migrants are included in this study, this chapter does not review specific estimates of their numbers, for several reasons. First, the number of undocumented refugees and migrants is nearly impossible to count or estimate, as many choose to hide their status and have no contact with organizations. The reasons for refugees not to register are sometimes linked to why they are a hidden population, because they face individual threats to their security from revealing their identities, or perceive discrimination in the registration process (Bailey 2004). Second, within each country, the estimates of undocumented refugees and migrants vary greatly depending on the source. For instance, in 2008 the Head of Research at the Refugee Law Project estimated that there were between 50,000 and 100,000 living in Kampala, while the same year, the Office of the Prime Minister of Uganda estimated there were 10,000 urban refugees in Kampala (Okello, personal interview, July 16, 2008). Lastly, it would be difficult to compare any estimates across countries because of the different hosting policies that host governments have for migrant and refugee populations, which would impact how the undocumented are counted. In a country like Kenya, with a strict encampment policy, a smaller number of undocumented urban refugees may exist, or such refugees may be more of a hidden population, out of fear of deportation. By contrast, in Uganda, which has an urban self-settlement policy, there may be fewer undocumented refugees than Kenya. It is also possible that there is a greater share, if refugees do not see a protection need in registering because legal status does not improve integration or access to services (Bailey 2004).

It should also be noted that for the majority of African countries, refugee and migrant stock data are not available before 1990, which is why the graphs below describe only the last 25 years. Moreover, stock data on asylum seekers are not available before 2000, so all graphs depicting forced migrant populations overtime include asylum seeker data from the year 2000 onwards. Similarly, data on international student migration in Africa are not available before 1998. For the purposes of this study, such a time frame is sufficient for getting a sense of the migration ties between countries and of how established are 
migrant and refugee populations within receiving countries. Additionally, in 2007, UNHCR changed the way it measured refugee and forced migrant populations, by including people in refugee-like situations in refugee estimates. Therefore, the data before 2007 cannot be compared with the data from 2007 onwards. This chapter has kept the data for these two time periods within the same graphs to better highlight the relative differences between countries.

Finally, in terms of international student migration, a number of African countries do not track their international student migrants. Kenya and Uganda are two of these countries. For this reason, stock data on Congolese and Somalia students are not accurate as these stocks are made up of data from countries that have such measurement capacity. As a result, the data on Congolese and Somali international student migration reveal considerable stocks in Europe and marginal stocks within their neighboring countries. In this way, looking at total stocks or stocks broken down by region and origin country is misleading. By contrast, South Africa tracks its international student population, enabling a discussion of the insights from these data.

\subsection{Data: Narratives of Refugees and Migrants Pursuing Higher Education}

This study seeks to understand how refugees and migrants who are pursuing higher education in asylum countries shape their forced displacement patterns in relation to higher education. In doing so, this research puts refugees' and migrants' accounts or narratives of their forced migration experiences and their understandings of forced migration and higher education at the center of analysis. Eastmond (2007: 249) argued that narratives are well suited to forced migration studies as they provide information on the lives of people who are embedded in contexts that an external researcher would otherwise be unable to access, and they value refugees' interpretations of their own experiences (see also Benezer and Zetter 2014: 313; Hinchman and Hinchman 1997; Powles 2004). Indeed, narratives are "grounded in the phenomenological assumption that meaning is ascribed to phenomena through being experienced and....we can only know something about other people's experiences from the expressions they given them" (Eastmond 2007: 249 citing Schutz 1972: 99-100).

Benezer and Zetter (2014: 313 citing Wong 1992) held that the narrative method is "the closest one can get to the experience itself from a retrospective viewpoint." Learning about the past displacement and education experiences and actions of refugees and migrants therefore requires the narration of first-hand experiences. Additionally, given that narratives are projections of refugees' and migrants' own selves, they are steeped in refugees' judgement, social relations, cultural repertoires, feelings, attitudes, and actions 
surrounding events (Benezer and Zetter 2014; Eastmond 2007: 250-251). Thus, they are an apt medium to study the agency of migrants and refugees pursuing higher education, which encompass aspirations, norms, and practices.

To answer this study's overarching research question, narrative data was obtained on refugees' and migrants' forced displacement and higher education trajectories. This included information on more objective elements of their movements, such as distances and destinations, dates of travel, modes of transportation, social contacts at destinations, company during movements, any migration statuses received, and any stated reasons for movements. Also included were more subjective elements, such as refugees' and migrants' experiences with conflict and crisis, socio-cultural norms and values toward movement and education, perceptions of acceptable and unacceptable reasons for movement and education, and personal attitudes and aspirations toward movement and education.

In the same vein, information was obtained on refugees' and migrants' educational and employment aspirations at different points in their lives up until the present and the experiences their friends and family members had with employment. While higher education is the focus of this study, information on employment was sought because education and employment are often inextricably linked. Tati (2010: 284) argued that "at the place of destination, getting better education is not incompatible with participating in the labor market." In his study on Congolese migrants in South Africa, he maintained that some migrants use higher education as a way to access foreign labor markets or they work and study simultaneously. Hence, collecting data on employment aspirations can provide insight into higher education strategies.

\subsection{Sampling Strategy}

Refugees and migrants pursuing tertiary education are likely to represent a self-selected group with high levels of agency within the total refugee population. They may have previous tertiary education experiences from their origin countries or may have graduated from secondary school, making them a highly educated group as compared to the wider refugee population. They may have high educational aspirations and come from families and communities with strong, positive tertiary education norms. Also, they or their families may have the resources required for tertiary enrollment or they may have secured a scholarship for their certificates, diplomas, or degrees. As a group with a high level of agency, refugees and migrants pursuing tertiary education may provide insight into what is possible in terms of being able to shape the when, where, and how of their forced displacement patterns. In other words, given their potentially high aspirations, 
positive norms, and advantaged socio-economic backgrounds, this group may be more likely to exercise greater choice and power over their forced movements.

To identify the refugees and migrants pursuing tertiary education to be included in this study, I applied a purposive sampling scheme at each research site based on: origin country, gender, education level, and relationship to tertiary education (Figure 6). Purposive selection allows the researcher to achieve heterogeneity and make comparisons along factors of interest to the study, in this case, factors related to tertiary education and origin country (Maxwell 2004: 90). Additionally, purposive selection provides a systematic approach when the total population is unknown and cannot be sampled in a representative way, as is often the case with refugees, asylum seekers, and unregistered refugees (Bloch 2007: 234). The following is a brief discussion of the rationale for my sampling criteria and a detailed description of the sample I collected.

Figure 6: Purposive Sampling Scheme

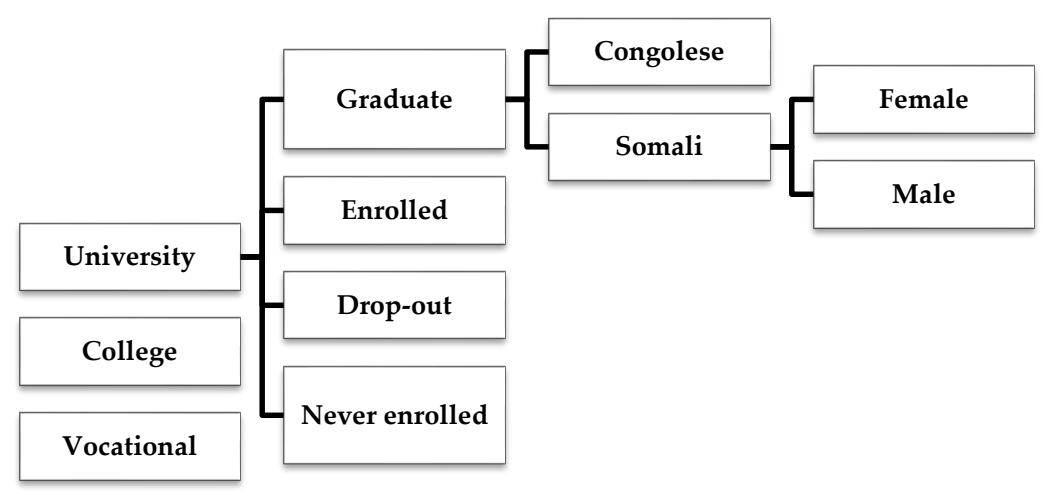

In terms of origin country, I targeted refugees from the Democratic Republic of Congo and Somalia. Both countries are experiencing protracted conflict and crisis and have vastly different migration histories and cultures. Moreover, considerable Congolese and Somali refugee and migrant populations may be found in all three research countries (Figure 7). This study focused on more than one origin country, should one country exhibit particular forced displacement patterns based on the nature of its conflict, or particular underlying mobility norms that might structure forced movements. Hence, the choice of both countries attempts to capture a diversity of forced displacement patterns. 
Figure 7: Congolese and Somali Migrants and Refugees in each Research Country in 2015

\begin{tabular}{lrr}
\hline & DRC & Somalia \\
\hline Kenya & 11292 & 488470 \\
South Africa & 70077 & 69688 \\
Uganda & 303580 & 28586 \\
\hline Source: UNDESA 2015 Revision
\end{tabular}

Gender was a component of the sampling scheme to learn whether the factors that shaped the forced displacement patterns of male refugees were the same as female refugees. Based on the way this study conceptualizes agency, as a combination of socio-cultural norms, individual aspirations, and constraints and opportunities, the agency of men and women is likely to differ. Women are subject to different social expectations and play different socio-economic roles in their households. In terms of education level, this study targeted refugees and migrants at universities, colleges, and technical schools. This was important as these education levels afford different opportunities, fee structures, and acceptance criteria more likely to accommodate the diverse needs and capabilities of refugee and migrant students. Lastly, relationship to tertiary education refers to four categories of refugees and migrants: graduates, those currently enrolled, dropouts, and those never enrolled. This dimension was perhaps the most important because it helped to isolate factors that are unique to refugee and migrant students. It does this by comparing graduates and currently enrolled students to students who have dropped out or never enrolled, to construct a quasi-counterfactual using qualitative methods. To compare refugees across these levels, respondents who never enrolled had to possess qualifications meeting the requirements of enrollment.

At each research site, I aimed to identify one respondent that met each unique combination of the sampling criteria. For instance, in Kenya, I aimed to interview one Congolese female who graduated from a college diploma program. This meant identifying 48 respondents at each research site and 144 respondents across all research sites. ${ }^{9}$ Figure 8 illustrates my projected sampling scheme for each research site.

\footnotetext{
${ }^{9}$ It should be restated that in South Africa, I carried out data collection in two locations: Cape Town and Johannesburg. In each city, I interviewed a number of respondents with the same combination of sampling criteria, so that I could compare their experiences. Thus, the number of interviews collected in South Africa exceed those of Kenya and Uganda. Moreover, I carried out a select number of interviews in Kakuma Refugee Settlement, as many if not most refugees living in Kenya settle in one of the country's settlements at some point during their displacement.
} 
Figure 8: Projected Purposive Sampling Scheme per Destination Country

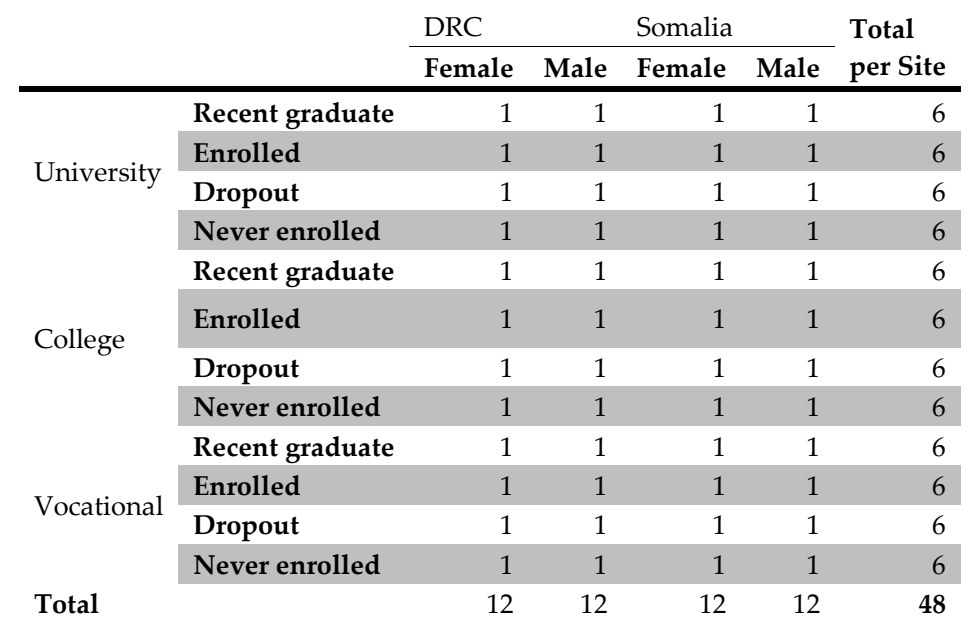

However, during the process of data collection, it proved difficult to identify respondents with certain characteristics, particularly respondents who had dropped out of their studies and female respondents. Moreover, respondents studying at the university level were more easily identifiable and, on occasion, I interviewed respondents with the same combination of sampling characteristics. Figure 9 shows the actual number of respondents that I interviewed at each research site (see Annex for full sample breakdowns). In total, I collected 149 interviews. Figures 10 through 13 provide details of the sample in each destination country broken down by the sampling criteria.

Figure 9: Sample in Destination Countries

\begin{tabular}{lllll}
\hline & Kenya & South Africa & Uganda & Total \\
\hline Refugee and Migrant Respondents & 38 & 62 & 49 & 149 \\
\hline
\end{tabular}

In terms of sampling by origin country, I aimed to interview 24 refugees and migrants from both Somalia and the DRC at each research site. Figure 10 shows that the number of respondents that I actually interviewed from Somalia and the DRC comes very close to or exceeds the desired targets, with the exception of Somali respondents in Kenya. 
Figure 10: Sample Breakdown by Origin Country

\begin{tabular}{lrrr}
\hline & DRC & Somalia & Total \\
\hline Kenya & 22 & 16 & 38 \\
South Africa & 32 & 30 & 74 \\
Uganda & 27 & 22 & 66 \\
Total & 81 & 68 & 149 \\
\hline
\end{tabular}

In terms of gender, this study set out to conduct interviews with an equal number of male (24) and female (24) respondents at each research site. However, I struggled to identify women and gain their permission to interview. In South Africa, I struggled to identify female respondents from Somalia, while in Uganda, I struggled to find female respondents from the DRC. By contrast, in Kenya, the number of male and female respondents was balanced for respondents from both origin countries. Figure 11 provides a breakdown of the gender balance of the respondents sampled at each research site.

\section{Figure 11: Sample Breakdown by Gender}

\begin{tabular}{lrrr}
\hline & Male & Female & Total \\
\hline Kenya & 19 & 19 & 38 \\
South Africa & 35 & 27 & 62 \\
Uganda & 27 & 22 & 49 \\
Total & 81 & 68 & 149 \\
\hline
\end{tabular}

Figure 12 reveals the breakdown of the sample by higher education level at each research site. These figures do not add up to the total sample figure of 149 as they exclude the 34 respondents who never enrolled in any form of higher education. According to the projected sample (see Figure 11), I aimed to interview 12 respondents at each level of tertiary education. I found it a challenge to identify the full number of respondents at colleges and technical schools, because I had less points of contact at such institutions. Also, certain trades and vocations are highly protected by national governments and are prioritized for citizens. One such example is the nursing profession in South Africa (Madikane and Brennan 2016, April, personal interview). Consequently, it is possible that fewer migrants and refugees are found at these institutions. Respondents at universities were the most readily identified for a number of reasons. First, I affiliated with a university at each research site and was therefore more embedded within the university environment. Second, the universities visited tended to have more developed student organizations than colleges or technical schools, which proved invaluable for identifying respondents. Lastly, universities had larger and more centralized administrations, and 
international student offices as well as university registrars were other good resources for making contacts with students.

Figure 12: Sample Breakdown by Tertiary Education Level

\begin{tabular}{lrrrr}
\hline & University & College & Technical School & Total \\
\hline Kenya & 8 & 11 & 10 & 29 \\
South Africa & 30 & 14 & 14 & 58 \\
Uganda & 17 & 5 & 14 & 36 \\
Total & 55 & 30 & 38 & 115 \\
\hline
\end{tabular}

Lastly, Figure 13 shows the breakdown of my sample by respondents' relationship to tertiary education at each research site. According to my sampling scheme, I aimed to collect 12 interviews for each relationship to tertiary education: graduated, enrolled, dropped out, and never enrolled. However, I was unable to identify many students who dropped out of higher education programs. As was explained by several respondents and key gatekeepers, this was likely because of the stigma attached to leaving school and because such individuals sometimes decide to move onward to other countries or to return to their origin countries after not succeeding in their educational plans. While this is an acknowledged limitation of the study, as it may exclude refugees from lower socioeconomic backgrounds or with lower education aspirations, the category of "never enrolled" may act as a suitable comparison group.

Figure 13: Sample Breakdown by Relationship to Tertiary Education

\begin{tabular}{lrrrrr}
\hline & Graduated & Enrolled & Dropped out & Never enrolled & Total \\
\hline Kenya & 12 & 14 & 3 & 9 & 38 \\
South Africa & 19 & 21 & 10 & 12 & 62 \\
Uganda & 14 & 21 & 1 & 13 & 66 \\
Total & 45 & 56 & 14 & 34 & 149 \\
\hline
\end{tabular}

Despite not identifying a respondent for every unique set of characteristics, the majority of the combinations of sampling criteria were identified, and the scheme succeeded in sampling for diversity as well as number. In discussing the use of quotas when a population - in her case a migrant population - cannot be sampled in a representative way, Bloch (2007: 235) argued that even when the exact quota target is not achieved, analysis may still be carried out on the explanatory variables of interest, if the selection of quotas was theoretically grounded. Moreover, proceeding with such an analysis might not have been possible if no quotas were set out. While this research is qualitative in 
nature and has both inductive and deductive elements to its analysis, this point on sampling that Bloch (2007) made when discussing her survey-based research can extend to sampling refugees and migrants for narrative data.

\subsection{Data Collection Instruments}

To obtain information on the structural factors shaping respondents' forced displacement patterns, I examined the secondary academic and policy literatures on forced displacement and migration patterns and drivers within Africa, migration and asylum policies, regional cooperation agreements, higher education policies, and the higher education sectors in this study's destination and origin countries. I also examined quantitative data on refugees, migrants, and higher education available for each country and carried out the aforementioned expert interviews to fill in the gaps in knowledge and obtain first-hand information on migration and education policies and practices.

To obtain narrative data on refugee and migrant experiences with displacement and the agency-based factors related to tertiary education that shaped their movements, I employed three complementary primary data collection methods: semi-structured biographical interviews, structured expert interviews, and participatory observation (see Appendix for instruments).

First, the main method of primary data collection in this study and the main source for respondent narratives was semi-structured, biographical interviews with refugee and migrant respondents. This method afforded the attainment of rich, subjective detail about a feature or set of features of a respondent's life - in the case of this research, detail about the mobility and education experiences of refugees over the course of their lives (Fetterman 1998: 52). Given their biographical and subjective nature, interviews were sensitive to time and space, as they prompted respondents to explore their pasts, presents, and potential futures. Questions prompted respondents to discuss their personal histories of education attainment, movement, and displacement; experiences with conflict and crisis; different aspirations and "visions" they have held over the course of their lives up until the present; the norms, values, and daily experiences of their families and communities related to education and mobility; individual and household socio-economic situation growing up and in asylum countries; interactions with education and/or refugee assistance structures in asylum countries; and experiences pursuing higher education in asylum countries. As part of these interviews, respondents and I traced their movement trajectories over time and space, at times on paper, to draw out the details of their moves, such as modes of transportation or who they moved with, to name two examples. 
Biographical methods such as life histories or unstructured biographical interviews would have been ill suited to this study, for while they obtain rich, subjective details about the lives of respondents, they are not guided by certain factors of interest. Instead, they provide in-depth information on what respondents perceive as important to the overarching narratives of their lives. As mentioned in the previous section, I conducted 149 biographical interviews (see the annex for full list).

Second, I carried out structured expert interviews with tertiary education administrators, student organization representatives, refugee and migrant development practitioners, refugee and migrant community-based organization representatives, and forced migration and education policymakers and scholars. These interviews provided an alternative information source and an additional perspective on refugees' and migrants' experiences with tertiary education and with asylum and migration regimes. Further, as interviewees were embedded within institutions working in the asylum, migration, and higher education fields, these interviews served as a key information source on the structural factors shaping forced migration patterns.

To identify individuals for expert interviews who were connected to higher education institutions, I emailed, called, and visited the international student offices and/or academic registrar offices at the institutions where respondents were enrolled or had been enrolled. I provided details of my research, interview questions, and ethical clearance to representatives so that they could determine who would be best placed to interview. In several cases, academic institutions declined to participate in this study. As the focus of this data collection method was to gain an alternative information source and learn the role that institutions might play in how refugees and migrants make decisions about their higher education attainment, it was not essential to sample every institution where Somalis and Congolese might be enrolled. Importantly, I was able to identify experts at the tertiary education institutions where many of my respondents were enrolled or had been enrolled. Moreover, I interviewed experts at institutions that were among the most well-known for enrolling foreign students, e.g. Makerere University and Kampala International University in Uganda, the University of the Western Cape and the University of the Witwatersrand in South Africa, and Daystar University and the University of Nairobi in Kenya. To identify individuals for expert interviews at refugee and migrant community-based organizations, non-governmental organizations, and international organizations working on issues of refugee higher education, I made a list of all the key institutions working in each of the research sites and similarly contacted these organizations asking for their participation. I drafted this list through online research, my own experience working in these countries, and through asking both my respondents and other experts with whom I should speak. Once again, not every organization or expert agreed to participate. However, the main organizations and 
United Nations implementing partners working on refugee higher education offered their time and input, including Windle Trust, the Jesuit Refugee Service, and the Danish Refugee Council. In total, I carried out 35 expert interviews (see Annex for full list). Figure 14 shows the number of expert interviews carried out in each research country.

Figure 14: Expert Interviews per Destination Country

\begin{tabular}{lllll}
\hline & Kenya & South Africa & Uganda & Total \\
\hline Expert and Key Stakeholder Interviews & 11 & 16 & 8 & 35 \\
\hline
\end{tabular}

I conducted all of the semi-structured, biographical interviews with refugee and migrant respondents as well as the expert interviews. This ensured consistency in the way that questions were asked as well as what lines of inquiry were pursued. Being the sole data collector also enabled me to better observe and compare the experiences of respondents and allowed me to identify any gaps within the questions and understand the most effective ways to formulate questions. For instance, early on in the data collection process at the first research country, it became clear that asking about respondents' future "aspirations" was not as clear as asking respondents about their "visions" for the future. I also learned early on that asking how respondents perceived the meaning of the word "refugee" was an important question to ask, and I adjusted my semi-structured interview guide accordingly.

Additionally, semi-structured, biographical interviews with respondents as well as expert interviews were conducted in English. This study took place in anglophone African countries. With the exception of South Africa, which has a bilingual - English and Afrikaans - higher education sector, the other research countries had higher education sectors that operated completely in English. Hence, for refugees and migrants to participate in higher education, they had to speak English at an advanced level. This meant that I could conduct interviews without an interpreter, and thus eliminated a potential barrier in communication and understanding. For the respondents who were not and had not enrolled in higher education, but who had the qualifications sufficient for enrollment, this included the ability to converse in English, as higher education institutions require proof of language skills. There were a limited number of exceptions made for the sub-category of "never enrolled" respondents, in that such respondents spoke in their mother tongue and I had to enlist the help of a translator. For this limited number of cases, I wanted to see whether the experiences and aspirations of these respondents with, and for, higher education were different from those who did have knowledge of the English language. 
I recorded semi-structured interviews with respondents and more structured interviews with experts with the consent of the research participants. All but two respondents agreed to be recorded. Interview recordings were transcribed verbatim, so as to maintain respondents' forms of self-expression, preserve the original structures of conversations, and ensure transcripts were as independent of the transcriber as possible. I enlisted the help of eight research assistants to transcribe the 149 respondent interviews and 33 expert interviews. To ensure accuracy and consistency across all assistants, I convened a training session on transcribing interviews; created a transcription guide with rules and a reference list of common and more colloquial words and phrases used by respondents from each country of origin and destination; and tasked one assistant with reviewing and checking the accuracy and consistency of all the transcriptions. I also reviewed the quality of transcriptions throughout.

The final primary data collection strategy I carried out was engaging in participant observation and regular field memo writing at contact points with refugees to better understand their perspectives and environments and to gain insights not possible through semi-structured, biographical interview data (Fetterman 1998: 35). This method also prompted regular contact with respondents and community groups and, hence, served to build trust between the research participants and me.

\subsection{Data Analysis}

While narratives serve as the central methodological frame of this study, interpretive analysis - originating within political studies and later used in the fields of migration and forced migration studies - provides a language and approach to examine these frames. Interpretive approaches start from the position that to understand refugees' actions, it is not enough to observe them taking place or to observe the attributes of refugees. Instead, interpretive approaches aim to uncover the meaning within the action, or the (embedded) beliefs, norms, and preferences of respondents, which exist within and underpin their actions and practices (Bevir and Rhodes 2002: 2; Geertz 1994; Wagenaar 2014: 43-44). For this reason, narratives, which are largely based on first-hand accounts of respondents' experiences and behaviors, are primary texts for interpretive analyses. Bevir and Rhodes (2002: 6) claimed that "[n]arratives are thus to political studies what theories are to the natural sciences."

In addition to understanding the more subjective aspects of how respondents experience an action, interpretive approaches also seek to understand how respondents perceive more objective notions, i.e., how they understand the institutions and structures within which their actions are carried out (Wagenaar 2014: 44). Interpretation is about situating 
respondents' actions within not only their sociocultural contexts, but also their larger (economic, political, legal) structural contexts.

This research assumes an interpretive approach in line with Bevir and Rhodes (2002), as it places refugee and migrant agency related to higher education at the center of analyses to understand how they experience forced displacement. At the same time, it remains sensitive to the structural webs which constrain and/or promote their movements, the socalled "objective elements." 10 For this reason, it was crucial to outline potential displacement and migration drivers and patterns structuring respondents' agency (Chapters Four and Five) and connect these structures to findings on respondents' higher education aspirations, norms, and practices related to the timing, destination and directness, and channel of respondents' movements (Chapters Six through Eight).

To analyze the narrative data on respondents' higher education and forced displacement trajectories and to understand how respondents shaped their movement through the pursuit of higher education, I used a combination of qualitative time-series analysis, which is a form of cross-case analysis, and thematic analysis. I employed qualitative timeseries analysis with the intention to identify and compare the main features of respondents' displacement patterns, so that I could then examine how they shaped these features through their aspirations, norms, and practices. Yin (2003: 148) argued that mapping and analyzing chronologies is a strength of case study analysis. Similar to pattern matching, this method involves the comparison of observed chronologies with those set out in theories.

In applying this analytical method, I first coded my data with NVivo software using existing theories and frameworks and their associated concepts as deductive codes, including Kunz's (1973) model of refugee movements and Van Hear's (1998) spatialtemporal model of proactive-reactive movement. Codes are labels for assigning units of meaning to data and can comprise words, phrases, or whole paragraphs (Miles and Huberman 1994). I also searched for chronological and spatial patterns arising from within the data, identifying inductive codes. Not surprisingly, I found that patterns

\footnotetext{
${ }^{10}$ Within political studies, numerous schools of thought have emerged and developed different interpretive approaches, in terms of their conception of meaning, theoretical assumptions, the role of the analyst, and the questions asked (Wagenaar 2014). More hermeneutic or ethnographic approaches examine intersubjective meaning, are more inductive in their analyses, and place actors and their experiences at the center of analysis (Bevir and Rhodes 2002, Geertz 1994). Discursive approaches identify larger webs of ideas, powers, and norms which structure behaviors (Miller and Rose 1986, Wagenaar 2014). Dialogical approaches see meaning as emerging from the (largely opposing and confrontational) dynamics of interactions (Wagenaar 2014). Such approaches may be emancipatory, as bringing the different sides of an interaction together can foster the creation of shared meaning and overcome the policy failures under review (Wagenaar 2014). Bevir and Rhodes (2002) put forth a hybrid approach, which combines the more agency-emphasizing aspects of ethnographic approaches with the structural-sensitive aspects of discursive approaches.
} 
arising from within the data on respondents' movements, i.e., the inductive codes, were often considerably more complex than a framework like Kunz's (1973), which recognized just one form of forced displacement from the origin to asylum country and two forms of exit related to timing (anticipatory and acute). Indeed, through this method I found that respondents exhibited a range of (forced) mobility patterns before and throughout their displacement journeys. Examples of spatial and temporal patterns included respondents engaging in single-vector moves between major cities, chronic internal displacement preceding international displacement, movements to and away from camps and settlements, and mobility continuing after reaching the country of first asylum. While mapping forced displacement chronologies illuminated the diversity and mobility within respondents' movement patterns, the insights produced by using this method were ultimately constrained by its conception of movement in stages. Such mapping obscured how respondents' agency related to their pursuit of higher education shaped forced movements and how such agency emerged. In other words, this method focused my attention on the physical maps generated by respondents, rather than on how respondents generated these maps.

The initial results of this method prompted me to take a broader view of my data and to reverse my approach by first considering respondents' expressions of agency and, second, constructing a larger picture of displacement patterns based on these expressions. Thematic analysis was best suited to examining respondents' agency related to higher education and the shaping of forced displacement. Thematic analysis is a qualitative method involving multiple coding levels and strategies to identify patterns within data, contextualize and interrogate their meaning, and abstract them to more generalizable theory (Boyatzis 1998: 4-5).

My first round of coding involved identifying deductive codes related to theories of forced displacement and migration - i.e. 'NELM' or 'anticipatory movement' - as well as aspirations, norms, and practices and any other aspects of respondents' agency. In this round I also assigned more inductive and descriptive codes based on themes arising from the data - i.e. 'refugee meaning' to describe respondents' own definitions of refugeehood. In subsequent coding rounds I identified different dimensions of displacement that respondents shaped: the timing, destination, and channel of entry and settlement. Within these dimensions, I uncovered more latent or emergent patterns explaining the various roles played by tertiary education and traced their connections to codes on the different aspects of respondents' agency. I also traced connections between codes and dimensions, to see that many overlapped and were not independent of one another. In identifying the dimensions of forced displacement as well as the emergent patterns related to higher education within each dimension, I coded the data until I reached a point of saturation and encountered no new themes with respect to movement or higher education. All 
coding was carried out in NVivo and I used various data displays to view the narrative data in different ways and to identify connections. NVivo also allowed me to make annotations and write analytical memos on emergent themes alongside my data.

\subsection{Validity and Limitations}

This research faces several validity challenges. This study relies on self-reported data, which might be consciously or unconsciously distorted if asking respondents about their movements prompted distrust, if their pasts were difficult to recall, or if respondents' accounts were shaped by how they perceived me as the researcher. To address these issues as much as possible, I undertook a number of steps. Participant observation allowed me to build rapport with refugee and migrant respondents, to better communicate research aims and ethical guidelines. Participant observation data also provided a check on biases embedded within respondent data, since the researcher generates such data. Semi-structured, biographical interviews, by contrast, provided selfreported data, but targeted different ways of perceiving the past and thus were useful in assembling a more complete picture. Such semi-structured interviews also included several questions and modules that asked around the same subject, but from different perspectives and using different language, allowing for some degree of verification or triangulation within each respondent interview.

More generally, the three data collection methods as well as the examination of the macro-level factors impacting forced displacement, migration, and higher education in this study's sending and receiving countries drew upon different sources of information and ways of thinking. This allowed me to triangulate or verify the themes and patterns that emerged through the respondent interviews, with those from my expert interviews, participatory observation, and examination of the historical-structural context (Maxwell 2004: 112). For instance, when finding no evidence of the timing of Somali respondents' movement being impacted by severe constraints in the higher education sector, but respondents nevertheless engaging in international student mobility, the data on respondents' life cycle mobility norms from the semi-structured interviews combined with the data on the collapse of the tertiary education sector in 1991 suggested that severe constraints had, in fact, transformed and internationalized Somali respondents' life cycle mobility patterns. Further, the themes and patterns that emerged through the analysis of respondent interviews on how they shaped the timing, distance and directness, and channel of their movements were further verified by grounding such findings in the forced displacement and migration literatures.

Also, in terms of how I was perceived by respondents, I explained my position as a researcher, my research objectives, and my not being affiliated with any assistance 
organizations or any governments. As this study was not about refugee livelihoods or vulnerability, which some scholars have cited as subjects being more susceptible to bias, and instead was oriented towards higher education experiences, aspirations, and norms, I believe this played a role in minimizing bias (Clark-Kazak 2009).

Narrative data are sensitive to not only how respondents perceive the researcher, but also how the researcher interprets respondents' narratives. In her work on narrative methods, Clark-Kazak (2009) noted issues of representation and the different ways migrants and researchers ascribe meaning to events. To face this challenge, I tried to be as reflexive as possible about how I was interpreting the data. Whenever I was unclear of the meaning behind respondents' accounts, I went back to my research journals for notes taken during interviews and to recordings to listen to respondents' tones and any other revealing sounds framing the conversation. In identifying patterns related to how respondents shaped their forced displacement related to higher education, I looked for evidence of respondents' agency being highly constrained and of forced displacement patterns being shaped by agency not related to higher education. By actively searching for discrepant evidence, I took care not to inflate the higher education patterns and themes that I did identify, and their implications.

Another challenge this study faces relates to selection bias and whether the findings on forced displacement dimensions and patterns related to higher education are unique to refugee and migrant students. One critique of purposive sampling techniques is the nonrandom nature of selection. So long as an individual meets the specified criteria, he or she is asked to be included in the study. This means that often the first (willing) person encountered who meets the criteria is interviewed, and this is a form of convenience sampling, which potentially introduces biases into the study (Bloch 2007 citing de Vaus 2002). To reduce such biases as much as possible, this study diversified its points of access to respondent populations, the organizations it approached to help with respondent identification, the different backgrounds of gatekeepers and research assistants who helped to identify respondents, and the different sites selected for participant observation. This study also limited the number of respondents identified through each point of contact. Additionally, while not a perfect counterfactual, including different relationships to tertiary education (graduate, enrolled, drop-out, and never enrolled) as a sampling criterion enabled a comparison between the forced displacement patterns of these different groups. I also searched for discrepant evidence, for instance, cases in which education played no role in the displacement patterns of graduates or current students, and attempted to understand how structural factors related to the destination country shaped their higher education attainment (Maxwell 2004: 112-113).

A final challenge relates to the generalizability of this study's findings. This research does not amass a representative sample of refugees and migrants within each country or across 
Africa and therefore cannot claim generalizability to any larger population of refugee or migrant students. However, with its careful selection of research sites and its purposive selection of respondents, it aims to identify patterns (e.g., across or within different types of refugee hosting countries, refugee nationalities, gender, or relationships to tertiary education) that are generalizable to a theoretical level. In other words, it examines the patterns and explanatory mechanisms that emerge regarding how agency related to tertiary education impacts forced displacement in light of their specific contexts and respondents' specific profiles to assess their wider applicability.

\subsection{Research Ethics}

I had to take several ethical issues into consideration while carrying out my research to ensure the security of the interviewees and to uphold the integrity of the interviews. As mentioned at the start of this chapter, before commencing data collection and initiating contact at each research site, this study underwent processes of research clearance and ethical review according to each country's guidelines. In Kenya and Uganda, I applied to their respective National Commissions for Science and Technology to obtain research clearance and undergo ethical review through local research institutions. Moreover, this study's research proposal and research instruments were reviewed by the institutions with which the researcher was affiliating. I also obtained research and ethics clearance from my home institution, Maastricht University, which was recognized by institutions where I affiliated in South Africa as well as institutions where I carried out data collection.

In this section, I will briefly describe ethical issues that I encountered related to gaining respondents' consent for interviews, protecting their identities, data protection and storage, compensation, and the location of the interviews. I will also explore my own positionality, or how my beliefs and identity may have impacted this study. Every respondent who participated in this study received information on the aims of this research, a description of interview questions or a copy of the interview guide, and an interview consent form. The consent form explained the scope of the research and interview questions; the confidentiality of respondents' data and the terms under which it would be used and stored; and respondents' rights to not answer questions, stop the interview, and withdraw their data.

In terms of protecting respondents' identities, every interviewee contributed to my research anonymously. This was important because a number of respondents did not have legal status and risked arrest if their identities were given to national authorities. Additionally, many respondents had left their origin countries because of insecurity. If rebel or government groups from their countries discovered their identities and locations, their safety would be jeopardized. All interview data was therefore stored on secured 
drives. To this end, transcription assistants had to sign non-disclosure agreements which outlined the sensitivities of the interview content. Whenever names were mentioned in recordings, transcribers were instructed not to record them.

In terms of compensation, I paid for respondents' transport costs if they had to travel to meet me for interviews and a refreshment and/or snack while we met. This is a fairly standard practice, given the amount of time respondents spent with me and away from their work and studies, and given that I did not want respondents to have to pay to be interviewed for this study. While in past research projects, offering no additional compensation meant that some did not consent to interviews, I did not encounter that in this study. On the contrary, many respondents refused travel compensation, and some wanted to treat me to refreshments, as I was seen as a guest in their countries. This might stem from the fact that these respondents were not struggling to provide for their livelihoods and were fairly successful relative to the wider population.

In determining the location of the interviews, I had to consider several factors depending on the country of research. For some, I had to take care how respondents would be perceived by members of their community for being interviewed or seen with a foreign researcher. Some respondents did not have a legal migration status or were registered refugees and did not want to be identified as such. In such instances I met respondents outside their neighborhoods or at the institutions where I was an affiliated researcher. In other cases, respondents were not comfortable conducting interviews where I had a desk or office, and preferred meeting at their education institutions or in their neighborhoods at cafes, public libraries, and other locations. Meeting in places that were familiar to respondents allowed me to see and better understand the context of their responses. To avoid putting respondents at risk or making them feel uncomfortable, we jointly determined the location of interviews and meetings.

Lastly, regarding my own positionality, I must recognize that my beliefs and identity as someone pursuing a terminal tertiary degree, as a female, as a white person, and as someone coming from the so-called global north are factors which undoubtedly shaped how I presented myself during fieldwork. These factors also impacted and continue to impact the framing and process of this research. Derry (2017) argued that, "even the most passive methods of data collection and quantitative analysis have some interactional aspects, and it is impossible to absolutely control for and ensure the unobtrusiveness of research applications and interventions." She further writes, "[p]ower dynamics flow through every vein of the research process." To the extent possible, while carrying out semi-structured interviews with refugees and migrants pursuing higher education, I had to ask myself whether my line of questioning was formed by my own educational experiences or theirs and whether my pursuing a terminal degree was more likely to elicit positive responses from respondents regarding their aspirations and norms related to 
tertiary education. My personal experiences were at times an asset in identifying questions on how respondents negotiated higher education institutions, but I had to take care to not assume that our educational experiences were comparable. I also had to continually asked myself how my interview questions might have been shaped by my being a white woman from the United States, and how someone with a different set of identities might interpret my questions. When conducting interviews in Kakuma Refugee Settlement, I was sensitive to the fact that I was likely seen as associated with an aid organization and, therefore, it may have been perceived that "correct" answers to interview questions could assist respondents in gaining access to educational programs or resettlement. In addition to attempts to be reflexive throughout the fieldwork, I shared and piloted my semi-structured interview guide with contacts I had at each research site, to learn the different ways in which my questions or the ordering of my questions might be interpreted.

Having studied and carried out research in Uganda and Kenya since my time as an undergraduate, I had a certain degree of familiarity with living and working in these countries and spending time in different refugee communities. Hence, I was aware of and sensitive to different gender and other social norms and customs and made every effort to respect these when entering community spaces, offices, and homes. At the same time, I recognize that there is a large presence of foreign workers and other migrants in all three research countries, and so my presence as a foreigner was not particularly uncommon.

\subsection{Conclusion}

This chapter provided a detailed outline of this study's research design, including the selection of Kenya, South Africa, and Uganda as research sites; methods of gaining access to respondents; narrative data required to answer this study's research question; sampling strategy, data collection instruments, and interpretive data analysis approach; issues related to validity and research limitations; and key ethical issues. This methodological chapter marks the end of Part One, which also set out this study's background and objectives and conceptual framing. Part Two examines the different macro-level forces across sending and receiving countries, which structure respondents' expressions of agency related to higher education. 

PART TWO 
This study examines how refugees express their agency in relation to higher education to shape their forced displacement patterns to asylum countries. No complete discussion can be had of refugee agency without an examination of the broader structures within which agency is expressed. In this study, structures refer to higher order rules, institutions, and patterns of behavior, which may "exercise their own causal powers, independently of the agency which produced them" (Parker 2000). While beyond the scope of this study, it should be noted that a vast literature exists, which seeks to define structures in relation to agency (for a synthesis see Bakewell 2010).

The connection to macro-level forces is often overlooked in micro-level analyses of movement. Hitlin and Elder (2007: 171 citing Flaherty 2003) argued that a temporal orientation is critical to the study of agency because time is "a fundamental aspect of social interaction." They maintained that actors employ different social-psychological processes and exhibit different forms of agency depending on the perceived space or time horizon. Aspirations may grow out of perceived structural opportunities, norms may deepen or transform with protracted constraints, and practices are sensitive to macrolevel factors which impact a person's capabilities.

The following chapters examine the different temporal and spatial structures that frame and influence respondents' forced displacement and higher education trajectories within and across this study's sending countries - the Democratic Republic of Congo and Somalia - and receiving countries - Uganda, Kenya, and South Africa. Chapter Four examines key drivers of forced displacement and migration, while Chapter Five explores key patterns of forced displacement and migration to situate respondents' movements within broader trends over space and time. The possible relationships discussed herein are not meant to be read as determinations or reductions between these factors and movement outcomes. Rather, the following two chapters seek to draw out patterns and structural conditions and show how refugees and migrants make decisions within them in relation to higher education and mobility. All data discussed in these two chapters come from 2015 and 2016 when I carried out the fieldwork for this study. 
CHAPTER 4 


\section{Framing Movement: Drivers of Forced Displacement and Migration}


This chapter weaves together the key macro-level events, processes, and policies that structured Congolese and Somali respondents' forced displacement and migration to Kenya, South Africa, and Uganda. In so doing, this chapter examines the main factors or drivers that constrained or enhanced respondents' agency related to tertiary education and movement. In the sections below on each of this study's sending and receiving countries, I outline forced displacement and migration drivers related to political stability, conflict and human security, human and economic development, and higher education. Abdi (1998: 336) argued that these factors are often interlinked and engaged in a "permanent relationship." Exploring these drivers provides insight into the constraints and opportunities that respondents perceived and interacted with in moving to asylum countries and pursuing higher education. More generally, examining the different structural contexts within this study's sending and receiving countries further illuminates the individual circumstances of respondents. For instance, if a Congolese migrant moved to Kampala, which ranks the lowest among receiving cities in terms of socio-economic development indicators, and which is the nearest city to the origin, this could signal that the respondent had relatively low capabilities and/or movement aspirations.

To ensure conceptual clarity across the succeeding sections, this study adopts a definition of human security put forward by the Commission on Human Security (CHS), established in 2001 by the United Nations Secretary General Kofi Annan. The Commission defined human security as:

“[P]rotecting fundamental freedoms... protecting people from critical (severe) and pervasive (widespread) threats and situations. It means using processes that build on people's strengths and aspirations. It means creating political, social, environmental, economic, military and cultural systems that together give people the building blocks of survival, livelihood and dignity" (UNOCHA 2009: 5 quoting CHS 2003: 4). ${ }^{11}$

Under this definition, no discussion can be had of human security without human and economic development, and no discussion of development can be had without education, including higher education. Rather than explore the full universe of indicators related to development and human security, and because quantitative data are scarce for these countries, I focus on gross domestic product (GDP) per capita based on purchasing power parity (PPP) and converted to international dollars; human development, which includes education attainment variables in its index; and life expectancy at birth to produce an

\footnotetext{
${ }^{11}$ Professor Amartya Sen was a member of the 12-persion Commission on Human Security, which likely explains the notions of freedoms and development within the concept of human security.
} 
overview of contexts of economic growth versus human capabilities and health outcomes. Moreover, I explore qualitative studies on the past and present contexts of political stability and security, development, and higher education to create a fuller picture of the main factors driving respondents' forced displacement and migration from the DRC and Somalia to Kenya, Uganda, and South Africa.

\subsection{Sending Countries}

This section examines the drivers of forced displacement and migration related to human security, development, and higher education within this study's sending countries: the Democratic Republic of Congo (DRC) and Somalia. I pay particular attention to their histories and present circumstances of instability and conflict as well as the impact of fragile governance and conflict on their education sectors.

\subsubsection{Democratic Republic of Congo}

The Democratic Republic of Congo (DRC) has been embroiled in political instability and developmental fragility since it gained independence from Belgium in 1960. Initially, instability stemmed from the lack of national cohesion of the Belgian-drawn provinces over the DRC's vast territory. Five years following independence, the DRC became a site for proxy Cold War moves and counter-moves between the United States and the Soviet Union, which led to the accession of Mobutu Sese Seko to power.

Jewsiewicki (2008) argued that, in an effort to consolidate his control, President Mobutu made Kinshasa the seat of the country's power; allowed schools, transportation networks, and communication infrastructures to collapse in the rest of the country; and bolstered the use of Lingala in the capital, to the exclusion of other national languages. The wider country was turned into a "backwater" of the capital with very little communication and movement between the core and peripheries. Mobutu systematically carried out such socio-political and economic centralization to the exclusion of developing cities elsewhere, particularly Kisangani and Lubumbashi, to prevent the emergence of rivals to his government. The movement of goods, information, and people was further constrained by the rise of rebel movements and foreign armies, which collected taxes from traders entering and moving within the country (Clark 1998; Reyntjens 2005). Smith (2011) maintained that where development did take place, it was carried out by foreign companies and functioned to extract and export raw materials and exclude the population from accessing such materials, rather than to improve connectivity between cities and between urban and rural areas. As a consequence, for marginalized and conflict-affected areas in the Eastern provinces, movement across the border to Uganda 
or across multiple borders to Kenya or South Africa was often a safer and less costly option.

More generally, since independence, the DRC has suffered from hyperinflation; economic bankruptcy; transitions between three currencies; and shocks from plummeting and soaring global commodity prices for coltan, gold, copper, uranium and other minerals (Clark 1998; Rubbers 2009; Smith 2011). An absence of development and infrastructural planning has caused "over-urbanization" in cities like Kinshasa in the last two decades (Koti 2010). Over-urbanization refers to the increase in slum areas; insufficient capacity to provide education, healthcare, sanitation, electricity, housing, and transportation; and insufficient employment opportunities, to name a few. Once again, such structural conditions meant that Congolese were likely to perceive fewer opportunities in large urban hubs inside the country than outside.

Additionally, since the mid-1990s, the country has suffered from a continuous series of conflicts, including the First (1996-1997) and Second (1998-2003) Congolese Civil Wars, which led to the ousting of Mobutu Sese Seko, and the election of Joseph Kabila in 2006 and his re-election in 2011, which sparked violence and unrest. Moreover, countless subnational political, ethnic, and resource-motivated violent conflicts have persisted until today over this 25-year period, including in North and South Kivu, Ituri, Katanga, the Kasai region, and Tanganyika. These conflicts have involved armed militias and have targeted civilian populations. IRIN (2018) estimated the existence of more than 40 armed groups operating in the Eastern provinces. Additionally, a small body of literature looks at the links between mining economies and local conflicts within the DRC, as rebel groups and militias find funding and manpower to conscript through these economies (Smith 2011). The presence of protracted conflict and violence, particularly in the Eastern provinces, has resulted in mass refugee flight to neighboring countries as well as mass internal displacement.

In 2010, the Congolese government signed the African Union Convention for the Protection and Assistance of Internally Displaced Persons in Africa (also called the Kampala Convention), which entered into force in 2012. While UNHCR stated that the government ratified the Kampala Convention in 2014 (Spindler 2014), this has yet to be reflected in the African Union's status list, which was last updated in 2017 (African_Union 2017). In 2014, humanitarian actors issued guidelines on the voluntary return of internally displaced persons (IDPs) in North Kivu (Spindler 2014). However, the security and rights of those displaced internally in the DRC remain at risk. Non-state armed groups have carried out attacks on IDP camps and the camps are located in close proximity to sites of conflict (Kpandji 2013). Moreover, at the end of 2014, state actors suddenly closed an IDP camp and forcibly removed its residents (Spindler 2014). Such 
attacks to the IDP protection regime no doubt prompt some, notably those with the resources to do so, to seek protection across the border.

Following from this brief history of political instability and conflict, in 2015, the Democratic Republic of Congo (DRC) had the third-lowest GDP per capita based on purchasing power parity (PPP) on the African continent, after the Central African Republic and Burundi (World Development Indicators 2018). This figure was lower than the average of any of the continent's sub-regions, and lower than the average GDP per capita PPP of Sub-Saharan Africa (Figure 15). In terms of levels of human development, in 2015, the DRC ranked 176 in the world out of 188, placing it towards the bottom of countries categorized as having low human development (Figure 16). On average, low human development countries have: a life expectancy at birth of 59.3 years, an expected 9.3 years of schooling for a child entering the school system, and 4.6 completed years of schooling if a person is 25 years of age or older (Human Development Index 2016). ${ }^{12}$

Figure 15: DRC GDP per capita PPP Compared to Regional Averages in 2015

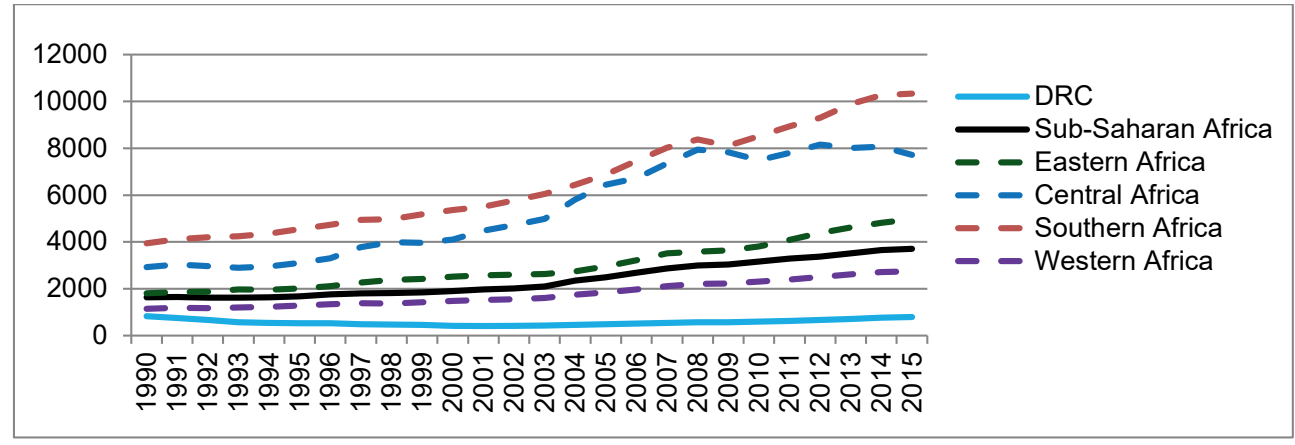

Source: World Development Indicators 2018, World Bank, GDP per capital PPP current international \$

\footnotetext{
${ }^{12}$ Once again, it should be noted that all data on structural drivers and patterns comes from 2015 and 2016, as this is when I carried out the fieldwork for this study.
} 
Figure 16: Human Development Levels of Sending and Receiving Countries in 2015

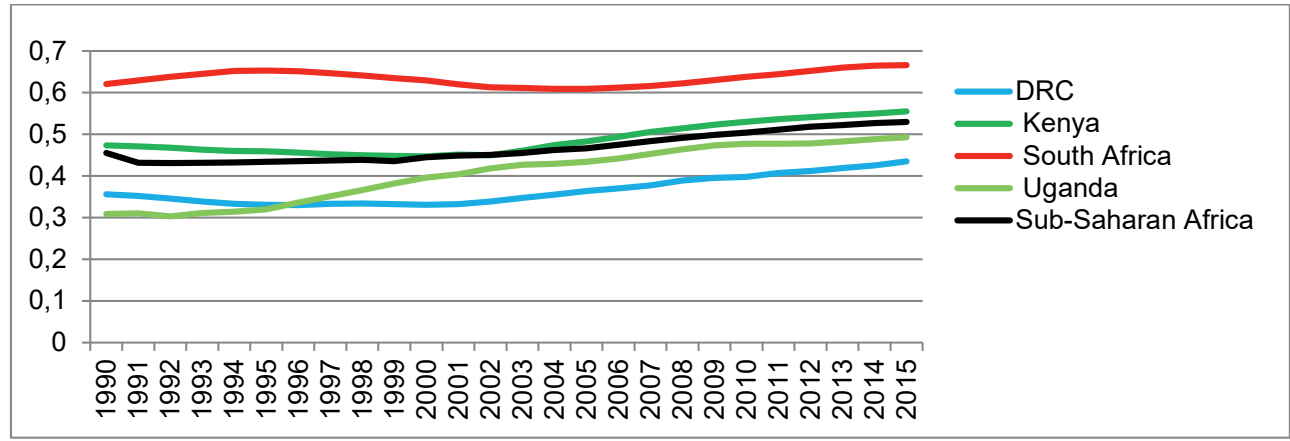

Source: Human Development Index 2016, UNDP

In 2015, Congolese enjoyed a higher life expectancy (58.1) than the average person in SubSaharan Africa (57.9) and were only marginally lower than that of Ugandans (58.6) and South Africans (59.5) (Human Development Index 2016). With such a high level of state fragility, it is not clear why life expectancy at birth was on par with South Africa, which was not only less fragile, but also had a higher level of human capabilities (Figure 17). This is likely less a comment on the DRC, as 58.1 years of age remains a dismal figure for life expectancy, and more a comment on high levels of inequality and HIV prevalence in South Africa, which will be discussed in a later section.

Figure 17: Life Expectancy at Birth in Sending and Receiving Countries in 2015

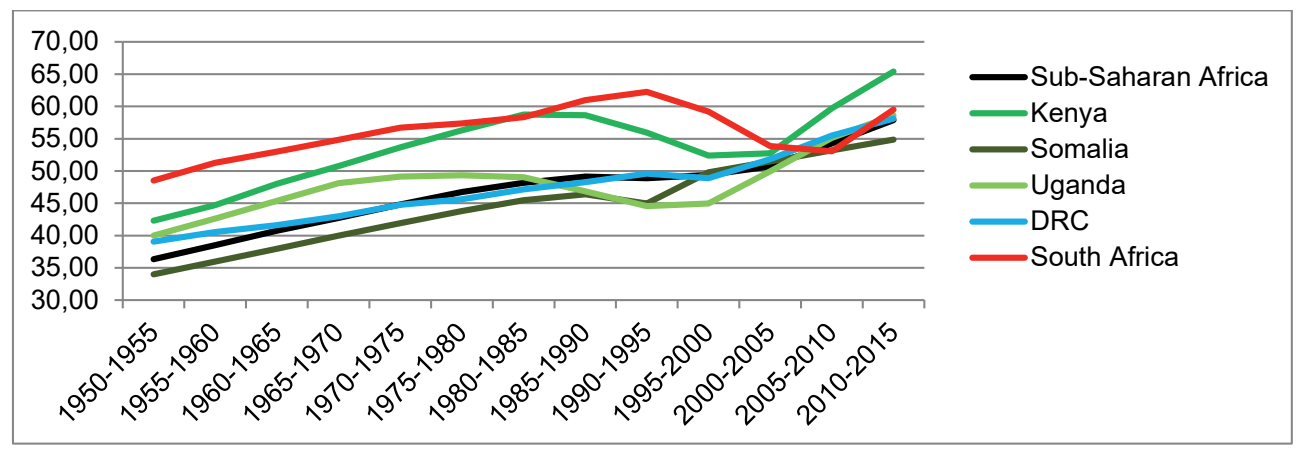

Source: Human Development Index 2016, UNDP 
The DRC also ranked as the fifth-most fragile state in the world in 2015 (Fragile State Index 2018). The Fragile State Index bases fragility on a range of dimensions related to governance, economics, rule of law, and public services, to name a few, which combine to assess a state's vulnerability. Additionally, in 2015, the Global Peace Index ranked the DRC as one of the countries in the world with the lowest levels of peace, at 154 out of 163 countries. This ranking was based on the fact that the DRC received the maximum points for the measures: access to weapons, homicide rates, violent demonstrations, violent crime, political instability, political terror, and internal conflicts (Global Peace Index 2019). In sum, when looking at just the socio-economic and political human security indicators, the DRC ranked among the lowest countries in terms of economic development, peace and security, opportunities, and well-being enjoyed by its citizens. This means that movement to virtually any country, particularly this study's receiving countries, would have offered Congolese refugees and migrants more opportunities than they enjoyed within the country.

Lastly, in terms of the DRC's higher education sector, a quote from a sector study by the World Bank (2009: 101) is telling: the "higher education sector in the DRC...is a picture of uncontrolled and imbalanced quantitative growth with a rapid deterioration in quality, operating in a confusing policy and legal framework." Prime examples of where a lack of cohesion exists include the relationship between public and private institutions, a scarcity of qualified teaching staff, a demand for intake which far outstrips the supply, the rapid opening and closure of institutions, the inequitable spread of institutions across the country, and challenges with access and attainment as well as quality (Chiteng Kot 2014; Mohamedbhai 2014; World_Bank 2009).

Oldenburg (2016) argued that since the 1980s, the DRC's higher education sector has declined rapidly, stemming from the end of the state's monopoly on higher education and the emergence of private institutions, severe financial pressures arising from structural adjustment programs, and a highly corrupt Mobutu regime. During Mobutu's tenure, government expenditure on education was the smallest amongst African countries (Boyle 1995). In an effort to increase the presence of higher education institutions across the country, the government created 256 new public institutions in 1993. The following year, just 60 remained open. In 1996 there were 256 private institutions, but by 2003, 130 remained (World Bank 2009). Writing in 2014, Mohamedbhai (2014) revealed that there were 36 public universities operating around the country. In 2015, the DRC's Ministry of Education recommended the closing of 175 "non-viable" higher education institutions. North and South Kivu and Equateur are the least-served provinces in the country by public higher education planning as well as financing, and the provinces most-troubled by insecurity and low development outcomes. In 2002, an estimated 197,285 students were enrolled in higher education 
institutions in the seven provinces surrounding Kinshasa, compared to 51,285 in the Eastern provinces (World Bank 2009). Youth looking to enroll at higher education institutions within the country, especially in Eastern provinces, therefore, have few options and are likely to look across the border for opportunities.

Looking at educational quality, we see that in 2009, annual enrollment figures were double the figures for intake capacity, suggesting considerably outstretched resources at higher education institutions. Indeed, the World Bank (2009) reported that for many practical subjects in the sciences, lab resources are lacking and so students may only study the theoretical components of their subjects. Moreover, students must often pay teachers for supplying notes and study guides. As of 2014, at the University of Lubumbashi, less than 30 percent of the 900-member faculty had doctorates (Chiteng Kot 2014). Using data from Transparency International, Chapman and Lindner (2016) found that in 2013, 75 percent of respondents in the DRC believed that their education sector was corrupt, compared to the global average of 41 percent. Poor education quality is also reflected in retention rates. At the University of Kinshasa, in 2009, 50 percent of students dropped out in the first year and another 35 percent dropped out the second year. Moreover, just 28 percent obtained a graduate degree and 18 percent without repeating a year.

Conflict and violence, particularly in the Eastern provinces, have added an extra layer to the stunted growth of the education sector and to issues of educational access and quality. Between 2013 and 2016, armed groups repeatedly attacked and destroyed primary and secondary schools and targeted both teachers and students as part of their campaigns for control (GCPEA 2018). Bennouna et al. (2018) documented 380 attacks on schools in North and South Kivu between 2012 and 2015; and attacks included the military use of schools, looting and extortion, rape, child abduction, and torture. At higher education institutions, more than 100 cases of student protesters being harmed or killed were identified between 2013 and 2017 (GCPEA 2018). Higher education students "are perceived as a potential threat to the social order as they are known for their political activism and...mobilization" (Oldenburg 2016: 7). Further, Oldenburg (2016) argued that the dynamics of violence and conflict that shape life in Goma, North Kivu, exist in parallel at universities and student groups mirror the city's socio-ethnic and political tensions. The targeting of educational institutions by armed groups and the reflection of conflict dynamics within educational institutions serve as additional drivers of displacement and seem especially pertinent for the respondents in this study seeking higher education attainment in asylum countries.

All of these events and factors create a picture of a struggling, unstable, and insecure higher education sector that was and is unable to accommodate the majority of secondary or high school graduates. Moreover, this brief summary has revealed that in areas impacted by insecurity and conflict, the higher education sector is even more constrained 
and may be a site for persecution. Hence, students living in the Eastern provinces are faced with the choice of traveling internally either 1,500 kilometers to Lubumbashi or 2,500 kilometers to Kinshasa, or far less of a distance internationally to reach either Nairobi or Kampala. Most other African countries would offer Congolese students relatively better higher education opportunities and in a safer and more stable environment, prompting those who can afford it to look abroad.

\subsubsection{Somalia}

The Republic of Somalia was created and became an independent state in 1960, formed from a United Nations Trusteeship area that was administered and formerly colonized by Italy in the south of the country and a British-colonized Somaliland in the north. Before the colonial period, ethnic Somalis resided in present-day Somalia, the Ogaden territory of Ethiopia, and Northern Kenya, and engaged in nomadic, pastoral livelihoods (Lindley 2009). Somalia experienced political instability in the early years of independence, owing to divided tribal loyalties, the centralization of power in Mogadishu, and challenges with corruption (Abdi 1998). In 1969, the military successfully engineered a coup d'état, led by General Mohamed Siad Barre.

Despite initial strong support from Somalis and the success of early "revolutionary" programs designed to build a national identity, by the late 1970s and early 1980s, political tensions rose as Cold War patronage fueled clientelism and the military government practiced clan-based favoritism and repression (Abdi 1998; Lindley 2009). From 1977 to 1978, the country was engaged in a border war with Ethiopia, which exacerbated a deteriorating economic and political situation. Following the war and coup attempt in 1978, no development programs for reconstruction were initiated and the military government became more repressive as it attempted to eliminate dissidents (Abdi 1998). Compounding matters, Abdi (1998: 335) argued that Cold War patronage by the Soviet Union and the United States led Somalia to become "one of the most militarized countries in the world." In 1984, the government spent 36 percent of its expenditures on defense and security, 10.5 percent on social programs and education, and 8 percent on economic development (Abdi 1998 citing Samatar 1988).

The deteriorating situation in Somalia reached a crescendo in 1991 with the collapse of the state and the takeover of so-called warlords (Abdi 1998). Lindley (2009: 15) maintained that, "in Mogadishu and elsewhere, opposing militia looted homes and businesses, robbed, kidnapped, raped and killed people associated (by clan) with 
opposing factions and minority groups." ${ }^{13}$ Between 1991 and 2004, there were 14 attempts to form a Somali government (Lindley 2009). The last attempt in 2004 established the Transitional Federal Government (TFG). After failing to consolidate power in Mogadishu, and after being temporarily ousted by the Islamic Courts Union (ICU) in 2006, Ethiopia, with support from the United States, began a military campaign to expel the ICU from South-Central Somalia (Lindley 2009). In 2007, the United Nations Security Council authorized the African Union-led peacekeeping Mission in Somalia (AMISOM) to support a national reconciliation process (AMISOM 2018). However, it was not until 2012 that the country re-established an officially recognized government. This brief review has shown that since the 1990s, Somalia has suffered from chronic political instability, violence and insecurity, prompting a critical humanitarian situation and internal and international displacement crises.

In 2009, the country became a signatory to the African Union Convention for the Protection and Assistance of Internally Displaced Persons in Africa; however, despite entering into force in 2012, the convention has yet to be ratified (African_Union 2017). In 2014, UNHCR received reports that state actors had forcibly evicted more than 20,000 Somalis, including some 9,000 IDPs from their homes in the capital. That same year, AMISOM launched a military offensive against the militant group al-Shabaab, displacing thousands in affected areas (UNHCR 2014b). Large-scale displacement has also been driven in part by incidences of extreme famine in 1991 and 2011 and periodic droughts (Lindley 2009; UNHCR 2014b). Since 2014, attempts by UNHCR and the Kenyan government to voluntarily return Somali refugees have largely been unsuccessful owing to the country's continued insecurity (Court 2017).

Based on this tumultuous history, for decades, Somalia has topped the Fragile State Index, and in 2015 occupied the position of second-most fragile state in the world after South Sudan (Fragile State Index 2018). According to the Global Peace Index, Somalia was among the countries with the lowest levels of peace, ranking 156 out of 163 countries. This ranking was based on the fact that Somalia received the maximum points for the measures: perceptions of criminality, access to weapons, intensity of internal conflicts, violent demonstrations, violent crime, political instability, and internal conflicts, to name a few (Global Peace Index 2019). Insecurity and a lack of governance is likely the reason why no data exists on GDP per capital PPP or HDI levels for Somalia. Data do exist for Somalia on life expectancy at birth, which is 54.9 years of age for both sexes combined (Figure 19). In 2015, Somalia ranked as the country with the eleventh-lowest life expectancy at birth rate in the world (Human Development Index 2016).

\footnotetext{
${ }^{13}$ It should be noted that insecurity and economic crisis did not impact the entire population en masse; rather, pockets of political order, governance, and trade did emerge. 
Lastly, higher education in Somalia is still largely in its infancy and has been highly constrained by state collapse and conflict. The military government expanded Somalia's single university, Somali National University, in 1970. Until the collapse of the state, the university had 11 faculties and 4,650 students (Abdi 1998). As of 2013, there were close to 50 higher education institutions operating across the country with more than 50,000 students (HIPS 2013). Constrained state capacity and a lack of regulation or academic standards have prompted the proliferation of private institutions, which run primarily on student fees, and have led many to look outside the country for higher education. At the same time, a lack of regulation and capacity of teaching staff (in 2013, 11 percent of lecturers had PhDs and 50 percent had MAs) has meant that the delivery of quality education is a significant challenge for higher education institutions (HIPS 2013). According to a 2013 survey of the higher education sector by the Heritage Institute for Policy Studies (HIPS) in Mogadishu, many institutions functioned without a library, IT facilities, or a science laboratory.

After 1991, Abdi (1998) held that educational institutions and facilities were among the first casualties in the conflicts and instability that ensued. In some cases, universities and other learning institutions, libraries, and laboratories were destroyed deliberately and the highly educated of warring clans were the targets of persecution. A 2018 report by the Global Coalition to Protect Education from Attack (GCPEA) found that the United Nations verified 195 attacks on schools between 2012 and mid-2016 in Somalia. From 2013-2017, it identified more than 100 cases of students, teachers, and other educational personnel being threatened, assaulted, or killed. Moreover, al-Shabaab actively recruited children and youth from schools and madrassas, and used education and educational materials as tools in their recruitment process (GCPEA 2018). Between 2013 and 2016, alShabaab attacked a number of higher education institutions and personnel, most notably bombing the Ministry of Higher Education and attacking Garissa University (GCPEA 2018). One can reasonably argue that the violence against educational institutions in Somalia and the considerable risk that Somalis who pursue education face, serve as drivers of displacement.

This brief overview of Somalia's postcolonial political, economic, and educational development reveals a context that offers Somalis little in the way of security and livelihoods maintenance. More telling than the Democratic Republic of Congo's low development indicators is Somalia's lack of indicators altogether, as the country's lack of national governance and stability has made measurement impossible. Since independence, the country, particularly its South-Central region, has encountered multiple periods of violence and conflict, prompting mass displacement and emigration. Additionally, the state of Somalia's higher education sector is one of extreme low capacity, a lack of regulation, and insecurity, which creates challenges for students not 
only in obtaining quality education, but also in attempting to pursue further studies elsewhere because of a lack of qualifications recognition.

\subsection{Receiving Countries}

This chapter now turns to discuss the contexts of human security and political stability, human and economic development, and education, including corresponding policies, within this study's receiving countries: Uganda, Kenya, and South Africa. Particular attention will be paid to the conditions within and experienced by refugee and migrant communities.

\subsubsection{Uganda}

Eight years following independence in 1962, Uganda was thrust into political turmoil and instability under the military dictatorship of Idi Amin (1970-1979) and the presidency of Milton Obote (1980-1985). ${ }^{14}$ During his tenure, Idi Amin dissolved the parliament, suppressed and manipulated the courts and press, and mismanaged the economy. Amin's Military Police, Presidential Guard, Public Safety Unit, and Bureau of State Research all carried out mass extrajudicial killings to prevent any subversion, including in northeast Uganda, wherein killings have been called genocidal (Byrnes 1992; Keatley 2003). Amnesty International estimates that the death toll was approximately 500,000 during this period (Keatley 2003). Countless others sought refuge in neighboring countries, including Kenya and the Democratic Republic of Congo. Moreover, Amin ordered the expulsion of approximately 50,000 citizens of South Asian descent, who controlled much of the country's businesses and were among its economic elite. The result was disastrous for the economy, as many of these businesses were given to military elite and run aground, and profits were channeled into expanding the military.

Despite having made refugees of tens of thousands of South Asian Ugandans and having caused many more Ugandans to seek refuge with its neighbors, Amin's government signed the 1951 Convention Relating to the Status of Refugees (hereafter referred to as the 1951 Refugee Convention) and its 1967 Protocol, which expanded the geographic and temporal limits of refugee protection. At this point, Uganda was already a signatory to the 1969 African Union Convention Governing the Specific Aspects of Refugee Problems in Africa (hereafter referred to as the OAU Convention). ${ }^{15}$ As of 1962, Uganda had its own

\footnotetext{
${ }^{14}$ Milton Obote was also the first Prime Minister of Uganda and served two terms between 1962 and 1971.

${ }^{15}$ As mentioned in Chapter One, the OAU Convention extended the definition of refugee to include those who "owing to external aggression, occupation, foreign domination or events seriously disturbing public order in any part or whole of his country of origin or nationality is compelled to leave his place of habitual residence" (art 1, para 2).
} 
domestic legislation for the management of its refugee populations through the Control of Alien Refugees Act. In practice, this meant that the government, in partnership with UNHCR, assisted refugees in temporary settlements based on the principles of emergency disaster relief. Moreover, refugees were not permitted to live outside settlements and they were dependent upon aid provided by external sources to live. Many of today's settlements were initially designated by Uganda's colonial government in 1960 and in the early years of independence and followed the same guidelines of isolation and containment (Bagenda, Naggaga and Smith 2003; Werker 2002). The colonial government allocated land based on the parcels' proximity to the border, low levels of settlement by nationals, and its undesirability. For instance, it provided the Nakivale Refugee Settlement land close to the Rwandan border that was largely unsettled because of a tsetse fly infestation (Bagenda, Naggaga and Smith 2003). In the early decades of independence, Uganda's refugee and asylum policy was one of control and containment, and would not have been considered favorable by refugees and asylum seekers, in contrast to today.

Under the presidency of Milton Obote, the situation did not improve as much of the government's resources were dedicated to fighting Yoweri Museveni's National Resistance Army (NRA). Byrnes (1992) argued that Obote's four-year military campaign to destroy the NRA resulted in vast devastation and greater casualties than during the Amin era. In one instance, more than 750,000 people deemed NRA sympathizers were uprooted and put into internment camps (Byrnes 1992). When opposition troops finally entered Kampala in 1985, Obote fled to Zambia with much of the country's treasury stocks (Byrnes 1992).

In 1987, Museveni became president and began a new era of military activism in the region as well as widespread recovery and development reforms at home (Liang 2004). During the 1990s, the Ugandan army supported Laurent-Désiré Kabila's attempted overthrow of President Mobutu in the First Congo War, and a number of Congolese rebel groups during the Second Congo War (Byrnes 1992). Since the late-1980s/early 1990s, Museveni's government, with the help of the African Union, has been fighting the Lord's Resistance Army, a religious fanatical rebel group originating from northern Uganda, which has carried out extreme forms of violence and human rights violations, and resulted in mass internal displacement in northern Uganda, South Sudan, the DRC, the Central African Republic, and Chad. In 2007, Uganda joined the African Union's Mission in Somalia (AMISOM) to fight al-Shabaab and became the mission's largest contributor of troops (AMISOM 2017). The country under Museveni's leadership has been and remains highly involved militarily in the region and, in particular, in the conflicts of this study's two sending countries. One result of such military activism, combined with the 
relative political stability of Uganda, is that the country has become a regional destination for forced migrants.

In terms of development reforms, in the early 1990s Museveni decentralized the government, to make local governing structures the main service providers. As part of this process of decentralization, in 1992, the government of Uganda introduced the first agricultural settlement program for Sudanese refugees in the northern region of the country, which allotted refugees land to settle and cultivate (Dryden-Peterson and Hovil 2003). The rationale behind this policy was to afford refugees the opportunity to be productive and obtain a degree of self-sufficiency. In 1998, the government in collaboration with UNHCR introduced the Self-Reliance Strategy, which amalgamated refugee and national development initiatives, and attempted to improve infrastructural service delivery to both by co-opting refugee settlements into (decentralized) village- and district-level socio-political structures (Bonfiglio 2009). Under this strategy, refugees living in rural settlements received land and the tools to produce their own means to survive as well as access to medical and educational services. Further, refugees living in rural settlements could sell their agricultural products in local markets and participate in local economies. Werker (2002) argued that few settlements can claim that their refugee residents have gained a high level of self-reliance under the Self-Reliance Strategy (see also Bonfiglio 2009). Since Werker's study in 2002 and my own study on refugee selfreliance in settlements in 2009, a far higher number of refugees have settled in Uganda's rural settlements, and land availability and land fertility have become increasing challenges (Summers 2017).

In 2006, Uganda passed a more progressive Refugees Act. The drafting process of this Act led to the creation of the Ministry of Refugees and Disaster Preparedness, under which the Director of Refugee role was created to liaise with the Public Service Commission to protect refugee welfare (Mulumba and Olema 2009). Significantly, the Act calls for Uganda's asylum policies to maintain key rights, for example freedom of movement and expression, self-settlement outside of refugee camps, and the right to work (Mulumba and Olema 2009). Although the Ugandan government acknowledges the right to freedom of movement, settlement residents must apply for travel permits issued by government-appointed Settlement Commandants, whenever they want to leave the settlement, for instance to sell their produce at external markets. Permits are time sensitive and have strict expiration dates, making it difficult for refugees to move about the country. Despite practical constraints and challenges with implementation, Uganda stands out among refugee-hosting countries for its liberal refugee policies. For this reason, refugees and asylum seekers from South Sudan, the DRC, Somalia, and Burundi, to name a few, perceive the country as an attractive destination. 
In practice, refugees in rural settlements and urban areas face barriers to employment. In rural settlements, isolated rural areas provide little demand for produce; requirements for movement permits pose obstacles for people wishing to conduct business between settlements and urban areas; and smaller, more marginalized populations have less demand for professionals in the formal employment sector (Werker 2002, Bonfiglio 2009). In addition, Mulumba and Olema (2009) argued that some land that is allocated to refugees is unsuitable for cultivation owing to poor soil quality. In urban areas, employers are often uninformed about refugees' right to work, and believe they cannot hire refugees. Others do not want to offer jobs to refugees over nationals. Taken together, these obstacles mean that many refugees, both in rural and urban areas, are confined to self-employment, particularly in the informal sector. In the case of settlements, refugees' agricultural activities are mainly confined to subsistence farming. In the context of displacement drivers, these obstacles mean that refugees arriving to Uganda are likely to come from lower socio-economic backgrounds. While Uganda is perceived as a relatively welcoming asylum country, it is also perceived as one with few economic opportunities.

In terms of economic growth, over the 1990s and 2000s, real GDP averaged at 7 percent per year and the number of people living below the poverty line declined by approximately three million (Hitchen 2016). Hitchen (2016) maintained that Uganda's growth has been largely achieved through massive overseas development aid, and its status as a "donor darling." In 2006, it comprised 42 percent of the government's budget, whereas in 2016, it comprised 53.2 percent of the budget (OECD 2018). As a country of stability surrounded by some of the most protracted conflicts on the continent, as an active military power in the region, and as one of the largest hosts of refugees on the continent, Uganda's geopolitical importance and external support is unlikely to change.

Figure 18: Uganda GDP per capita PPP Compared to Regional Averages in 2015

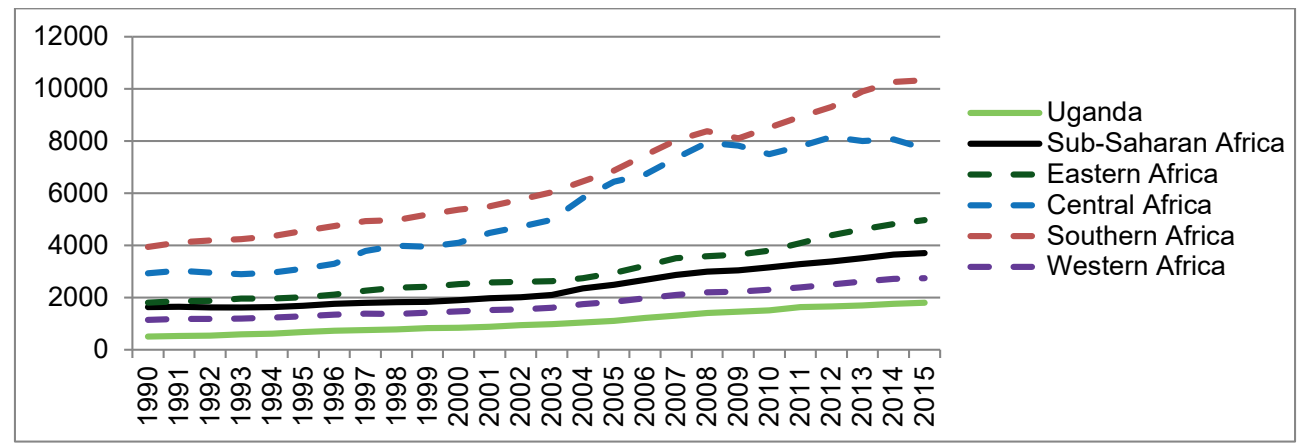

Source: World Development Indicators 2018, World Bank, GDP per capital PPP, current international \$ 
Looking at Uganda's growth relative to its neighbors, the country ranked eighth out of 14 in Eastern Africa and $17^{\text {th }}$ in the continent in GDP per capita PPP (World Development Indicators 2018). In terms of human development, in 2015, Uganda ranked 163 out of 188 in the world. Similar to the DRC, this ranking puts Uganda among the countries categorized as having low human development and below the average for Sub-Saharan Africa and Eastern Africa. Despite decades of recovery, and overall political stability in the south of the country, in 2015, Uganda struggled with a low record of economic and human development and ranked the lowest of this study's three receiving countries by these measures (Figure 18). Uganda also had one of the lowest life expectancies at birth after the DRC, ranking the $18^{\text {th }}$ in the world, alongside Zimbabwe and Guinea in 2015 (Human Development Index 2016). This suggests that while the Somalis and Congolese who arrived in Uganda were able to mobilize the resources to leave their origin countries, they were likely to come from lower socio-economic backgrounds than those moving to countries with higher levels of development.

In terms of tertiary education, Uganda stands out as a leader. At the time of independence, the country had one of the more highly regarded tertiary education sectors on the continent (Ngolovoi and Marcucci 2006). With the political and economic turmoil of the 1970s and 1980s, the education sector atrophied. However, under Museveni, investments in primary (especially universal primary education), secondary, and tertiary have resulted in increased enrollment in tertiary education, decades later. Liang (2004) argued that the country's higher education sector is growing rapidly, as is the demand for higher education. In 2011, Uganda was home to 187 tertiary institutions, which included five public universities, 29 private universities, and 151 institutions authorized to award diplomas and certificates. Of all tertiary institutions operating in 2011, 73 percent were private (NCHE 2013b).

There are persistent challenges with the sector related to coordination and quality. The three governmental bodies that supervise tertiary education: the Higher Education Department; the Department of Business, Technical and Vocational Education; and the Ministry of Education and Sports, ${ }^{16}$ do little to collaborate and each has a different governing structure and relationships with tertiary institutions. Additionally, none of these bodies carries out universal quality assurance for tertiary institutions (Liang 2004). In 2011, just 11 percent of academic staff at tertiary institutions held PhDs, 42 percent held MA degrees, and 34 percent held BA degrees (NCHE 2013). It should be noted that these figures are on par with, or are slightly worse than, the qualification rates of Somalia's academic staff.

${ }^{16}$ The teacher education department sits within the Ministry of Education and Sports. 
Despite Uganda's low development indicators and challenges within the higher education sector, the country still hosts the fourth-best university in Africa, Makerere University, according to the Times Higher Education's World University Rankings 2018. This is the only university in the top five that is not South African, and in the top ten that is not South African or Egyptian according to Time Higher Education 2017. Established in 1922, Makerere is one of the oldest universities in East Africa, where several heads of state have been educated, and is a big draw for international students. As a result, the university has created an international student office that caters to international student needs, including students with refugee status.

\subsubsection{Kenya}

Kenya gained independence from Britain on December 12, 1963. Shortly following, in 1966, Kenya became a signatory to the 1951 Refugee Convention. Three years later, in 1969, it signed the OAU Convention, and in 1981, it became a signatory to the 1967 protocol, thereby recognizing the right of refugees from any origin country to international protection. In 1967, Kenya also recognized refugees' right to work, and created a special permit (called a Class M permit) which grants them this right.

In 1963, the newly independent government, led by President Jomo Kenyatta, declared a state of emergency in the northeastern region of the country, in response to an emerging secessionist movement led by ethnic Somali residents and supported by the new Government of Somalia. For the next four years, the Shifta (meaning bandit or rebel) conflict ensued, until the signing of the Arusha Memorandum in 1967 (Hogg 1986; Whittaker 2012). Oyugi (2002) maintained that ethnic Somalis in this region continue to see themselves as in opposition to the Kenyan state and have strong ties to their co-ethnics across the border. The government, for its part, never carried out adequate post-conflict reconstruction and development to connect the region to the rest of the country. A welltrodden movement corridor between Somalia and Kenya has been reinforced through this context, which has been further activated by Somalis displaced by insecurity.

Following the collapse of the Somali government in 1991, the Kenyan government, in partnership with UNHCR, established the Dadaab refugee complex in the northeast to provide protection and assistance to the large numbers of incoming Somali refugees. Dadaab has since become the largest refugee complex in the world, comprising several of the world's largest settlements, and has solidified Kenya's position as the largest host of Somali refugees and asylum seekers, as well as the northeastern region's position as an active migration and forced migration corridor. 
In addition to conflict and instability in the north east, heightened tensions and conflict between Kenya's diverse ethnic groups have dominated much of the country's contemporary socio-political history and have been instrumentalized in electoral politics. A key source of tensions relates to the rights to "ancestral" lands," particularly in the fertile Rift Valley. The notion of ancestral lands is a contested one, for while ethnic groups tended to settle in particular localities, it was not until the British colonial government created ethnically homogenous "native" reserves, that areas because ethnically exclusive (Kasara 2017). Kenyans were required to live in such reserves when they were not working on European farms or living in urban areas. In this way, colonial settlement policies "established a social norm that ethnicity is the primary aspect of identity that confirms the right to reside" (Kasara 2017: 6 citing Médard 1999). The government of President Jomo Kenyatta, an ethnic Kikuyu, enacted a policy of market-based land allocation, which, in the 1960s and 1970s, paved the way for land-buying companies formed by the Kikuyu, Meru, and Embu ethnic groups to buy and settle large tracts of land in the Rift Valley that had been traditionally settled by the Kalenjin, Maasai, and others (Kasara 2017; Oyugi 2002).

Kasara (2017) argued that when multi-party politics was reintroduced with the general election in 1992, the Rift Valley experienced large-scale violence and displacement along ethnic lines. Such violence was incited strategically by politicians to expel potential opposition voters (ethnic foreigners) from voting districts (Kasara 2017). From 1991 to 1997, 2,000 people were killed and 400,000 were displaced (Kasara 2017 citing Human Rights Watch 2002). These tensions were ignited once again following the 2007 general election, when an estimated 1,100 people were killed and 350,000 were displaced, based on their ethnic identity and political party affiliation (Kasara 2017: 3).

While Kenya's ethnic violence has largely been contained within its borders (fewer than 2,000 people out of the 350,000 who were displaced in Kenya sought asylum across an international border) (Kasara 2017), the effects of the crisis have been felt more broadly across the region, including in the areas of development and migration. Kenya is the economic and transportation hub of the East African region. More than 80 percent of Uganda's imports and nearly all of Rwanda's imports come from the port of Mombasa in the south. Burundi, South Sudan, and Tanzania also rely on trade from the port (Kimani 2008). Thus, the $2007 / 2008$ election crisis in Kenya led to a drop in GPD for all countries within the East African Community (EAC) by 1.5 percent from what was anticipated for 2008 (Kimani 2008). Kenya is also a hub for international development and aid agencies, hosting more organizations than any other country in Africa. The crisis impeded the delivery of humanitarian aid to refugees and other persons affected by conflict in the DRC and South Sudan. Moreover, it disrupted the delivery of basic needs and services to refugee communities within Kenya (Kimani 2008). Hence, during this period, it is likely 
that movement to and within Kenya was constrained, as were the livelihoods of migrants and refugees.

Kenya adopted the Refugees Act in 2006 and its subsidiary legislation, the Refugee Regulations, in 2009. These pieces of domestic legislation were responsible for the introduction of the Department of Refugee Affairs (DRA), which in 2014 assumed responsibility for refugee status determination (RSD) from UNHCR. The 2006 Act also called for all asylum seekers and refugees to live in either the Dadaab or Kakuma Refugee Settlements, unless they had authorization to reside elsewhere (Pavanello, Elhawary and Pantuliano 2010). In 2011, the Dadaab complex was expanded to accommodate Somalis displaced by drought and fleeing the terrorist group al-Shabaab. That same year, Kenya joined the African Union's Mission in Somalia, and has since been the target of increased al-Shabaab attacks. In 2015, during the time of fieldwork, al-Shabaab attacked Garissa University, near the Somali-Kenyan border, killing 147 students (Sterley and Hiebert 2016). Sterley and Hiebert (2016) maintained that the insecurity caused by al-Shabaab has had dire consequences for Kenya's economic growth and tourism. Between January and May 2015, tourism, which is one of the country's main industries, declined by 25 percent, and 4.3 percent over the same period the preceding year. It is not unreasonable to assume that alongside economic growth, immigration trends may have also been constrained, as labor market demand and immigration trends are often interlinked.

In 2012, out of apparent concerns for national security, the government called for all asylum seekers to relocate to one of Kenya's two designated refugee camps, with the possibility of being deported should they not comply. However, in 2013, Kenya's High Court ruled this measure, and particularly the threat of deportation, a violation of the constitutional right of movement and the principle of non-refoulement enshrined in the 2006 Refugees Act and other international instruments (Goitom 2016; Okumu 2013). In 2014, citing national security, the Kenyan government amended the Refugees Act of 2006 and once again called for all asylum seekers and their families to remain in settlements until status determination has been completed (UNHCR 2014a). Moreover, the government closed all refugee registration centers, with the exception of those located in the two settlements, to discourage asylum seekers to self-settle (Goitom 2016). Despite these incentives to relocate to the settlements, because of their challenging living conditions, many continue to reside in urban locations and face the risk of arrest, being fined, or deported.

Furthermore, in 2014, the Department of Refugee Affairs attempted to impose a cap on the total number of asylum seekers and refugees at 150,000 people, which the High Court ruled against the following year (Goitom 2016). In 2015, al-Shabaab's attack on Garissa University, as well as others in Mombasa and Nairobi, prompted the government to dissolve the Department of Refugee Affairs and declare its intention to close the Dadaab 
Refugee Complex and repatriate its occupants. Once more, the High Court intervened and blocked the settlement's closure. The back-and-forth between Kenya's legislative and judiciary arms of government has created considerable confusion concerning where asylum seekers and refugees can settle and has left the future of Kenya's refugee hosting policies and procedures highly uncertain. It is possible that such policy confusion, negative political discourse, and the threat of arrest or deportation would feature in the decision-making of migrants and refugees about whether to settle in Kenya or avoid settlement in favor of another safe country.

Despite the aforementioned struggles with political instability and violence during election periods and resulting from al-Shabaab attacks, Kenya remains East Africa's economic, transportation, and development aid powerhouse. In 2008, the government introduced its Kenya Vision 2030, an ambitious development plan to transform the country into a middle-income economy by 2030 (Kivati 2017: 18 citing GoK 2007). Globally, Kenya is a leader in the export of tea, ingredients for insecticides, and cut flowers (Kimani 2008); and it has the second-highest GDP per capita PPP in Eastern Africa after Djibouti and excluding Mauritius and the Seychelles, and the fourth-largest economy in Sub-Saharan Africa after Nigeria, South Africa, and Angola (Owino, Wamalwa and Ndekei 2017).

In terms of human development, in 2015, Kenya ranked 146 out of 188 countries, placing it nearly last among countries categorized as having medium human development. On average, medium human development countries have a life expectancy at birth of 68.6 years, an expected 11.5 years of schooling for a child entering the school system, and 6.6 completed years of schooling if a person is 25 years of age or older (Human Development Index 2016). In 2015, Kenya had the $15^{\text {th }}$ highest life expectancy on the continent, and if you exclude Northern African countries and higher income islands, it ranked second behind Senegal. In terms of education, the government spends more than any other East African country, both as a share of government spending and as a share of GDP on education; and introduced universal primary education in 2003 (Martin and Pimhidzai 2013). Hence, the picture emerging from the quantitative data on Kenya is of a country that, relative to other African states, is doing well economically and developmentally, and is an attractive continental destination for refugees and migrants. 
Figure 19: Kenya Life Expectancy at Birth Relative to Regional Averages in 2015

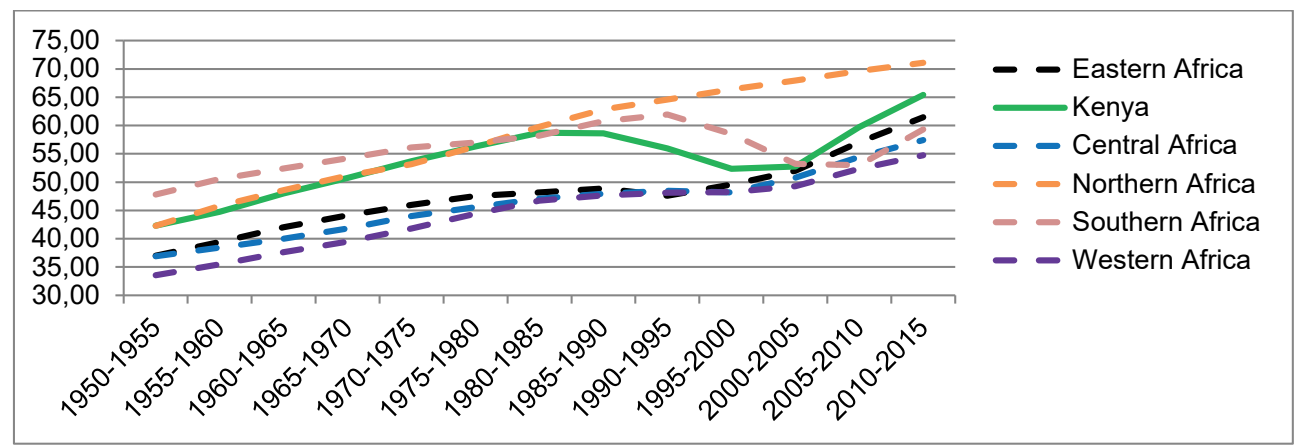

Source: Human Development Index 2016, UNDP

Turning to consider security and development within refugee communities, Kenya's two refugee complexes, Dadaab and Kakuma, suffer from extremely low basic education standards. Mackinnon (2014) argued that insufficient and poor-quality basic education has contributed to some youths being involved in drugs and crime, and to being recruited into al-Shabaab. Moreover, both complexes, but particularly Dadaab, have high incidences of violence and gender-based attacks on women, shootings, and explosions (Mackinnon 2014). The insecurity within, and threatened closure of, Dadaab in 2015 has led some families and individuals to move to Kakuma or to return to Somalia. Indeed, some of the respondents in this study moved to Kakuma for these reasons. A study by Samuel Hall (2015) found that many of those who repatriated have since indicated their regret for doing so because of continued instability in Somalia. While Kenya is an attractive destination for migrants and refugees, the poor conditions within the country's refugee complexes make them destinations of last resort.

In terms of higher education in Kenya, as mentioned previously, Kenya's history of higher education is intertwined with that of Uganda. The University of Nairobi, Kenya's oldest and most prestigious institution, grew out of what was Makerere University and the University of East Africa (Kivati 2017). Since independence, the sector has grown rapidly. As of 2016, it was comprised of 68 institutions, up from 58 in 2011 (ICEF 2016). The higher education sector boasted 25 universities, 18 of which were private and seven were public (Ministry of Education 2016). ${ }^{17}$ Most of the sector's growth has occurred in the establishment of private institutions. Between 2012 and 2014, total enrollment in higher education doubled (ICEF 2016).

\footnotetext{
17 There are conflicting accounts of these numbers. Kivati (2017) stated that Kenya has 22 public universities and 17 private universities. This thesis uses the numbers cited by Kenya's Ministry of Education on its website.
} 
With such rapid growth, the sector has faced challenges related to financing, quality, and access. In 2017, 21 out of 33 public higher education institutions operated at a deficit; and an auditor general's report maintained that 11 universities, including the University of Nairobi, were insolvent (ICEF 2017). In terms of quality, a 2017 review by the Commission of University Education revealed that admission and graduation requirements were inadequate, certain degree programs should be recalled, and at least three institutions should be closed (ICEF 2017). The Commission also maintained that the decline in quality was a trend that has accelerated over 20 years (ICEF 2016).

In terms of access, in 1995, approximately 7 percent of secondary school (or high school) graduates accessed public universities. In 2005, only approximately 4 percent of graduates accessed public higher education (Kinyanjui 2007). Drives for universal primary education and investments in secondary education have made more students eligible for tertiary education and driven up demand. Today, the scarcity of available places in the higher education sector is a significant challenge for nationals, let alone refugees and migrants. This, combined with one of the fastest-growing college-age populations in the world, and considerable challenges with higher education quality and financing, has prompted many young Kenyans to look to other African countries to meet their higher education needs.

Despite these challenges, or perhaps because of financing challenges, the Commission on University Education has identified attracting international students and positioning Kenya as a regional tertiary education hub as a priority. In this vein, it has eliminated student visas for students coming from East African Community countries (ICEF 2016). Such students would provide a much-needed revenue stream because the tuition rate for foreign students is significantly higher than domestic students. A report from the Commission stated:

"Universities should strive to have, in the long term, ten to fifteen per cent of their students as international...the Ministries of Education and Foreign Affairs should market Kenya as an education destination for students from the region. Kenya should formulate policies to mobilize resources and identify strategic areas for education and training of professionals from neighboring countries (Southern Sudan, Somalia and Democratic Republic of Congo) to enhance regional reconstruction, peace building and security" (Kinyanjui 2007: 5).

The Kenyan government not only sees international students as an asset and actively seeks their recruitment, but also sees Kenyan higher education as an important vehicle for peacebuilding in the two countries of origin included in this study. Despite weaknesses in the country's higher education sector, it remains stronger and offers more 
opportunities than conflict and crisis-affected countries like Somalia and the DRC. With the region's strongest economy, foreign students are likely to see the higher education sector as a way to tap into the Kenyan labor market, as education and employment sectors are inextricably linked (Tati 2009).

\subsubsection{South Africa}

In 1910, the British government ceded power to the white residents of South Africa, ending colonial rule. In 1961, the country became the Republic of South Africa. However, it was not until 1994 that the state-sponsored segregation and oppression of black and colored South Africans, known as apartheid, ended and a liberal-democratic constitution was drafted, international sanctions were lifted, international human rights instruments were signed, and the South African state re-entered the international political sphere. Hence, between 1995 and 1996, South Africa signed the 1951 Refugee Convention, the 1967 Protocol, and the 1969 OAU Convention. Around the same time, South Africa became a member of the Southern African Development Community (SADC), which promotes the harmonization of migration policies of member states and the facilitation of regional migration (SADC 2012).

In 1998, the South African government introduced domestic legislation on refugees and asylum seekers with the Refugees Act (Handmaker, De la Hunt and Klaaren 2001). Prior to 1998, the country dealt with issues of asylum and refugee protection according to the apartheid-era Aliens Control Act of 1991. The Aliens Control Act governed matters of general immigration and was, in essence, a framework for regulating the recruitment of cheap labor from neighboring countries (Rutinwa 2017; Tati 2008). This meant that crucial elements of legislation concerning refugees and asylum seekers were lacking, such as the definition of a refugee, the position of the state on non-refoulement, a framework for dealing with mass influx, and how the state would provide international protection (Rutinwa 2017). Not only did the lack of a defined framework deter individuals from seeking asylum in South Africa, but also the Act was centered on the notion of controlling the immigration of the "prohibited person." Such persons included individuals who entered South Africa without a valid passport and visa. Although potential asylum seekers could request a temporary permit to enter the country, when this expired, they would face the policies against "prohibited persons." In addition, the Act stated that all immigrants who applied for permanent residence should be "readily assimilable by the white inhabitants," thereby further discouraging black individuals from seeking asylum in South Africa (Peberdy and Crush 1998). 
The 1998 Refugees Act and accompanying Regulations (2000) expanded upon the refugee definitions put forth in the 1951 Refugee Convention and 1969 OAU convention by including gender, sexual orientation, disability, class, and caste in its specification of a "social group." Since 2003, South Africa's asylum seeker permit has granted individuals the right to work and study, including at the tertiary level, and has protected them against deportation (DHASA 2017; Landau 2006). ${ }^{18}$ Asylum seekers also receive the same tuition fees at higher education institutions as nationals. In other African countries, only refugees are granted employment and higher education rights. Additionally, South Africa has a self-settlement refugee-hosting policy, which means that refugees and asylum seekers have the right to move freely around the country and settle where they desire. In essence, refugees and asylum seekers enjoy similar rights as naturalized citizens, barring the right to vote and stand in national elections. They also have the right to healthcare, and most government schemes for free or low-cost public services for poorer households are open to refugees and asylum seekers. According to the Act, after settling in the country for five years, if refugees are still unable to repatriate, they may apply for permanent residence (Crush, Skinner and Stulgaitis 2017). In this way, South Africa boasts a relatively progressive asylum and refugee hosting regime and has become a top destination for those seeking international protection on the continent.

That being said, South Africa's Department of Home Affairs has faced considerable challenges in implementing its progressive asylum policy, prompting Landau (2006: 309) and Amit et al. (2009) to question whether the system enables the conversion of legal rights into "effective protection." In 2011, the government attempted to close Refugee Reception Offices (RROs) in major cities and move them to the country's northern border. RROs are where asylum seekers must register and apply for asylum and it is where applicants must go to regularly renew their permits. While this measure was challenged in South African courts, such moves and others including the pre-screening of applicants have constrained access to asylum and refugee protection (Crush, Skinner and Stulgaitis 2017; Harris 2018). Moreover, although refugee status determination should take no more than six months, it is not uncommon for claims to take years to process. ${ }^{19}$ While asylum seekers are granted the same rights as refugees, long waiting times for asylum decisions puts individuals in states of extreme uncertainty, which may deter them from seeking

\footnotetext{
${ }^{18}$ The 2003 case of Watchenuka v. the South African Minister of Home Affairs overturned the prohibition on asylum seekers' working or studying, which was set out in the 2000 Regulations.

${ }^{19}$ It was previously argued by the government that long waiting times were caused by an over-burdening of the asylum system. In 2015, it reported and UNHCR subsequently published that the country had more than one million asylum seekers awaiting status determination relative to approximately 120,000 refugees (UNHCR 2018). This figure has since been challenged and the government has revealed it was calculated in error and was closer to 80,000 in 2015. The one million figure had been used by the government to argue that the country was among the top destinations for asylum seekers and to legitimize the need to limit access to rights (Crush, Skinner and Stulgaitis 2017).
} 
out educational opportunities that require greater time commitments. Rather than an issue of rights conversion, Crush, Skinner and Stulgaitis (2017: 755) argue that South Africa's refugee policy may be described as an inevitable "shift from rights and protection towards exclusion and control." 20

Although refugees and asylum seekers have the right to work, employers are often more likely to employ naturalized South Africans who are not at risk of having their status papers expire. Also, some employment sectors, such as nursing, are protected and have extremely high barriers to entry for foreign nationals. Furthermore, bureaucratic processes requiring passport documentation often prevent migrants from setting up bank accounts, and many schools prefer to avoid the complication of accepting foreign students who require help with overcoming language barriers (McKnight 2008).

Another factor that has impacted the development and integration of refugees and asylum seekers in South Africa, which may be seen as a migration deterrent rather than driver, has been the strong and widespread xenophobic sentiments and attacks against migrants and refugees. The xenophobic violence in May 2008 resulted in more than 60 causalities and the displacement of approximately 100,000. Another period of lootings, killings, and displacement was initiated in early 2015 after inciting remarks by traditional leaders (Misago, Freemantle and Landau 2015). In February 2017, President Jacob Zuma justified the xenophobic activity as "anti-crime not anti-foreigner," the same month that anti-foreigner marches took place (BBC 2017). Amnesty_International (2017) maintained that many disenfranchised South Africans as well as political leaders are using foreigners as scapegoats over the chronic lack of jobs, housing and crucial services.

Morris and Bouillon (2001) argued that apartheid taught many oppressed South Africans that South Africa was a closed society and, therefore, the welcoming of foreigners, especially into township regions where many are still socially and economically experiencing marginalization, is negatively perceived by some. McKnight (2008) contended that some black South Africans feel more oppressed now than they did under apartheid, given their economic disenfranchisement. Moreover, he argued that many foreigners are perceived as taking advantage of South Africa's new democracy and strong economic power, which have only recently been made available to the black South African population. The high levels of insecurity that refugees and asylum seekers face in South Africa have led some to look to other countries for refuge.

\footnotetext{
${ }^{20}$ Indeed, on December 14, 2017, the Refugees Amendment Act was signed into law, however, at the time of writing had yet to come into force. The Act represents a further shift towards the exclusion and control described by Crush, Skinner and Stulgaitis (2017) and would seek to eliminate the right to study and work of asylum seekers, place strict temporal conditions on asylum applications, expand the grounds on which people may be excluded from refugee status, and increase to 10 years the time frame a refugee must live in the country before applying for permanent residency, to name a few (Scalabrini 2019).
} 
In terms of development, prior to the end of apartheid, all initiatives were highly centralized, supported the ruling white minority, and systematically excluded black and colored South Africans. For instance, the "job reservation" system, which was brought into being through the Mines and Work Act of 1911, effectively reserved highly skilled and high-paying jobs for Whites (Tambe Endoh 2015 citing Walkt 2006). In 1913, the government adopted the Native Land Act, which stated that Blacks, who comprised 70 percent of the population, could own just 7 percent of the country's land (Tambe Endoh 2015 citing Kon and Lackan 2008). The result was that black South Africans were forcibly displaced to overcrowded and underproductive reserves (Tambe Endoh 2015). Further, the 1953 Bantu Education Act restricted the school curricula of black South Africans, making it nearly impossible to achieve higher learning and educational advancement. With extreme racial segregation, confinement, and disenfranchisement characterizing both colonial and apartheid South Africa, the country not only remained relatively closed to black African migrants, but also did little to attract them.

Since 1994, the country has faced significant challenges related to high levels of inequality stemming from the aforementioned policies. Following apartheid, there was no mass education and skills training infrastructure, the majority of black South Africans did not have sufficient education and skills training, and there was no class of medium-skilled workers. In 2005, President Mbeki launched the Accelerated and Shared Growth Initiative for South Africa, a strategy aimed at halving unemployment and poverty, improving employment equity, and enhancing black economic empowerment (McGrath and Akoojee 2007). A crucial component of this strategy focused on investing in education and skills through curriculum reform, a reorganization of the higher education sector, an expansion of adult basic education, and a new skills development system.

Figure 20: South Africa GDP per capita PPP Compared to Regional Averages in 2015

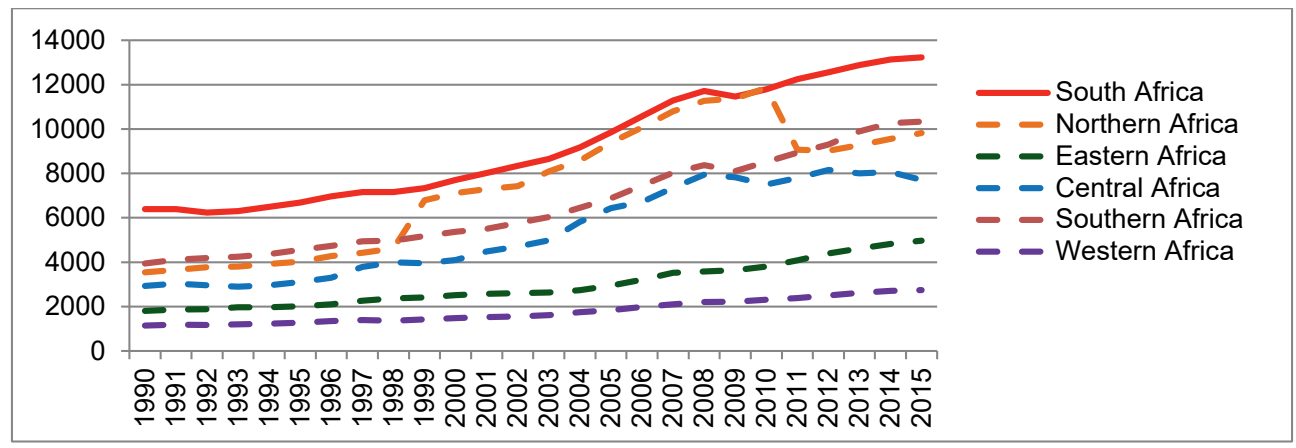

Source: World Development Indicators 2018, World Bank, GDP per capital PPP, current international \$ 
In 2015, the country had the ninth-largest GDP per capita PPP on the African continent, including Northern Africa. Moreover, its GDP was higher than any sub-regional average on the continent, including Northern Africa. In terms of human development, in 2015, it ranked 119 out of 188 countries, placing it nearer the top of countries in the medium human development group. Interestingly, South Africa's life expectancy (59.5) in 2015 was lower than that of Kenya, despite having a higher GDP and HDI ranking. This may be the result of the high degree of inequality that persists today in the country. McGrath and Akoojee (2007) estimated that between 45 percent and 55 percent of the population were living in poverty and between 20 percent and 25 percent were living in extreme poverty in 2007 . Low life expectancy may also be the result of the country's high rate of HIV prevalence, at 18.9 percent in 2015. To put this figure in perspective, Uganda's HIV prevalence rate was 6.7 percent in 2015, while Kenya's rate was 5.6 percent (World Development Indicators 2018). Still, South Africa's reputation as Africa's economic giant, its connection to global markets, and its position as the leader in higher education on the continent, make it an attractive host nation for individuals seeking asylum.

In terms of higher education, South Africa sees this sector as a key tool of national and regional development. According to the Department of Higher Education and Training (DHET) (2012: 51):

"Hosting tens of thousands of SADC students represents a major contribution by South Africa to the development of the sub-continent.... [and] to the development of South Africa, because all countries in our region are interdependent and the strengthening of Southern Africa economies must inevitably result in the strengthening of South Africa's own economy."

For this reason, in 1997, South Africa signed the SADC Protocol on Education and Training, which allowed students from SADC member countries (which includes the DRC) to enjoy the same higher education fees as South African nationals and not pay higher international student tuition rates (SADC 1997). Additionally, in 2005, Southern African countries established the Southern African Regional Universities Association (SARUA), which promotes university linkages and wider development within SADC (DHET 2012). These measures are likely the reason why 70 percent of South Africa's international student population come from SADC countries.

As of 2015, South Africa's higher education sector was comprised of 26 public universities, including 11 general academic universities, nine comprehensive universities, and six universities of technology; the National Institute for Humanities and Social Sciences; and 125 private higher education institutions (DHET 2015). The sector is no exception in dealing with the legacies of colonialism and apartheid. Given the poor 
quality of basic education in many predominantly black communities, black South Africans are not being sufficiently prepared for further studies. In 2010, 38 percent of doctoral graduates were African students, compared to 48 percent who were white (DHET 2012). The category of African students includes foreign students from other African countries, so the proportion of black South African graduates is smaller still. To further put these figures in perspective, the 2011 Census reveals that black South Africans comprise approximately 80 percent of South Africa's total population (SAStats 2011). In 2003, at the country's best university, the University of Cape Town, black African students comprised 25 percent of the student body (Sennett et al. 2003).

Similarly, the higher education sector lacks differentiation and there are significant challenges with capacity at colleges and technical schools for mid-skill training (DHET 2012). Differentiation at the lower end of the tertiary scale is important as it creates greater enrollment (and employment) opportunities for lower-achieving secondary school leavers as well as refugees and asylum seekers who may have struggled with educational attainment. Historically, universities with a majority of white students have received the greatest share of education investments. In 2012, the Department for Higher Education and Training estimated that university students outnumbered college students three to one, creating an "inverted pyramid" of skill levels that continues to cause challenges for the labor market (DHET 2012). The current structure of South Africa's higher education sector suggests that universities are the primary destinations for international students, including refugees and asylum seekers pursuing higher education. International students are therefore more likely to have educational profiles that meet the high standards of university admission. Moreover, they are more likely to come from families who can afford university school fees. By extension, students looking to pursue technical diplomas and certificates are less likely to find opportunities in South Africa.

At the time of writing, South Africa ranked first on the continent for university education. As mentioned previously, four of the top five and seven of the top ten universities on the African continent are South African institutions, according to the Times Higher Education's World University Rankings 2018. Many of these institutions were formally Whites-only institutions. Historically black universities score much lower in today's rankings and continue to struggle with a lack of resources and capacity (DHET 2012). The prestige of South Africa's universities is a considerable draw for the brightest secondary school graduates who can afford tuition fees. 


\subsection{Conclusion}

This examination of the key macro-level drivers of migration and forced displacement from the Democratic Republic of Congo and Somalia and toward Uganda, Kenya, and South Africa has generated several insights. In terms of sending countries, both the DRC and Somalia have experienced chronic poverty and conflict since the 1960s. In the DRC, the marginalization of the Eastern provinces was a strategy of President Mobutu, which reinforced the relationship between the East and its international neighbors, and reinforced movement between the DRC and Uganda, Kenya, and South Africa. Since the 1990s, the country has suffered a continuous series of internal conflicts with more than 40 armed groups, leading to massive internal and international displacement. In Somalia, the early 1990s also saw a peak in international displacement, with the collapse of the government. Moreover, a well-trodden movement corridor exists between Kenya and Somalia, given their shared border and the large numbers of ethnic Somalis who live in northeastern Kenya. Further, in both the DRC and Somalia, the lack of security and some of the lowest levels of development and education capacity on the continent have meant that movement to almost any other country provides greater safety and opportunities.

Figure 21: Summary of Development and Human Security Indicators

\begin{tabular}{lrrrr}
\hline & $\begin{array}{c}\text { GDP per capita } \\
\text { PPP (current } \\
\text { international \$) }\end{array}$ & $\begin{array}{c}\text { Human } \\
\text { Development } \\
\text { (ranking out of } \\
\text { 188) }\end{array}$ & $\begin{array}{c}\text { Life Expectancy } \\
\text { at Birth (years) }\end{array}$ & $\begin{array}{c}\text { State Fragility } \\
\text { (ranking out } \\
\text { of 178) }\end{array}$ \\
\hline DRC & 799 & 176 & 58.1 & 5 \\
Somalia & no data & no data & 54.9 & 2 \\
\hline Uganda & 1,802 & 163 & 58.6 & 23 \\
Kenya & 3,019 & 146 & 65.4 & 113 \\
\hline South Africa & 13,127 & 119 & 59.5 & 21 \\
\hline
\end{tabular}

Sources: World Development Indicators 2018, World Bank; Human Development Index 2016, UNDP; Fragile States Index 2018, Fund for Peace

In terms of receiving countries, an exploration of the different contexts of human security and political stability, economic and human development, and higher education has yielded several insights about the different drivers and patterns of migration and forced displacement in each country, as well as the different types of migrants and forced migrants they host. Uganda experienced significant political violence and displacement under the rules of Presidents Amin and Obote, making the country a net sending country. Since the mid-1980s, migration inflows have exceeded outflows. Today, the country's relative stability, combined with its progressive refugee hosting policies and protracted 
conflict in neighboring countries, has meant that it is now one of the largest hosts of refugees on the continent. This is despite the fact that Uganda has the lowest levels of human and economic development of the three receiving countries in this study, and some of the lowest levels on the continent. The country's proximity to the DRC and Somalia combined with its low levels of development makes it probable that the migrants and refugees in Uganda come from lower socio-economic backgrounds than those in South Africa and Kenya; countries with a higher cost of living. This is because those with less means are often unable to afford the costs of moving over longer distances. In terms of higher education, however, the country has the fourth best university in Africa and a well-renowned higher education sector, which draws international tertiary students.

Unlike Uganda, Kenya is the economic and transportation powerhouse of East Africa and is the hub for the continent's humanitarian aid and development organizations, and therefore attracts labor migration. The political instability and insecurity the country has experienced from ethnic violence in the early 1990s and at the end of 2007, have largely been confined to the local population, though tourism and certain forms of labor migration have been constrained. In terms of forced migration, Kenya's well-known and strict encampment policies, as well as the challenging conditions that exist within settlements, are likely to play a role in structuring refugee movements. Those who have little choice but to live in settlements seek their protection, while those who have some means and/or aspirations to work or gain further education are likely to risk living in Nairobi or attempt the journey to South Africa. The higher education sector in Kenya is overburdened and demand outstrips supply for the national population. While this leaves few opportunities at public universities for refugees and migrants, the Commission for University Education of Kenya has made it a part of its strategic plan to increase international student enrollment.

Lastly, South Africa is the economic, development, and higher education hub of the African continent, which is a considerable draw for asylum seekers, refugees, international students, and other migrants. However, it was not until the 1990s with the end of apartheid and the passing of domestic refugee legislation, that the country became open to migration and forced displacement and signed international agreements that protected the rights of migrants and refugees. South Africa has a relatively liberal asylum and refugee policy, as it hosts no camps or settlements and grants asylum seekers and refugees the right to settle themselves around the country. Moreover, it grants asylum seekers the right to work and enroll in higher education while their claims are being processed. Such policies are likely to attract forced migrants who are looking to rebuild their lives outside of their countries of origin. Given its geography at the end of the continent and across multiple national borders, movement to South Africa requires the mobilization of significant resources. Hence, refugees and migrants who make the 
journey, particularly from countries such as Somalia and the Eastern provinces of the $\mathrm{DRC}$, are likely to come from higher socio-economic backgrounds than those who move from neighboring countries. While South Africa has not experienced conflict or major instability since 1994, xenophobic violence has displaced many refugees and migrants and causing some to reconsider South Africa as a desirable destination. 
CHAPTER 5

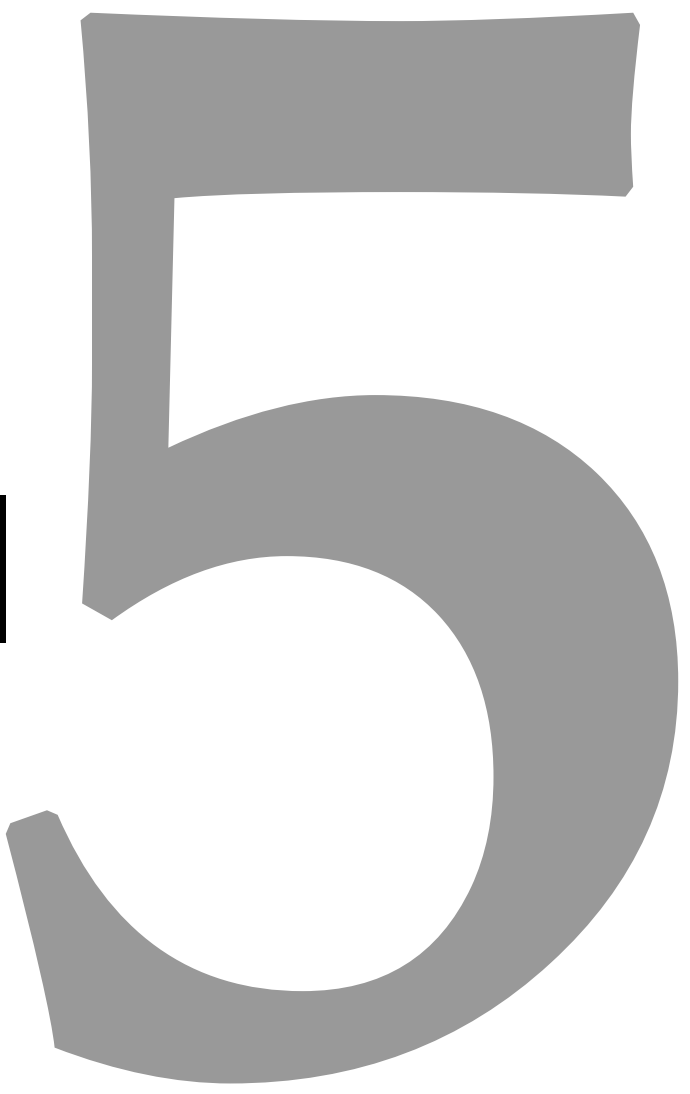




\section{Framing Movement: Patterns of Forced Displacement and Migration}


This chapter examines macro-level patterns of migration and forced displacement from, to, and between this study's sending and receiving countries to situate respondents' movements within broader movement trends taking place over time and space. Scholars like Castles (2010) and Skeldon (2014) discussed the importance of grounding the migration behaviors of individuals in their temporal and spatial contexts. Using data on stocks of different categories of migrants and forced migrants, this chapter reveals how established are the movements from the Democratic Republic of Congo (DRC) and Somalia to Uganda, Kenya, and South Africa. Such information provides insight into whether the respondents within this study are behaving more like pioneers in the vein of Bakewell, de Haas and Kubal (2011) or are following well-trodden routes and engaging in a form of chain migration. Further, it sheds light on whether Kenya, South Africa, and Uganda are hubs for migration, forced displacement, and/or student migration on the continent, whether these hubs overlap, and which national populations are principally drawn to them. Importantly, analyzing patterns of movement may reveal insights about the processes of migration and forced displacement that were not apparent from the previous chapter's examination of movement drivers. While macro-level drivers have a powerful influence on movement, they do not wholly determine or predict it. Other underlying macro, meso, and micro-level factors may be at play.

To analyze movement patterns at the macro-level, this study obtained quantitative data on migrant stocks from the United Nations Department of Economic and Social Affairs (UNDESA), which include stocks on refugees and persons in refugee-like situations; data on the population sizes of refugee camps from the United Nations High Commissioner for Refugees (UNHCR); and data on stocks of international tertiary education students from the United Nations Economic, Social and Cultural Organization (UNESCO), which are only available for South Africa. Chapter Three provided an in-depth discussion of these data and their limitations. All migrant and forced migrant stocks cover the years up to and including 2015 to correspond with the timing of fieldwork for this study.

\subsection{Sending Countries}

In 2015 among African countries, the DRC had the third-largest emigrant and refugee population settled on the continent and the seventh-largest settled anywhere in the world. For the same year, Somalia had the second-largest emigrant and refugee population settled on the continent and the third-largest settled anywhere in the world (Figure 22). Having some of the largest populations abroad could mean that Congolese and Somali migrants and refugees have more extensive migration networks, which can reduce the costs of their migration and forced displacement (and thus facilitate movement) by providing much-needed information about the journey and destination 
societies, financial support, and housing and employment upon arrival to a destination country, to name a few. In exploring the migration and forced displacement patterns of these two sending countries, this section examines the main destination regions and countries for Congolese and Somali migrants and forced migrants over time.

Figure 22: Congolese and Somali Emigrant and Refugee Populations in 2015

\begin{tabular}{lrrrr}
\hline Country & $\begin{array}{c}\text { Emigrants (including } \\
\text { Refugees) within Africa }\end{array}$ & $\begin{array}{c}\text { Rank among } \\
\text { African } \\
\text { Countries* }\end{array}$ & $\begin{array}{c}\text { Emigrants (including } \\
\text { Refugees) Worldwide }\end{array}$ & $\begin{array}{c}\text { Rank among } \\
\text { African } \\
\text { Countries* }\end{array}$ \\
\hline DRC & $1,192,697$ & 3 & $1,403,757$ & 7 \\
Somalia & $1,276,600$ & 2 & $1,998,764$ & 3 \\
\hline
\end{tabular}

Source: UNDESA Population Revision 2015

*Rank is based on absolute figures

\subsubsection{Democratic Republic of Congo}

For the Democratic Republic of Congo (DRC), the available migrant and refugee stock data reveal that the overwhelming majority of emigrants (including refugees) remained within Sub-Saharan Africa in 2015. This pattern was consistent from 1990 to 2015 and an average of 85.7 percent of Congolese migrants and refugees moved to a country within the sub-continent over this period. Looking only at the data on Congolese asylum seekers, refugees, and persons in refugee-like situations, an average of 92.3 percent remained within the sub-continent over the same period. In this way, the stock data on Congolese international migration and international forced displacement follow similar trends. Congolese international migrants move slightly farther afield than their forced migrant counterparts, with a greater share of their population moving to Europe. This reflects the lower capabilities and aspirations that forced migrants have relative to migrants, given the circumstances of conflict, violence, and persecution surrounding their movements. 
Figure 23: Congolese Migrants and Refugees by Regional Destination

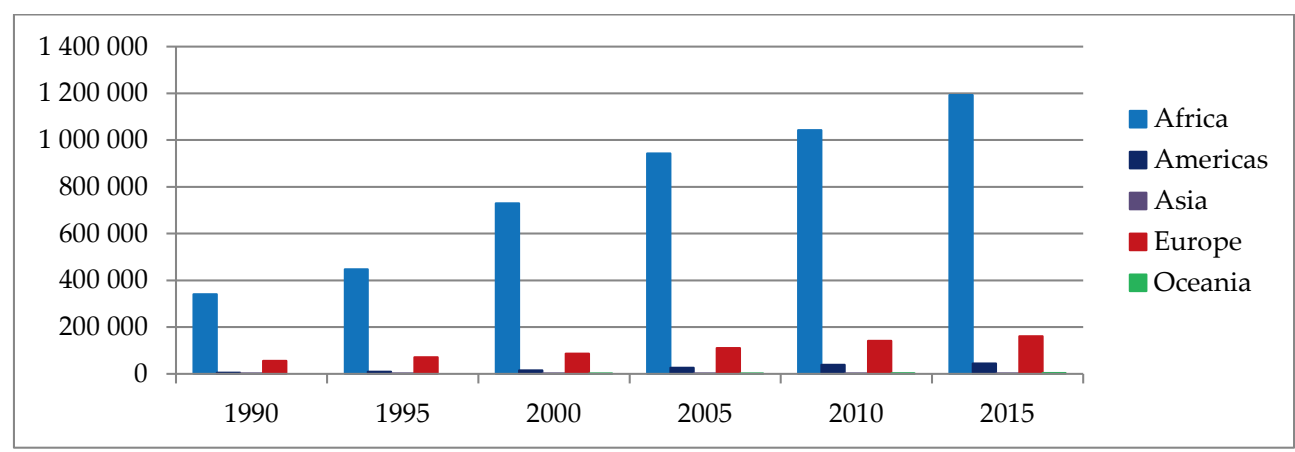

Source: UNDESA Population Revision 2015

Figure 24: Congolese Refugees and Asylum Seekers by Regional Destination

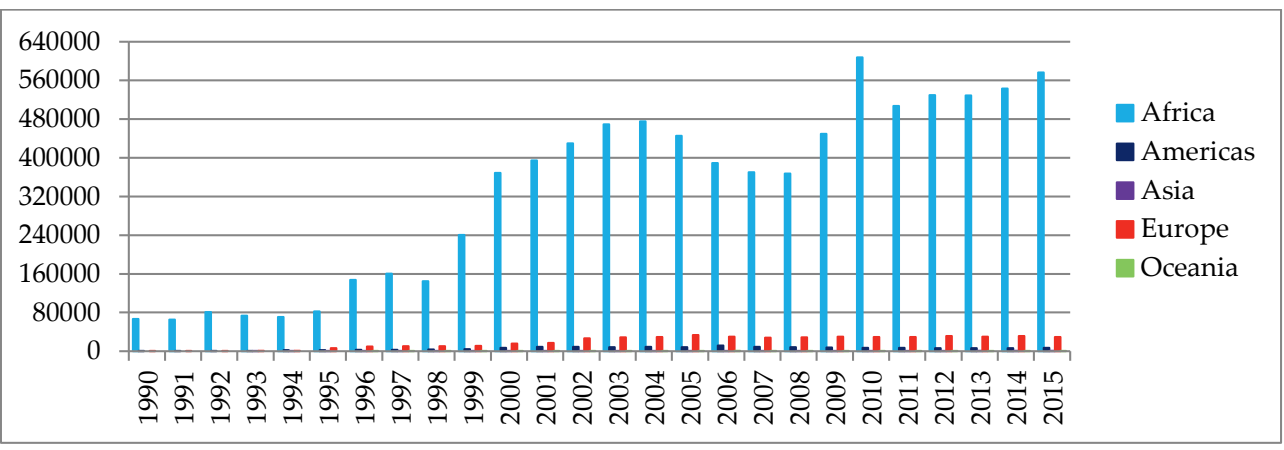

Source: UNHCR Population Statistics 2018

Of the Congolese migrants and refugees who stayed within Sub-Saharan Africa, an average of 65.5 percent moved to a country within Eastern Africa from 1990-2015 (Figure 25). For Congolese refugees and asylum seekers, the average share was nearly identical at 65.6 percent. In 2015, the number of Congolese migrants and refugees was almost double that of Congolese refugees and asylum seekers. Hence, the equal proportions are not the result of the population of migrants being wholly comprised of refugees. Instead, these comparable proportions suggest that Congolese forced displacement to Eastern Africa follow broader migration patterns. This also suggests that the capabilities and aspirations of Congolese migrants are relatively constrained, as we do not see evidence of their moving farther afield. Western Africa received similarly marginal shares of Congolese migrants (including refugees) and refugees and asylum seekers at less than 1 
percent. The Congolese stocks in Southern Africa, by contrast, diverge for migrants and forced migrants, with 14.9 percent of migrants and refugees versus 3.3 percent of refugees and asylum seekers moving to the sub-region. The higher proportion of migrants moving to Southern Africa stems from the high financial costs of the journey, the greater distance to certain countries in this region, the greater number of national borders that must be crossed, and the higher cost of living. Few forced migrants have the resources to make the journey. Moreover, the migrants undertaking this journey are likely to come from higher socio-economic backgrounds and have higher capabilities and aspirations than those moving to Eastern Africa. Overall, the stock data on the sub-regional destinations of Congolese migrants and forced migrants align with the data on drivers of migration and forced displacement from the DRC to this study's receiving countries.

Figure 25: Congolese Migrants and Refugees by African Regional Destination

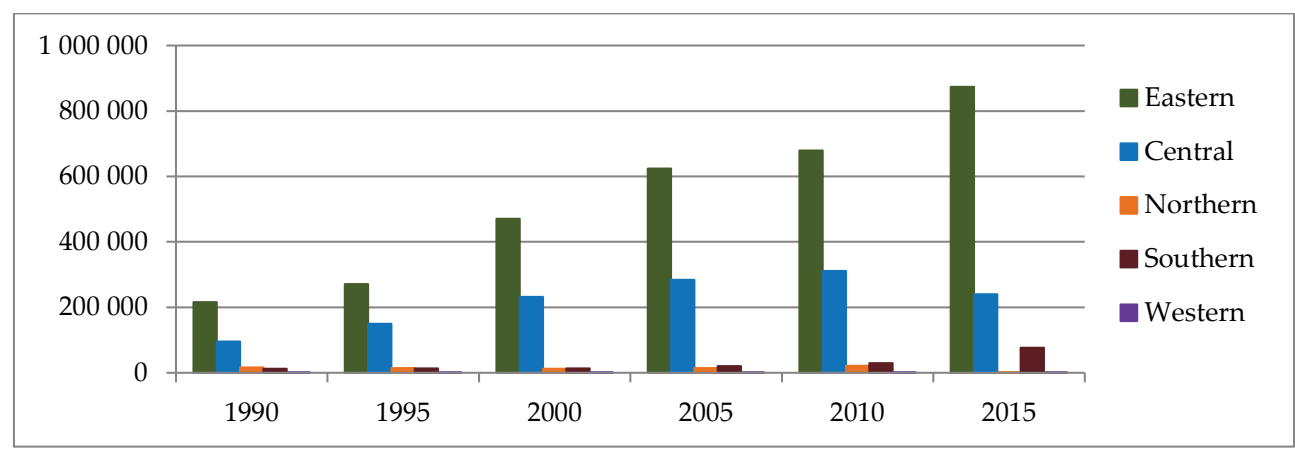

Source: UNDESA Population Revision 2015

Figure 26: Congolese Refugees and Asylum Seekers by African Regional Destination

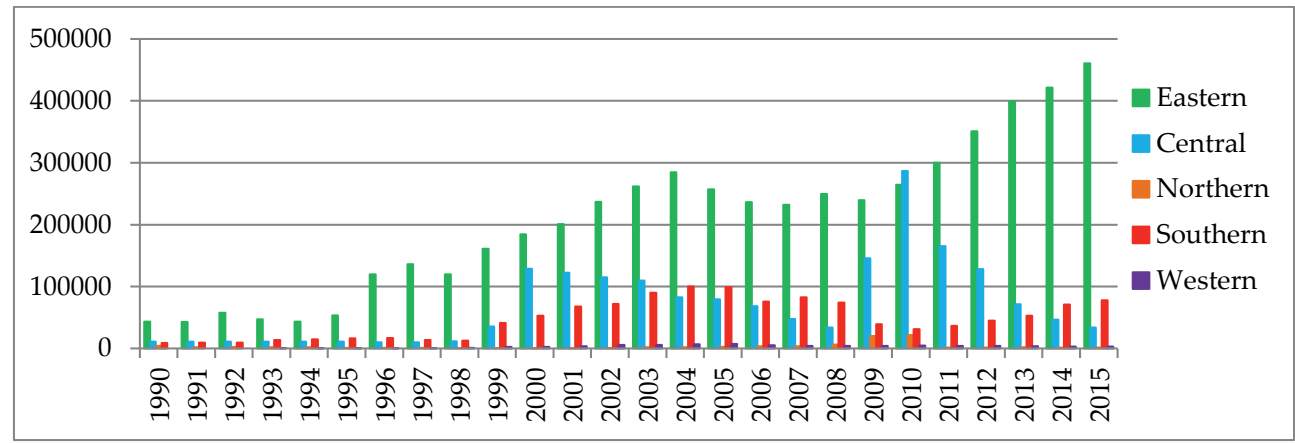

Source: UNHCR Population Statistics 2018 
Moving beyond the regional level to examine the country level, we see that, with the exception of a brief period of time in the early 2000s, Uganda, Rwanda, and CongoBrazzaville have shared and exchanged the top three positions for hosting Congolese migrants and refugees, with Burundi coming in fourth (Figure 27). This is expected as these countries all neighbor the DRC. Since 2010, South Africa has steadily increased its numbers of Congolese migrants and refugees, and the country was the sixth-largest hosting nation on the continent in 2015. This fact was all but obscured by the regional data. Based on the low levels of migration to Southern Africa, relative to other regions on the continent, South Africa appears to be the primary destination for most migrants and refugees moving south. Kenya, on the other hand, which sits in the region with the highest number of Congolese migrants and refugees (Eastern Africa), has consistently ranked just outside the top ten hosting countries for Congolese, at number 11. The low number of Congolese in Kenya is surprising given that the country is an economic hub in Eastern Africa and given its relative proximity (a day's bus drive) to Eastern Congo.

The (receiving) country level data on stocks of Congolese refugees and asylum seekers largely resemble the data on Congolese migrants and refugees, with Uganda hosting the greatest number of Congolese migrants and forced migrants by a large margin (Figure 28). In the case of Tanzania (which ranks seventh in hosting Congolese migrants and refugees), migrant stocks resemble forced migrant stocks because the former are made up wholly of refugees. For the other top destination countries, the stock patterns appear to behave in the same way, but the numbers of migrants exceed the numbers of refugees. If one subtracts the refugee stock data from the migrant stock data to examine the stock patterns without refugees, the remaining migrants also appear to exhibit the same patterns as refugee stocks. This means that Congolese migrants and refugees respond to the same structural constraints and opportunities and experience similar expressions of agency in carrying out their movements. 
Figure 27: Top African Destinations plus Kenya and South Africa for Congolese Migrants and Refugees

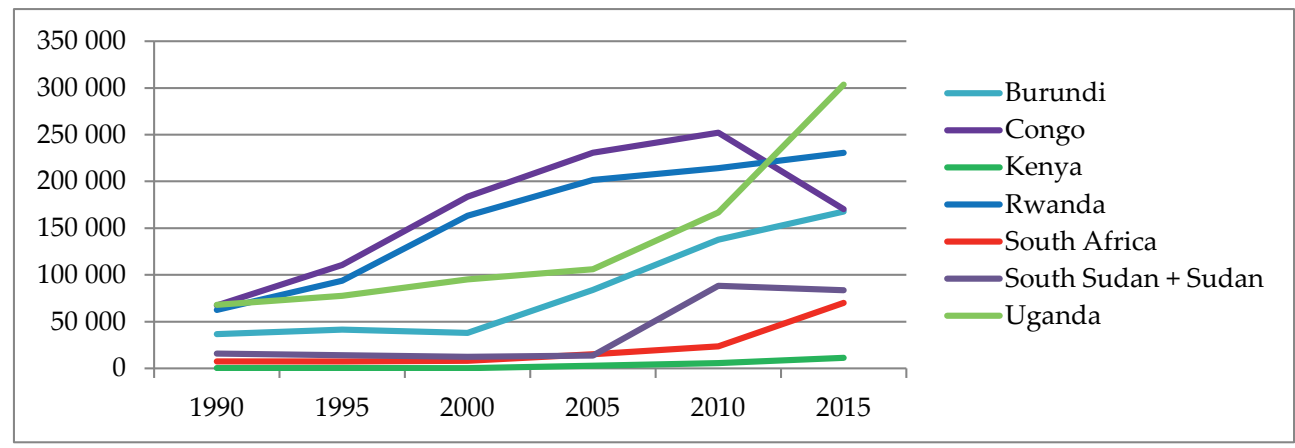

Source: UNDESA Population Revision 2015

Figure 28: Top African Destinations plus Kenya and South Africa for Congolese Refugees and Asylum Seekers

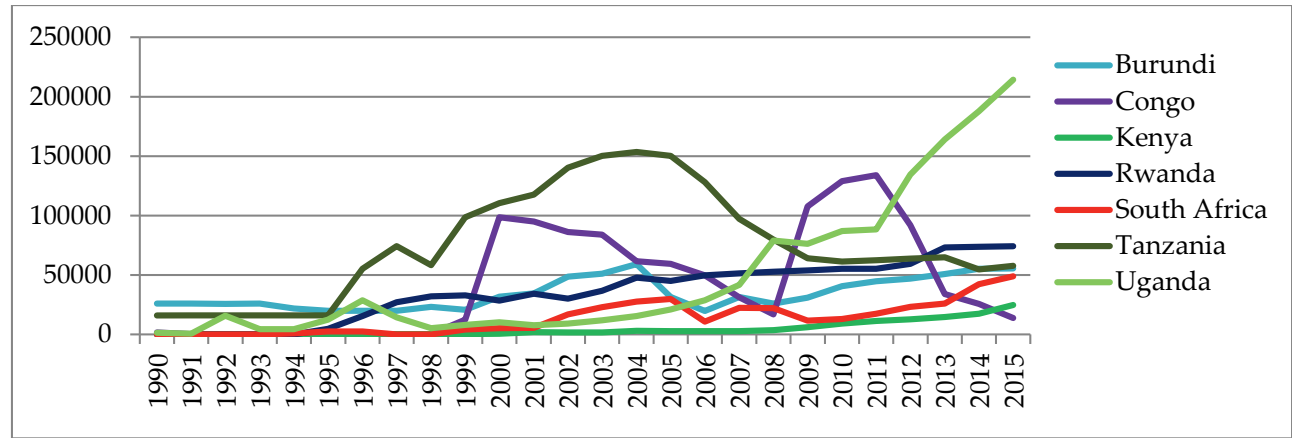

Source: UNHCR Population Statistics 2018

Based on the country-level data, we can also observe three periods in time in which migrant and forced migrant stocks appear to peak: from the mid-1990s until 2000; then they steadily rise until another peak in 2005; and migrant stocks continued to rise until 2010 for some receiving countries, while in others they declined over the same five-year period, signaling a possible population exchange. These time periods overlap with major political events and conflicts in the DRC, including the First (1996-1997) and Second (1998-2003) Congolese Civil Wars, and the election of Joseph Kabila in 2006 and his reelection in 2011, which sparked violence and unrest. Moreover, subnational conflicts and 
violence have persisted over this 25-year period, including in North and South Kivu, Ituri, the Kasai Region, and Katanga.

Based on this brief overview of the data on Congolese migrant and forced migrant stocks, it appears that migrants respond to similar structural constraints and opportunities as forced migrants. While they are not seeking out formal international protection, the act of migrating may serve as a protection and/or livelihood strategy. Additionally, we see that the migration patterns revealed by the stock data largely align with the data on drivers of migration and forced displacement. Based on the greater distances of their moves, Congolese migrants appear to have greater capabilities and/or aspirations than Congolese refugees and asylum seekers and, hence, are better able to express their agency. Furthermore, the data on Congolese migrant and forced migrant stocks highlight the differences in the migration patterns to this study's receiving countries. Uganda is the closest country with the lowest levels of development and a progressive refugee-hosting policy; it therefore hosts the greatest number of migrants and forced migrants, who likely face highly constrained capabilities and aspirations. Kenya, on the other hand, hosts the fewest migrants and forced migrants, owing to its greater distance away, restrictive refugee-hosting policy, and struggling higher education sector. Those with more resources are likely to journey to South Africa, which has a progressive asylum policy and is the most prosperous of the three countries. This explains why we see more migrants moving to South Africa than forced migrants.

\subsubsection{Somalia}

In Somalia, as in the DRC, we see that between 1990 and 2015, the majority of Somali migrants and forced migrants remained within Sub-Saharan Africa. However, since the 1990s, the share of emigrants and refugees moving to destinations outside of Africa has been steadily increasing. In 1990, 86.5 percent of Somali emigrants and refugees and 98.7 Somali refugees and asylum seekers remained in Sub-Saharan Africa while in 2015, just 56.5 percent of migrants and refugees and 66.2 percent of refugees and asylum seekers remained (Figures 29 and 30). Not surprisingly a greater share of Somali forced migrants remained within Sub-Saharan Africa over this period, owing to the greater constraints they faced and their lower aspirations to move. That being said, both groups exhibited the same trend of declining movement to destinations within Africa and increasing movement to regions farther afield. Such a trend is not likely to reverse as Somali emigrant networks have become established in non-African destination countries and patterns of chain migration have emerged. 
An additional difference between the movement patterns of Somali migrants versus forced migrants at the global level is that Europe is the second most popular destination for Somali migrants and refugees, while Asia is the second most popular destination for Somali refugees and asylum seekers. For these forced migrants, Europe was the second most popular destination until 2004, although the differences between Europe and Asia until then were slight. Since 2004, the stocks of Somali forced migrants in Asia have grown considerably and in 2015, they were approximately double those in Europe. The greater stocks of forced migrants in Asia can be wholly attributed to the large population of Somali refugees in Yemen, which comprises, on average, 95.5 percent of Somali forced migrants in Asia from 1990-2015.

\section{Figure 29: Somali Migrants and Refugees by Regional Destination}

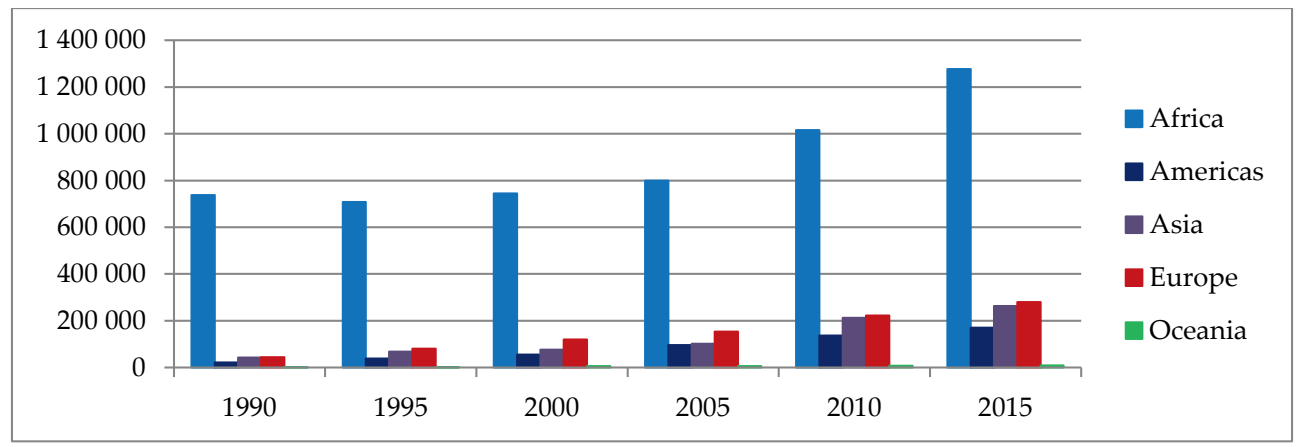

Source: UNDESA Population Revision 2015

Figure 30: Somali Refugees and Asylum Seekers by Regional Destination

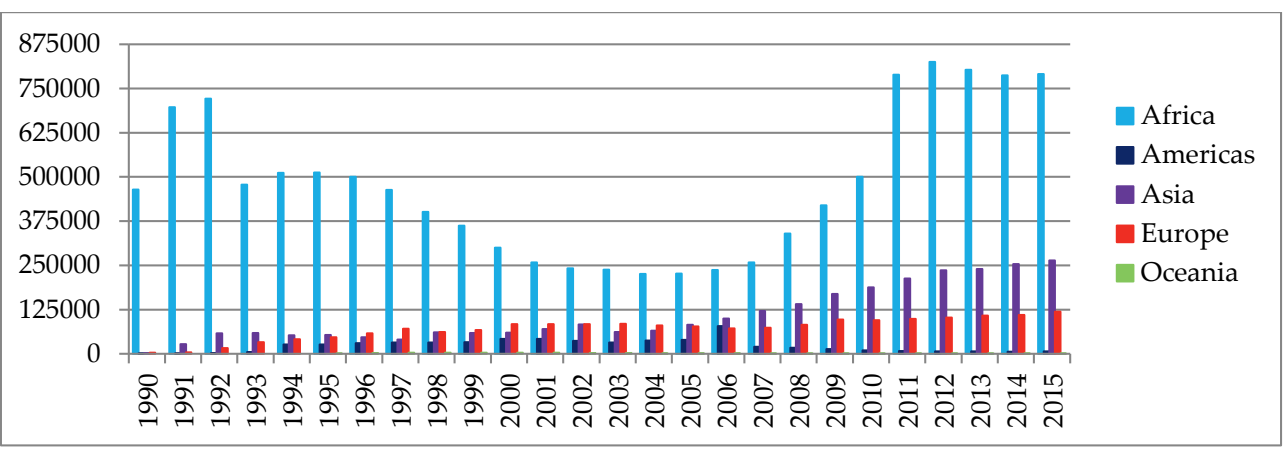

Source: UNHCR Population Statistics 2018 
Nearly all of the Somali migrants (98 percent) and forced migrants (97.1 percent) who remained in Sub-Saharan Africa moved to a country within Eastern Africa from 19902015 (Figures 31 and 32). This is the result of the vast and well-established refugee settlements near Somalia's borders and the large communities of ethnic Somalis within Ethiopia and Kenya, which serve as destinations for Somali migrants and forced migrants. The small shares of migrants and forced migrants outside of Eastern Africa move to Southern Africa; in 2015, this represented 6.2 percent of Somali migrants and refugees and 5.9 percent of Somali refugees and asylum seekers within Sub-Saharan Africa. Between 1990 and 2015, no Somali migrants and refugees and few asylum seekers were recorded moving to countries in Central or Western Africa. The small numbers of Somali forced migrants in Central Africa (approximately 2,200) and Western Africa (approximately 100) in 2015 may explain why the percentage who are displaced to Eastern Africa is slightly lower than the percentage of migrants in Eastern Africa. While seemingly counter-intuitive that there should be Somali forced migrants in these farther away sub-regions and not migrants, their numbers are small and do not suggest that Somali forced migrants are more mobile and have greater capabilities or aspirations. The greater number of Somali migrants (approximately 150,000) than forced migrants (approximately 10,000) in Northern Africa in 2015, speaks to their greater capabilities, aspirations, and mobility. On the whole, this brief review of African sub-regional destinations for Somalis highlights the fact that, with the exception of movement to Northern Africa, continental migration patterns appear to mirror forced displacement patterns.

Figure 31: Somali Migrants and Refugees by African Regional Destination

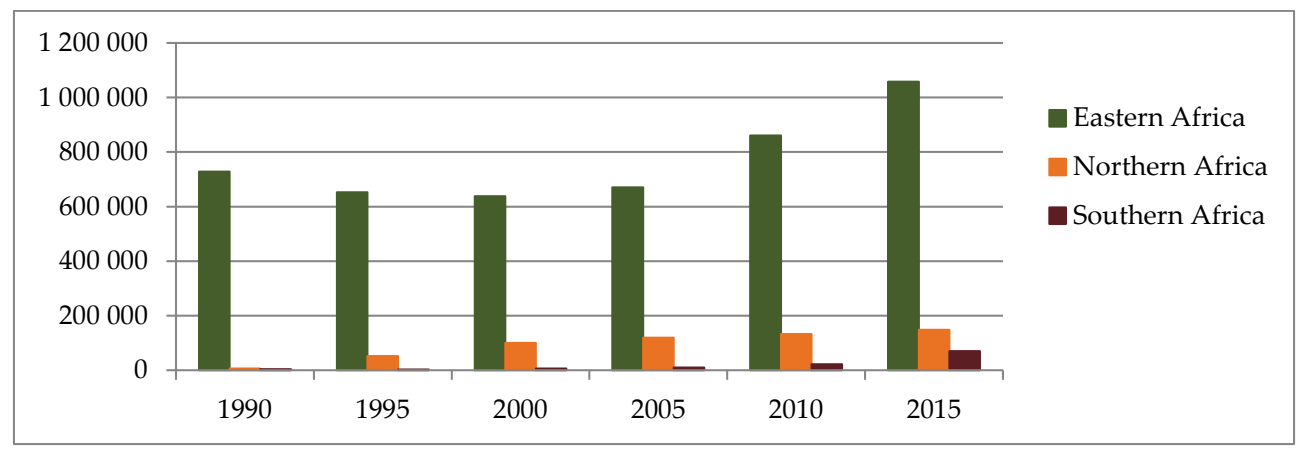

Source: UNDESA Population Revision 2015 
Figure 32: Somali Refugees and Asylum Seekers by African Regional Destination

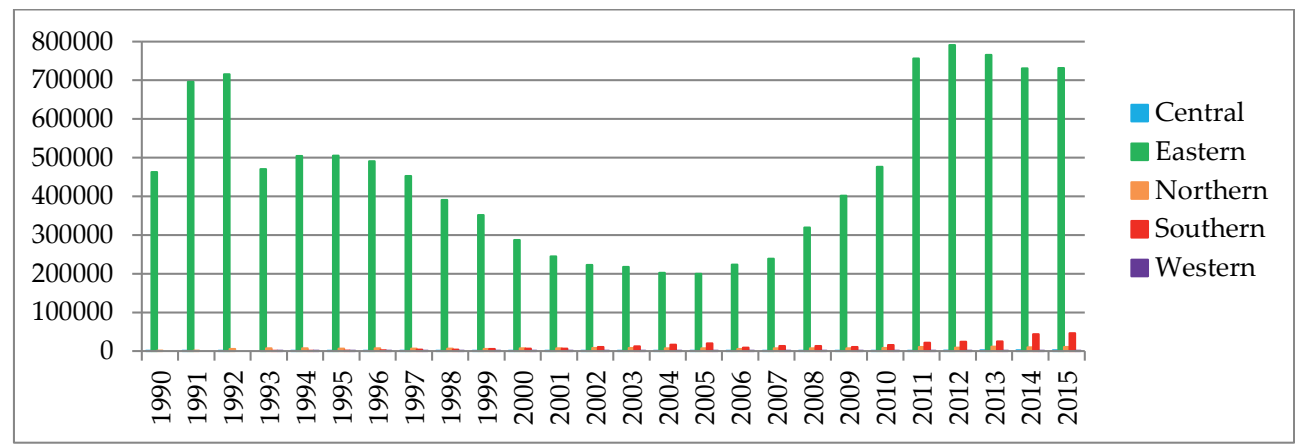

Source: UNHCR Population Statistics 2018

The country-level data confirm our assumptions regarding which countries in Eastern Africa host the largest Somali migrant and forced migrant stocks (Figures 33 and 34). The high number of Somali migrants and refugees in Ethiopia in the early 1990s corresponds to the start of protracted civil war in Somalia in 1991; however, the decline in stocks in Ethiopia may be linked to violence and political tensions in the destination country. Additionally, since 1990, Somali migrant and refugee stocks in Kenya have been steadily increasing, without signs of slowing in 2015. Similar to Congolese stocks, Somali migrant stocks in South Africa increased after 2010. In 2015, there were approximately 70,000 Somali migrants and refugees in South Africa and approximately 29,000 in Uganda.

The data on Somali refugees and asylum seekers largely reflect the data on migrants and refugees. Further, these figures reveal that nearly all of the Somalis in Uganda and Kenya ${ }^{21}$ were refugees in 2015, while refugees represented just over half the total migrant population in South Africa. In 2015, Kenya hosted the largest number of Somali migrants and forced migrants on the continent. South Africa hosted the fifth-largest number of Somali migrants and refugees and the third-largest number of Somali refugees and asylum seekers. Lastly, Uganda hosted the sixth-largest number of Somali migrants and refugees and the fourth-largest number of refugees and asylum seekers. The countrylevel data on the African destinations for Somali migrants and forced migrants highlight the importance of this study's destination countries in understanding Somali movement patterns. For Somali migrants, Kenya, South Africa, and Uganda are three of the top five destinations, and for forced migrants, they are three of the top six destinations. Interestingly, for both populations, South Africa outranks Uganda as a destination,

\footnotetext{
${ }^{21}$ Not including Somali Kenyans, who are Somali by ethnicity, but Kenyan by nationality.
} 
despite being a much greater distance away from Somalia and having a much higher cost of living. This suggests that not only does a strong movement corridor exist between Somalia and South Africa, facilitated by migration networks, but also Somalis are mobilizing the resources to make the long journey and are aspiring to move south.

Figure 33: Top African Destinations plus Uganda for Somali Migrants and Refugees

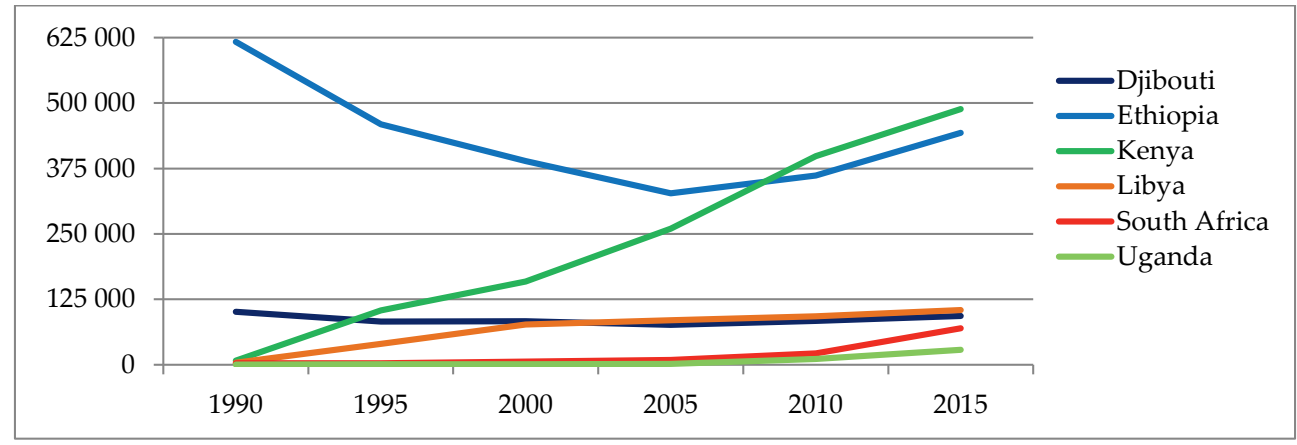

Source: UNDESA Population Revision 2015

Figure 34: Top African Destinations for Somali Refugees and Asylum Seekers

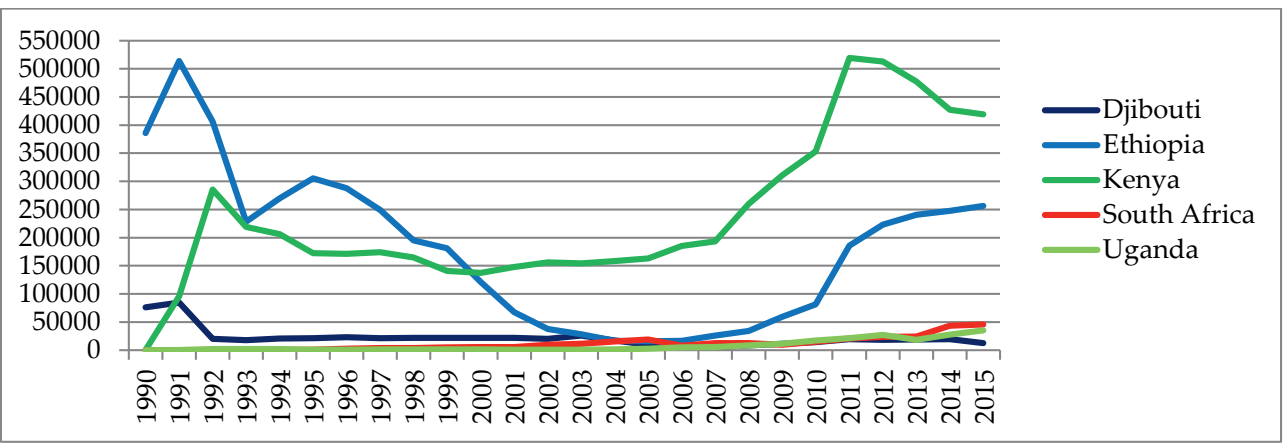

Source: UNHCR Population Statistics 2018

Several insights may be drawn from this cursory exploration of the available stock data on Somali migrants and forced migrants by region and country of destination. As is the case for their Congolese counterparts, the majority remain in Sub-Saharan Africa. Eastern Africa has been and continues to be the most important destination region for Congolese and Somalis, as neighboring countries have the largest migrant and forced migrant 
stocks. The major difference between Somali and Congolese movers is that over time, both Somali migrants and forced migrants have been moving increasingly to regions beyond the African continent. Such a trend is not likely to reverse, as migration networks have been established, the desirability of migration has increased and become routinized, and the costs of movement have decreased. The similar movement patterns between migrants and forced migrants suggest that these groups respond to the same structural constraints and opportunities. While migrants are not seeking out formal international protection, the act of migrating from these countries impacted by conflict and crisis serves as a protection and/or livelihood strategy.

Additionally, we see that the movement patterns revealed by the stock data largely align with the data on the drivers of migration and forced displacement and highlight the differences that exist among this study's receiving countries. The majority of Somalis moved to their closest neighbor, Kenya, as the majority of Congolese moved to their closest neighbor, Uganda. Interestingly, increasing distance from the origin was not an adequate predictor of migrant or even forced migrant stocks for these nationalities, as South Africa had greater stocks of Somalis than Uganda and greater stocks of Congolese than Kenya. Hence, once Somalis and Congolese movers were able to mobilize the resources to move farther afield than the immediate neighboring country, they made the journey to where they perceived was the most attractive destination within Africa and where they had established networks.

Lastly, while the movement patterns of Somali and Congolese migrants and forced migrants largely followed the same trends, migrants moved greater distances than their forced migrant counterparts. This is explained by migrants' greater capabilities and aspirations, which enabled them to better express their agency. Moreover, a greater share of Somali migrants and forced migrants moved to regions beyond the African continent, indicating that they had greater capabilities, higher aspirations, and/or stronger mobility norms than their Congolese counterparts.

\subsection{Receiving Countries}

After discussing the patterns of migration and forced displacement from the Democratic Republic of Congo and Somalia, this section turns to consider the patterns of migration, including student migration, and forced displacement to this study's receiving countries: Uganda, Kenya, and South Africa. As mentioned in Chapter Three, on the African continent, these three countries stand at the top of rankings of destinations for both international migrants and forced migrants. In 2015, South Africa ranked first for hosting international migrants and first for hosting refugees, people in refugee-like situations, 
and asylum seekers. Kenya followed South Africa as a main African destination, ranking fourth for hosting international migrants and third for hosting international forced migrants. Uganda ranked eighth for hosting international migrants, and fourth for hosting international forced migrants. Only two other countries ranked in the top ten for both categories, Ethiopia and the Democratic Republic of Congo. Ethiopia did not have the same diversity of refugee populations as Kenya, South Africa, and Uganda and the DRC ranked the lowest of all the countries in the top ten for hosting international forced migrants and international migrants.

Figure 35: Refugees and Migrants in Kenya, South Africa and Uganda in 2015

\begin{tabular}{lrrrr}
\hline Country & $\begin{array}{c}\text { Refugees and Asylum } \\
\text { Seekers }\end{array}$ & $\begin{array}{c}\text { Rank within } \\
\text { Africa }\end{array}$ & $\begin{array}{c}\text { International } \\
\text { Migrants including } \\
\text { Refugees }\end{array}$ & $\begin{array}{c}\text { Rank within } \\
\text { Africa }\end{array}$ \\
\hline Kenya & 593,881 & 3 & $1,084,357$ & 4 \\
South Africa & $1,217,708$ & 1 & $3,142,511$ & 1 \\
Uganda & 512,966 & 4 & 704,676 & 8 \\
\hline
\end{tabular}

Sources: UNHCR Population Statistics 2018 and UNDESA Population Revision 2015

\subsubsection{Uganda}

Uganda has a long history of receiving migrants, refugees, and asylum seekers. During the Second World War, Uganda was host to European refugees and in 1955, 80,000 asylum seekers fled to the country from Sudan (Lomo, Naggaga and Hovil 2001; Mulumba and Olema 2009). Shortly thereafter, the country was host to refugees from most of its neighbors, as they fought independence wars and related conflicts. Uganda also received migrants and refugees from Ethiopia and Somalia in the early independence period (Lomo, Naggaga and Hovil 2001). Since then, the country has hosted thousands of migrants, refugees, and asylum seekers, mostly from its neighbors, including Sudanese escaping civil war from 1962-1972 and 1983-2005, ${ }^{22}$ Rwandese Tutsis escaping political turmoil in the 1960s and fleeing the genocide in 1994, and more than one million South Sudanese fleeing civil war in 2017 (UNHCR 2018c). Since 2016, Uganda has become Africa's largest refugee-hosting nation, with the latest influx of refugees from South Sudan (UNHCR 2018c). The migrant and refugee stock data from 1990 to 2015 reflect many of the aforementioned conflicts. In 2005, we see the beginning of a decline in Sudanese migrant stocks as the Comprehensive Peace Agreement was signed and repatriation exercises began. We also see that migrants and refugees from the DRC

\footnotetext{
${ }^{22}$ It should be noted that the sets of years are not strict start and end points and they do not include the war in Darfur or conflicts in South Kordofan and the Blue Nile region.
} 
(totaling 303,580) and Somalia (totaling 28,586) were among the largest foreign populations in the country in 2015.

Figure 36: Top Migrant and Refugee Populations in Uganda plus Somalia

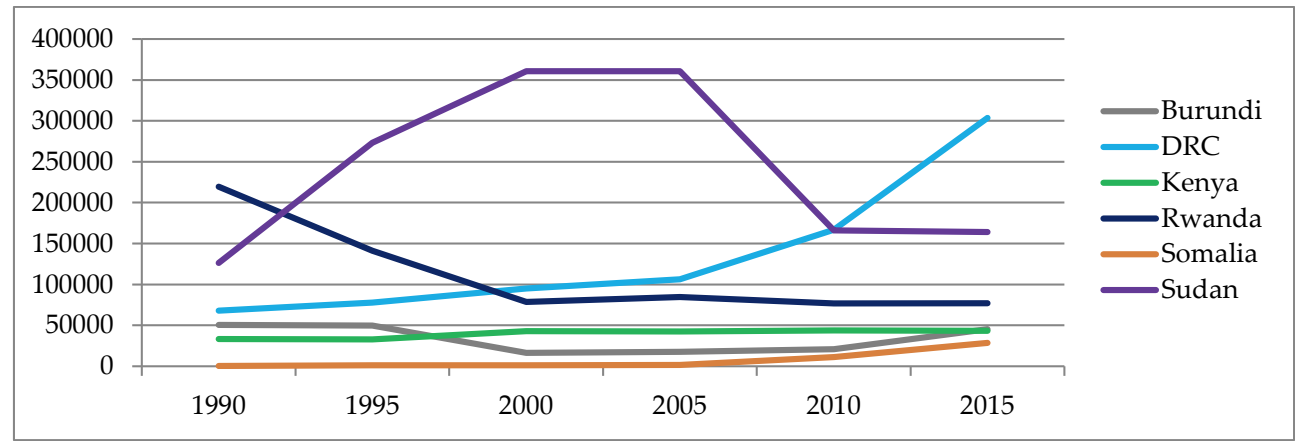

Source: UNDESA Population Revision 2015

Figure 37: Top Refugee and Asylum Seeker Populations in Uganda

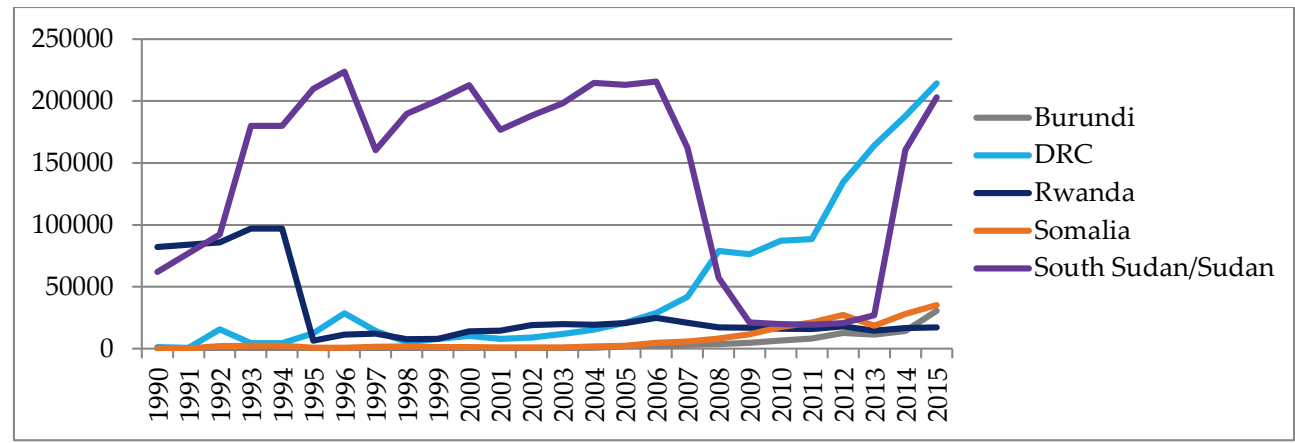

Source: UNHCR 2018 Population Statistics

The data on asylum seekers, refugees, and people in refugee-like situations reveal several additional insights. First, we see that, with the exception of Kenya, the main sending countries of forced migrants are the same as those for migrants. Moreover, the patterns of movement for these forced migrants mirror those of their migrant counterparts: they increase and decrease to similar degrees and over the same periods of time. For Somalia, this is the case because migrant stocks are made up almost entirely of refugee stocks. This is not the case for the remaining countries, which have migrant stocks significantly larger 
than their refugee stocks. For instance, in 2015, there is an increase in the number of Congolese migrants in Uganda, totaling approximately 300,000, but only 200,000 of them are refugees. This signals that emigrants and refugees from the DRC experienced similar constraints which prompted their moves to Uganda; some had the capabilities to move through "voluntary" migration channels, while others required international protection.

In examining the forced displacement patterns to Uganda, it is also important to consider refugee camp and settlement figures. In 2015, Uganda was home to the second-largest set of planned refugee camps in the world, the Adjumani camps, with 120,181 inhabitants. With the most recent crises in South Sudan and the DRC, at the time of writing in 2018, Uganda's Bidi Bidi settlement in the Yumba district hosted approximately 287,000 refugees and the Adjumani camps hosted approximately 240,000 refugees (UNHCR 2018d). Refugee camps and settlements are not only home to considerable refugee populations but also assistance structures, subsidized economic activities, and markets. With the majority of locations near the country's borders with the DRC and South Sudan, they attract refugees and migrants and enhance short-term and short-distance mobility.

While Uganda does not report international student migrant stock data, a report on the state of Uganda's higher education sector estimated that in 2011, 17,156 international students were enrolled in tertiary institutions, up from 16,244 in 2010 . While the number of foreign students in absolute terms increased, relative to the whole student population, the share of foreign students was in decline (0.4 percent) in the early 2010s (NCHE 2013a). Further breakdowns are not available for these figures because while institutions are required to disaggregate their data, in practice, they do not. From the institutions that do report disaggregated enrollment data, we know that most foreign students come from Kenya, Tanzania, Rwanda, Burundi, South Sudan, Somalia, and the Democratic Republic of Congo; and, in 2011, they enrolled in theological colleges (15 percent), universities and affiliated colleges (11 percent), and management and social development colleges (10 percent) (NCHE 2013a).

\subsubsection{Kenya}

Kenya is geographically situated near or adjacent to several countries affected by protracted conflict and crisis and has experienced large influxes of asylum seekers since the country's independence in 1963. In 2015, the greatest numbers of migrants and refugees originated from Somalia (almost 500,000). Migrants and refugees from the DRC comprised the sixth-largest group in Kenya at approximately 11,300 in 2015 (Figure 39). As mentioned in the preceding section, Somalia has experienced considerable social, political, and economic instability and conflict since 1991. The remaining largest migrant 
and refugee populations are all, not surprisingly, from neighboring or nearby countries. Kenya is a member of the East Africa Community (EAC), which gives its citizens the right to live and work in other EAC countries. This explains the significant number of Ugandans living in Kenya. More generally, it explains the fact that most of Kenya's largest migrant groups originate from EAC countries.

\section{Figure 38: Top Migrant and Refugee Populations in Kenya plus the DRC}

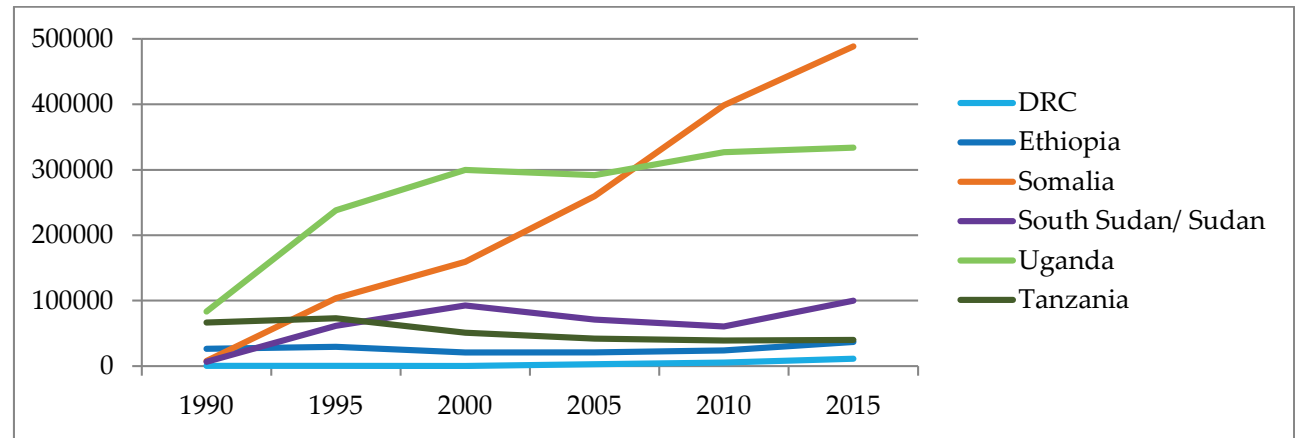

Source: UNDESA Population Revision 2015

Figure 39: Top Refugee and Asylum Seeker Populations in Kenya

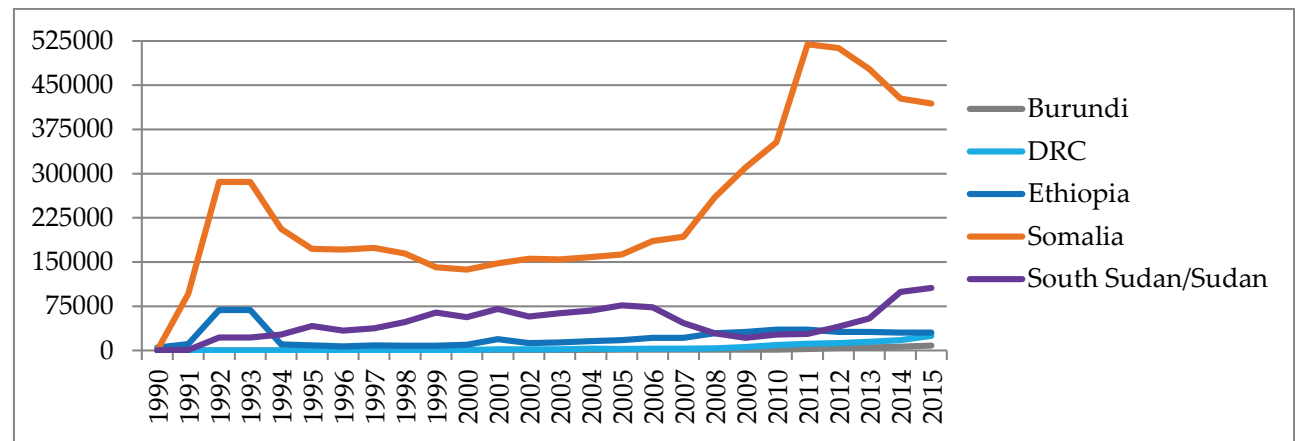

Source: UNHCR 2018 Population Statistics

The data on refugees and people in refugee-like situations provide further insight into Kenya's in-migration patterns. The data on Somalia, Sudan and South Sudan, Ethiopia, and the DRC remain much the same, meaning that these stocks from 1990 to 2015 are primarily comprised of forced migrants. In contrast, the sizable stocks of migrants and 
refugees from Uganda and Tanzania are largely absent in the forced migrant data, indicating that these stocks are mainly comprised of migrants. This aligns with what we know about Uganda and Tanzania's political environment during this period.

Other key forced migration figures to consider are refugee settlement patterns, as Kenya requires all refugees to live in planned/managed camps. The country hosts two planned camp complexes for refugees and asylum seekers: Dadaab and Kakuma. They are referred to as complexes because they comprise multiple camps, in the case of Dadaab, and multiple zones, in the case of Kakuma. Dadaab is a complex of five camps (Dagahaley, Ifo, Ifo 2, Hagadera, and Kambioos), located to the east of the country in Garissa County, near the Somali border. It has a population which is predominantly Somali and had approximately 347,980 inhabitants at the end of 2015 (UNHCR 2016a). ${ }^{23}$ The Kakuma Refugee Complex is located towards the west of country in Turkana County, near the Ugandan and South Sudanese borders. Kakuma is divided into four zones (numbered one to four), and had approximately 184,550 inhabitants, with the majority being from South Sudan, in 2015 (UNHCR 2016a). Kakuma was designed to host 70,000; hence, with its outstretched capacity, in 2015, the Turkana Country Government and the Central Government provided the land for a new settlement to be created nearby, named Kalobeyei (UNHCR 2018b).

Figure 40: Largest Planned/Managed Refugee Camps Worldwide in 2015

\begin{tabular}{lr}
\hline \multicolumn{1}{c}{ Planned/Managed Camp } & Population \\
\hline Kakuma Zones 1-4 (Kakuma, Kenya) & 184,550 \\
Adjumani camps (Uganda) & 120,181 \\
Hagadera camp (Dadaab, Kenya) & 105,998 \\
White Nile camp (Sudan) & 97,505 \\
Dagahaley camp (Dadaab, Kenya) & 87,223 \\
Ifo camp (Dadaab, Kenya) & 84,089 \\
Zaatari camp (Jordan) & 77,781 \\
\hline Source: UNHCR Global Trends 2016
\end{tabular}

UNHCR's Global Trends in Forced Displacement 2015 revealed that the camps comprising the Dadaab and Kakuma Refugee Complexes were among the largest in the world. Such centers for refugee settlement and assistance structures play a role in how Kenya is perceived as a country of asylum. Moreover, they play a role in refugee movements within Kenya, as refugees and asylum seekers are required to live in these

${ }^{23}$ At one time, estimates of the population of the Dadaab Refugee Complex were as high as 400,000 - 450,000. 
complexes and not self-settle among the Kenyan population. Unlike Uganda's refugee settlements, there is little integration between the refugee and host communities in Kenya. While some services and development initiatives are indeed shared, refugees are not well-integrated into local trade and labor markets. Moreover, these markets, themselves, are highly constrained and cut-off from the rest of the country, as the Turkana and Garissa counties have been and continue to experience economic and social marginalization. For this reason, these areas attract few migrants who are not refugees. The creation of the new Kalobeyei settlement was an attempt not only to relieve pressure from Kakuma, but also to create a new, more integrated and self-reliant refugee hosting model. Hence, it is possible that as a more locally integrated community grows, in the future, we might see more migration to these counties.

\subsubsection{South Africa}

South Africa does not have a long history of accepting migrants and forced migrants because of its strict controls on movement and because it was not a signatory to international human rights instruments during apartheid. For this reason, we do not have consistent data on South Africa's migration and refugee stocks before 1994. Figure 42 shows that from 1994 to 2015, the majority of migrants in South Africa came from countries within the Southern African Development Community (SADC) and the largest populations came from Zimbabwe and Mozambique in 2015. Since 2000, we can see a steady rise in stocks across the main migrant and refugee groups entering the country, and a higher rate of increase from 2005. This aligns with the strong economic growth the country experienced over the same period. Moreover, we would expect that upon the opening up of the country to migrants and refugees, it would take some time for migration patterns to become established and for migrant communities to grow and create self-sustaining migration systems. In this sense, five to ten years is a relatively short period of time for migration patterns to evolve in the way they have to South Africa. In 2015, the country was home to more than three million migrants (UNDESA 2017a). Unlike Kenya and Uganda, a major migrant group in South Africa comes from outside of Africa, that of British migrants. This is not surprising given the country's more recent break from its colonial experience.

Turning to consider South Africa's forced migration patterns, between 2006 and 2012, the country received the largest number of asylum seekers in the world (Wellman and Landau 2015). The majority of the country's refugees and asylum seekers are not from neighboring countries, but from countries farther afield in Africa and beyond (Figure 43). From 1994 to 2015, the only neighboring country in the top five for forced migrants was Zimbabwe. This stands in contrast to the patterns we observed for South Africa's 
migration stocks. As of 2009, South Africa hosted asylum seekers from 52 different countries (UNHCR 2009). While the top five forced migrant populations all came from African countries, forced migrants from two Asian countries featured in the top 10: Bangladesh and Pakistan. Given that the majority of forced migrants in South Africa come from non-neighboring origin countries, South Africa has a more self-selected forced migrant population, relative to other African countries. Those who fled conflict, violence, and/or persecution in Somalia or Pakistan, for instance, had the financial resources, social capital, and/or aspirations to journey to South Africa and not seek asylum in a number of safe countries closer to their origin communities.

Figure 41: Top Migrant and Refugee Populations in South Africa plus Somalia and DRC

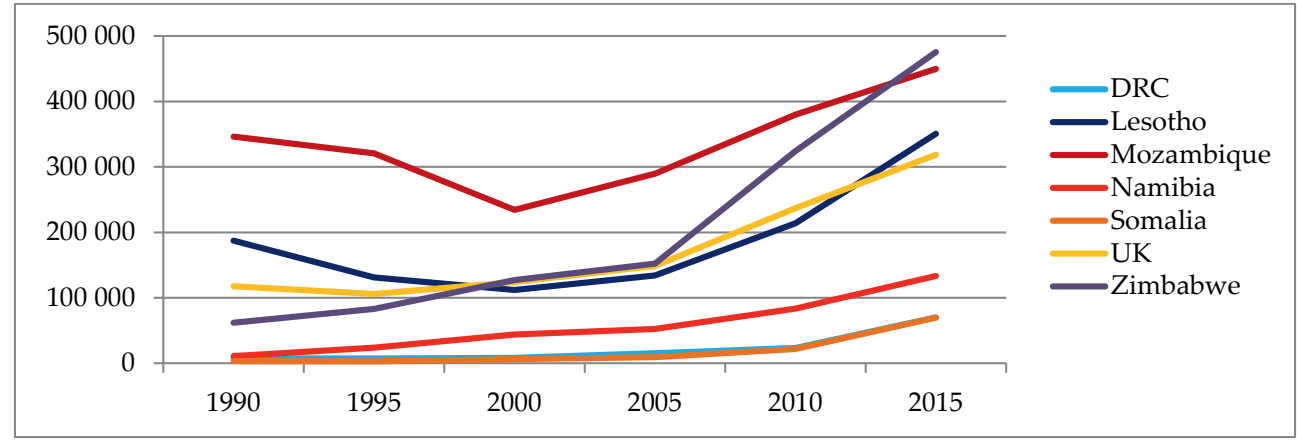

Source: UNDESA Population Revision 2015

Figure 42: Top Refugee and Asylum Seeker Populations in South Africa

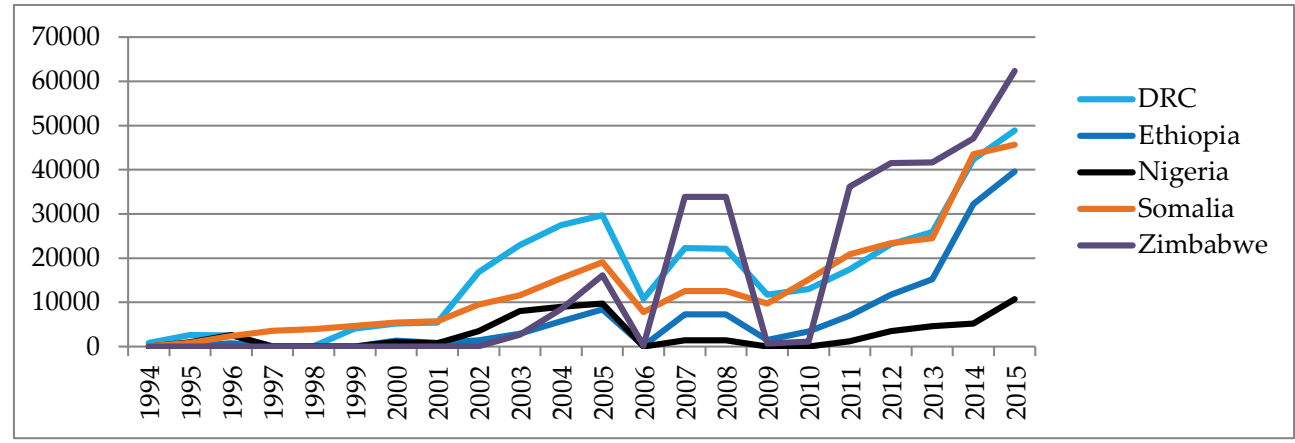

Source: UNHCR 2018 Population Statistics 
Patterns of forced migration diverge from patterns of migration in South Africa, in part, because the country's immediate neighbors are not experiencing active conflict and, with the exception of Zimbabwe, are not major generators of forced migration. Figure 43 shows that the main origin countries for South Africa's refugees and asylum seekers are among the main source countries for forced migrants on the continent: the DRC, Ethiopia, and Somalia. Another reason why patterns of forced displacement and migration diverge is because of South Africa's unique asylum situation. As mentioned previously, until 2015, South Africa had the highest asylum seeker caseload on the continent and an insufficient capacity to carry out refugee status determination. This resulted in waiting times spanning years rather than months and led the government to grant asylum seekers the right to study and work in 2003. Landau (2006: 309) argued that immigration legislation "encourages economic migrants to use the asylum process as a 'back door' to legalizing their stay in the country." As a result, asylum seekers comprised a significant proportion of forced migration stocks. In 2015, the ratio of refugees to asylum seekers for the DRC was 2:1; for Ethiopia, it was 1:1; and for Somalia, it was 10:1. On the other hand, for Nigeria it was 1:10,000 and for Zimbabwe it was 1:9; similar disparities may be observed for forced migrants from Bangladesh and Pakistan. This is also why, in Figure 43, we see sharp drops in forced migrant populations for the years 2006, 2009, and 2010, as asylum seeker data are not available for those years.

In examining the movement patterns of forced migrants once they arrive in South Africa, as mentioned previously, the country grants asylum seekers and refugees the right to self-settle wherever they choose and is not home to any planned/managed camps or settlements. While UNHCR does not have data on the locations where refugees settle in South Africa, the StatsSA Survey 2016 and Gauteng City-Region Observatory (GRCO) reveal that the province of Guateng, wherein Johannesburg is the largest city, houses the greatest number of foreign nationals. This is not surprising as Gauteng is the economic hub of the country. The Western Cape, where Cape Town is located, houses the secondlargest population of foreign nationals (Meny-Gibert and Chiumia 2016; Peberdy 2013). 
Figure 43: Top Student Migrant Populations in South Africa plus Somalia

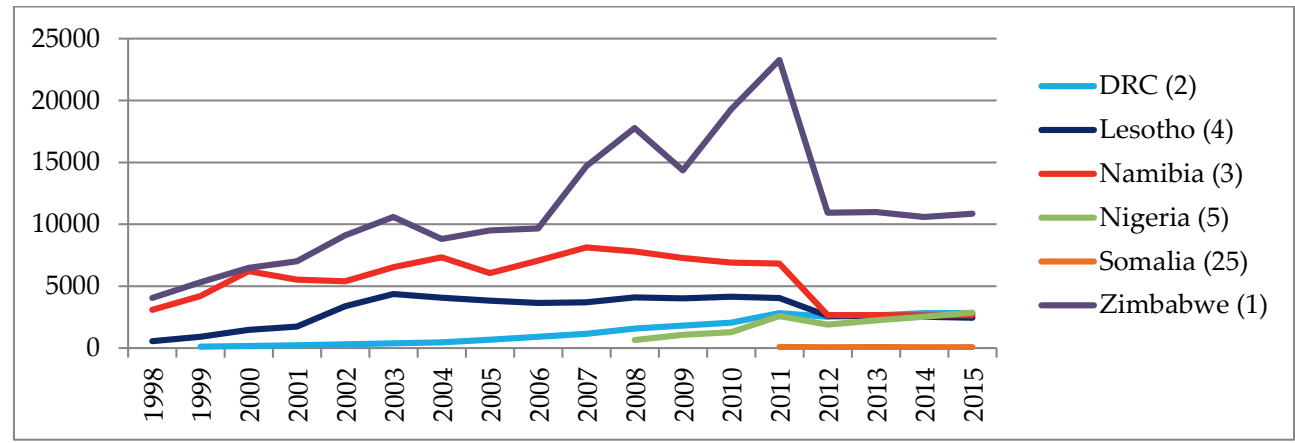

Source: UIS.Stat UNESCO 2018

In terms of international student migration, the top African sending countries between 1998 and 2015 came from the Southern Africa Development Community (SADC), mirroring the patterns observed for migration stocks. Regional student mobility is facilitated not only by distance but also by policy in that South Africa grants students from SADC countries the same tuition fees as nationals. For Congolese students, who benefit from SADC tuition rates, student mobility may also serve as a strategy to avoid instability and a constrained labor and education market in the DRC, as well as to avoid entering asylum channels. Nigeria, which featured as a main forced migration origin country alongside the DRC, ranked fifth in terms of student mobility. It is possible that the student migration channel also offers Nigerians another way to access the country. Moreover, Nigerians represented a large population from 2008 to 2015 because the country is one of the more economically prosperous on the continent and its school system is anglophone. The cost of tuition and cost of living in South Africa is, therefore, less likely to be an obstacle for these students. By contrast, Somalis comprised the 25largest population of international students with 73 students in 2015. It is important to note that the figures on international student migrants do not include refugees and asylum seekers. These figures could be much higher if they accounted for international students who are also forced migrants; however, such data are not available.

Several insights may be drawn from this cursory exploration of the available stock data on migrants and forced migrants in Uganda, Kenya, and South Africa. First, all of the largest migrant and forced migrant populations in Kenya and Uganda, and all of the largest migrant populations in South Africa, come from neighboring or nearby countries. This reinforces what we know about migration and forced displacement being predominantly intra-regional. Additionally, South Africa's largest populations of forced migrants mirror those of Kenya and Uganda, highlighting that those who make the 
journey south are a self-selected population. Second, all three of this study's receiving countries have Congolese and Somalis as part of their top five forced migrant populations and top ten migrant populations. This means that the movements of this study's Congolese and Somali respondents are part of well-established migration systems and are not the movements of so-called pioneer migrants.

Third, migrant and forced migrant stocks from the same country of origin appear to behave in similar ways in a given receiving country, regardless of the share of refugees within a migrant stock, meaning they tend to increase and decrease to similar degrees and over similar periods of time. This suggests that migrants and forced migrants, particularly from the DRC and Somalia, are responding to the same structural constraints and opportunities in their movement patterns. In this way, mobility serves as a livelihood or protection strategy for those not seeking out formal international protection through humanitarian channels.

Fourth, based on their refugee hosting policies, Uganda and Kenya have large refugee populations living in settlements and are home to the largest settlements in Africa. Such concentrations of forced migrants near the borders to origin countries, and corresponding concentrations of assistance structures and economic activities, also stimulate mobility from other migration categories. This is particularly true in the case of Uganda where refugee settlements are more integrated into local economies and are situated in less marginalized, albeit impoverished, areas relative to Kenya. Lastly, Uganda, Kenya, and South Africa rank the highest among African countries which have the greatest migrant populations and asylum seeker and refugee populations. However, these countries greatly differ in their ratios of migrants to forced migrants. In Uganda, migrant populations are dominated by refugees, whereas in Kenya, refugees are closer to half the population of migrants (meaning they are of roughly the same size). In South Africa, refugees and asylum seekers represent around one-third of migrants. Drawing upon these insights on patterns of migration and forced displacement from the DRC and Somalia and towards Uganda, Kenya, and South Africa, the chapters in Part Three shall shift to the micro-level to examine how respondents moving within these wellestablished corridors shaped their movements according to their aspirations, norms, and practices related to tertiary education. 



\section{PART THREE}


Zolberg, Suhrke and Aguayo (1986) argued that violence and conflict alone do not explain the dynamics of forced displacement; rather they point to the grounds for claiming the legal status of the refugee. Drawing upon 149 interviews with Congolese and Somali migrants and refugees living in Kenya, South Africa, and Uganda, this study finds that respondents expressed their agency in relation to tertiary education to shape their forced migration patterns along three main dimensions: in the timing, destination, and channel of their forced movements. Timing refers to when respondents initiated their international displacement. Destination refers to where they sought asylum-in this study, Kenya, South Africa, or Uganda. Lastly, channel refers to the legal or irregular pathways that they moved into and out of when entering and settling in a destination, such as student, asylum, refugee, or undocumented channels.

This study does not claim that these three dimensions and their associated patterns are the only ones comprising refugees' and migrants' displacement patterns. For instance, Kunz (1973) discusses routes and stages in his typology of refugee movements and Richmond (1988) examines the composition, scale, and direction of movements. Rather, these are the main dimensions that were expressed and negotiated by the Congolese and Somali respondents of this study who were pursuing higher education in asylum countries. Moreover, these were the dimensions that I identified through an inductive examination of their aspirations, norms, and practices - i.e., their agency - related to higher education and mobility.

Additionally, not every respondent shaped all three dimensions of his or her displacement patterns based on higher education. For instance, the timing of a respondent's movement might indeed have been based on his or her graduation from high school and transition to higher education, while the destination of his or her movement might have been highly constrained to the nearest international border. By contrast, the timing of a respondent's displacement might be highly acute, while the destination of displacement might have been shaped by where he or she perceived the best opportunities to pursue higher education and become self-reliant.

The following three analytical chapters examine these dimensions in turn. In so doing, each chapter identifies and defines the different ways in which respondents shaped a particular dimension and examines how respondents expressed their agency explicitly in relation to higher education for each type of pattern. Each chapter also considers the different ways respondents shaped each dimension where higher education appeared not to play a role and also draws upon interviews with those who never enrolled in any form of higher education. This aims to provide some basis of comparison and to understand the extent to which the observed patterns are unique to respondents pursuing higher education. 
Furthermore, each chapter considers the profile of respondents who shaped each dimension of forced movement and the different cases that comprised each dimension, in an effort to learn whether any emergent tendencies or themes exist. This study makes no causal claims between respondents' profiles and their carrying out certain patterns of forced movement. Instead, this exploration seeks to understand better the movement patterns themselves and to start a discussion on whether certain patterns are exhibited by certain groups of respondents in this study (see the Annex for a breakdown of all the movement patterns by profile characteristics). A separate quantitative study is better suited to examine any significant associations between the identified patterns and processes of forced movement vis-à-vis respondent profiles.

Taken all together, by identifying and defining the different dimensions along which this study's respondents shaped their forced movements; examining how they were formed out of their aspirations, norms, and practices related to higher education; and exploring the profiles of respondents who exhibited these patterns, the following chapters seek to identify and understand the larger process of how a select group of Congolese and Somali refugees and migrants shaped their forced displacement patterns through their pursuit of higher education. 


\section{CHAPTER 6}

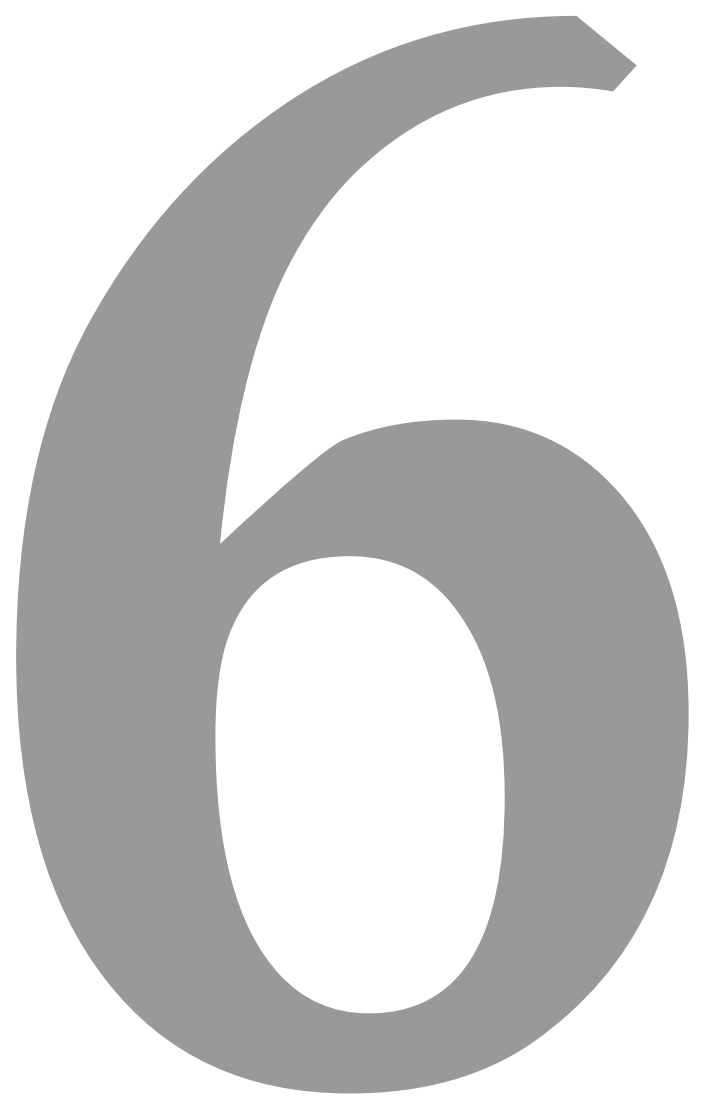


Timing 


\subsection{Introduction}

The aim of this chapter is to understand how Congolese and Somali respondents' tertiary education aspirations, norms, and more practical considerations shaped the timing of their departures from origin countries. The timing of movement can be considered from a diverse array of perspectives and analytical levels: at the macro level in describing the movements of mass populations versus the micro level describing how individuals exit from their origin countries; in terms of an external, event-based timeline versus a person's individual timeline; and in terms of anticipation versus reaction. The findings presented in this chapter largely reflect the diversity within the literature and go a step further by exploring the processes linked to agency through which different timing patterns related to tertiary education emerged. These patterns were inductively developed based on micro-level, self-reported data on respondents' movement and higher education trajectories. Broadly speaking, the patterns highlight that tertiary education considerations indeed play multiple roles in how certain refugees and migrants negotiate their exits from origin countries. This is important because it sheds light on the ways in which factors outside of violence and persecution interact with dimensions of conflict to impact departure. In particular, given that refugees perceive education as a key resource for rebuilding their lives in displacement, this chapter highlights how tertiary education considerations shape their exit decisions.

This chapter begins by defining the timing of movement. It then presents and examines five timing patterns related to higher education that respondents expressed in their narratives of their movement and higher education trajectories, and analyzes the emergence of these patterns through respondents' aspirations, norms, and practical evaluations. To provide some basis of comparison and context for the higher education insights identified on timing, this chapter also examines cases in which higher education appeared to play no role in the movement timing of respondents who pursued higher education in destination countries as well as cases in which higher education did play a role in the movement timing of respondents who never enrolled in higher education programs in destination countries. This chapter concludes with a discussion on the implications of these findings, particularly as they relate to issues of gender, country of origin, and the relationship to conflict and/or violence.

\subsection{Defining the Timing of Displacement or Exit}

This chapter defines the timing of movement in terms of when Congolese and Somali respondents initiated their international displacement or exit from their origin country, which ultimately led them to settle in Kenya, South Africa, or Uganda. Hence, the timing 
of movement refers to when respondents crossed an international border. Few respondents had previous experiences with temporary international movement for tourism, family migration, employment, and/or primary or secondary education attainment. In such cases, the timing of movement refers to when these respondents most recently left their countries of origin to seek asylum in, or move to, one of this study's research sites. This chapter isolates and examines specific periods of exit within respondents' movement trajectories to better compare these exits across respondents. The specific period being considered by this chapter in no way intends to overshadow respondents' previous experiences with mobility. A number of respondents had previous experiences with (chronic) internal displacement and involuntary immobility stemming from insecurity. This study argues that such experiences are crucial to consider when examining how refugees and migrants who are pursuing higher education express their agency in negotiating their movements. For this reason, the mobility experiences of respondents will be examined in Chapter Seven on destination outcomes.

\subsection{Findings: Key Timing Patterns Related to Higher Education}

Within the contexts of protracted conflict and crisis in the Democratic Republic of Congo and Somalia, refugee and migrant respondents exhibited several distinct patterns with regard to the timing of their forced international movements related to tertiary education. These patterns include:

1. Movement following the achievement of an educational milestone

2. Movement upon securing a higher education opportunity in the destination

3. Movement in response to severe higher education constraints in the origin

4. Movement as part of life cycle transition linked to higher education

5. Movement in response to persecution resulting from higher education

These five timing patterns are not mutually exclusive and may operate together to shape the timing of respondents' displacements. The following sections discuss each of these inductively derived patterns in turn, including how these patterns were formed from respondents' aspirations, norms, and practices related to higher education and what are the profiles of respondents who exhibited these patterns. Hence, the cases outlined below are intended to illustrate the processes behind the timing patterns. 


\subsubsection{Movement Following the Achievement of an Educational Milestone}

The timing pattern "movement following the achievement of an educational milestone" refers to displacement or exit that a respondent initiated according to when he or she completed an educational degree, program, or some other significant educational achievement. Most often, the educational milestone was the completion of high school or a BA program. For some Congolese moving to South Africa, the educational milestone was the achievement of two years of university education in the DRC, as this is the educational equivalence requirement set by the South African Qualifications Authority (SAQA) for Congolese students to enroll in their first year at university.

An essential feature of this timing pattern is that respondents perceived the achievement of an educational milestone as necessary for their forced displacement or migration, for they perceived the milestone as crucial to pursue higher education in the destination and, more generally, to secure their livelihoods. This perception was based either on a concrete plan in which respondents had specific knowledge of the requirements to enroll in higher education in the destination, or on a more general belief about what was required to gain admission to higher education institutions in the destination. Further, all respondents who exhibited this timing pattern had been living within contexts marked by conflict and/or crisis and had delayed their movement to Kenya, South Africa, or Uganda until they had attained their milestone.

"Movement following the achievement of an educational milestone" was the third mostcited timing pattern at 8 percent of the total sample, or 12 respondents. Overall, the distribution of respondents who exhibited this pattern across this study's destination countries was fairly balanced, albeit with a slightly greater share of respondents moving to South Africa. Two respondents (5 percent) moved to Kenya, three (6 percent) moved to Uganda, and seven (11 percent) moved to South Africa. Given that South Africa has the highest ranked tertiary education sector on the continent, with the highest standards regarding academic pre-requisites and issues of academic equivalency, it stands to reason that a larger share of respondents shaped their timing in relation to achieving a certain academic milestone.

In terms of the profile of respondents who expressed this pattern, several insights may be observed with regard to gender, origin country, migration status, and level of tertiary education. Male respondents cited the "milestone" timing pattern more than their female counterparts, at 11 percent (nine respondents) versus 4 percent (three respondents). While these numbers are small and difficult to compare, this shows that male respondents more than female respondents had persisted in contexts of conflict and had delayed their exits until they achieved a certain education qualification. By contrast, the distribution of 
respondents who exhibited this pattern across this study's two origin countries was fairly balanced with seven Congolese (9 percent) and five Somalis ( 7 percent) expressing this pattern. Also fairly balanced was the distribution of respondents across different migration statuses at the time of entering destination countries. Eight percent (two respondents) of student migrants and 9 percent (10 respondents) of asylum seekers cited this timing pattern. Regarding the level of higher education, 5 percent (two respondents) who pursued vocational certificate programs, 14 percent (four respondents) who pursued diplomas, and 10 percent (five respondents) who pursued undergraduate and graduate programs described the "milestone" timing pattern. Although these numbers are small, it is not clear why the greatest share of respondents was those pursuing diplomas. This finding may stem from the fact that higher levels of tertiary education have more advanced educational pre-requisites.

The following is an example of the primary way in which this pattern was expressed. In outlining this example, I examine how the respondent's aspirations, norms, and practices related to tertiary education shaped this pattern. Where relevant, I discuss any structural factors cited by the respondent, either directly or indirectly, as impacting the dimensions of his agency.

\section{Case 1. Joseph. ${ }^{24}$ Delaying long-distance for short-distance displacement until graduation}

Joseph, a Congolese man who completed a college diploma in Nairobi, represents a typical case of "movement following the achievement of an educational milestone." He engaged in shorter-distance - both internal and international - displacement and delayed longer-distance international movement until he completed his secondary education. Joseph explained:

"I did primary school in Congo, even my secondary up to form three. ${ }^{25}$ After form three, there was a war and I fled to Burundi and that is where I finished my secondary school. I finished my secondary school in 2009 .... and, in 2009 I came to Kenya and started to search for sponsorship because I wanted to go beyond secondary school."

Joseph detailed how, between 1994 and 2006, he experienced chronic instability, conflict, and internal forced displacement in different areas within South Kivu and Katanga, in

\footnotetext{
${ }^{24}$ Not his real name. All names mentioned in this chapter are aliases. All quotes from Joseph come from interview: DRC_College_Compl_M_NBO.

${ }^{25}$ Form three refers to the third year at secondary school. Secondary three, S3, and form three are synonymous.
} 
Eastern and Southeastern DRC, where he completed his primary education and most of his secondary education. As mentioned in Chapter Four, this was a period in the DRC, including in the Eastern Provinces, which suffered from a continuous series of conflicts, violence, and forced conscriptions. He finally fled across the border to Burundi in 2007, where he had a cousin who was a refugee there. He stated, "I could not finish [secondary school] because of war, so I finished it in Burundi." As with the DRC, Burundi has a similar francophone education system, which allowed Joseph to enroll in his final year of schooling without repeating a level. Joseph stayed in Burundi for just one year to gain his secondary school ${ }^{26}$ diploma, as the country was also experiencing instability. He maintained that the period he was there was just a few years after the "trouble in Burundi," referring to the Gatumba massacre of Banyamulenge, and that the country was still experiencing conflict. Unable to return to the DRC, he left for Kenya to find security and to pursue higher education, though he had little prior knowledge of English.

As mentioned previously, the way in which Joseph delayed longer-distance displacement until graduation and engaged in shorter-distance forced movements whilst pursuing his educational milestone represents the majority of respondents who exhibited this timing pattern. Few respondents delayed forced movement entirely until graduation. This may stem from the protracted nature of the conflicts from which respondents fled, causing conflict and crisis to become features of daily life. In terms of the profile of respondents, this may also explain why mostly Congolese respondents exhibited this pattern, as violence and conflict in the Eastern Provinces had been active throughout the 1990s and 2000s, with frequent increases in insecurity levels as different armed groups emerged and sought control over specific territories and resource-rich areas.

Additionally, this pattern highlights the fact that education institutions were often used to facilitate shorter-distance movements in that children and youth enrolled in (or were sent by parents to enroll in) primary and secondary boarding schools in areas deemed safe (or less insecure) or enrolled in day schools in safe(r) areas where they had extended family. In Joseph's case, he moved to different internal and international locations according to where he could avoid rising conflict, had family, and could secure a place at school. At one stage in his displacement trajectory, Joseph explained that his father explicitly cited schooling as the reason for telling Joseph to move with him to South Kivu. Turning to Joseph's aspirations, norms, and practices to understand how the timing of his movement coincided with the achievement of an educational milestone, it appears that despite widespread instability, Joseph engaged in short-distance forced displacements so as not to disrupt his studies and, on a practical level, to stay within a

\footnotetext{
${ }^{26}$ In this study, "high school" and "secondary school" are the same and used interchangeably, depending on the language used by the respondent.
} 
similar francophone education system. This allowed him to continue at the same grade level without having to repeat any years of schooling or enroll in language classes. He also moved to locations where he had family or extended family members from his coethnic community, who were strong supporters of his education attainment. Though they had few resources, Joseph's parents were instrumental in the planning of his internal movements to complete his basic education. He explained that this may be because his family members have very low education attainment rates; in fact, he is the only one among them to pursue any tertiary level education and both of his parents are illiterate. Hence, it was important to them that he further his education.

Beyond his family, Joseph maintained that pursuing higher education was a socially valued action in the DRC, over and above gaining employment. He believed that most of his age mates would choose to pursue higher education following graduation from secondary school if they had the resources. Similarly, on a practical level, he perceived that when applying for a job, higher education set one apart and improved one's chances of being employed, as most people only have a diplôme d'état, i.e., a secondary school diploma. We can consider Joseph's evaluations of insecurity and securing a place at school as part of his practices, as it describes Emirbayer and Mische's (1998) assessment of the "contingencies of the present."

On an aspirational level, the timing of Joseph's exit to Kenya was intertwined with his aspiration to pursue higher education. Joseph said, "there is someone on Facebook who told me Nairobi is a city where it is secure, you know.... And I would like to go somewhere where it is safe and I can do my vision." The concept of "vision" was widely invoked by both Congolese and Somali respondents and referred to their overall life aspirations. In Joseph's case, his vision was linked to higher education, his future employment aspirations, and his identity. Joseph identified as Banyamulenge, which means he is Congolese and ethnically "Tutsi." Banyamulenge are a persecuted minority in Eastern DRC. His vision was to pursue a course in criminology so that he could help bring justice to his community, particularly in identifying the perpetrators of atrocities committed against Banyamulenge in Burundi and the DRC. Joseph felt that the only way he could pursue his vision was to seek out higher education opportunities in Nairobi.

In this way, Joseph's norms, personal aspirations, and practical considerations prompted him to persist within areas of insecurity in Eastern DRC and Burundi and to engage in short-term forced displacements to complete his secondary education and subsequently undertake longer-distance displacement after graduation to a destination he perceived was safer and offered him better opportunities for higher education. 


\subsubsection{Movement upon the securing of a higher education opportunity in the destination}

This timing pattern refers to displacement or exit that a respondent initiated upon attaining a higher education opportunity in one of this study's destination countries. Higher education opportunities include being accepted to enroll in a higher education institution or being awarded a scholarship to pursue higher education. For some respondents, this was achieved by applying to schools over the internet or by mail, submitting applications through friends already enrolled in higher education institutions abroad, or applying to institutions abroad through international outreach offices located in their home countries. Outreach offices were more a feature of private rather than public higher education institutions.

"Movement upon the securing of a higher education opportunity in the destination" does not describe the displacement of respondents who intended to seek out opportunities in the destination; rather, it describes a situation in which higher education opportunities were secured in advance of displacement, while respondents were still in their home countries. Securing a higher education opportunity in the destination precipitated or triggered forced movement to Kenya, South Africa, or Uganda. Similar to the pattern "achievement of an educational milestone," this timing pattern involved the delaying of displacement and persisting in contexts marked by conflict and/or crisis. Unlike the previous migration pattern, given that these respondents secured their acceptance into higher education programs prior to their arrival in Kenya, South Africa, and Uganda many are, or arrived as, student migrants and not asylum seekers. Indeed, four of the 26 respondents who entered their destination countries as student migrants cited this pattern, relative to two out of 114 of asylum seekers.

Overall, this timing pattern was expressed by just 5 percent of respondents, or seven respondents in total, and was the least expressed of all the timing patterns. This may be the result of the obstacles that youth who are living in conflict-affected communities undoubtedly face in applying for tertiary education, including advanced academic and linguistic requirements for a successful application, resources to apply, physical or electronic access to information about institutions and their applications, and/or transcripts or documentation of educational qualifications, to name a few. Moreover, as with the previous timing pattern, such respondents persisted in conflict-affected areas, which risked putting them in more acute displacement situations.

The distribution of respondents who expressed this pattern across this study's destination countries was fairly balanced, suggesting that this pattern is not dependent on the destination country's higher education sector. One respondent (3 percent) who moved to Kenya, three respondents (6 percent) who moved to Uganda, and three 
respondents (5 percent) who moved to South Africa cited this pattern. Similarly balanced were the gender and origin country distributions of respondents who exhibited this "opportunity" pattern. Four men (5 percent) and three women (4 percent), and three Congolese (4 percent) and four Somalis (6 percent) exited their origin countries upon securing a higher education opportunity in the destination. The fact that the gender distribution was balanced indicates that women shaped the timing of their movements in relation to higher education in ways comparable to their male counterparts.

In terms of the level of higher education of respondents who cited this timing pattern, the data reveal a tendency towards those pursuing undergraduate and graduate degrees at universities. Six out of 50 respondents pursued higher education at the university level, while no respondents pursued college diplomas and just one out of 37 respondents pursued a technical certificate. This aligns with the fact that universities rather than colleges and technical schools tend to engage in international recruitment and have outreach offices. Moreover, vocational and technical programs tend to be embedded in national labor markets and are less likely to be pursued by foreign students. Instead, respondents' narrative data reveal that certificate programs are more often pursued after spending some time in the destination country, as part of a livelihood strategy to gain skills. Furthermore, respondents who were able to delay their movements until they could secure a higher education opportunity in the destination exhibited a high degree of agency and tended towards higher levels of tertiary education. The following example demonstrates the high levels of resources, social support, aspirations, and academic ability that combined to form this timing pattern.

\section{Case 2. Francis. ${ }^{27}$ Securing admission to pursue an MA degree.}

Francis, a Congolese man who completed an MSc and then a PhD in Cape Town, South Africa, demonstrates why "movement upon securing a higher education opportunity in the destination" is a more exceptional timing pattern. In the early 1990s in Bukavu, which is the provincial capital of South Kivu in the DRC, Francis was pursuing his BA degree. By way of providing context on the higher education system in the DRC, Francis explained that his degree was split into two parts. The first part was three years and qualified him for a teaching degree, while the second part was two years and granted him an honors degree that enabled him to pursue graduate education. He said:

"I did my teaching degree, three years, and then when I finished, there were problems in DRC. The regime and education were kind of having problems

\footnotetext{
${ }^{27}$ All quotes from Francis come from interview: DRC_Univ_Compl_M_CT_2.
} 
so I couldn't continue straight because there was a gap year for the whole nation. All institutions were closed that year, so it was called année blanche."

As a result of political instability or "regime problems," which led to the closing of education institutions across the nation, Francis left the DRC with only the first part of his undergraduate degree completed. For this reason, this case also aligns with, or is an example of, the timing pattern "movement in response to severe higher education constraints in the origin." Francis explained that because his and all other higher education institutions closed, he left the country and took up a teaching position in Rwanda where he had friends and where there was a high demand for teachers, especially in the sciences and mathematics.

"[S]o I went to teach there. I taught there for two years and after the two years that's when the [1994] genocide started. I went back home and furthered my studies, so I did another two years. After those two years I went to Rwanda again because that's when the Congolese war also started in 1996...It was becoming difficult to survive as a teacher in Bukavu. So, I decided to go back to Rwanda, but I was not fully satisfied as I was not happy with my degree. I wanted to further my studies, but at my institution....and, in fact, throughout the country it was difficult to pursue a master's degree or a PhD degree.... Because of that I was looking for opportunities up there and then I learnt that there was an institute starting in South Africa. I applied and I was accepted. That's how I came to South Africa. What I did is, because I was living in Rwanda with my family, I took them back home and I came alone here for that year of study."

Francis actively pursued opportunities in his field outside of the DRC and aspired to gain graduate level education and a terminal degree. He perceived that political crisis throughout the country, widespread insecurity, and the risk of further closers of educational institutions meant that remaining was not an option for him. Whilst in Rwanda, he applied and gained admission to a South African higher education institution. The same institution awarded him a scholarship and paid for his travel expenses and accommodation. With these opportunities secured, he returned to the DRC and then made the journey to South Africa.

Francis' experiences with school closure, political instability, and insecurity provide some insight into his practical considerations as well as the structural factors shaping his forced displacement and higher education trajectories. Additional factors mediating his practices include his relatively high level of education and cross-border networks, which put him in a position to apply for graduate studies and provided him with employment 
in Rwanda when his socio-economic situation and security became highly constrained. Further, his securing a full scholarship to pursue graduate studies greatly expanded his scope for moving farther afield and pursuing higher education.

In terms of Francis' aspirations related to higher education, he explained that rather than having a single vision driving his trajectory, many of his educational and professional aspirations were tied to more practical considerations. Attending university was the only constant in his changing aspirational landscape. Reflecting on his aspirations when he finished secondary school, he stated:

"I wanted to do engineering at university, but in our city, there was no university offering engineering. Since both my parents are teachers, and they were not earning much, so that they can't send me to other provinces where there was engineering. So, I was forced or obliged to study in Bukavu, and the only thing I saw I could do was mathematics."

This quote provides insight into not only his aspirations, but also his socio-economic background and the higher education offerings in Bukavu. As teachers, Francis' parents could not afford to send him to Lubumbashi or Kinshasa for university; however, they were able to financially support him to obtain the first part of his BA program in Bukavu. While financial support was limited, their encouragement of his education was high. Francis came from a family that highly valued education. He maintained that both of his parents had completed secondary school and, in their village, this meant that his family was among the most educated.

"So, because of that they knew the value of education, they insisted that I should go and study even though they did not have the means to help me study well. And studying well means studying what I wanted to study, engineering. So, they didn't have those means, but, they said, 'Ok at least you can do something else."

While the norms of his family strongly supported higher education, the same does not appear true for his community. This stands in contrast to the social norms encountered by Joseph in the previous case, which were in line with those of Joseph's family. Francis held that his community, which was located in a remote part of the country that had no access to electricity or cars, "didn't understand the value of higher education." In this way, he described his family and their values as being different and responsible for his "making it out" of the village, unlike many of his age mates. 
Having completed his degree in mathematics in Bukavu, Francis, as previously quoted, was not satisfied with his undergraduate education and aspired to go further in his studies, which he could not do in the DRC. Elaborating on his aspirations in coming to South Africa, he once again cited practical considerations:

"[M]y idea in coming [to South Africa] was to study some applied mathematics, so that I can work in other sectors except teaching.... when I finished my master's, I couldn't get a job. I couldn't get a job and as my family was here already, I said, 'No, I have to do something, without a job, I won't survive. Let me try and start a PhD.' Because I knew me being a PhD student with my teaching experience, the department would give me some teaching, and with my teaching I can look after my family, so that's what I did....it was not that I liked, I wanted to do a PhD, it was just a survival thing to do. So, I started my $\mathrm{PhD}$ and I started making some progress. Then I saw myself becoming an academic. So, my initial plan of working in other areas, I forgot about it."

More than once, in discussing his higher education aspirations as well as his displacement trajectory, Francis mentioned his need to provide for his family. For this reason, it appears that his aspirations were less individualistic and more shaped by his need to ensure the survival of his family. Overall, it appears that Francis' agency with respect to higher education was largely driven by his practical considerations, stemming from the great opportunities and constraints he faced over the course of two decades.

Additionally, Francis' experiences with short-distance displacement to nearby Rwanda mirror those of Joseph to Burundi. Both respondents expressed considerable agency when engaging in short-distance displacement to where they had social networks and so as not to disrupt their desired education trajectories, until such time that they could plan longer-distance exits that were aligned with their aspirations, norms, and practices. In this way, their forced displacements are more accurately described as forced mobility. Further, mobility and higher education, combined, appear to be a livelihood and protection strategy for both respondents.

\subsubsection{Movement in response to severe higher education constraints in the origin}

This timing pattern refers to displacement or exit that a respondent initiated in response to highly constrained conditions in the higher education sector which prevented his or her higher education attainment. Constrained conditions include, but are not limited to, the schools or educational institutions in a respondent's area of origin closing 
indefinitely, and perceived high corruption and/or discrimination within the local and national education sector preventing access to institutions. For some conditions, particularly the closing down of educational institutions, a direct link to conflict and political instability exists. We saw this with Francis' displacement to Rwanda during what he referred to as the année blanche, when all schools shut down. We also saw this happen in Burundi in 2015 when key universities in Bujumbura shut because they represented centers of political opposition to the incumbent political regime of Pierre Nkurunziza. For other conditions related to corruption and discrimination, more indirect links to conflict and political crises exist.

Respondents who moved in response to severe higher education constraints had more direct experiences with the crisis and conflict that impacted their communities. While the previous two patterns involved the delaying or deferring of movement until a specified moment, "movement in response to severe higher education constraints" describes more reactionary movement stemming from their pursuit of tertiary education. Moreover, this pattern describes exits which are more dependent on structural conditions and less dependent on respondent's personal timelines. For instance, one respondent's repeated experience with ethnic and class-based discrimination barred his access to university and gradually led to his exit from the DRC. Another respondent's experience of the widespread and indefinite closure of all public universities within the DRC triggered his more immediate exit. The variation between more graduate and immediate reactive movements is reflected in the legal statuses that respondents who expressed this pattern adopted to enter destination countries. A relatively balanced share of asylum seekers (four out of 26) and student migrants (14 out of 114) expressed this timing pattern.

"Movement in response to severe higher education constraints in the origin" was the second-most cited timing pattern by respondents, at 13 percent of the sample or 20 respondents. The DRC and Somalia have tertiary education sectors that have been highly constrained by conflict and crisis and such conditions not only impact the sector, but also the ability of students to access the sector. For this reason, we might have expected more respondents to have described this pattern. However, it is possible that constrained higher education structures have become a "normal" feature for Congolese and Somali learners, which have shaped their higher education mobility strategies, as described by Bakewell and Bonfiglio (2013). Having become a part of daily life, such structures are not explicitly expressed as drivers. In examining the origin countries of respondents who cited this pattern, we see that Somalis and Congolese similarly expressed this timing pattern at seven respondents (10 percent) and 13 respondents (16 percent), respectively. 
Turning to examine respondents' destination countries and levels of tertiary education, one respondent ( 3 percent) who moved to Kenya, five (10 percent) who moved to Uganda, and 14 (23 percent) who moved to South Africa expressed this timing pattern. It might appear that conditions in the destination country, described by this timing pattern, should be independent from respondents' destination outcomes. However, the data on the distribution of destination countries suggest an increasing trend in "movement in response to severe higher education constraints in the origin" towards countries with more developed tertiary education sectors and not overall economic development. This indicates that respondents whose exit was shaped explicitly by higher education constraints went on to the shape their displacement destination outcomes in relation to the quality and standards of a destination's higher education sector. This aligns with the data for this timing pattern on levels of tertiary education, which show a tendency towards higher levels of tertiary education. Four respondents (11 percent) pursued vocational certificates, four (14 percent) pursued diplomas, and 11 (22 percent) pursued undergraduate and graduate degrees.

In terms of gender, men overwhelmingly expressed this timing pattern more than women, at 17 respondents ( 21 percent) as compared to three respondents (4 percent). In other words, a greater share of male respondents expressed the systemic constraints they encountered within their origin country's tertiary sector when narrating the timing of their departures. The following example demonstrates how respondents experienced severe constraints in the higher education sector, and in so doing, how the process of this timing pattern takes place.

\section{Case 3. Jean-Paul. ${ }^{28}$ Displacement following university closure.}

Jean-Paul is a Congolese man who completed a university degree in Nairobi. At the time of his exit, he was enrolled at a university in Bukavu and was on track to pursue a medical degree. It was 2002, and after two years at university, he explained, it shut because of conflict. He stated, "because of war, we did not go to school.... There was some time it shut down and sometimes there was unrest and we did not complete. Sometimes it can take two years because of unrest. And I left Bukavu in 2005."

Jean-Paul remained in Bukavu for approximately two years following the closure of his university, in hopes that it would re-open. In contrast to Francis, who left Bukavu to work in Rwanda and returned once security improved and schools re-opened, Jean-Paul remained in Bukavu and got a job at a human rights NGO to support himself. Ultimately, the security situation which had prompted the closure of his university worsened and

${ }^{28}$ All quotes from Jean-Paul come from interview: DRC_Univ_Compl_M_NBO. 
began to impact his own personal safety as a human rights worker. In this way, conflict and crisis took shape or took effect in multiple arenas of Jean-Paul's life; the university closing was part of a larger context of crisis and conflict. At this point, Jean-Paul left for Kenya with the support of his family.

Given the structurally dependent nature of this timing pattern, practical considerations play the greatest role in its development. Jean-Paul did not actively seek out opportunities abroad and did not express such aspirations during his formative years. Further, he did not have friends or age mates studying at universities in neighboring countries. Instead, he described growing up with the desire to be a medical doctor, and aspiring to attend a Catholic university. Jean-Paul discussed persisting in Bukavu and working until he could continue his medical degree. It is possible he persisted for some two years because studying abroad would have meant starting over and, most likely, being unable to access a medical program as a foreign student. Moreover, his working with an NGO was not related to his vision, but was necessary work while he waited to continue his studies.

Jean-Paul's agency with respect to his norms and family values also appeared to play a role in his timing pattern. His parents were educated people and highly supported his education. His father had studied abroad in West Africa. His mother dreamed of his being a doctor. Once his personal security became threatened, he explained, "my family decided," "they told me to go," and "they told me to leave the place." The timing of JeanPaul's movement was therefore a practical determination, based largely on the closure of his university and threat to physical safety, enabled by the support of his family, who valued his tertiary education attainment.

\subsubsection{Movement as part of a life cycle transition, of which higher education is a part}

This timing pattern refers to displacement or exit that a respondent initiated as part of a life cycle transition related explicitly to the pursuit of higher education. Here, life cycle transition refers to the reaching of new stages in one's life, for instance, graduating from secondary school, securing a new job, forming a family, or pursuing higher education. As discussed at the start of this chapter, the anthropological literature on migration shows how mobility is often intertwined with the changing phases of one's life. While this timing pattern overlaps with the previous three, particularly the achievement of an educational milestone and the securing of a higher education opportunity in the destination, I have identified it as its own pattern to highlight distinct features that I observed amongst certain respondents' movement and higher education trajectories. 
First, this timing pattern does not require the delaying of movement until a specific opportunity is secured. Respondents exhibiting this pattern arrived at their asylum or destination countries and began their search of higher education opportunities, surveyed higher education institutions, enrolled in English language classes, learned about the process of enrollment, and sought out funding opportunities. The time dimension here is more a function of a respondent's own coming-of-age and aspirations and norms for higher learning. In this way, the timing of his or her displacement aligns with the initiation of his or her pursuit of higher education.

Second, and relatedly, most respondents who exhibited this timing pattern had no overt or direct experiences with conflict or crisis at the time of their movement, as they described it, and did not exit their origin countries in an acute fashion. For these respondents, displacement was not delayed or associated with increasing constraints. That said, these respondents came from countries and, more specifically, communities of origin identified as unsafe and meeting the grounds for refugee status. Some of them had experiences with conflict and displacement during their childhood. Also, many gained asylum seeker or refugee status in their destination countries.

Third, a smaller group of respondents who expressed this timing pattern had direct experiences with insecurity. In fact, it was their broader life cycle transition to adulthood and out of childhood that was partly responsible for their insecurity, in that they became targeted by armed groups for recruitment or for being perceived as oppositional. A Somali respondent named $\mathrm{Ali},{ }^{29}$ who I interviewed in Cape Town where he was enrolled in college, recalled such a circumstance: "I left home in 2010, when things in Mogadishu were getting really, really bad and worse. My mother wanted me to go to Sudan and complete my studies there, but she couldn't afford to pay..." He went on to share the circumstances surrounding his insecurity:

"[E]very young man who is living in the country, he was always a victim, either by al-Shabaab side or the government side....to be honest with you al-Shabaab and those guys, they had access to everywhere they wanted...So, the truth was it was easy for them to find out who is alShabaab and who is not al-Shabaab. In the end, the people are always the victims....al-Shabaab will just tell you that you are a member of the government, either you are a spy or someone [like them]. If you are not working with them, they expect you to come and support them, fight for them. So, it was not easy. When one day I was with my mum and we came to a point where these groups were and then they checked me and searched

${ }^{29}$ All quotes from this respondent come from interview: Som_College_Enroll_M_CT. 
me. Then one of them threatened me... and when we left, we got to another point and there was al-Shabaab and the same thing happened. My mother couldn't, you know, resist and she thought of all of the things that could happen and that she has seen. She said, 'ok, son, you won't stay in this country like this."

Ali maintained that his being a man in Somalia made him a target because it made him a potential fighter, either for al-Shabaab or the government. He had had previous experience with conflict and violence in Mogadishu, and had been internally displaced. However, it was not until he came of age that he initiated his international displacement. Moreover, it was also at this point in his life that he began pursuing higher education opportunities abroad. With the help of his mother, he left Somalia and went to South Africa in search of security and tertiary schooling.

"Movement as part of a life cycle transition, of which higher education is a part" was the most commonly expressed timing pattern by respondents. Approximately 29 percent of respondents, totaling 43 respondents, identified their displacement in this way. Moreover, this pattern was the most-cited by respondents from each origin country. Twenty-one Congolese (26 percent) and 22 Somalis (32 percent) described the timing of their departure as part of a life cycle transition. It is possible that for these respondents, conflict and crisis in their origin countries prompted the internationalization of their higher education and/or created a culture of migration (or culture of displacement) as part of part of life cycle transition, rather than an explicit or direct response to severe constraint and conflict. This was particularly true for Somali respondents whose higher education sector collapsed in 1991 and has been slow to recover. Both Congolese and Somali respondents recalled growing up with mobility-related aspirations, perhaps born out of a context marked by conflict and crisis, and having limited tertiary education opportunities, or perhaps because they simply valued educational mobility. With the first three timing patterns, we see higher education and conflict both playing a more direct role in shaping displacement, whereas with this timing pattern we see their indirect and almost structural impacts, stemming from and solidified by decades of crisis and conflict.

In terms of destination country, once again, we find that respondents who cited the "life cycle" pattern moved to each destination country, and that this pattern was the mostcommonly cited within each destination country. Five respondents (13 percent) who moved to Kenya, 17 (27 percent) who moved to South Africa, and 21 (43 percent) who moved to Uganda described their departure as part of a life cycle transition. The smallest share of respondents in Kenya reflects what we know about the quality and international appeal of Kenya's tertiary education sector, relative to the other two countries. By 
contrast, the fact that respondents in Uganda expressed this pattern far more than their counterparts in South Africa is unexpected, given that South Africa's tertiary education sector is ranked the highest on the continent. One might have assumed that more "normal" (and less acute) movements as part of the life cycle would have resulted in greater movements to South Africa. The high share of respondents who exhibited this pattern within Uganda perhaps indicates that its greater proximity to origin countries, its lower cost of living, and its lower barriers to entry in terms of adopting more voluntary movement channels, make it a suitable destination for a wider variety of Somalis and Congolese who have come of age. Also, the high share of respondents within Uganda suggests that they do not come from elite backgrounds. Instead, they appear to represent a generation of young people who are moderately better-off and more highly educated than their predecessors, and whose tertiary education attainment has been internationalized by conflict and crisis in their origin countries.

Similar to previous timing patterns, the share of respondents who expressed the "life cycle" pattern increases with the level of tertiary education. Eight percent (three respondents) who pursued vocational and technical certificates, 39 percent (11 respondents) who pursued diplomas, and 46 percent (23 respondents) who pursued undergraduate and graduate degrees cited this pattern. In terms of gender, the distribution of respondents is relatively balanced, with 19 women (28 percent) and 24 men (30 percent). Unlike the previous timing pattern, this highlights that female respondents shaped the timing of their exits in ways similar to their male counterparts. The balanced gender distribution also highlights that tertiary education featured in the life cycle transitions of women, just as it did men.

Turning to look at the migration statuses of respondents upon entering destination countries, we see that 23 out of 26 student migrants and 17 out of 114 asylum seekers expressed the "life cycle" pattern. This reflects the more indirect experiences with conflict and crisis that respondents described and reinforces that fact that the respondents who expressed this pattern saw themselves more as international students than forced migrants. To further understand the emergence of this timing pattern, I will now examine the experiences of a Somali respondent who, like the majority of respondents exhibiting this pattern, had no direct experiences with conflict or crisis shaping his movement.

\section{Case 4. Qasim. ${ }^{30}$ Pursuing higher education abroad after high school.}

Qasim is a Somali man who completed a college degree in Kampala and was enrolled in a BA program at the time of the interview. When he arrived in Kampala, he was just 20

${ }^{30}$ All quotes from Qasim come from interview: Som_College_Compl_M_Kla. 
years' old. He explained, "at the time I came here, I finished my high school" and "I came here just to study." Qasim came to Kampala before applying to any higher education programs, but knew the institution he wanted to study at and had gathered information on it prior to his departure. He did not apply to any higher education institutions based in Somalia. He maintained, "in Somalia there's no...higher study or higher education is not effective yet." He also said that in Somalia, "We don't have a government" and implied that for this reason "you know, Somalis are refugees, most of them." Thus, while he described having no direct experiences with conflict and crisis, Qasim saw himself as a refugee and had refugee status.

While the timing of Qasim's movement is similar to or could be seen as "movement upon the securing of an educational milestone" or "movement in response to severe higher education constraints in the origin," or both, the lack of a direct conflict experience prompts us to delve deeper and appears to create a distinct timing pattern for Qasim and other respondents with similar experiences. Qasim did not delay his movement or move acutely; rather, he moved when he came of age and his higher education attainment was internationalized by the context of crisis and conflict that marked his country. This is reinforced when he stated, "in Somalia there's no...higher study or higher education is not effective yet...so that's why I came here, to be at least better than the other ones."

Qasim's aspirations, norms, and practices related to higher education allow us to better understand this timing pattern. Qasim had aspired to obtain a university education since he was in primary and secondary school. According to him, "it was one of my dreams." In discussing his ultimate vision, he stated, "I want to study really well and to serve my country and my people. I want to be an educated man." After completing his BA program, Qasim planned to pursue an MA in Kampala. On a practical level, he was able to pursue higher education in Kampala with the financial support of his uncle and with assistance from his friends who were already enrolled in higher education in Kampala and advised him on where and how to apply. In many ways, Qasim followed in the footsteps of his friends and relied on their information.

In terms of family norms, he had their support and encouragement to pursue higher education in Uganda, being the first born amongst his siblings and being the first person in his family to pursue such an aspiration. Apart from his uncle, Qasim did not consider his family to be wealthy. His father was a mechanic and his mother a housewife. In his opinion, studying abroad was the only desirable or valued reason for moving. Otherwise, in his family, moving to pursue opportunities was frowned upon because they associated it with the great risks that youths took to reach countries in the Gulf or Europe, or even South Africa, which was experiencing widely-publicized xenophobic violence at the time. 
He said, "They like to be home...they face the challenges, you know, it's not easy from one country to another. You will feel, you will face a challenge, and maybe you will lose your life. That's why they don't like."

Qasim's individual aspirations, the norms of his friends and family, and his practices suggest that the timing of his movement was far from exceptional, reactionary, or proactive. Instead, they create a picture of growing up and making the transition to adulthood via tertiary studies. It happens that for Qasim and other respondents exhibiting this pattern, while they did not express direct experiences with conflict and violence, their countries and communities were nevertheless impacted over the course of years or decades. This was their reality, so much so that international (forced) mobility became a part of their normal life. Qasim showed without question that his mobility did not change his feelings of refugeehood.

\subsubsection{Movement in response to persecution linked to tertiary education attainment}

The fifth and final timing pattern which was exhibited by respondents and related to tertiary education is "movement in response to persecution linked to tertiary education attainment." This pattern describes more acute forced exits connected to respondents' activities at their higher education institutions in their origin countries, which made them targets for persecution. Activities cited by respondents included participating in student protests against the government, being affiliated with political or human rights student groups, or simply attending university and perhaps refusing to campaign for political incumbents on campus. One Somali respondent explained that simply by having higher education, he and his mother feared for his persecution. He stated that his mother told him, "Please, have your own family, you have to grow up now, you have to leave from here. Because, now...maybe you will be shot or maybe you are a problem because you are educated." 31 These respondents often had their higher education interrupted because of such persecution. All arrived at countries of asylum with some form of higher education experience, making them a small minority of highly educated individuals within the wider refugee population.

This timing pattern reflects the more historical literature on refugees in higher education, mentioned in Chapter Two, which argues that youth enrolled in universities and colleges are often targeted and persecuted during the early stages of conflicts and crises, given that they are perceived as the new generation intellectual elites who might challenge the political status quo. Buckland (2005: 18) wrote, "[s]tudents are often involved, especially

${ }^{31}$ This quote comes from interview: Som_College_Compl_M_JHB. 
at the tertiary level, as activists in the political struggles that precede conflict, and so universities and postsecondary colleges tend to be targeted more often." In this way, students and intellectuals tend to comprise the first cohorts of refugees from a country, which represents another aspect of the timing of forced displacement.

Similar to those respondents whose movement was linked to severe higher education constraints, the respondents exhibiting this pattern were engaging in more reactive movements. For these respondents, this is movement that would have otherwise not taken place, as they were already enrolled in higher education institutions. This aligns with the picture that emerges from examining respondents' migration status upon entering destination countries. None of the respondents who expressed this timing pattern entered as student migrants. In fact, all respondents entered as asylum seekers. Also similar to those respondents who experienced severe constraints, the targeted violence and persecution these respondents experienced at higher education institutions reflects the broader conflict and/or crisis impacting their countries of origin.

"Movement in response to persecution linked to tertiary education attainment" was the least-cited timing pattern after "movement upon securing a higher education opportunity," with just eight respondents or 5 percent of respondents describing this pattern. The distribution of respondents who expressed this acute timing pattern across destination countries is fairly balanced. One respondent ( 3 percent) moved to Kenya, three (6 percent) moved to Uganda, and four (6 percent) moved to South Africa.

Turning to examine the profile of respondents exhibiting this pattern, given that the overall number of respondents who cited this pattern is relatively small, it is difficult to compare their characteristics. Most of the respondents who expressed this timing pattern were Congolese. Seven Congolese, which represented 9 percent of all Congolese respondents, as compared to one Somali, which represented 1 percent of Somali respondents, expressed this pattern. Somali respondents' lack of expression of this pattern may stem from the fact that Somalia's higher education sector collapsed in 1991, alongside the collapse of the government, and has made little progress since. Consequently, many Somali youth who pursue tertiary studies, do so abroad. In contrast, the DRC's tertiary education sector is more developed and more Congolese respondents had previous experiences with higher education in their origin countries. In terms of higher education level, the expression of this pattern was fairly balanced. Just one respondent pursued a vocational certificate program, two respondents pursued college diplomas, and two respondents pursued undergraduate or graduate university degrees. 
Lastly, in terms of gender, six males (7 percent) and two females ( 3 percent) expressed this pattern. Respondents' narrative data provide some insight into a possible "male experience" of this timing pattern. Both Congolese and Somali male respondents described coming of age and receiving a higher level of education as associated with being a threat to the regime or an armed group and with being ripe for recruitment, either from the military or armed groups. Such 'militarization' was not something that female respondents expressed. To better understand how this timing pattern emerges, the following section examines the aspirations, norms, and practices of one respondent who moved in response to persecution linked to his tertiary education attainment.

\section{Case 5. Patrice. ${ }^{32}$ Persecuted for protests at university.}

Patrice is a Congolese man who was currently enrolled in a college diploma program and living in Johannesburg at the time of the interview. He first came to South Africa in 1989. Then, he had been enrolled in a civil aviation program in the DRC and it was his vision to join the national air force. However, he described this period as marked by political unrest: "[T]here were riots." "[P]eople were fed up with the dictatorship of Mobutu." Opposition groups were formed, but operating unofficially out of Belgium. In terms of his own position and actions, he stated:

"As students, we were informed of what was happening...every moment felt like the soldiers were there. The students and military, they were not going along [with Mobutu]. So, there was a small incident that caused a fire [at school], and during that riot...during that movement, I got shot.... I got shot, I was totally paralyzed."

Patrice then explained that because there was an insufficient medical infrastructure in the DRC, "the hospital, the doctors and the institute where I was studying, they asked the government - because I was under the supervision of the government - if they could not send me abroad, for further medical treatment." The government was unwilling to send him to Europe, despite this being the common practice in those days. "I couldn't be sent to Europe...if those people see a case like this it will be a problem for them that the regime is killing the students.... they decided to send me to South Africa, during that time South Africa was under apartheid, so no foreigners were coming."

The timing of Patrice's movement was entirely controlled by the Mobutu regime, which physically transported him to South Africa after seriously injuring him at a school riot. Once he recovered and had assessed that the situation in the DRC had not improved,

32 All quotes from Patrice come from interview: DRC_College_Enroll_M_JHB. 
Patrice applied for asylum in South Africa. For others exhibiting this timing pattern, their displacement tended to be acute, in response to the violence or threats of violence they were experiencing in connection with their activities at higher education institutions. We can recall the aforementioned case of Jean-Paul in Bukavu, who was persecuted for his human rights work.

Given the seriousness of Patrice's injuries and the circumstances surrounding his displacement, his case represents an extreme one within this timing pattern. On the whole, based on the nature of this timing pattern and its connection to individualized violence and persecution, this pattern elicits more acute displacement outcomes, relative to the other four timing patterns. I have chosen to highlight and elaborate upon Patrice's case here because in examining respondents' agency related to higher education in shaping the timing of their movements, Patrice's experiences reveal a situation in which he could express no agency. Patrice was physically moved. Thus, his higher education aspirations, norms, and practices do not apply in examining the process behind his timing or initial destination choice. He did, however, express his agency in remaining in South Africa and in applying for refugee status. These other aspects of displacement will be discussed in the succeeding chapters.

\subsection{Putting Findings into Context: Non-Exhibitors and Never Enrolled}

Having identified and examined the different ways in which respondents shaped the timing of their international forced displacement based on considerations related to higher education, this chapter now explores the displacement timing of respondents who similarly pursued higher education in asylum countries, but for whom aspirations, norms, and practices related to higher education were completely absent. Further, this section examines the displacement timing of respondents who never enrolled in higher education programs in asylum countries. Taken together these steps provide some basis of comparison and context for the higher education insights identified on timing.

By examining the timing of respondents who ultimately pursued higher education but who expressed no agency related to higher education in their timing, this section seeks to better understand how higher education considerations emerge in this dimension of the displacement process. By examining the displacement timing of respondents who never enrolled in any higher education, this section seeks to understand the extent to which the observed higher education patterns are unique to respondents pursuing higher education. For instance, it might be that we discover that higher education aspirations and norms are so strong and widely held that higher education considerations also 
impact the timing of refugees and migrants coming from countries marked by conflict who never make it to enrollment.

Fifty-four respondents out of a total of 115 who gained some form of tertiary education did not exhibit any of the five timing patterns. In other words, just over a third of the respondents who gained tertiary education in destination countries did not shape the timing of their exits from origin countries in relation to tertiary education. Their narrative data reveal two dominant themes as to why they did not exhibit: direct violence and age. The first theme refers to the fact that many respondents who appeared not to express agency related to higher education had direct or more acute experiences with violence and persecution which constrained their ability to express any or few aspirations, norms, and practices - regardless of their association with higher education - to shape the timing of their movements. In fact, 40 out of 54 non-exhibitor respondents (74 percent) described having an experience with violence and conflict during their exits from origin countries, as compared to 27 of the 61 respondents (44 percent) who gained higher education and exhibited a timing pattern. To put this in perspective, 80 out of the total 149 respondents (54 percent) had a conflict experience during their exits from origin countries. The timing of the displacement of non-exhibitors therefore appears more reactive and acute.

The narrative data reveal that some non-exhibitor respondents reacted to particular rapid-onset violent events or circumstances, while others had perceived that threats to their safety had reached some untenable threshold, in a slower-onset escalation of violence. For instance, Aurora, ${ }^{33}$ a Congolese woman living in Nairobi described suffering an injury in the DRC that brought her to Kenya to seek asylum and medical treatment. In the DRC, her husband was involved in politics and she worked as a nurse. Aurora had had no aspirations for further higher education. However, in Nairobi, she struggled to be self-reliant. With a scholarship from the Jesuit Refugee Service (JRS), she retrained to improve her employment prospects and obtained a diploma in beauty and hairdressing. Marin, ${ }^{34}$ a Congolese woman living in Cape Town, described leaving Bukavu with her children when the threat of violence became too great. She had persisted in Bukavu through the early 2000s when insecurity kept her and her family from leaving their home. Then, Marin said, "we start[ed] to hear rumors, they are raping people, some areas it was house to house. Some areas they were just taking [women] randomly." She explained that her anxiety and fear became so great that she stopped being able to cope and her family helped her leave for South Africa. After several years in South Africa, she enrolled at university with financial support and encouragement from her family.

\footnotetext{
${ }^{33}$ Information on this respondent comes from interview: DRC_College_Compl_F_NBO_2.

${ }^{34}$ Information and quotes from this respondent comes from interview: DRC_Univ_Compl_F_CT.
} 
The second theme, age, refers to the fact that several non-exhibitor respondents were displaced as children and thus their displacement predated the period in their life cycle when they would pursue higher education. ${ }^{35}$ Most of the respondents who arrived at asylum countries as children did so with their parents or other members of their families. Upon arriving, they enrolled in national primary and secondary schools and eventually obtained national high school diplomas. When pursuing higher education, this was advantageous to their admission, since no qualifications recognition was necessary. Moreover, their familiarity with the language and education system of asylum countries appeared to enhance their success in higher education institutions.

Non-exhibitor respondents moved to each of this study's destination countries, although the largest share could be found in Kenya. Some 76 percent (22 respondents) who gained tertiary education in Kenya exhibited none of the timing patterns related to tertiary education. In contrast, 33 percent (12 respondents) who gained tertiary education in Uganda and 40 percent (20 respondents) who gained tertiary education in South Africa were non-exhibitors. These figures align with what we know about Kenya on a macrolevel in terms of its higher education sector and encampment refugee hosting policies. Simply put, Kenya is the least attractive of the three destination countries as a place of higher education and refugee settlement.

In terms of countries of origin, respondents coming from the DRC and Somalia had roughly the same share of non-exhibitors, at 46 percent (28 respondents) and 48 percent (26 respondents) respectively. Combined with the fact that origin country distributions were fairly balanced for each of the timing patterns related to tertiary education, this suggests that structural factors within the DRC and Somalia, on their own, did not elicit or shape the timing of respondents' departures. Two features of non-exhibitor respondents' profiles in which we see some trends are migration status and gender. Some 61 percent (51 respondents) who entered their destination countries as asylum seekers were non-exhibitors, relative to 4 percent (one respondent) who entered as student migrants. This aligns with the fact that non-exhibitors tended to have more direct experiences with violence and conflict at the time of their departure from their origin countries. Thirty female respondents, or 57 percent of women who gained tertiary education in the destination, were non-exhibitors as compared to 24 male respondents, or 39 percent. In other words, the majority of female respondents were unable or

\footnotetext{
${ }^{35}$ In carrying out the data collection for this study, I did not want to include age of initial displacement or age of arrival to the asylum country in the inclusion criteria so as not to limit the displacement and migration trajectories I would observe. Moreover, I did not want to assume that people who sought asylum as children did not express agency in shaping their displacement and I wanted to be open to observing instances in which displacement was part of a larger household protection strategy.
} 
unwilling to shape the timing of their exits in relation to tertiary education, while the majority of male respondents did. Several female respondents cited normative reasons why women experience greater challenges in pursuing higher education than men. In Somalia, some respondents explained that education is seen to "spoil" or "ruin" a woman and thus her marriage prospects. More generally across both country of origin groups, respondents explained that in a situation of finite resources, it is perceived that educating a girl means not educating a boy. One female respondent ${ }^{36}$ maintained:

"I don't know if you'll understand, but in Somalia certain places are more religious than others and the expectation is for you [women] to get married... and if you are the type who wants further education there's this view that some of my community have whereby if you're a girl there's no match if you are going into education. Also, there is no need...your parents provide for you, you get married, your husband provides for you. So that's the mentality most people have."

In sum, examining the data on respondents who ultimately pursued higher education in countries of asylum, but who expressed no agency related to higher education in the timing of their exits, revealed several insights about the emergence of higher education considerations. First, and perhaps not surprisingly, not all refugees and migrants pursuing higher education shaped the timing of their movements with respect to higher education. For some respondents, their circumstances were too constrained and too acute to express any aspirations, norms, or practical considerations, let alone those related to higher education, in negotiating the timing of their exits. Hence, there has to exist some space in which to express agency, for higher education considerations to emerge. Second, higher education considerations emerged only when the timing of displacement or exit aligned with the appropriate period in one's life cycle. For most, this was the period when a respondent was close to graduating or had recently graduated from high school. For a smaller number of respondents, this period was extended into their 30s and 40s when they were considering accessing higher education later in life. Lastly, gender appears to play a role in the emergence of higher education considerations, as it is men more often than women who are supported by their families in initiating their pursuit of higher education opportunities in destination countries.

Turning now to examine the data on the timing of displacement or exit of respondents who never enrolled in any higher education, one might expect none of these respects to exhibit any timing patterns related to higher education. In fact, we see the opposite. Figure 45 reveals that nine of the 34 respondents who never enrolled in tertiary education

${ }^{36}$ This quote comes from the interview: Som_Univ_Enroll_F_CT. Her case is explored in Chapter 7. 
nevertheless exhibited at least one timing pattern related to tertiary education, particularly "movement as part of a life cycle transition."

Figure 44: Timing Patterns of Respondents who Never Enrolled in Higher Education

\begin{tabular}{lc}
\hline \multicolumn{1}{c}{ Higher Education Timing Pattern } & $\begin{array}{c}\text { Respondents who Never } \\
\text { Enrolled in Higher } \\
\text { Education }(\mathbf{N = 3 4 ) *}\end{array}$ \\
\hline Movement following the achievement of an educational milestone & 1 \\
Movement upon securing a higher education opportunity in destination & 0 \\
Movement in response to severe higher education constraints in origin & 1 \\
Movement as part of life cycle transition linked to higher education & 6 \\
Movement in response to persecution resulting from higher education & 3 \\
Exhibited 0 Patterns (Non-Exhibitors) & 25 \\
*Some respondents who never enrolled in higher education exhibited more than one timing pattern.
\end{tabular}

A Somali man ${ }^{37}$ living in Johannesburg, explained that he left Somalia after he finished high school and perceived higher education as offering him a way to put his life together; however, since his arrival to South Africa, he has yet to amass the funds for enrollment. Miriam, ${ }^{38}$ a Congolese woman who had refugee status and was living in Cape Town at the time of the interview explained that in the DRC, she had completed a law degree and the timing of her displacement was aligned with her desire to pursue graduate-level higher education in South Africa. However, since her arrival she had failed to enroll in any programs. In addition to lacking sufficient financial resources, Miriam had also lost the documentation proving her educational attainment during her journey, which prevented her from applying for scholarships or any educational programs. Further, her educational mobility went against the wishes and norms of her family and community members, and her former classmates held successful careers back in the DRC. The feelings of failure she held kept her from asking for their help.

The respondents who never enrolled in tertiary education but nevertheless exhibited the timing pattern "movement as part of a life cycle transition, of which higher education is a part" all had high aspirations for tertiary education. They were unable to enroll in higher education because of constrained practices leading to an inability to achieve their

\footnotetext{
${ }^{37}$ Information on this respondent comes from interview: Som_Univ_Never_M_JHB_2.

${ }^{38}$ Information on this respondent comes from interview: DRC_Univ_Never_F_CT.
} 
aspirations. To this end, a third respondent ${ }^{39}$ who expressed this timing pattern maintained:

\begin{abstract}
"So far, you know if someone's stomach is hungry, you cannot think about education. So far, I was struggling with my living and how to be stable. If I get a stable living, a place to study, and stop worrying about my future, you know then the mind is set, then I can get an education."
\end{abstract}

The necessary conditions for this timing pattern, therefore, are the aspiration to pursue higher education and the ability to leave origin countries impacted by conflict and crisis. Hence, this timing pattern is not unique to refugees who gained tertiary education in asylum countries. This same logic extends to the other timing patterns, with the exception of "movement upon securing an educational opportunity in the destination country." These other patterns are contingent upon respondents' aspiring to pursue higher education in asylum countries, but not on having already secured an opportunity.

\title{
6.5 Implications and Conclusion
}

Analyzing the narrative data on when Congolese and Somali respondents initiated their international displacement or exit to Kenya, South Africa, and Uganda revealed five timing patterns related to higher education. They are:

1. Movement following the achievement of an educational milestone

2. Movement upon the securing of a higher education opportunity in the destination

3. Movement in response to severe higher education constraints in the origin

4. Movement as part of a life cycle transition, of which higher education is a part

5. Movement in response to persecution experienced as a result of higher education

Broadly speaking, these patterns revealed that for the select group of refugees and migrants who pursued higher education in their destination countries and even for some who did not, the prospect of higher education had an impact even at the "early" stages of the displacement process, when such individuals were planning and executing their exit from origin countries. In this way, higher education played a role in initiating the search for asylum and/or becoming a refugee. This is important because, as outlined in Chapter Two, the literature on refugee tertiary education highlights the impact that tertiary education has on refugees' displacement patterns and experiences after their arrival in asylum and resettlement countries. It is mainly in the historical literature on

\footnotetext{
${ }^{39}$ Information on this respondent comes from interview: Som_Tech_Never_M_JHB.
} 
higher education and forced displacement where we find evidence of tertiary education impacting the timing of exit, either because it is connected to why refugees face persecution or because it provides refugees with the capabilities to anticipate danger and move proactively (Kunz 1973). By analyzing the different components of respondents' agency, this chapter revealed a wider and more nuanced range of higher education impacts related to respondents' capabilities and experiences with persecution, life cycle transitions and norms, perceptions of constraints and opportunities, and education aspirations and strategies.

These findings confirmed what Cantor (2014) and Lindley (2011) found related to the timing of forced exits in Central America and Somalia, respectively, which is that refugees express their agency in shaping whether and when to leave and in avoiding, delaying, and planning the timing of their movements. Also in line with Cantor (2014) and Lindley (2011), this chapter's timing patterns related to tertiary education and its analysis of how they were formed from respondents' aspirations, norms, and practical considerations demonstrated the way in which forced displacement patterns can overlap with mobility patterns, in this case educational mobility patterns. The transition to adulthood and to tertiary studies, the pursuit of cultural rites of passage, and the experience of educational constraints were aspects of timing expressed by respondents and found within the international student migration literature (Punch 2007a; Black et al. 2006; Black, Hilker and Pooley 2004).

This chapter also revealed that the timing of respondents' movements had a range of relationships to conflict and violence, structural dependencies, and expressions of agency. In terms of their relationships to conflict and violence, respondent cases ranged from very direct to indirect. On one side, in all cases in which respondents cited "movement in response to higher education persecution," respondents expressed direct relationships to conflict and constrained agency. On the other, respondents who "moved as part of a life cycle transition" mostly cited indirect links to conflict and were in a greater position to shape the timing of their movements. For such respondents, violence and conflict were protracted conditions that had become fused with the realities of their daily lives. Consequently, they rarely expressed their movement in terms of forced displacement and, instead, such conditions internationalized their educational mobility. In between the two poles fell the patterns of achieving an education milestone, securing an opportunity abroad, and experiencing higher education constraints. These patterns displayed different timing dynamics, such as highly acute and reactive movements, delayed movements, anticipatory movements, and movements aligning with more "normal" life cycle transitions. 
The patterns on higher education constraints and persecution were more dependent on local structural conditions and the consequences of protracted conflict and crisis. As a result, such conditions could be observed within respondents' practical considerations. By contrast, the patterns related to "achievement of an educational milestone," "securing an opportunity," and "life cycle transition" were more driven by factors related to the individual. For these latter patterns, practical considerations most often reflected respondents' individual socio-economic circumstances, and aspirations and norms featured more prominently in shaping exits. Thus, the timing of movement is not only a function of macro-level events and forces, such as the collapse of a higher education sector. Timing is also a function of refugees and migrants' own timelines, defined by, for instance, their coming of age, pursuit of cultural rites of passage, or achievement of educational milestones.

The data on respondents who gained higher education in destination countries, but who expressed no agency related to higher education in the timing of their exits, reveal several insights on the emergence of higher education patterns. First, and perhaps not surprisingly, not all refugees and migrants who gained higher education shaped the timing of their movements with respect to higher education. For some respondents, their circumstances were too constrained to express any aspirations, norms, or practical considerations, let alone those related to higher education, in negotiating their departures. In other words, there has to exist some space in which to express agency, for higher education considerations to emerge. Second, higher education considerations emerged only when the timing of movement aligned with the appropriate period in one's life cycle. For most, this was the period when a respondent was close to graduating or had recently graduated from high school. For a smaller number of respondents who pursued tertiary education later in life, this period was extended into their 30s and 40s. Third, gender played a role in the emergence of higher education considerations, as it was men more often than women who were supported by their families to pursue higher education opportunities. Just two of the five patterns had a gender balance. More than half of men cited at least one timing pattern, while less than 40 percent of women cited at least one timing pattern. Norms played a greater role in shaping the agency of female respondents, or rather a more visibly constraining role, as they impeded women's access to and aspirations for higher education. Furthermore, the data of respondents who never enrolled in tertiary education who nevertheless exhibited timing patterns related to higher education, particularly "life cycle transition," revealed that high aspirations for tertiary education were a necessary condition for expressing a timing pattern, and not actual enrollment.

Lastly, in terms of connections to other dimensions, a relationship between the timing of movement and destination choice exists. Most respondents initiated their displacement 
or exit to a specific destination and information about the destination featured in when movement was initiated. With the pattern "securing an educational opportunity" we see that timing is not only connected to the destination, but also the migration channel, as respondents arrived as students. The subsequent chapters will tease out these links between dimensions. 
CHAPTER 7

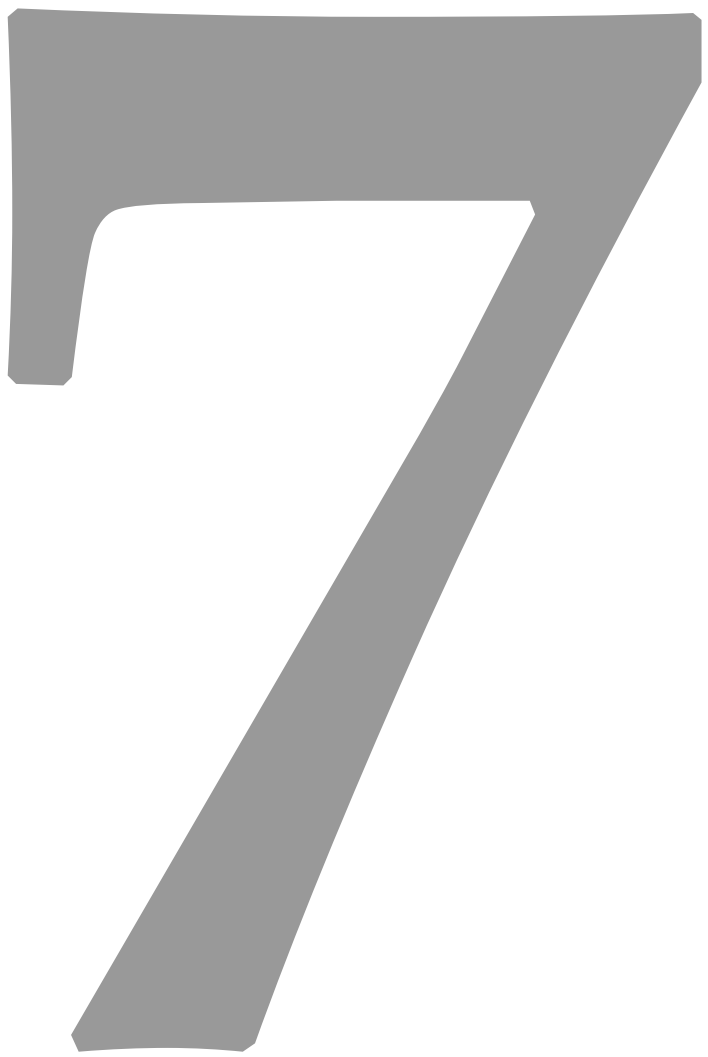




\section{Destination}




\subsection{Introduction}

The aim of this chapter is to understand the roles played by higher education in determining the destination of respondents' movement and to consider how these roles were shaped by respondents' agency. The destination of movement can be considered from a diverse array of perspectives and analytical levels. Chapter Two revealed that refugees' and migrants' destination outcomes may be influenced by macro-level socioeconomic and political factors such as the destination country's labor market, level of economic development, higher education sector, and migration and asylum policies. They may also be impacted by more meso and micro-level factors related to refugees' and migrants' sociocultural norms, the spread and depth of their social networks, and individual or household capabilities and aspirations. Further, destination outcomes may be shaped by a country's geographic proximity and its linguistic or cultural similarity to the origin country. The findings related to higher education presented in this chapter mirror the diversity within the literature and go a step further by exploring the processes linked to agency through which different destination patterns emerged. These destination patterns were inductively developed based on respondents' narratives of their movement and higher education trajectories. They demonstrate that higher education considerations play multiple and multidimensional roles in how certain refugees shape their destination outcomes. This is important because it underscores that educational and employment opportunities factor into the choice of destination alongside or as part of safety and security.

This chapter begins by defining the destination of movement. It then presents and examines four destination patterns related to higher education that respondents expressed in their narratives of their movement and higher education trajectories. The chapter goes on to analyze the emergence of these patterns through respondents' aspirations, norms, and practical evaluations. To provide some basis of comparison and context for the higher education insights identified, this chapter also examines cases in which higher education appeared to play no role in the destination outcomes of respondents who pursued higher education in asylum countries, as well as cases in which higher education did play a role in the destination outcomes of respondents who never enrolled in higher education programs in asylum countries.

\subsection{Defining the Destination of Movement}

This chapter defines the destination of movement (or destination outcome) as the country and city wherein Congolese and Somali respondents were settled at the time of the interview between 2015 and 2016. In this study, the three countries of destination were 
Kenya, South Africa, and Uganda and the cities of destination were Nairobi, Kakuma Refugee Settlement, Cape Town, Johannesburg, and Kampala. I include both countries and cities in the definition of destination outcome because I observed this distinction within respondents' narratives. Some respondents discussed the process of reaching their destination outcomes solely in terms of reaching South Africa or Kenya and without reference to any specific location within a country's borders. Others framed their destination outcomes in terms of reaching a particular city, without reference to the wider country. Moreover, some respondents expressed destination patterns linked to higher education that impacted the destination country, while non-higher education factors impacted the destination city. The reverse was also true, wherein non-higher education factors impacted the destination country, while higher education destination patterns shaped the destination city. Hence, this chapter examines both countries and cities as destinations, to reflect the different perspectives on the meaning of destination.

While the terms "destination country," "destination city," and "destination outcome" imply a finality with respect to movement, this study does not claim that these destinations are at all end points or final destinations. Nor does it equate the destination of movement with where respondents ultimately desired to settle. Moreover, this study recognizes that respondents may have settled in previous "destinations" before their movement to one of this study's research sites. Hence, in the context of this study, destination of movement refers to the aforementioned countries and cities at a specific period in time.

\subsection{Findings: Key Destination Patterns Related to Higher Education}

Congolese and Somali respondents exhibited several distinct destination patterns related to tertiary education, in their movements to Kenya, South Africa, and Uganda. These patterns include:

1. Movement to a higher education institution or sector

2. Movement to an anglophone study destination

3. Movement to a higher education regime

4. Movement to a labor market

These four destination patterns may coexist to shape the respondents' destination outcomes. The following sections discuss each of these inductively-derived patterns in turn, including how these patterns were formed from respondents' aspirations, norms, and practices related to higher education and the particular profiles of respondents who 
exhibited these patterns. Hence, the cases outlined below are intended to illustrate the processes behind the destination patterns.

\subsubsection{Movement to a higher education institution or sector}

The destination pattern "movement to a higher education institution or sector" refers to a destination outcome based on a specific program of study or higher education institution and/or the wider higher education sector in a destination country. When expressing this pattern, it was not enough that respondents went on to pursue higher education or had a general aspiration for higher education. Rather, respondents exhibiting this pattern had explicitly sought out a specific institution or the wider higher education sector, or both, in the destination country.

This pattern was the most-cited by respondents of the four destination patterns related to higher education, with 54 respondents, or approximately 36 percent of the sample, describing movement to a higher education institution or sector. Most often, respondents who exhibited this pattern described moving to a country's higher education sector, rather than a specific institution. In so doing, respondents had considered the academic prestige of a country's top institutions, the perceived opportunities available for admission and scholarships, or the perceived qualities of a higher education sector, for instance its degree of "openness" or cosmopolitanism. Moreover, respondents exhibiting this pattern chiefly described their movement to South Africa and Uganda, at 29 out of 62 respondents and 22 out of 49 respondents, respectively. Just three out of 33 respondents who moved to Kenya cited movement to a higher education sector or institution. This reflects what we know about the higher education sectors in these three countries, as detailed in Chapter Four. South Africa's higher education system is ranked the highest within Africa, with four of the top five and seven of the top ten universities on the continent being South African institutions. Uganda is the only other Sub Saharan African country with a university in the top ten continental rankings and is highly regarded. In contrast, Kenya's higher education sector struggles to meet its domestic demand for enrollment, leaving few opportunities for international students or refugees.

For the minority of respondents who discussed moving to a particular program of study or higher education institution, roughly equal numbers described applying to their institution of choice before their departure from their origin country versus moving to a destination city and submitting their application for study after getting settled. In the former case, we can seek a link between this destination pattern and the timing pattern "movement upon the securing of a higher education opportunity in the destination." Most of the respondents who moved to a particular program or institution stressed that 
their destination outcome was linked to a particular institution rather than course. These respondents determined their program of study based on the course offerings and where they gained admission. In just a few cases, the destination outcome was linked to where respondents could pursue their academic interests, for instance, a degree in environmental management, and so the program of study was the primary factor within this pattern. While movement to a higher education sector impacted a respondent's movement to a destination country, movement to a higher education institution or program of study determined a respondent's movement to a destination city. In some instances, a respondent expressed moving to both a sector and an institution, showing how the destination outcome for the country and city was shaped by higher education.

In terms of the profile of respondents exhibiting this destination pattern, most respondents went on to enroll in undergraduate and graduate programs at universities in the destination country, rather than diploma programs at colleges or certificate programs at vocational and technical schools. Thirty respondents (60 percent) who were studying or had studied at the university level in destination countries exhibited this pattern, relative to 12 respondents (43 percent) at the college level and seven respondents (19 percent) at the technical or vocation level. This may be linked to the fact that the destination countries' higher education sectors and their reputations are skewed towards university education. Technical and vocation forms of tertiary education are severely constrained and do not attract international students the way universities do. Moreover, many of the courses that technical schools offer may be a part of apprenticeship or employment schemes that are reserved for nationals.

Additionally, approximately an equal share of Congolese (35 percent or 28 respondents) and Somalis (38 percent or 26 respondents) expressed "movement to a higher education institution or sector." Similarly, 32 males (40 percent) versus 22 females (32 percent) expressed this destination pattern. While these shares are not exactly equivalent, this destination pattern was the most-cited of the four patterns by both male and female respondents. This suggests that, perhaps contrary to both real and perceived negative norms and practices surrounding female higher education attainment, females coming from countries impacted by conflict similarly considered higher education institutions and infrastructure in shaping the destination of their movements. In further support of this point, looking only at respondents with refugee status at the time of the interviews, movement to a higher education institution or sector remained the most-cited of the four destination patterns by both men and women, at 27 percent and 18 percent, respectively. 
Looking more broadly at respondents' migration status at the time of the interview ${ }^{40}$ reveals a split between so-called voluntary migration channels and forced or more precarious migration channels. Twenty-one student migrants (88 percent) and both higher skilled labor migrants cited this pattern, as compared to 20 refugees (22 percent) and seven asylum seekers (37 percent). The overwhelming majority of respondents who held more "voluntary" and skilled migration statuses shaped their destination outcomes in relation to a particular higher education institution or sector. Not surprisingly, for student migrants this was the case as their status was predicated upon their affiliation with a higher education institution. Respondents who were refugees, asylum seekers, and undocumented migrants at the time of the interview did not express this destination pattern in such large shares as their "voluntary" counterparts. That said, like their counterparts, "movement to a higher education institution or sector" was the most-cited of the four destination patterns. Moreover, when one considers that such respondents were forced migrants and moving under more precarious conditions, then the fact that 20 refugees and seven asylum seekers expressed this pattern is noteworthy. Further, it suggests that for some forced migrants, higher education planning begins before and/or during the process of displacement.

The following is an example of the primary way in which this destination pattern was expressed. In outlining this case, I examine how the respondent's aspirations, norms, and practices related to higher education shaped this pattern. Where relevant, I discuss any structural factors cited by the respondent, either directly or indirectly, as impacting his or her agency.

Case 6. Clara. ${ }^{41}$ Choosing the best in higher education.

Clara is a Congolese woman who was enrolled in a doctoral degree program in Cape Town at the time of the interview in early 2016. She was also a registered refugee and had originally come from Eastern DRC. At the time Clara left the DRC to move to South Africa, she was in her second year of university. When describing her destination outcome, she explained:

"I was there [in Congo] waiting. I was not supposed to study at university in Congo in the first place. At the time, my mom was trying to find for me instead

\footnotetext{
${ }^{40}$ The data on higher education destination patterns by migration status at the time of entry into the destination countries reveal much the same patterns in terms of the distribution of exhibited patterns within each migration category. The only differences are that the respondents who became higher skilled migrants entered as student migrants and the respondents who became refugees entered as asylum seekers.

${ }^{41}$ All quotes from Clara come from interview: DRC_Univ_Enroll_F_CT.
} 
an opportunity to study in Europe. I was waiting to go to a university in Europe. And it took time, it took time and I became impatient."

Clara also said:

"It was simple. South Africa is not like Uganda. There is one of the best [universities] in South Africa. You always want to go to the best one. When you can't make it to Europe, that's when you take the option to go to South Africa."

Clara's destination outcome was linked to her aspiration to study within a highly ranked tertiary education sector. Once it became clear that studying in Europe would not be possible and the barriers to entry were too high, she re-evaluated her options and picked the country within Africa with the best ranked higher education sector. This is an experience shared by several respondents, men and women, Congolese and Somalis, alike, albeit for varied reasons. For these respondents, their destination outcome was a "next best option" after plans to study outside of Africa in North America, Europe, and Asia did not materialize because of insufficient means, qualifications, language abilities, or family constraints and challenges. In a small number of cases, respondents had unfulfilled aspirations to study in other African countries, such as the Sudan or Kenya.

In her narration of her destination outcome, Clara did not cite a particular university or program of study. This is because her aspirations centered around gaining higher education and working in academia rather than a passion for a subject or an aspiration to study at a specific institution. It was the overall ranking of the country's universities that impacted her decision-making and ultimately shaped to which institutions she applied. Similarly, she traveled directly to Cape Town as that is the city where, according to her, one went to study. Indeed, the Western Cape province, where Cape Town is located, has four universities in the top ten, which is more than any other province in South Africa. In discussing her educational and professional aspirations, she stated:

"I always wanted to go to university. That's what I came to do in the first place, but I didn't know what to do with my life. I always had this dream that I wanted to be an academic. To write, teach if possible.... I always wanted to study. I always wanted to be a doctor in something, a PhD in something. Not a doctor in medicine. I always wanted to study a lot and to have many degrees. It might have to do with my mom always telling me everything she wanted to be. She was and she is a very intelligent woman." 
Clara had both a strong personal drive and strong family norms for higher education. Not only did her mom actively encourage Clara's further studies, but she also had a tertiary degree and came from a line of family members with tertiary degrees. Moreover, all of Clara's siblings were enrolled or planned on enrolling in some form of higher education. In fact, one of her brothers had also studied in Cape Town.

Despite the educational background of her family and the fact that they had the means to support her travel to South Africa, Clara did not come from a highly privileged family. In discussing the more practical considerations shaping her destination outcome, Clara had to pay for all of her tuition fees and living expenses. She had to work in Cape Town for several years before enrolling at university and continued to work throughout her studies. During this time, she secured several scholarships designated for refugees, which enabled her to pursue her MA and PhD in Cape Town after completing her BA degree.

Other evidence of the practical considerations she faced can be found in her journey to South Africa. Clara did not fly directly to Cape Town. Instead, she took a series of buses and one flight with a family member, stopping in a number of countries before reaching South Africa. The journey took her two weeks. Despite such stops, Clara's journey to South Africa can be described as relatively direct, based on the short time she spent in transit and the fact that her destination outcome was set before leaving home. Some respondents who exhibited this destination pattern traveled in a single day, while others spent months or years from the time they left their origin country to the time they arrived in their destination country. For respondents with more indirect journeys, in some cases their destination outcomes were not fixed and evolved over the course of their movements while in others, their destinations were fixed but respondents had to stop and earn money en route to fund their movement. Within this destination pattern, there is a slight trend towards respondents engaging in more direct movements to destination countries. This is likely because their destination outcomes were tied to specific higher education structures (the sector, institution, or study program) and enrollment plans.

\subsubsection{Movement to an anglophone study destination}

The destination pattern "movement to an anglophone study destination" refers to a destination outcome based on the desire to learn and study in English and to obtain an anglophone tertiary degree. The destination countries within this study are all anglophone, while the two origin countries are non-anglophone. In the DRC, the language of instruction is French. In Somalia, the languages of instruction vary according to region and level of education. Arabic and Somali dominate instruction in every region, particularly at the primary level and in Quranic schools. Increasingly, English is also 
taught at the secondary level; in Somaliland, it is often a main language of instruction, while in the South Central region and Puntland, it is often a course (UNICEF 2016).

This destination pattern was the second-most cited of the four destination patterns, at 26 respondents or approximately 17 percent of the total sample. The largest proportion were those who moved to Uganda, some 18 respondents or 37 percent of the respondents in Uganda. This stands in contrast to the three respondents in Kenya and five respondents in South Africa, which comprises approximately 8 percent of their respective samples. The small share of respondents in Kenya who expressed this pattern mirrors the distribution observed for "movement to a higher education institution/s," and, therefore, may similarly reflect the lack of opportunities available in the Kenyan tertiary education sector. Interestingly, for respondents in South Africa and Uganda, this pattern departs from the distribution observed for the first destination pattern, for which respondents who moved to South Africa featured most prominently. While overlap exists between these two destination patterns, this contrasting finding for the country of destination suggests that respondents concerned with gaining quality tertiary education and targeting specific institutions moved to South Africa, while respondents concerned more generally with studying in English and gaining an anglophone degree moved to Uganda.

For many of the respondents who expressed this pattern, gaining an anglophone tertiary degree was important because it was perceived as opening up more opportunities for the future. Clara, the aforementioned Congolese respondent who was living in Cape Town, also exhibited this pattern and explained "I wanted to study in an English country, it can open more opportunities for you." This theme of openness was one repeated by several respondents who moved to South Africa. Not always linked with South Africa being an anglophone country or linked explicitly to tertiary education, the theme of openness related to possibilities for socio-economic mobility and less corruption in the destination and, often, perceived high corruption in the origin country.

Similarly, many respondents perceived gaining an anglophone tertiary degree as crucial to excel in their desired fields. To this end, a male Congolese respondent ${ }^{42}$ living in Johannesburg stated:

“The beginning wasn't specifically [to study at a particular university], the beginning was just education, English. I think technology goes along with English. I had been studying in French speaking countries, and the

\footnotetext{
${ }^{42}$ Information on this respondent comes from interview: DRC_Univ_Enroll_M_JHB_2.
} 
opportunity for me based on the fields I wanted to do, was always to go to an English-speaking country."

For this respondent, studying Information Technology (IT) in English was important because the English language dominates the IT profession. This belief was also held by several respondents pursuing higher education in various fields of healthcare. Such respondents explained that the ability to communicate in English and to know English healthcare jargon was absolutely necessary to assist patients and work with other professionals. Interestingly, one respondent who described his destination outcome in terms of his desire to learn English, did so to be prepared for any future eventuality "because we never know what will happen tomorrow." ${ }^{43}$ For this respondent, learning in English was shaped by his experiences with conflict and being a refugee, and his desire to prepare for an uncertain future.

In terms of the profile of respondents, a similar share of Congolese (16 percent or 13 respondents) and Somalis (19 percent or 13 respondents) cited studying in English and gaining an anglophone tertiary degree as tied to their destination outcome. For Congolese respondents, this stemmed from their desire to step outside the francophone system, while for Somali respondents, this stemmed from their desire to step outside the Arabic and Somali language of instruction. Additionally, approximately an equal share of men (19 percent or 15 respondents) and women (16 percent or 11 respondents) expressed this destination pattern. Once again, this suggests that contrary to both real and perceived negative norms and practices surrounding female higher education attainment, female respondents coming from the DRC and Somalia similarly consider the attainment of an anglophone tertiary degree as well as learning and studying in English in shaping the destination of their movements.

In terms of the level of higher education, most respondents (34 percent or 17 respondents) who exhibited this destination pattern had completed or were enrolled in degree programs at universities. This highlights the overlap that exists between the destination pattern "movement to a higher education institution or sector" and "movement to an anglophone study destination." Four respondents (11 percent) who had obtained or were pursuing tertiary certificates at technical schools and two respondents (7 percent) who had obtained or were pursuing college diplomas exhibited this destination pattern. While the numbers are small and therefore difficult to compare, a higher share of respondents at the technical level may stem from the fact that a number of these respondents were pursuing English language certificates.

\footnotetext{
${ }^{43}$ Information on this respondent comes from interview: DRC_College_Compl_M_Kla. 
Lastly, in terms of migration status, 12 of the 24 student migrants cited "movement to an anglophone study destination." This represented the largest share of any of the migration status categories. The higher prevalence of student migrants expressing this destination pattern once again mirrors the distribution observed for "movement to a higher education institution or sector," and suggests a link between the aspiration to study at a specific institution or in a particular country's higher education sector and the aspiration to study in English. Moreover, the expression of this destination pattern by respondents with a student migrant status, which requires admission to a higher education institution, highlights that English as a language of instruction is a factor in its own right shaping the destination outcome. No respondents in a higher skilled labor migrant category or family migrant category expressed this pattern. Concerning respondents with a humanitarian status at the time of the interview, 11 refugees (12 percent) and two asylum seekers (11 percent) expressed this destination pattern. Despite moving under more constrained circumstances, such respondents shaped their destination outcomes in relation to where they could learn and study in English and gain an anglophone tertiary degree. As mentioned at the start of this section, respondents associated learning in English with expanding opportunities and being prepared for future uncertainty. In this way, learning in English became a part of their forced displacement and livelihood strategies.

The following example reveals how this destination pattern was expressed. In outlining this example, I examine how the respondent's aspirations, norms, and practices - i.e., the dimensions of agency - related to higher education shaped this pattern. Where relevant, I discuss any structural factors cited by the respondent, either directly or indirectly, as impacting his or her agency.

\section{Case 7. Idil. ${ }^{44}$ Learning a universal language.}

Idil is a Somali woman who was enrolled in a BA program in Cape Town at the time of the interview in early 2016. She also had the legal status of refugee, although she did not identify with the refugee label. When explaining her destination outcome, she stated:

“I just felt, 'I want to study'...My English wasn't perfect. In Somalia, you would only be taught in either Arabic or Somali and then you would learn English as a subject... I wanted to study medicine and thought if I want to become a doctor, I need to study anatomy and all that. I wanted to study in a universal language, so that wherever I go I'll understand people and people will understand me."

\footnotetext{
${ }^{44}$ All quotes from Idil come from interview: Som_Univ_Enroll_F_CT.
} 
Idil saw English as a "universal" language, and one that would help her transcend borders and excel in her career path. She explained that she had considered moving to an Arabic-speaking country, as Arabic is also a widely-spoken language. However, her plans to move to such a country had failed and, in her words, she "didn't get the opportunity." Hence, turning to the anglophone world was shaped by her aspiration to study in a universal language as well as by more practical considerations about where she had the opportunity and capability to move. This was a theme expressed by several other Somali respondents, who were similarly torn between moving North or East toward Arabic-speaking countries versus moving South toward anglophone countries.

Other practical considerations that Idil faced in shaping her destination outcome were challenges with qualifications recognition and raising the funds for enrollment. In fact, Idil's movement to Cape Town was not direct. Upon finishing secondary school, Idil first moved to Nairobi to pursue higher education and avoid persecution in Somalia. Once there, she had limited access to information about the higher education scholarships available to refugees or how to get her Somali transcripts translated and certified, and could not afford the tuition fees. After a year of struggling, a family member based in Cape Town arranged for her travel there and informed her of higher education resources for refugees. Thus, the constraints that Idil faced centered on her lack of social capital and information on the asylum and higher education systems in Kenya, and the greater resources or perceived resources at her disposal in South Africa to pursue her higher education aspirations.

In terms of Idil's aspirations which shaped the emergence of this destination pattern, she expressed both the aspiration to gain an anglophone tertiary degree and move to a particular higher education sector, which she perceived offered more opportunities for enrollment. During the course of our conversations, Idil stated, "When I came [to South Africa] my sole purpose was to get a tertiary level of education." Both destination patterns stem from her aspirations to gain higher education and pursue a career in healthcare. When discussing her educational and professional aspirations, she said:

"When I was in high school, whenever there was a role whereby I could be a doctor, I always used to love it. And I used to watch Grey's Anatomy...then, I don't know I have this passion... I feel like if I want to do something, or if I want to spend my time and money on something it has to be something that I like, not just something I just choose because of money or other reasons."

Idil's aspirations to study and pursue a career in healthcare were reinforced by the fact that she was the first-born in her family and felt a strong desire to set an example for her 
siblings. She explained that it was not enough for her siblings to see her educational trajectory and wish to do the same. Instead, she wanted them to see what she accomplished and believe that they could go even farther.

On a normative level, Idil's higher education and movement to Cape Town were strongly supported by her family in Somalia. While neither of her parents had gained higher education, they encouraged her to pursue tertiary studies. Idil explained that her father was active in tracking her progress in primary and secondary school. She described him as the "pillar" of her education and said that his unfulfilled aspirations for higher education had been transferred to her, as his first-born child. Consequently, when she completed primary school and reached the age that female children typically dropped out and married, he sent her out of their village to live with family in Mogadishu and to enroll in a well-regarded school and gain a secondary school diploma that would be recognized outside of the country. Hence, it appears that her tertiary education mobility was being planned for while she was still in secondary school.

Idil explained that the high value that her family placed on tertiary studies did not align with her wider community's beliefs and values on female education. By pursuing secondary and tertiary education, Idil and her family were risking her marriage prospects. Describing her community's beliefs she said:

"I don't know if you'll understand, but in Somalia certain places are more religious than others and the expectation is for you [women] to get married....and if you are the type who wants further education there's this view that some of my community have whereby if you're a girl there's no match if you are going into education. Also, there is no need...your parents provide for you, you get married, your husband provides for you. So that's the mentality most people have."

Idil's narration of her higher education and movement trajectories reveals that her movement to an anglophone study destination was shaped by her passion to work in the field of healthcare and the belief that studying in English was crucial to excel in this work. At the same time, the practical considerations she faced reinforced her movement south to Nairobi and then Cape Town. Furthermore, the conservative socio-cultural norms she encountered in her community of origin and the strong values her parents held for tertiary education prompted her internal move for secondary schooling and ultimately, her pursuit of higher education outside Somalia. 


\subsubsection{Movement to a higher education regime}

The destination pattern "movement to a higher education regime" refers to a destination outcome shaped by higher education ministries and higher education policies and procedures in the destination country. Policies and procedures may relate to, amongst others, fee structures, admissions criteria, qualifications recognition, and ability to work, especially as they pertain to asylum seekers and refugees. This pattern was cited by nine respondents, or 6 percent of the total sample, and was the least cited of the destination patterns related to higher education. More generally, respondents in this study did not have in-depth knowledge of the higher education or migration and asylum regimes of their destination countries prior to their movement, or the relative differences in higher education or asylum and migration regimes among potential destination countries.

The nine respondents who exhibited this destination pattern did so in a variety of ways. Some had carried out research or had members of their social networks inform them of favorable asylum and refugee policies as they related to working and studying in a destination. Others had more vague impressions of the policy environments in a destination country, relative to other countries. Several respondents who exhibited this pattern had first-hand experiences with highly constrained higher education or asylum and refugee regimes in initial countries of arrival, and so their onward movements to destination countries were shaped by the prospect of a better alternative.

Most of the respondents (seven out of nine) who exhibited this destination pattern had moved to South Africa as their destination outcome. None of the respondents in Kenya and just two respondents in Uganda expressed this destination pattern. Following Chapter Four's review of the asylum and refugee policies in this study's destination countries, we know that South Africa is a unique refugee hosting country in that it grants both asylum seekers and refugees the right to study, work, and move freely about the country. Moreover, as part of their right to tertiary studies, the country extends to asylum seekers and refugees the same tuition fees as nationals, rather than international students. This is not the case in either Kenya or Uganda. While refugees and asylum seekers are permitted to enroll in higher education institutions, and in Kenya this provides refugees with the grounds to live outside of refugee settlements, the Kenyan and Ugandan governments do not exempt them from paying high international student fees. High education institutions are given the discretion to determine the fee structures of refugees, asylum seekers, and international students.

Additionally, several respondents who expressed this destination pattern had moved to South Africa indirectly after a negative experience with the asylum regime in their initial country of arrival. In all such cases, the initial arrival country was Kenya. Respondents 
described challenges with applying for asylum and getting identification documents (i.e., asylum papers), the harsh conditions in refugee settlements and lack of opportunities for higher education within the settlements, police harassment and arrest, being unable to work or being unable to obtain the permit that refugees need to work, and being unable to afford higher education tuition fees or find scholarships.

In terms of the profile of respondents, several trends emerge which suggest that the experience of "movement to a higher education regime" was highly self-selected. This stands in contrast to the previous two destination patterns, which had wider profile distributions. First and foremost, given the explicit relationship between this destination pattern and the asylum regime, it is no surprise that only respondents registered as refugees and asylum seekers expressed this pattern. Six out of 89 refugees and three out of 19 asylum seekers cited this pattern. Moreover, based on South Africa's inclusive policy towards asylum seekers, it is no surprise that nearly twice as many asylum seekers than refugees cited "movement to a higher education regime."

Additionally, all respondents but one who expressed this pattern were from Somalia. It is possible that Congolese respondents did not express this destination pattern related to higher education, save for one, because the DRC is a member of the Southern African Development Community (SADC) and South Africa grants SADC residents the same tuition fees as nationals. Hence, Congolese asylum seekers and refugees would not necessarily perceive their status in terms of tertiary study rights. That being said, no respondents cited the SADC in relation to any of the destination patterns.

Regarding the level of tertiary education of respondents, respondents who had completed or were enrolled in a diploma program most frequently cited "movement to a higher education regime" (three out of 28 respondents) relative to those enrolled at an undergraduate or graduate degree program (three out of 50 respondents) or certificate program at a vocational school (one out of 37 respondents). While these numbers are small and therefore difficult to compare, this represents a departure from what was observed for the first two destination patterns and may stem from the fact that respondents expressing this pattern often cited practical considerations related to fees, admissions criteria, qualifications recognition, and the ability to work in discussing their destination outcomes. Respondents pursuing undergraduate and graduate-level degrees at universities, on the other hand, most often linked their destination outcome with higher education prestige and educational ambitions.

In contrast to the other profile characteristics, the gender distribution of respondents who exhibited this destination pattern was more balanced. Six men (7 percent) and three 
women (4 percent) cited "movement to a higher education regime." This suggests that female respondents coming from the DRC and Somalia are shaping their destination outcomes in relation to higher education in ways comparable to their male counterparts.

The following example reveals how this destination pattern was expressed. In outlining this example, I examine how the respondent's aspirations, norms, and practices - i.e., the dimensions of agency - related to higher education shaped this pattern. Where relevant, I discuss any structural factors cited by the respondent, either directly or indirectly, as impacting his or her agency.

Case 8. Abdullah. ${ }^{45}$ Moving to a country that helps refugees.

Abdullah is a Somali male living in Johannesburg who, at the time of the interview in early 2016, had never enrolled in tertiary education and had been living in South Africa for ten years. Abdullah moved to and sought asylum in South Africa when he was twenty years old. When we met, he had refugee status and identified with the refugee label. Despite his unfulfilled aspirations for higher education, the prospect of tertiary studies nevertheless shaped his movement from Somalia to South Africa. He stated:

"I had heard about South Africa. There are many people from my country [Somalia] in that country. After the war erupted, many people migrated to South Africa. I kept hearing in the news about South Africa, South Africa, South Africa.... Kenya, I didn't try [to reach]. I only tried South Africa because I heard South Africa is a country that can help refugees better than Kenya. They give refugees integration. They say if you come to South Africa, you can study immediately. You can do business or you can study."

Abdullah revealed that prior to his movement, he had received information about South Africa's refugee policies. He learned that not only did South Africa help refugees more, relative to other countries, but also South Africa gave refugees the opportunity to be integrated and study immediately, referring to the fact that he could enjoy these rights as an asylum seeker, waiting for refugee status determination. It appears from Abdullah's narration of his decision-making that he did not carry out research on South Africa's policies on higher education for asylum seekers and refugees. Instead, his repeated reference to having heard about the country's policies suggests that Abdullah received and relied on information through his social networks. Such networks as channels through which Abdullah gained information are a type of resource that featured in his more practical considerations.

${ }^{45}$ All quotes from Idil come from interview: Som_Tech_Never_M_JHB. 
Abdullah had few financial resources at his disposal and so like other respondents with insufficient funds to make the long journey to South Africa, he relied on sponsorship from members of his community. He explained, "There was...a friend, some people who are 'well-wishers,' who helped me with the transport. They didn't travel with me. There was a guy, I didn't know his name, he just brought me to here, to this country, and I paid him." The man who brought Abdullah to South Africa was someone he paid to help him cross the border. The term "well-wisher" refers to someone who provides charity, rather than a loan. Abdullah's overland journey from Somalia was highly indirect and took one month, which also demonstrates the few resources he had.

Another practical consideration that shaped his journey related to language. Prior to his departure, Abdullah had enrolled in an English language course. Describing his decision to learn English, he said, "You know in some major countries, subjects are not taught in any other language apart from English. I studied English because English will boost my... anything and then I can be able to study any subject. I can get an understanding of any subject." Abdullah's account indicates planning and preparation for studying in a country like South Africa, where the language of instruction is English.

We can also see Abdullah's destination outcome based on the asylum and refugee policies related to higher education as being shaped by his aspirations. Abdullah revealed his strong desire to serve his community. He said:

"I need to help the community. Helping the community is my passion that I have had from when I was young up to now. So still up to now my vision has not changed. I have a vision and mission still and I am planning to join university, starting from a bridging course and then going to university."

It appears that when Abdullah talked about service to his community, he was also talking about his family, for he later said that one of his dreams was for all of his siblings to finish university and to leave behind their pastoral livelihoods. Moreover, Abdullah believed that education was the key to achieving his vision of service. He explained, "After education then everything will come. You cannot just be able to go anywhere, you need education. Let's say you want to start a business, you need education. People need to learn and go to school, and they need to improve." By gaining university, Abdullah sought to be a catalyst for his family.

In terms of the norms and values shaping his destination pattern, however, it appears that Abdullah's aspirations largely contravened the norms and beliefs of his family and community. Abdullah grew up in a family of pastoralists. His parents raised cattle and 
camels. They never went to school and only learned oral recitations of the Quran. Describing the beliefs of his parents, he stated:

"You know our parents, they don't have the vision of taking their kids to school. For them it was not important, the school. But for us, who are now living in another country... I am trying to push [my siblings]. I tell them, leave the cows, stop hiding the animals in the bush. Let them even die with the drought. You have to go back to school to study."

Abdullah believes that the only way that his siblings will value education will be if he gets a degree and begins to remit funds back to his family. If he sends them money, he will be seen as the breadwinner and will be thought of as successful. In this way, rather than impede his movement to South Africa, Abdullah's socio-cultural context, in particular the changing and development of that context, works together with his individual aspirations to shape his destination pattern.

\subsubsection{Movement to a labor market}

The destination pattern "movement to a labor market" refers to a destination outcome shaped by the opportunities for employment and other income-generating activities in the destination country. Here, the full range of paid work in the formal and informal labor markets is considered. This destination pattern is included as a pattern related to tertiary education because higher education and employment are often inextricably linked. Tati (2010: 284) argued that "at the place of destination, getting better education is not incompatible with participating in the labor market." In his study on Congolese migrants in South Africa, he maintained that some migrants use higher education as a way to access foreign labor markets, or they work and study simultaneously. More generally, the accounts of Clara and Idil in this chapter's examination of "movement to a higher education institution or sector" and "movement to an anglophone study destination" as well as examples from other respondents provided in these two sections, revealed that respondents' educational aspirations often reflected their career aspirations and vice versa. Therefore, this study argues that examining respondents' destination outcomes through the lens of employment and work is crucial to an understanding of respondents' agency with respect to higher education.

"Movement to a labor market" was the third-most cited of the four destination patterns related to higher education, at 17 respondents or 11 percent of the total sample. When expressing this pattern, respondents discussed moving to a destination country and enrolling in higher education as an investment in their future employment prospects in 
the destination. Higher education was a means to access a particular destination country's labor market. Other respondents expressed this pattern in terms of being able to work and study at the same time in a destination. They had moved to countries which they perceived offered the opportunity to work immediately, so that they could raise the funds for their enrollment and then work part-time throughout their studies. Working alongside their studies was the only way these respondents could gain higher education.

Fourteen of the 17 respondents who cited this destination pattern had moved to South Africa, as compared to two respondents in Uganda and one in Kenya. South Africa boasts a progressive labor market integration policy towards refugees and asylum seekers and the highest levels of development and labor market opportunities in Sub-Saharan Africa. In Kenya and Uganda, challenging labor market conditions exist for asylum seekers and refugees. As mentioned in Chapter Four, Kenya has an encampment refugee hosting policy and few refugees lawfully reside in Nairobi. Moreover, asylum seekers do not have the right to work and refugees in Nairobi may only work if they are in possession of a Class M permit. However, many are unaware of the permit's existence or how to apply for it. Consequently, Kenya's labor market is largely perceived as inaccessible. Of the destination countries, Uganda has the lowest levels of development. Despite a more open policy environment than Kenya, few opportunities exist within the labor market for nationals, let alone refugees and asylum seekers.

Additionally, many of the respondents expressing this destination pattern came from lower socio-economic backgrounds. This stands in contrast to the first two destination patterns, which were exhibited mostly by student migrants who came from relatively higher socio-economic backgrounds, and whose destination outcomes were largely driven by aspirations and norms surrounding higher education institutions and anglophone study options. With this destination pattern, the concern for employment appears driven by practical considerations.

In terms of other profile characteristics, this was the third-most cited destination pattern for both Somali and Congolese respondents, at 11 respondents (16 percent) and six respondents (7 percent), respectively. More striking, the gender distribution of these respondents was highly skewed towards men. This is the first pattern to reveal a great disparity of experiences with respect to gender. For Congolese and Somali youth, males typically have a greater responsibility to be the breadwinners of their families. Indeed, their movements are often sponsored by their families to spread risk and gain a remittance income. This may explain why males comprised 16 of the 17 respondents who described their destination outcomes in terms of employment and work. 
The data reveal a varied distribution with respect to the types of tertiary education that respondents pursued in the destination. Five respondents (18 percent) had completed or were enrolled in diploma programs, three (8 percent) had completed or were pursuing vocational certificates, and six (12 percent) had completed or were enrolled in university degree programs. While the numbers are small and therefore difficult to compare, the larger share of respondents connected to diploma programs may reflect the greater importance of practical considerations for respondents who exhibited this pattern. It may also reflect the more professional and less academic nature of their tertiary studies, which would orient them towards direct employment. On the surface, this potential explanation does not align with the fact that so few respondents pursuing technical or vocational certificates expressed this pattern. However, the in-depth interviews reveal that many of the respondents pursuing certificates did so after a long period of settlement in the destination. These respondents often had more acute displacement experiences and began to pursue technical or vocational programs after receiving support from nongovernmental or international organizations as part of livelihoods-enhancing development programs.

Lastly, in terms of migration status, only refugees (11 respondents), asylum seekers (three respondents), and undocumented migrants (two respondents) expressed this destination pattern. No respondents with more "voluntary" migration statuses cited "movement to a labor market." This is surprising as we might have expected student migrants to have expressed their longer-term employment prospects, or their ability to work and study within a country, in shaping their destination outcomes. The fact that forced migrants exclusively expressed this pattern may stem from their coming from more constrained socio-economic backgrounds. The greater share of asylum seekers (16 percent) than refugees (12 percent) may be linked to the fact that most respondents exhibiting this pattern moved to South Africa.

The following example reveals how this destination pattern was expressed. In outlining this example, I examine how the respondent's aspirations, norms, and practices, that is, the dimensions of agency, related to higher education shaped this pattern. Where relevant, I discuss any structural factors cited by the respondent, either directly or indirectly, as impacting his or her agency.

\section{Case 9. Hassan. ${ }^{46}$ The Prospect of a Good Job}

Hassan is a Somali male who completed an MSc at a university in Johannesburg. At the time of the interview in early 2016, Hassan was a registered refugee in South Africa, but

\footnotetext{
${ }^{46}$ All quotes from Hassan come from interview: Som_Univ_Compl_M_JHB_2. 
did not identify with the refugee label. Back in Somalia, Hassan had completed a BA degree and after graduation, he had started working with a South African NGO providing humanitarian relief in Somalia. After he worked with them for some time, the NGO offered to sponsor his further tertiary studies in South Africa. In shaping his destination outcome, Hassan exhibited both "movement to a higher education institution/s" and "movement to a labor market." Describing his experiences, he stated:

"I did research about the best universities in Africa, and actually at that time, seven out of ten were South African universities. Then I said, I will go to South Africa. It will help me. That was the first choice. And the second choice was, you know, if [my colleagues from the NGO] bring me to South Africa and I finish my degree, they might give me a good job. Then I would stay there and work with them. If I studied in Kampala, I would have to go back home [after my studies]."

The first factor shaping Hassan's decision-making about his movement to South Africa was the quality of the higher education institution and sector. He revealed that he had carried out research on the best-ranked institutions on the continent. The second factor shaping his destination outcome relates to employment prospects with the humanitarian NGO for which he worked in Somalia. Hassan believed that if he accepted their offer of support for his tertiary studies in South Africa, and went on to complete his MA degree, they might offer him a job in South Africa upon his graduation. If we were to study anywhere else outside of Somalia, he would not have the same kind of employment prospects upon graduation.

Understanding the emergence of Hassan's destination outcome in the context of his practical considerations, the humanitarian NGO once again features prominently, as they provided the support that made his long-distance movement possible. Hassan explained:

“That's how I got here, you see. They helped with everything I needed. I gave them copy of my certificate, passport, they arranged everything...they sent me an admission letter from university and a comprehensive scholarship from them saying that they gave me a full scholarship."

This NGO helped Hassan apply to a higher education institution and chose the institution for him, paid for his tuition and accommodation fees, and support his enrollment in a sixmonth English language course prior to his tertiary enrollment. Other practical considerations Hassan faced related to his socio-economic background. Hassan described himself as an orphan, as his father died when he was very young, and as someone who 
was supported by the international aid community throughout his upbringing. In fact, his university education in Somalia was entirely funded by such support and enabled him to qualify for graduate level tertiary studies in South Africa. For him, employment, especially with an international NGO, represented an invaluable opportunity. He had no familial safety net or financial resources of his own. Securing his future and providing for his livelihood was paramount to any other consideration.

In terms of Hassan's aspirations, he explained that when he graduated from university in Somalia, he was considering shifting his career trajectory from one that was business oriented to one focused on international aid and development. He applied for a job with the South Africa humanitarian NGO to get a sense for working in this field and, since then, his ambitions have been to work in this sector. Speaking of his career aspirations and plans for the future, Hassan said:

"I want to work at an international organization like the United Nations, European Union, or African Union, you see. When I finished my degree, I saw my future career as working for an international NGO. I said I am not going to business work. I want to work as a political officer. The problem I have now is that I don't have much experience with real work, you see, in fragile states or post-conflict governance system. There is a United Nations mission in Somalia. That's my plan to return."

Thus, the possibility of continuing and advancing his work with the NGO after graduation in South Africa aligned with Hassan's aspirations to have a career in the field of international politics and conflict resolution.

Regarding the norms and values that shaped Hassan's destination outcome, he said that he remembered his mother encouraging his schooling when he was very young. He also remembered that neither of his parents had received any formal schooling. Hassan explained that he was seen as successful by those back in Somalia not because of his higher education, but because he regularly sent remittances back to his mother. This suggests that Hassan's community values employment and income more than it values higher education for its own sake. Over the course of the interview, Hassan's community and upbringing featured sparingly in his narration of his educational and movement trajectories, perhaps revealing that his more practical considerations and individual aspirations played a stronger role in shaping his destination outcome. 


\subsection{Putting Findings into Context: Non-Exhibitors and Never Enrolled}

Having identified and examined the different ways in which respondents shaped the destination of their international forced displacement in relation to higher education, this chapter now explores the destination outcomes of respondents who similarly pursued higher education in asylum countries, but for whom higher education considerations were absent in the shaping of their destination patterns: I call this group "non-exhibitors." This section also examines the destination outcomes of respondents who never enrolled in higher education programs in asylum countries. Taken together these elements provide some basis of comparison and context for the higher education insights identified on the destination of movement.

By examining the destination outcomes of respondents who ultimately pursued higher education but who expressed no agency related to higher education in shaping their destinations, this section seeks to better understand how higher education considerations emerge in this dimension of the displacement process. Respondents who did not exhibit any of the destination patterns represent just over half of the total sample (80 respondents) and just under half of those with some form of tertiary education (54 out of 115 respondents). The data on the forced displacement destination outcomes of respondents who ultimately pursued higher education in countries of asylum, but who expressed none of the destination patterns related to higher education, reveal two key themes. First, as with the data on the timing of respondents' movement, a significant share of these respondents engaged in more acute movements, wherein their practical considerations were highly constrained by the conflicts and crises they fled. Some of these respondents described being physically moved owing to injury or sickness and having no choice with respect to their destination outcomes. Others described moving to a destination with a perceived openness toward refugees or to the nearest international destination offering safety. One such respondent from the DRC explained:

"When I lost my parents, I tried to stay in Congo but I could not stay because of war... I even tried to move from to another town, but still I felt insecure. The easiest way was to come to Uganda because Uganda was near, and I couldn't afford the transport at that time. I decided to come to Uganda and not any other country." 47

For this respondent, staying close to his origin country was both "easy" and affordable. Practical considerations related to distance and safety appeared to drive his destination

\footnotetext{
${ }^{47}$ This quote comes from interview DRC_Univ_Enroll_M_Kla_5.
} 
outcome, rather than any aspirations, norms, or more practical considerations associated with higher education. For another Congolese respondent, while Uganda was geographically the nearest country, he did not perceive it as safe because it was too close to the conflict from which he was fleeing. This respondent stated, "I came to Kenya because I wanted to go far away, Uganda is too near. We still shared a border with South Kivu, which is terrible. I decided to go far away from there." ${ }^{48}$ Security and distance are dominant features of this respondent's practical considerations. Aspirations and norms related to a destination country or related to higher education are absent.

Not surprisingly, for these more acute movers, practical considerations constrain the destination outcome and eclipse the expression of other aspects of agency. For respondents to shape their destination outcomes in relation to their higher education norms, aspirations, and more practical considerations, the conflict-related constraints they face in their origin countries cannot be too great. This aligns with the findings on the timing of respondents' movements. However, the threshold of constraints for respondents' destination outcomes appears higher than for the timing of movements. Fewer respondents experienced high constraints on their destination outcomes than their timing. This might indicate that respondents' agency is in flux; after their initial acute exit, respondents may regain some of their ability to express their agency in shaping their destination outcome. This might also suggest that in the process of forced displacement, the destination of movement is more easily shaped than the timing of exit.

The second main theme arising from the data on the destination outcomes of nonexhibitors is the importance of social networks in destination countries. Many respondents shaped their movements according to where they had family, friends, or distant contacts. On a practical level, respondents perceived the presence of social networks as a crucial source of information and of support for integrating into a new country and society, navigating the asylum system, and gaining employment or housing. On a normative level, social networks provided respondents with a community and system of social support. For many young female respondents, the presence of family or kin in the destination provided them with the opportunity to move away from their homes and parents in a culturally acceptable way. Non-exhibitors who cited the importance of social networks in shaping their destinations did not describe any strong aspirations and norms related to tertiary education. The importance of social networks is not exclusive to non-exhibitors. Many respondents who expressed one or more of the destination patterns related to higher education also described the presence of family, friends, or other contacts in a destination country as a feature shaping their destination outcome. Taken together, the two themes expressed by non-exhibitors reveal that for

${ }^{48}$ This quote comes from interview DRC_College_Enroll_M_NBO. 
tertiary education to feature in respondents' destination outcomes, the combination of aspirations or norms related to tertiary education and some degree of capabilities unimpeded by constraints must be present.

Turning to examine the profile of non-exhibitor respondents to gain insight into why or how higher education considerations did not emerge, several patterns may be observed with respect to respondents' countries of destination, type of tertiary education, countries of origin, gender, and migration status. The largest share of non-exhibitors who gained tertiary education within a destination country was in Kenya, at 25 out of 29 respondents. South Africa and Uganda, on the other hand, had similar shares of non-exhibitors at approximately one-third of their respective samples. This reinforces what we have learned about the macro-level forces shaping movements to these countries. Kenya has the least favorable asylum policies related to higher education and employment, the fewest opportunities for enrollment within its tertiary education sector, and its higher education sector is the lowest-ranked of the three destination countries. Hence, we would expect that movements to Kenya would be the least likely to exhibit destination patterns related to higher education. By contrast, South Africa and Uganda have highly regarded higher education sectors. We might have expected South Africa to have a lower rate of non-exhibitors than Uganda, given its favorable asylum policies related to higher education and employment. Also, of the three destination countries, South Africa is the farthest away from Somalia and the DRC. Consequently, one might have anticipated that movements to South Africa would be more likely to reflect higher education norms, aspirations, and practical considerations.

Regarding the type of tertiary education that non-exhibitors pursued, 27 respondents (73 percent) completed or were enrolled in technical certificate programs. This stands in stark contrast to the 28 percent who pursued university degrees (14 respondents) and 46 percent who pursued college diplomas (13 respondents). The in-depth interviews shed light on why the largest share were those pursuing technical programs. Many of these respondents pursued their programs after a long period of settlement in the destination. These respondents often had more acute displacement experiences and pursued their tertiary programs after receiving support from a development organization. Hence, tertiary education considerations generally did not feature in the shaping of their destination outcomes. In contrast, the relatively low share of non-exhibitors among respondents pursuing university degrees suggests that for respondents who (successfully) seek out this level of tertiary studies, higher education factors related to the destination country largely did feature in the shaping of their displacement patterns. 
In terms of origin country, 33 of the 61 respondents from the DRC were non-exhibitors who gained higher education versus 21 of the 54 respondents from Somalia. For Congolese respondents, non-exhibitors outnumbered exhibitors, while the reverse was true for Somalis. The greater share of Congolese non-exhibitors may stem from the nature of conflict and crisis in Eastern DRC and that many of the non-exhibitors had more direct experiences with conflict and engaged in more acute movements. By contrast, fewer respondents from Somalia had acute experiences with conflict at the time of the movement, allowing for a greater degree of agency in determining a destination country.

The gender distribution of non-exhibitors reveals a slight tendency towards female respondents not expressing a destination pattern related to tertiary education. Thirty women (57 percent) versus 24 men (39 percent) were non-exhibitors who gained tertiary education. While the gender distributions for the patterns "movement to a higher education institution or sector," "anglophone study destination," and "higher education regime" were largely balanced, the highly-skewed distribution of "movement to a labor market" towards male respondents explains the skewed distribution of non-exhibitors towards female respondents. As a result, female respondents who gained tertiary education are more likely to be non-exhibitors because they did not shape their destination outcomes in relation to tapping particular labor markets.

In terms of migration status at the time of this study's interviews in 2015 and 2016, most non-exhibitors were refugees and a small minority were student migrants. Forty-three refugees (65 percent) were non-exhibitors who gained higher education, as compared to two student migrants (8 percent). The largest share of non-exhibitors being forced migrants is not surprising given that many engaged in more acute movements. What is surprising is the existence of a small number of student migrants, who moved to Kenya and South Africa and who did not express a destination pattern related to tertiary education. Respondents with a student migrant status by definition should express some agency related to higher education in shaping their destination outcomes, as their status is based on their enrollment in higher education. Upon examining their narratives of their higher education and movement trajectories, all of these respondents emphasized that while they were committed to studying abroad, they had no plan to study in a particular country or institution. Rather, the presence of social networks in a destination country shaped their destination outcome. Moreover, for this study's destination countries, it is possible to obtain a student migrant status after one's arrival to the country. This highlights the fact that enrollment in higher education is not sufficient to assume that it played a role in the destination outcome.

Turning to examine the destination outcomes of respondents who never enrolled in any higher education, this section seeks to understand the extent to which the observed 
higher education patterns are unique to respondents pursuing higher education. We might expect that all of the respondents who never enrolled in any form of tertiary education were non-exhibitors. On the contrary, the data reveal that eight out of the 34 respondents who never-enrolled, exhibited at least one of the destination patterns related to higher education (see Figure 46).

\section{Figure 45: Destination Patterns of Respondents who Never Enrolled in Higher Education}

\begin{tabular}{lr}
\hline \multicolumn{1}{c}{ Higher Education Destination Pattern } & $\begin{array}{c}\text { Respondents who Never Enrolled in } \\
\text { Higher Education (N=34) }\end{array}$ \\
\hline Movement to a Higher Education Institution or Sector & 5 \\
Movement to an Anglophone Study Destination & 3 \\
Movement to a Higher Education Regime & 2 \\
Movement to a Labor Market & 3 \\
Exhibited 1+ Higher Education Pattern & 8 \\
Exhibited 0 Higher Education Patterns (Non-Exhibitors) & 26
\end{tabular}

The case of Abdullah, outlined in the section on "movement to a higher education regime," demonstrates that the respondent never enrolled in any form of tertiary studies, yet he had strong aspirations for tertiary education, which shaped his displacement outcome, as well as the desire to change the negative norms and values related to tertiary education held by his family and community. For Abdullah, his high aspirations for tertiary education combined with his ability to mobilize resources for his journey from Somalia to South Africa were sufficient to shape his movement. While he did experience negative norms in relation to tertiary education, they did not impede his movement. Instead, his desire to change them to benefit younger members of his community further fueled his aspirations. Abdullah's accounts of his movement and educational trajectories reveal that "movement to a higher education regime" is a destination pattern that is not unique to those who gain tertiary studies.

Extending this same logic to the other destination patterns related to higher education, it follows that "movement to a higher education institution or sector," "movement to an anglophone study destination," and "movement to a labor market" are also not exclusive to individuals who gain higher education in the destination. Indeed, a Congolese female respondent named Mary ${ }^{49}$ who moved to Cape Town and has not enrolled in any tertiary

\footnotetext{
${ }^{49}$ All information from the respondent comes from interview DRC_Univ_Never_F_CT.
} 
studies in South Africa expressed "movement to a higher education institution or sector." Mary explained that since she could remember she had wanted to move to South Africa, and that it was her dream country in which to study. Moreover, she had contacts in South Africa who said they would help her secure a bursary to finance her higher education. After completing her BA degree in Lubumbashi, she decided to move to Cape Town to pursue an MA degree. While she did not have a specific institution in mind and had not applied to any institutions in advance of her movement, she did move to a particular country's (South Africa's) higher education sector. However, while en route, she lost all of her educational transcripts and certificates. Unable to tell her family that she had lost her educational documentation, for they had not wanted her to study abroad, she remained in South Africa, applied for asylum, and took up a lower-skilled, minimum wage job. At the time of the interview, more than ten years after her arrival in South Africa, Mary had received support from a local non-governmental organization to obtain proof of her educational qualifications and get them recognized by South Africa's Qualifications Authority. Her plan in the near future was to apply for an MA program.

Mary's situation revealed that having the aspiration to study within a destination country's higher education sector and having the resources to move were sufficient to exhibit "movement to a higher education institution or sector." In her case, as in the case of Abdullah, negative norms related to studying abroad did not deter her movement, although they did deter her from seeking help once she lost her documentation. Unlike Abdullah, Mary had secured the resources to study at the time of her move. From these two cases and the other cases of respondents who never-enrolled, it appears that having higher education and/or employment aspirations is crucial in the expression of a destination pattern related to tertiary education. Moreover, it appears that the type of aspiration, whether it involves studying at a particular institution or in a particular language, is crucial to which destination pattern is expressed.

It is possible that this same logic extends to norms, for instance if a respondent's destination outcome was shaped by his or her desire to study in the country or at the institution where all of his or her family members studied, or if obtaining an anglophone degree was highly valued by a respondent's family. However, few such instances exist in the narratives of respondents. Norms outside of higher education played a strong role in shaping the destination country and/or city for many respondents. For instance, for many female respondents, the destination outcome was shaped by where they had kin abroad, as they were unable to live by themselves and travel outside of family networks.

Practical considerations influenced the emergence of destination patterns in two important ways. First, for respondents who never enrolled as well as those that did, they had to have some minimum level of capabilities to complete their journeys to destination 
countries. In this way, capabilities enabled the expression of higher education destination patterns. The case Abdullah, who came from a family of pastoralists and was the first among them to complete high school, revealed that even respondents coming from lower socio-economic backgrounds can have sufficient capabilities. Second, practical considerations can also play a prominent role in shaping the expression of higher education destination patterns; "movement to a higher education institution or sector" and "movement to a labor market" grew out of the opportunities and constraints that respondents created for themselves. For instance, respondents secured admission to a higher education institution or secured employment in advance of movement, which influenced their movement to a destination city. The patterns "movement to an anglophone study destination" and "movement to a higher education regime" are reliant on more macro-level conditions that may not be negotiated by respondents. Practical considerations come in to play for these two latter patterns mainly in terms of respondents obtaining and evaluating information on the linguistic or policy options in potential destinations.

In a divergence from what was observed for the timing of movement, more respondents who never enrolled in any form of tertiary education expressed a destination pattern related to higher education. While the majority of respondents who never enrolled were non-exhibitors, this majority is smaller than for the timing of movement. This suggests that respondents who exhibited a timing pattern were more likely to go on to enroll in higher education and perhaps had more formalized plans for enrollment than respondents who only exhibited destination patterns. This is likely the case as timing patterns were more rooted in respondents' present circumstances, while destination patterns were more rooted in what respondents desired for their futures.

\subsection{Implications and Conclusions}

Analyzing the narrative data on the destination outcomes of Congolese and Somali respondents revealed four destination patterns related to higher education. They are:

1. Movement to a higher education institution or sector

2. Movement to an anglophone study destination

3. Movement to a higher education regime

4. Movement to a labor market

These patterns are not independent of each other and many operated together to shape respondents' destination outcomes. They demonstrate that tertiary education considerations can play multiple and multidimensional roles in how certain refugees and 
migrants negotiate their destination outcomes. This is important because it underscores that educational and employment opportunities factor into the choice of destination alongside or as part of safety and security concerns.

The destination patterns and their associated insights on migrant and refugee agency in the context of higher education align with many of the destination drivers identified by the international student migration literature, suggesting that these "voluntary" migration dynamics inform and overlap with forced migration dynamics. Similarly, this chapter showed that "voluntary" dynamics related to the destination of movement can extend to refugees and migrants coming from areas of conflict and crisis. For instance, "movement to a labor market" and "movement to a higher education regime" reflect what Tati (2010) and Rafi and Lewis (2013) observed regarding the impact of labor market opportunities and student visa policies for the destination decisions of student migrants. "Movement to an anglophone study destination" confirms Baláž and Williams's (2004) finding that anglophone countries are especially attractive to international students as learning English and obtaining English degrees are perceived as being beneficial to tapping into international labor markets. Further, "movement to a higher education institution or sector" aligns with studies by King and Raghuram (2013) and Tati (2009), which highlighted the recruitment function of higher education institutions and the role they play in structuring migration processes.

Turning to discuss the profiles of respondents, this chapter revealed that male and female respondents shaped their destination outcomes in relation to higher education in similar ways, except when movements were guided by the prospect of tapping into a destination country's labor market. Respondents who pursued university degrees and college diplomas tended to express destination patterns more than their counterparts who pursued certificates at technical schools. The same was observed for respondents who had student visas versus those with humanitarian statuses in the destination country. In terms of origin country, Somali respondents tended to express destination patterns related to higher education more than their Congolese counterparts.

Examining how destination patterns emerged through respondents' tertiary education aspirations, norms, and practical considerations also revealed insights about how respondents interacted with their structural environments, perceived language as a factor in their destination outcomes, experienced socio-cultural norms, and moved directly or indirectly to their destination countries. In terms of respondents' structural environments, the respondent cases demonstrated a strong alignment between what respondents experienced and perceived on an individual and community level and what factors and trends were operating on a macro level in destinations. For instance, the largest share of respondents who moved to a higher education sector or institution, 
regime, and labor market moved to South Africa, which is the destination country with the best-ranked higher education institutions, the higher education sector with the greatest capacity, the most progressive higher education policies, and the most developed and differentiated labor market. By contrast, respondents who moved to Kenya expressed the fewest destination patterns and represented the majority of non-exhibitor cases. Of the three destination countries, Kenya's higher education sector faces the greatest constraints and its higher education policies for refugees and asylum seekers are the least accommodating.

In terms of language, the narrative data showed the aspirational role that language can play in shaping the destination outcomes of refugees and migrants pursuing higher education. While the majority of respondents were not fluent in English prior to their arrival to Kenya, South Africa, or Uganda, and many had no prior experience with English language instruction, respondents did not perceive this as an obstacle to their movement. Instead, English was a criterion upon which their destination outcomes were based because they perceived English as a language that would create opportunities and enable the pursuit of certain professions.

This chapter also further illuminated how socio-cultural norms function as a part of respondents' agency to shape their destination outcomes. Norms can have a reinforcing role, for instance, when strong community values towards higher education promote or discourage an individual's positive or negative aspirations, respectively. On the other hand, this chapter highlighted several cases in which negative norms or values promoted positive individual aspirations. In so doing, the agency of respondents did not simply amount to the contravention of norms, rather the negative norms took on an unexpected positive force. For instance, the narratives of Idil and Abdullah showed that a family and/or community's discouragement of education led to respondents' desires to change the deeply rooted norms of their societies.

In terms of the directness of journeys to destination countries, this chapter showed that some respondents travelled in a single day, while others spent months or years from the time they left their origin country to the time they arrived in the destination. For respondents with more indirect journeys, in some cases their destination outcomes evolved over the course of their movements while in others, their destination countries were fixed but respondents had to stop and earn money en route to continue their movement. This study observed direct and indirect movements within all four destination patterns. Not surprisingly, the indirect journeys with longer time-frames were largely confined to movements to South Africa, given the proximity of Uganda and Kenya to the DRC and Somalia. 
Putting the aforementioned findings into context, this chapter analyzed the higher education and movement trajectories of respondents who pursued higher education in destination countries, but who did not exhibit any of the destination patterns, as well as respondents who did not enroll in any form of higher education in the destination. In the case of the former, this chapter found that not all refugees pursuing higher education shaped their destination outcomes with respect to higher education. For some respondents, the circumstances of their flight were too acute to express any aspirations, norms, or practices related to higher education in negotiating their destinations. In such situations, respondents were either physically moved to a destination or crossed the nearest international border. In other words, there has to exist some space in which to express agency for higher education considerations to emerge. This chapter also found that in situations in which respondents had strong social networks in the destination combined with dominant socio-cultural norms, these norms outweighed any other norms or aspirations and practical considerations related to higher education.

For the respondents who never enrolled in higher education, but nevertheless exhibited a destination pattern, all had higher education and/or employment aspirations rooted in their destinations. Moreover, the type of aspiration that respondents held, whether it was to study at a particular institution or in English, was crucial to which destination pattern/s they expressed. Hence, aspirations shaped whether respondents exhibited a destination pattern and which pattern they exhibited. Practical considerations played the same dualrole of determining and structuring. Capabilities "unlocked" respondents' abilities to express higher education destination patterns. How respondents created or encountered and evaluated opportunities and constraints at the micro versus macro level shaped which destination pattern/s they expressed. This finding on the role of aspirations and capabilities within respondents' expressions of agency aligns with de Haas' (2014) aspirations and capabilities framework. 
CHAPTER 8

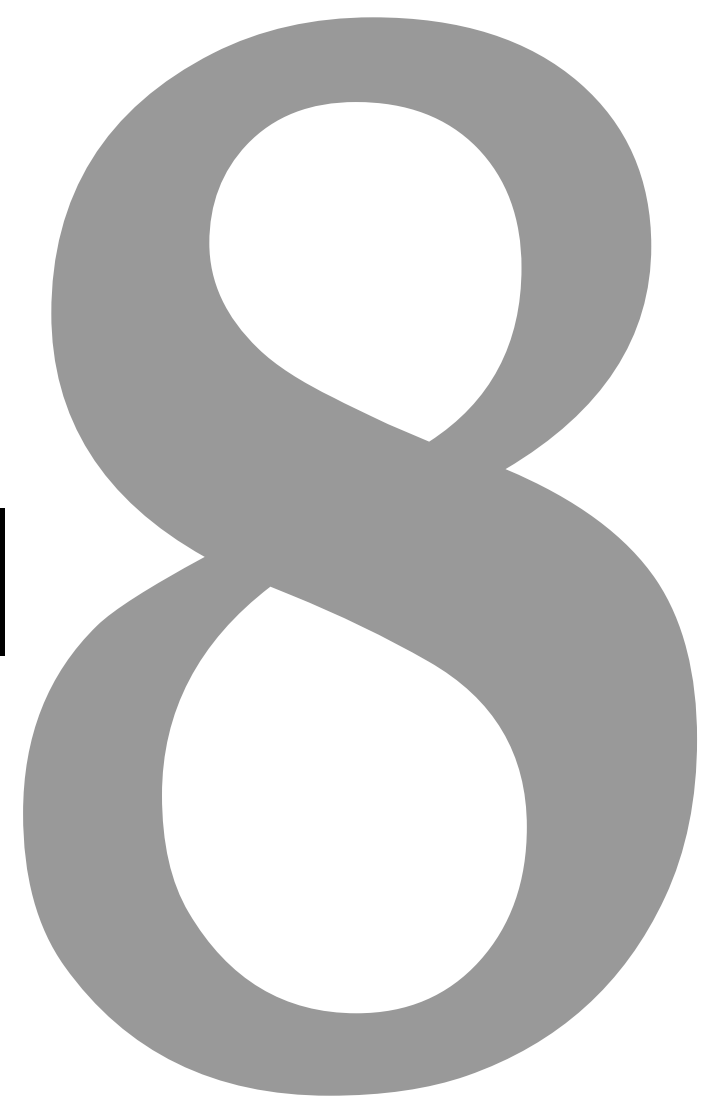




\section{Channels of Entry and Settlement}




\subsection{Introduction}

While Chapters Six and Seven explored when respondents moved and where they moved, this chapter considers how they moved or the legal conditions of their entry and settlement in destination countries. Thus, this chapter aims to understand the roles played by tertiary education in impacting the legal or irregular channel of respondents' entry and settlement and to consider how these roles were shaped by respondents' agency. This is important because channels determine how refugees and migrants access protection and socio-economic rights. Channels of entry and settlement can be considered from a diverse array of perspectives and analytical levels. Chapter Two revealed that the channel within which refugees and migrants enter and settle may be influenced by macro-level socio-economic and political factors, such as the refugee hosting policy or migration and asylum policies related to higher education and employment. When such factors serve to constrain access to a particular channel and/or open up opportunities to enter into another channel, this can lead to displacement effects between channels, or what Czaika and De Haas (2013) refer to as "substitution effects." At the individual level, the legal or irregular statuses that refugees and migrants acquire may be shaped by their desire to achieve greater freedom of movement, seek out goods and opportunities, and enhance their social mobility and self-identity. The findings presented in this chapter mirror the diversity within the literature and go a step further by exploring the processes linked to agency through which different patterns on channels of entry and settlement emerged. These patterns were inductively constructed based on respondents' narratives of their movement and higher education trajectories.

This chapter begins by defining the channels of entry and settlement. It then presents and examines three patterns related to tertiary education that emerged from respondents' narratives of their movement and higher education trajectories and analyzes the emergence of these patterns through their aspirations, norms, and practical evaluations. To provide some basis of comparison and context for the higher education insights identified, this chapter also examines cases in which higher education did not play a role in shaping the channels of respondents who went on to gain higher education in destination countries, as well as cases in which higher education did play a role in the entry and settlement channels of respondents who never enrolled in higher education.

\subsection{Defining the Channels of Entry and Settlement}

This chapter defines the channels of entry and settlement as the legal or irregular means through which Congolese and Somali respondents arrived and/or settled in a destination country. The channel not only encompasses the migration status that respondents 
adopted, but also the legal pathways, procedures, and rights connected to a given status that respondents traversed. For a respondent who entered Kenya as an asylum seeker, the channel refers to his or her humanitarian status as well as the conditions, rights, and procedures of that status, including the logistics of the registration and renewal of his or her asylum claim, the refugee status determination process, the settlement in a refugee camp, and the right to non-refoulement and international protection, to name a few.

Entry and settlement channels have both temporal and spatial dimensions. The same channel may change over time alongside shifts in policies and political cycles within a destination country. Also, channels may afford both entry and settlement, while others, such as a tourism or asylum channel, are mainly for the purposes of entry and temporary settlement. Of course, it must be recognized that in this study's destination countries, the processing times for refugee status determination can be severely delayed, prompting the asylum-seeking channel to become one of settlement as well. As mentioned in other parts of this study, this was the case for several respondents who had been living in their destination countries for years as asylum seekers. Channels are spatial because they are context-dependent. An asylum channel in Kenya is qualitatively different from an asylum channel in South Africa, given the different rights and procedures these countries link to the asylum seeker status.

As has already been implied, channels include "voluntary" legal statuses and pathways, such as student migration or labor migration channels, as well as forced statuses and pathways, such as asylum and refugee channels. They also include movement through irregular or illegal means, in the case of respondents entering and settling in a destination country as undocumented migrants. Additionally, some respondents moved through a single legal channel in entering and settling in a destination country, while others moved through several channels over the course of their time in a destination country. This study also observed a small number of respondents who moved within more than one channel at the same time during their stay in a destination country, following their attainment of different identity documents. Respondents with indirect movement trajectories may have moved through channels in other countries, prior to their arrival in the destination country. This chapter, however, shall focus on only those channels that respondents used to enter and remain in Kenya, South Africa, and Uganda.

\subsection{Findings: Key Channel Patterns Related to Higher Education}

Tertiary education considerations impacted how Congolese and Somali respondents negotiated legal or irregular channels of entry and settlement in three main ways. These include respondents': 
1) Entering student or humanitarian channels to access tertiary education,

2) Avoiding humanitarian channels to access tertiary education, and

3) Switching channels to access tertiary education and employment.

Unlike the patterns related to the timing and destination of movement, which were defined by specific aspects of tertiary education arising from conditions in this study's sending and receiving countries, the patterns on channels are constrained by the fixed legal categories and policy regimes of destination countries. The channels that respondents in this study moved within and through include asylum, refugee, student, labor, family, tourism, and undocumented channels. As mentioned previously, they are context-dependent; hence, it is not sufficient to examine which channels respondents interacted with, but how they exercised their agency in relation to higher education to negotiate these channels.

Additionally, these three patterns operate at different periods of time, with the first two largely confined to the channels that respondents used to enter a destination and the third confined to the channels that respondents used to settle in a destination over the longerterm. Hence, the first two patterns are not mutually exclusive, for entering a channel may have meant avoiding another. Some respondents exhibited all three, albeit at different times, over the course of negotiating their arrival and settlement in a destination country. The following sections discuss each of these inductively-derived patterns in turn, including how these patterns were formed from respondents' aspirations, norms, and practices related to higher education, and also the profiles of respondents who exhibited these patterns. Hence, the cases outlined below are intended to illustrate the processes behind the patterns.

\subsubsection{Entering student or humanitarian channels to access tertiary education}

The pattern "entering student or humanitarian channels to access tertiary education" refers to respondents' opting into a particular migration or humanitarian legal status and its associated procedures and rights to obtain tertiary education. Access may result from respondents gaining the right to study in a destination country, receiving lower tuition and other costs associated with enrollment, or becoming eligible for scholarship opportunities, for example. Opting in requires that respondents expressed a conscious and targeted selection of a status, wherein educational access considerations featured. As will be explained in the next section, moving within an irregular channel does not qualify as opting into that channel, particularly for the purpose of accessing tertiary education, but instead represents the avoidance of other channels. 
Moreover, opting into a particular channel describes the legal pathway that respondents used to enter a destination country and also the first legal pathway that respondents used to remain in a destination country, should the entry channel have been a temporary one. Opting in does not describe switching between channels. This distinction is important because in entering a channel, respondents moved from a condition of being without international protection and/or rights as a foreigner, to a condition of receiving protection and enjoying rights. In the case of channel switching, respondents moved from one protection and rights regime to another.

"Entering student or humanitarian channels to access tertiary education" was the mostcited of the three channel patterns related to higher education, at 51 respondents or 34 percent of the total sample. When expressing this pattern, the majority described opting into either asylum channels (22 respondents) or student channels (26 respondents). Asylum seekers who expressed opting in represent 19 percent of all respondents who entered their destination countries as asylum seekers. For entrance or settlement through a humanitarian channel to be classified as opting in, it is not enough that a destination country had a favorable higher education policy for asylum seekers and/or refugees. Respondents must have expressed awareness of the policy or the desire to pursue higher education through the channel. Through their narrations of their movements and educational trajectories, some respondents explained that entering asylum channels provided them with greater flexibility in pursuing higher education. For instance, it allowed them to enter destination countries in advance of admission and apply for higher education programs from the destination. Asylum channels also provided respondents a route to study in the destination when the costs of entering a student channel were too high. Additionally, other respondents cited the ability to access the labor market through asylum channels. They spoke of having to enter asylum channels despite their intention to move through student channels because other family members who lived in the destination and who had arrived first, had asylum seeker status. Such respondents were required to remain in the destination under the same status.

In the aforementioned examples, respondents perceived that the high constraints in "voluntary" channels gave them little choice but to enter and settle through asylum channels. However, the conscious and targeted selection of a humanitarian status does not mean that these respondents had exploited a channel for which they did not qualify. On the contrary, the respondents in this study came from communities impacted by conflict and crisis. They had "made use" of asylum channels because conflict and crisis in their home countries had constrained their abilities to study and work; for them, crossing an international border meant becoming a refugee. 
Seventeen of the 22 respondents who expressed this pattern by entering an asylum channel had moved to South Africa, which represents 34 percent of all the respondents in South Africa who entered the country as asylum seekers. Five respondents had moved to Uganda, representing approximately 17 percent of all respondents in Uganda who entered as asylum seekers. None of the respondents had moved to Kenya. Kenya's lack of respondents exhibiting this pattern aligns with the fact that the country has neither attractive policies for asylum seekers or refugees pursuing higher education, nor a highly regarded tertiary education sector, relative to the other two destination countries. South Africa's majority share of respondents reflects its favorable tertiary education policies for asylum seekers and refugees and the high costs and limited opportunities in accessing student channels. This suggests the presence of substitution effects between South Africa's student and asylum channels, for migrants and displaced persons coming from countries impacted by conflict and crisis.

Turning to examine student channels, all 26 respondents who expressed this pattern by opting into a student channel, entered their destination countries as student migrants. At its core, the act of becoming a student migrant is an act of opting in because enrolling in tertiary education - at a particular institution and in a particular program - is the fundamental condition for obtaining a student migrant status. Thus, the distribution of "entering a student channel to access tertiary education" across the destination countries is a direct reflection of the number of respondents who were student migrants in these countries. Uganda had the greatest number of student migrants (16 respondents), followed by South Africa (seven respondents), and Kenya (three respondents). This is somewhat surprising as we might have expected South Africa to be the destination country with the most student migrants based on its tertiary education reputation and the fact that respondents moving to South Africa tend to come from higher socioeconomic backgrounds. That being said, if we consider the higher barriers to entry to its student channel (with its high costs, requisite medical exams, and high standards of academic equivalency), relative to the student channels of other countries and relative to the other channels within South Africa that provide tertiary education opportunities, then this counter-intuitive finding reinforces the presence of substitution effects.

Not all respondents who expressed this pattern enrolled directly in degree or diploma programs at universities and colleges. A number of respondents entered student channels by first gaining admission to English language certificate programs in the destination. Upon completion, respondents applied for more-advanced tertiary programs and then attempted to renew their student visas. Through their narrations of their movements and educational trajectories, respondents described entering student channels as a costly and time-consuming process that involved securing and paying for medical coverage, getting medical examinations, paying for the application process, getting their previous 
qualifications recognized, and verifying their admission into an approved tertiary education program. Given the barriers to entry, several respondents described being "fortunate" to have entered student channels, or having the "choice" or opportunity to enter a student channel rather than a humanitarian channel. Such respondents came from higher socio-economic backgrounds or were able to mobilize the necessary resources.

In terms of the profile of respondents who expressed this channel pattern, a fairly even distribution exists across gender and origin country, irrespective of whether they entered student or asylum channels. Twenty-two women versus 29 men and 25 Congolese versus 26 Somalis entered channels to access tertiary education (Figure 47). This suggests that female respondents coming from the DRC and Somalia are shaping their entry and settlement channels in relation to higher education in ways comparable to their male counterparts. In terms of the type of higher education, the rate of expressing this pattern increases with the level of academic achievement, irrespective of whether respondents entered student or asylum channels. Five respondents (14 percent) pursued certificates, 11 (39 percent) pursued diplomas, and 32 (64 percent) pursued university degrees. This trend stems from the fact that universities tend to attract and actively recruit international students more than colleges and technical students. For respondents who entered asylum channels to access higher education, the meaning behind this trend is less clear. It is possible that respondents who pursued university degrees had more concrete education plans, higher tertiary education aspirations, and were better able to mobilize their resources than their counterparts seeking out certificates and diplomas. Moreover, in the case of South Africa, those pursuing university degrees through the asylum channel experienced greater relative benefits than those pursuing diplomas or certificates, in terms of the differences in fees for international students and asylum seekers.

Figure 46: Respondent Profiles: Entering Channels

\begin{tabular}{|c|c|cc|c|c|c|}
\hline \multicolumn{2}{|c|}{ Gender } & \multicolumn{2}{c|}{ Origin Country } & \multicolumn{3}{c|}{ Type of Higher Education } \\
Women & $\begin{array}{c}\text { Men } \\
(\mathbf{6 8 )}\end{array}$ & $\begin{array}{c}\text { DRC } \\
(\mathbf{8 1})\end{array}$ & $\begin{array}{c}\text { Somalia } \\
\mathbf{( 8 1 )}\end{array}$ & $\begin{array}{c}\text { Certificate } \\
\mathbf{( 6 8 )}\end{array}$ & $\begin{array}{c}\text { Diploma } \\
\mathbf{( 2 7 )}\end{array}$ & $\begin{array}{c}\text { Degree or } \\
\text { Higher } \\
\mathbf{( 5 0 )}\end{array}$ \\
\hline $22(32 \%)$ & $29(36 \%)$ & $25(31 \%)$ & $26(38 \%)$ & $5(14 \%)$ & $11(39 \%)$ & $32(64 \%)$ \\
\hline
\end{tabular}

The following example delves deeper into how this channel pattern was expressed. In outlining this example, I examine how the respondent's aspirations, norms, and practices - i.e., the dimensions of agency - shaped his entering into an asylum channel to access tertiary education. Where relevant, I discuss any structural factors cited by the respondent, either directly or indirectly, as impacting his or her agency. 


\section{Case: George. ${ }^{50}$ Finding a way to get education}

George is a Congolese male who completed a BA program at a university in Cape Town. At the time of the interview in early 2016, he was a registered refugee in South Africa and had recently started an MA program. To understand George's entering into an asylum channel to access tertiary education, it is necessary to begin with his initial displacement from the DRC and to explore the evolution of his aspirations, norms, and more practical considerations. In 2000, just after finishing high school in Ituri province, George's family was killed during an outbreak of inter-ethnic violence. His parents had been from different ethnic groups that had been in conflict with each other, which had caused them to be targeted. He fled alone, as a youth and with no resources, across the border to Uganda, where he received refugee status and settled in Kyangwali Refugee Settlement. He explained, however, that he did not stay long in Kyangwali because "I realized that my aspiration for education was limited."

"By that time there were no schools established in Kyangwali...so I thought, if I stay in this refugee camp, my life will revolve around the refugee camp and I might never go far. My losses [acute conflict experience and displacement] should not be an impediment to my personal progress. So, we - I along with some Congolese refugees who were older than me - escaped the refugee camp and found ourselves on the streets of Kampala."

George fervently believed in the ability of education to improve his circumstances and was acutely aware of the limited educational opportunities available in the refugee settlement. George came from a well-educated family, with strong education norms. Both of his parents had received university degrees and worked in well-regarded professions. They had instilled in him the importance of gaining an education. For his own part, since he was a child, George described himself as "passionate about becoming this greater lawyer and diplomat." He explained that he had always had high aspirations for tertiary education. Even at the early stages of his displacement process, his aspirations and norms related to higher education shaped his movement, as did his constrained capabilities.

In Kampala, George completed an English language non-formal education course, found a job, and built up savings. He then moved to Nairobi in search of better work and educational opportunities. While in Nairobi, he re-enrolled in high school because, "I wanted an English high school diploma. Also, remember when I said earlier that I had left everything [in Congo]? My transcript and high school certificate papers? I could not prove that I had completed high school." However, providing for his livelihood proved too difficult in Nairobi, so George returned to Kampala before he could graduate, and

${ }^{50}$ All quotes from George come from interview: DRC_Univ_Compl_M_JHB. 
took back his old job so that he could replenish his savings. Given his lack of a family safety net, George's displacement decision-making was shaped in part by his ability to work and by the collective decision-making of his group of friends who had similar acute experiences of family loss and displacement.

It was at this point that George and his friends planned their overland journey to South Africa. They believed the country would afford them more employment opportunities, a "better life," and "a chance to receive education." Here, we can see that his adoption of an asylum channel to access higher education overlaps with his expression of certain destination patterns related to higher education, namely "movement to a labor market" and "movement to a higher education institution or sector." In 2004, George crossed the border into South Africa as an irregular migrant, as he had no formal travel documents. He stated:

"We did not know where to go, where to live and anytime we could get arrested. You know, be questioned about why and how we got into the country and so on. We had travelled without passports, without formal documents, just going through the borders anyhow, risking life. Then I was taken to Home Affairs in 2004 and got formal recognition for being an asylum seeker."

When George explained that he "was taken" to Home Affairs, as opposed to "went" to Home Affairs, he was referring to the fact that he had received help from co-nationals to navigate entrance into an asylum channel. Numerous respondents from across the destination countries described receiving such information and assistance. For some, it was simply being told where to register; for others, assistance involved receiving shorter processing times or being advised on how to answer questions during the interview.

When discussing his initial entrance into an asylum channel in South Africa, George stated, "My aim was to find a way to get educated because that was the only hope I was left with." He knew that asylum seekers had the right to access higher education, that South Africa had a highly-regarded tertiary education sector, and that there were greater employment opportunities in South Africa, which would allow him to save up the money for tuition fees. That being said, George's opting into an asylum channel to access tertiary education in no way detracts from his claims to asylum. This section has shown that the high educational constraints (i.e., the lack of educational opportunities) in George's first country of asylum, where he was more acutely displaced, as well as the highly constrained livelihood opportunities in Kenya shaped his looking farther afield to South Africa. George's high aspirations and strong norms for higher education as well as his drive to support his own educational attainment through employment brought to light the structural constraints and opportunities and the more practical considerations surrounding both his destination country and channel of entry. 


\subsubsection{Avoiding humanitarian channels to access tertiary education}

The pattern "avoiding humanitarian channels to access tertiary education" refers to respondents' having forgone asylum and refugee channels and their associated statuses to gain higher education. Within this pattern, respondents identified with the refugee label and expressed their destination country as a place of asylum, stability, and security. However, they made the express decision to avoid asylum seeker and refugee statuses, a decision which they perceived would enhance their access to tertiary education. To better understand humanitarian channel avoidance, it is necessary to understand how respondents defined what it meant to be a refugee or asylum seeker. Irrespective of their migration status, respondents put forward a markedly consistent image of refugees. The common words and phrases used to describe this image were poor, helpless, insecure, in search of peace, and miserable. Moreover, refugeed has bleak prospects and were marginalized because of their status. One Congolese respondent explained, "It's a class....It's where you don't have anywhere to sleep, nothing to eat, nothing to wear. Everything you have is coming from help. So when you call me a refugee, understand what I mean by that." 51 Consequently, the expression of this pattern by respondents cannot be seen purely in terms of seeking a better alternative; instead, this pattern describes situations in which respondents explicitly rejected asylum and refugee channels because of what they represented, regardless of whether they had alternative pathways to enter and settle in a destination.

This pattern does not include respondents who may have registered as asylum seekers (or refugees) and then opted out of the asylum channel in favor of a more "voluntary" channel. Such a situation describes switching channels, which will be examined in the third and final pattern. In contrast, this "avoiding" pattern describes a situation in which respondents forewent or by-passed humanitarian channels altogether, and describes respondents who chose to have no contact with asylum and refugee regimes.

This is the least-cited of the three channel patterns, with just seven respondents and approximately 5 percent of the total sample expressing this pattern. The low rate of expression may be considered from several perspectives. First, consciously avoiding refugee status is a difficult decision to make. Although assuming an alternative legal status provides the right to remain in a destination country for a period of time, it does not protect against refoulement, or the forcible return to a country where one is at risk of persecution. Moreover, in the case of forgoing a humanitarian status and choosing to remain undocumented, a respondent enjoys few if any rights in a destination country and is at great risk of being deported. Second, the low rate of expression may stem from an identification issue. If respondents coming from areas of conflict have the capability to

${ }^{51}$ This quote comes from interview DRC_Univ_Compl_M_Kla. 
become student migrants, for instance, then they may not self-identify as refugees and, thus, not cite the avoidance of humanitarian channels in the narratives of their movement trajectories. Third, as mentioned previously, this pattern covers respondents who have had no contact with the asylum or refugee regimes in a destination country and therefore does not include those who have opted out of their refugee status and switched from a refugee channel to a more "voluntary" entry and settlement channel.

Respondents who expressed this pattern avoided humanitarian channels in two ways, by forgoing an asylum channel in favor of a student channel and by forgoing an asylum channel and choosing to remain undocumented in the destination. Five out of seven respondents described avoiding asylum channels and opting into student channels. For these respondents, their expression of "entering a student channel to access tertiary education" occurred alongside their expression of "avoiding humanitarian channels to access higher education." Moreover, for their In Chapter Six on Timing, the case of Francis revealed that the respondent avoided the asylum channel and became a student migrant to enter South Africa. This case also revealed that once Francis finished his degree and determined that the security situation in his home community had further deteriorated, he applied for a graduate degree so that he could renew his student visa and stay within South Africa. It should be emphasized that opting into a channel does not always imply avoiding another, as just five of the 26 respondents who expressed the first channel pattern also cited this second pattern.

Just two respondents avoided an asylum channel and chose to remain undocumented. They explained that because their educational attainment was not hampered by their lack of status, and because they did not want to enter asylum channels, they preferred to remain undocumented. Their cases reveal that avoiding a channel does not automatically imply entering an alternative channel and vice versa. Although not the case for any of the respondents who exhibited this pattern, it is conceivable that some (forced) migrants could avoid asylum channels in favor of skilled labor channels. Following a person's completion of a tertiary education degree in a destination country, rather than return to his or her origin country, the person could become a skilled migrant. This would be an instance of both avoiding humanitarian channels and transferring between channels.

The respondents who exhibited this channel pattern had moved to each of this study's destination countries. For those who avoided humanitarian channels and moved through student channels, two respondents moved to Kenya, one respondent moved to South Africa, and three respondents moved to Uganda. Although these numbers are small and therefore difficult to extrapolate from, we might have expected a greater number of respondents exhibiting this pattern to have moved to South Africa, given that such respondents tended to have higher capabilities than their counterparts in other countries. 
However, the issue of capabilities may be precisely why a greater number of respondents expressing this pattern moved to Uganda. The barriers to enter student channels are significantly lower in Uganda than South Africa and also lower than Kenya. The cost of the visa is lower; one may get a student visa upon arrival rather than in advance; qualifications recognition is less costly; and challenges with academic equivalency are fewer. Moreover, the asylum and refugee channels in Uganda offer few advantages when it comes to accessing tertiary education. In sum, the conditions in Uganda appear more suitable for a person attempting to avoid contact with the asylum and refugee regimes, in favor of "voluntary" channels. Furthermore, one of the two respondents who avoided humanitarian channels and chose to remain undocumented also moved to Uganda. As will be explained in the case analysis later on in this section, this respondent's narration of his displacement and higher education trajectories echoes the relative differences among the channels observed at the macro-level and suggests that having a legal status in Uganda was not necessary for settling in the country and pursuing higher education. This stands in contrast to accounts from respondents who moved to South Africa who felt that some form of legal status was necessary, and from those who moved to Kenya who perceived that even with a legal status, they were subjected to police harassment and the threat of deportation.

In terms of the profile of respondents who exhibited this channel pattern, the distributions by origin country and gender are relatively balanced, given the small number of respondents. Five out of 81 Congolese versus two out of 68 Somalis, and five out of 81 men versus two out of 68 women expressed this pattern. A balanced gender distribution suggests that female respondents shaped their channels of entry and settlement in relation to higher education in ways comparable to their male counterparts. In terms of the type of higher education, this pattern was expressed by respondents in all three destination countries. The greatest number of respondents were those pursuing university degrees. This mirrors what we observed for the "opting in" pattern because all but one of these respondents avoided humanitarian channels and opted into student channels, and because universities tend to attract and recruit international students more than colleges and technical students.

Figure 47: Respondent Profiles: Avoiding Humanitarian Channels

\begin{tabular}{|c|c|c|c|c|c|c|}
\hline \multicolumn{2}{|c|}{ Gender } & \multicolumn{2}{|c|}{ Origin Country } & \multicolumn{3}{|c|}{ Type of Higher Education } \\
\hline $\begin{array}{l}\text { Women } \\
(68)\end{array}$ & $\begin{array}{l}\text { Men } \\
(81)\end{array}$ & $\begin{array}{l}\text { DRC } \\
(81)\end{array}$ & $\begin{array}{c}\text { Somalia } \\
\text { (68) }\end{array}$ & $\begin{array}{l}\text { Certificate } \\
\text { (37) }\end{array}$ & $\begin{array}{l}\text { Diploma } \\
\text { (27) }\end{array}$ & $\begin{array}{c}\text { Degree or } \\
\text { Higher } \\
(50)\end{array}$ \\
\hline 2 & 5 & 5 & 2 & 1 & 1 & 5 \\
\hline
\end{tabular}


The following example delves deeper into how avoiding an asylum channel and choosing to remain undocumented to access higher education was expressed. In outlining this example, I examine how the respondent's aspirations, norms, and practices - i.e., the dimensions of agency - related to higher education shaped their expression of this pattern. Where relevant, I discuss any structural factors cited by the respondent, either directly or indirectly, as impacting his or her agency.

\section{Case: Pierre. ${ }^{52}$ Avoiding refugee status to be an undocumented student}

Pierre is a Congolese male who completed a college diploma in Kampala. While Pierre entered Uganda on a tourist visa in 2009, he was an undocumented migrant for the majority of his tertiary studies between 2009-2012 and at the time of this study's interview in 2015. In shaping his channel of entry and settlement in Uganda, Pierre avoided moving through asylum and refugee channels and instead chose to remain undocumented. In describing his actions, he stated, "I didn't have a passport. I came with a travel document and that was for a month, and I got a tourist visa for three months. And then my friend told me, here in Uganda there is no problem, people can live here without even a visa." On the surface, Pierre expressed his channel avoidance in very practical terms. He determined that having a legal status was not necessary to remain in Uganda.

Another aspect of his expression of this channel pattern was his deliberate avoidance of asylum and refugee channels. Although he identified with the refugee label, Pierre sought to distance himself from his experiences with conflict and crisis. That being said, when discussing what it means to be a refugee, he said:

"A refugee is someone who has a problem, like war... [it is someone] that has to run from my country. It's someone who...is like me. I can say that I am a refugee because this isn't my country and people know that in my country there are big problems. That's why most of us [Congolese] are here, they always call us refugees. Even the police know that us foreigners are supposed to be refugees."

Pierre's experience as a refugee was connected to how Ugandans and particularly police officers viewed him. This suggests that being seen and labelled as a refugee by state security forces meant that having legal status was not necessary. His experience was also defined by the violence and conflict to which he was exposed and his flight from the DRC. Elsewhere in his narration of his movement and educational attainment, he explained: "Most people want to send their children out of the country because of insecurity. They want to protect them because they are targeting youth. When there is war, they are targeting youth. That is how it is. That's why people started coming to Uganda." Pierre

\footnotetext{
${ }^{52}$ All quotes from Pierre come from the interview: DRC_College_Compl_M_Kla.
} 
explained that youth represented a challenge and threat to the older political guard. Thus, his pursuit of tertiary education in Kampala was part of his protection strategy and a core part of his refugeehood.

Examining the emergence of Pierre's channel pattern in the context of his practical considerations, we see that the role of his Ugandan friend and the political structures within Uganda feature prominently. Pierre's friend was a Ugandan national, who helped him navigate bureaucratic procedures and extended to Pierre the connections within his social network. With this friend's assistance, Pierre obtained a residency card, which is an identification card typically reserved for nationals and is obtained from the chairperson of one's Local Council, the smallest unit within the country's decentralized system of governance. This identification card was not a national identification card and did not provide Pierre with citizenship or a legal basis for remaining in Uganda. However, showing this card gave Pierre the appearance of having a legal status. Consequently, it enabled him to pursue a college diploma in Kampala, without revealing his irregular migration status.

Similarly, the political structures in Uganda, to some extent, allowed for Pierre to remain undocumented. Not only did he interact with his higher education institution using his residency card, but he also interacted with the police and felt safe and integrated within Ugandan society. When speaking about his life in Uganda, Pierre explained:

“To compare Uganda and Congo, it's almost the same. Here you are free to move any time you want, you can do whatever you want, anytime you want. Maybe I'll never been arrested [for being undocumented] here in Uganda. I can move at night. Even if I am found by police, they can just ask me for my ID and then they can leave me be."

While his experience of freedom of movement and his ease of access with state political structures may be exceptional relative to other migrants and refugees within Uganda, in Pierre's case, these factors supported his avoidance of asylum and refugee channels.

Examining the emergence of Pierre's channel pattern in the context of his socio-cultural context reveals that his network of family and friends played a key role in shaping his movement to Uganda. His father had completed a tertiary degree and strongly encouraged Pierre's attainment of tertiary education abroad. In particular, Pierre's father urged his movement to Uganda so that he could begin work in the family's business, be primed to take it over, and assume the responsibility of caring for the family. As the youngest child of his parents, and with many of his siblings having been resettled as refugees to Europe, Pierre described being his parents' successor. He stated, "I was following my parents and they were teaching me, they were telling me that maybe let's 
help you because you're still young and we never know about tomorrow." In this way, studying abroad and taking over the family's business in Uganda was part of a livelihood and protection strategy that his family helped to create for him.

While Pierre was in his last few years of high school, several of his friends went to Uganda for their tertiary studies. When they returned to the DRC during their school holidays, they would talk about life in Kampala and their positive experiences at a particular university. They encouraged him to follow in their footsteps, learn English, and helped him apply for admission. English, he explained, was valued because it would help them to prepare for future uncertainty and avoid more acute displacement experiences. Additionally, Pierre's refugee definition reveals the negative norms and values that he attached to the label. A refugee was someone who did not belong and who was linked to problems and came from a country of problems. A refugee was also readily identifiable. Relating these aspects of Pierre's normative environment to his channels of entry and settlement, it is possible that the support of family and friends, the strong and positive values surrounding his proactive movement, and his negative perceptions of refugeehood, made him less inclined to move within an asylum channel.

In Pierre's narrations of his movement and educational trajectories, he spoke little of his individual aspirations. Aside from his desire to study computing and work in a technological field, Pierre's aspirations did not feature in his movement patterns. Contrary to other respondents, his norms and more practical considerations dominated his expressions of agency related to tertiary education and shaped his avoidance of asylum and refugee channels in favor of an undocumented channel.

\subsubsection{Switching channels to access tertiary education and employment}

The pattern "switching channels to access tertiary education and employment" refers to respondents' transferring from one channel to another or moving within multiple channels at the same time, either to access higher education or because they had gained higher education and were attempting to access employment. In this way, switching channels involves both opting out of a channel as well as opting in. While the first channel pattern, and to some extent the second, described how respondents entered a destination country, channel switching describes their settlement in the destination. Figure 49 shows the channels that respondents who exhibited this pattern opted into to enter destination countries versus those they were connected to at the time of the interview. It should be noted, however, that several of these respondents had entered more than two channels over the course of their stay in destination countries. 
Figure 48: Entry and Exit Channels of Respondents who cited Switching Channels

\begin{tabular}{|l|r|r|r|r|r|r|r|}
\hline $\begin{array}{l}\text { Migration } \\
\text { Channel }\end{array}$ & Tourism & Asylum & Refugee & Student & $\begin{array}{c}\text { Skilled } \\
\text { Labor }\end{array}$ & $\begin{array}{c}\text { Permanent Resident } \\
\text { or Citizen }\end{array}$ & Family \\
\hline Entry & 1 & 8 & 0 & 2 & 0 & & 0 \\
\hline Interview & 0 & 0 & 2 & 2 & 2 & 4 & 1 \\
\hline
\end{tabular}

Eleven respondents, or 8 percent of the total sample, cited switching between channels, making it the second-most cited channel pattern. Figure 49 shows a clear trend in that tourism and asylum channels were opted into to enter destination countries, while refugee, skilled labor, citizenship, and family channels were switched into later on in respondents' settlement in destination countries. In other words, over time respondents who pursued higher education in destination countries tended towards exiting humanitarian channels and entering more "voluntary" channels. From eight forced migrants at entry, two remained at the time of the interview. The student channel, on the other hand, was one of entry and settlement and did not show a clear temporal trend.

Examining the individual cases of respondents as they switched from one channel to another, we see a wide variety of trajectories. Two respondents opted out of the refugee channel and entered a skilled labor channel, following the completion of their studies. Several respondents moved from a refugee channel to a citizen channel after they had completed their tertiary education. Two respondents, who defied the trend of exiting humanitarian channels and entering more "voluntary channels," moved from student to refugee channels. One of these respondents described transferring to a refugee channel to access the local labor market after finding it too costly to enter a labor channel. The other transferred to a refugee channel to continue his studies and bring his family to the destination country as refugees, after an escalation in conflict and violence in the DRC. While not the case for any respondents in this study, it is also possible for people to transfer from a refugee channel to a student channel.

In terms of simultaneous movement through multiple channels, this occurred when respondents were able to obtain multiple identity documents, tied to different migration statuses, at the same time and employed whichever status and its accompanying rights and procedures were best suited to a given situation. This aspect of channel switching was rarely expressed by respondents, either because strict migration and asylum procedures prevented the adoption of multiple statuses, or because respondents did not feel comfortable sharing their strategic adoption of multiple statuses. Respondents who described simultaneous channel switching explained that they used their passports when interacting with tertiary education institutions or in accessing certain jobs, while they used their refugee status to remain in the country and to access resettlement. 
While channel transition was the second-most cited channel pattern, the fact that just 11 respondents cited this pattern is relatively small. This could be the case, first and foremost, because of this study's sampling strategy. This study did not use the year of entry into the destination country and the amount of time spent in the destination country as part of its inclusion criteria. While years of entry range from 1991 to 2015, 87 respondents (58 percent) had arrived in the last six years (since 2009). Given that a respondent's channel of entry and settlement was linked to the time spent in a destination country, respondents who arrived more recently were less likely to have switched between channels. Setting aside methodological explanations, transitioning between channels was a costly and time-consuming endeavor, which involved considerable knowledge of the policy process. Such high barriers to entry dissuaded many from taking part. Further, as mentioned previously in the case of respondents moving through multiple channels at once, respondents may have been less likely to express their channel transitions, fearing a challenge to their claims to rights or fearing discrimination. Consequently, it is possible that this pattern is underreported.

Respondents who cited channel switching had moved to each of this study's destination countries. One respondent moved to Kenya, two moved to Uganda, and eight moved to South Africa. While numbers are small and therefore difficult to compare, respondents in South Africa had the highest incidence of channel switching perhaps because of the greater differences in entitlements and procedures between categories and because respondents who moved there tended to have higher capabilities and were more informed about migration policies and ways of accessing the labor market. The few respondents who had moved through multiple channels at the same time had moved to Kenya and Uganda, and none had moved to South Africa. This may stem from the fact that South Africa's migration channels and procedures for obtaining identity documents are more rigid than those of Kenya and Uganda. Moving through multiple channels at the same time may also be less likely to be expressed in South Africa, given the high levels of xenophobic violence.

In terms of the profile of respondents, Figure 50 shows that roughly comparable numbers of men (seven respondents) and women (four respondents) and Congolese (five respondents) and Somalis (six respondents) cited switching between channels. As with other patterns, this underscores that fact that female respondents are shaping the channels of their movements in relation to higher education in ways similar to their male counterparts; and that these movement dynamics are not specific to a particular country of origin or conflict. Regarding the type of tertiary education, the distribution is skewed towards university degrees, although the numbers are small. Just one respondent pursued a certificate program and two respondents pursued a diploma program, versus eight respondents who pursued a undergraduate or graduate program. The rate of 
expression increasing with the level of academic achievement mirrors what we observed for the first two channel patterns. However, while there was overlap between entering and avoiding channels, no such overlap exists with switching channels. Thus, while channel transitions appear to exhibit a similar trend in the type of higher education, it is for different reasons. The rate of expression increasing with the level of academic achievement stems from the fact that certain channels, such as the Exceptional Skills channel in South Africa, require a high level of tertiary education. Additionally, higher levels of tertiary education take significantly more time than certificate or diploma programs, and such time spent in the destination country qualifies respondents for permanent residency. Thus, it is the nature of these higher levels of tertiary education that creates the conditions for channel switching.

Figure 49: Respondent Profiles: Switching between Channels

\begin{tabular}{|c|c|c|c|c|c|c|}
\hline \multicolumn{2}{|c|}{ Gender } & \multicolumn{2}{|c|}{ Origin Country } & \multicolumn{3}{|c|}{ Type of Higher Education } \\
\hline $\begin{array}{c}\text { Women } \\
\text { (68) }\end{array}$ & $\begin{array}{l}\text { Men } \\
(81)\end{array}$ & $\begin{array}{c}\text { DRC } \\
(81)\end{array}$ & $\begin{array}{c}\text { Somalia } \\
\text { (68) }\end{array}$ & $\begin{array}{c}\text { Certificate } \\
\text { (37) }\end{array}$ & $\begin{array}{l}\text { Diploma } \\
\text { (27) }\end{array}$ & $\begin{array}{c}\text { Degree or } \\
\text { Higher } \\
(50)\end{array}$ \\
\hline 4 & 7 & 5 & 6 & 1 & 2 & 3 \\
\hline
\end{tabular}

The following example delves deeper into how a respondent switched between channels. In outlining this example, I examine how the respondent's aspirations, norms, and practices - i.e., the dimensions of agency - related to higher education shaped their expression of this pattern. Where relevant, I discuss any structural factors cited by the respondent, either directly or indirectly, as impacting his or her agency.

Case: Francis. ${ }^{53}$ From student to refugee to highly-skilled

We return to the case of Francis, who is a Congolese man who completed both an MA and $\mathrm{PhD}$ in South Africa and was a university lecturer at the time of the interview. ${ }^{54}$ Between the time he first entered South Africa in 2003 and the time of the interview in early 2016, Francis had switched between channels twice. First, he transferred from a student to a refugee channel and second, he moved from a refugee to a highly-skilled channel. In describing these transitions, Francis stated:

\footnotetext{
53 All quotes from Francis come from interview: DRC_Univ_Compl_M_CT_2.

${ }^{54}$ Chapter Six examined how Francis expressed the timing pattern "movement upon securing a higher education opportunity in the destination."
} 
"I was about to go back to Congo, because [my postgraduate] program [in South Africa] had ended in June 2004, but then another war started in Bukavu, where I had left my family. My wife and kids and my other siblings were living in that city when [Laurent] Nkunda Batware and [Jules] Mutebusi invaded. These guys invaded the city, with their soldiers and they were raping street by street, house by house, and so on. So, I said that I cannot go back to that place. On the contrary, I advised my wife to leave. She left with the kids without money, because I didn't have money, I was a student...At the time, luckily, I got accepted into a master's program and so I waited for my family to come..."

“...When they arrived, I was on student permit. Then I went to Home Affairs with them trying to see what is going to happen. They told me no, these people are refugees, so since they are refugees and you are a family, you have to have the same status. So, I became a refugee at that time. I finished my master's as a refugee, I completed my PhD as a refugee. When I finished my PhD, I went home [to the DRC] and applied for an exceptional skills permit [for South Africa]. When I got that one, then my family also joined me under that permit."

Francis' account reveals different kinds of channel switching. In opting out of the refugee channel and into the highly-skilled channel, Francis made a proactive move based on his skill level and what he wanted for his future. He could have remained with his family in the refugee channel and had the right to work as a refugee, but preferred to become a highly-skilled migrant. Moreover, he perceived that the highly-skilled channel provided a more promising pathway to permanent residency, which he had applied for at the time of the interview. In contrast, Francis' move from a student to a refugee channel could more accurately be described as channel displacement. Unable to bring his wife and children under his international student status, Francis was forced to become a refugee or risk the refusal of his family's asylum claim.

Francis' high skill level, his knowledge of South Africa's migration and asylum regimes, the constraints and procedures surrounding the country's asylum process, and his family's experiences with acute flight from the DRC provide some insight into his practical considerations as well as the structural factors shaping his channel switching. Additional factors mediating his practices include his ability and resources to return to the DRC to apply for an exceptional skills permit and his highly skilled job within a South African university. Francis explained that very few employers would have offered him a permanent position as a refugee and that he saw his university as exceptional. These factors created the conditions for his channel pattern and are aspects of Francis' agency that few Congolese migrants and refugees share. 
As we saw in Chapter Six, many of Francis' educational and professional aspirations were strongly tied to practical needs, such as providing support for his family, rather than a single "vision" providing motivation. For instance, part of his motivation for remaining in South Africa and entering a pathway to permanent residency was that by moving onward to a third country or returning to the DRC, he would have to rebuild his career and he would have to make his children change schools. On this subject, he stated:

"I don't want to start again. I know I can stay here because all my kids are now in school here and they are used to the environment. Taking them back to DRC, it would be difficult for them. Taking them to another country, they would be starting over. Maybe it would be good for them, but not for me, so I prefer they continue their studies here. Maybe later for university they can go anywhere else they want to go, but they must finish their high school here."

In this way, Francis' aspirations were shaped by not only his own career ambitions but also his educational ambitions for his children. Here and elsewhere in his narration of his movement and education trajectories, it appears that Francis' aspirations were less individualistic and more shaped by his need to ensure the survival and success of his family. While sociocultural norms did feature in the timing of his exit from the DRC and his entry to South Africa, they were absent from the discussions of his channels of entry and settlement. Overall, his agency in switching channels was largely driven by his practical considerations, particularly the opportunities and constraints he faced in South Africa's migration and asylum policy environment and labor market.

\subsection{Putting Findings into Context: Non-Exhibitors and Never Enrolled}

Having identified and examined the different ways in which respondents shaped their entry and settlement channels in the destination based on considerations related to tertiary education, this chapter now explores cases in which respondents similarly pursued higher education in destination countries, but did not exhibit any of the channel patterns related to tertiary education. This section also examines cases in which respondents never enrolled in higher education programs in asylum countries. Together, these steps provide some basis of comparison and context for the higher education insights identified on the channels of entry and settlement, and shed light on how higher education considerations emerge or do not in this dimension of the displacement process.

Fifty-nine respondents, who went on to gain some form of tertiary education in the destination, did not exhibit any of the entering, avoiding, or switching channel patterns, which represents approximately 40 percent of the total sample and 52 percent of those who received tertiary education. In other words, approximately half of the respondents 
who gained tertiary education in destination countries did not shape their channels of entry and settlement in relation to tertiary education. Their narrative data reveal several insights as to why this occurred, related to their pursuit of protection, struggle to navigate migration and asylum regimes, and timing of movement. The first insight refers to respondents' practical need for rights and recognition overwhelming any aspirations, norms, or practical considerations related to the pursuit of higher education. These respondents engaged in acute movements and had direct experiences with conflict. In fact, 44 out of 59 non-exhibitor respondents who gained higher education, which amounts to 75 percent, described having an experience with violence and conflict during their exits from origin countries. In comparison, 23 percent of those who opted into student and humanitarian channels, 14 percent who avoided humanitarian channels, and 45 percent who switched between channels to access tertiary education, had a conflict experience during their exits from origin countries.

Direct conflict experiences and acute movements may appear as factors confined to the timing and destination of movement, by prompting more reactive exits to cross-border destinations. However, these factors also shaped respondents' legal or irregular entry and settlement in destination countries, by constraining their pathways to rights and protection and their ability to move through "voluntary" channels within destination countries. Simply put, highly acute displacement experiences limited respondents' ability to influence their channels of entry and settlement. Similarly tied to their experiences of acute displacement, several non-exhibitor respondents who were in pursuit of protection arrived at camps and settlements upon entering Kenya and Uganda. As much as they are sites for emergency assistance and shelter, camps and settlements are also political spaces where status determination, resettlement procedures, and other legal processes are carried out. In this way, camps and settlements structured the entrance of respondents into refugee channels.

The second theme, the struggle to navigate migration and asylum regimes, describes the failed attempts of respondents to shape their entry and settlement channels. Respondents who expressed this theme entered destination countries as asylum seekers and at the time of their interviews for this study were either undocumented or were still waiting for refugee status determination. Those who were undocumented had tried and failed to enter refugee channels because their asylum claims had been rejected. Those who were still asylum seekers had been waiting for refugee status determination for years - some as many as ten years - and found themselves stuck in a state of legal limbo. The nonexhibitor respondents who struggled to navigate migration and asylum regimes did not have passports and had no other protection pathways open to them. The high constraints they faced prevented them from shaping their channels. Often, their tertiary education 
attainment came after having spent considerable time in their destination countries and took the form of certificate programs at vocational schools. Moreover, their tertiary education attainment was less linked to their aspirations for tertiary education than their desire to gain a skill to better provide for their livelihoods.

The third and final theme that arose for non-exhibitors was the timing of their movements within their life cycles. This theme describes respondents who arrived to destination countries as infants or young children and so tertiary education did not feature in the shaping of their entry and settlement channels. Often, the family and kin of such respondents determined their channels. This was the case for the two non-exhibitors who arrived as asylum seekers with their families and became permanent residents before their graduation from high school. This was also the case for many respondents who arrived as asylum seekers and obtained refugee status with their families. In sum, these three themes illustrate that respondents' individual and family circumstances, as well as the structural conditions in origin and destination countries, can constrain the agency of respondent in shaping their channels and cause their practical considerations to outweigh the other dimensions of their agency. For respondents to shape their channels in relation to their tertiary education, there has to be some space in which to express their tertiary education aspirations, norms, and practical considerations.

Non-exhibitor respondents moved to each of this study's destination countries, although the largest share could be found in Kenya. Twenty-five out of the 29 respondents who gained higher education in Kenya exhibited none of the channel patterns related to higher education. This stands in stark contrast to the shares of non-exhibitors in Uganda (14 out of 36) and South Africa (20 out of 49), which were smaller than the shares who expressed at least one channel pattern related to higher education. These figures align with what we know about Kenya on a macro-level in terms of its higher education sector and refugee-hosting policies. Simply put, Kenya is the least attractive of the three destination countries as a place of higher education. Its strict encampment policies leave little room for switching channels and attract those forced migrants with more acute displacement experiences. Additionally, with such a high share of non-exhibitors, Kenya's data skew the total share of non-exhibitors amongst those who received tertiary education to just over half of the sample. If we were to focus only on the data from Uganda and South Africa, the share of non-exhibitors would be 40 percent, which would be the smallest nonexhibitor rate of the three displacement dimensions (timing, destination, and channel).

Turning to examine the profile of non-exhibitor respondents to gain insight into why or how higher education considerations did not emerge, several patterns may be observed with respect to respondents' migration status, destination countries, type of tertiary education, origin countries, and gender. All non-exhibitor respondents entered their destination countries through an asylum channel, which represents 70 percent of all 
respondents who entered as asylum seekers and went on to gain higher education. It is not surprising that non-exhibitor respondents did not cite alternative and more voluntary channels given that migration systems are largely predicated on education and skill level. What is unexpected is that no respondents settled within undocumented channels when they first arrived at destinations. Many entered destination countries through irregular means, but they registered as asylum seekers in the first days and weeks of their stay.

By the time of this study's interviews in 2015 and 2016, five respondents had remained within asylum channels, two respondents had moved into permanent resident channels, one had moved into an undocumented channel, and 50 (representing 76 percent of all respondents with refugee status who gained higher education) had moved into refugee channels. Hence, the majority of non-exhibitor respondents entered as asylum seekers and, after some time, had positive refugee status determination processes and became refugees. This trajectory reflects the more acute displacement experiences that nonexhibitor respondents expressed.

Figure 50: Entry and Exit Channels of Non-Exhibitor Respondents

\begin{tabular}{|l|r|r|r|r|}
\hline Migration Channel & Undocumented & \multicolumn{1}{|c|}{ Asylum } & \multicolumn{1}{c|}{ Refugee } & $\begin{array}{c}\text { Permanent Resident } \\
\text { or Citizen }\end{array}$ \\
\hline Entry & 0 & $58(70 \%)$ & & 0 \\
\hline Interview & $1(25 \%)$ & $5(50 \%)$ & $50(76 \%)$ & $2(33 \%)$ \\
\hline
\end{tabular}

In terms of origin country, 36 out of 61 Congolese and 23 out of 53 Somalis who gained some form of tertiary education did not exhibit any of the channel patterns. In other words, Congolese non-exhibitors outnumber exhibitors, while for Somalis, the reverse is true. The greater share of Congolese non-exhibitors may stem from the nature of conflict and crisis in Eastern DRC and that many non-exhibitors had more direct experiences with conflict and engaged in more acute movements. By contrast, fewer respondents from Somalia had acute experiences with conflict at the time of the movement, allowing for a greater degree of agency in shaping their channels of entry and settlement.

The gender distribution of non-exhibitors who gained tertiary education reveals a tendency towards women not expressing a channel pattern related to tertiary education. Fifty-seven percent of women (totaling 30) versus 48 percent of men (totaling 29) were non-exhibitors. Looking more closely at the data, we see that female respondents shaped their channels mainly in terms of entering student channels, and in this sense were on par with their male counterparts. However, none entered highly-skilled channels or chose to remain undocumented. Men expressed a greater variety of alternative channels. 
This suggests that while male and female respondents both shape their channels of entry and settlement in relation to higher education, access to particular channels is unequal.

In terms of type of higher education, the greatest share of non-exhibitors was those pursuing certificate programs at vocational schools (30 out of 37), followed by those pursuing diploma programs at colleges (15 out of 28), and those pursuing degree programs at universities (14 out of 49). This reflects the same trend observed for the channel patterns, albeit in reverse. Namely, that those unable or unwilling to shape their channels of entry and settlement in relation to higher education tended to pursue "lower" levels of tertiary education. As mentioned previously, this may stem from the fact that respondents pursuing vocational certificates tended to come from more constrained socio-economic backgrounds and had more acute displacement experiences. Their tertiary education attainment was less often planned in advance and a part of their educational aspirations, but more a function of their desire to expand their livelihood opportunities in asylum countries. Fewer non-exhibitors at the university level is likely linked to the fact that these respondents tended to have higher capabilities and their education qualified them for more "voluntary" migration statuses, so they were more able to shape their channels. Additionally, university degree programs take significantly more time to complete than certificate or diploma programs, and such time spent in the destination country provided respondents with a greater opportunity to switch channels. Thus, it is both the nature of these higher levels of tertiary education that creates the conditions for expressing channel patterns and the self-selected respondents who gain higher levels of tertiary education who are more adept at shaping channel patterns.

Turning to examine the narrative data of respondents who never enrolled in higher education, this section now seeks to understand the extent to which the observed channel patterns were unique to respondents who gained higher education. We might expect that the respondents who never enrolled also never shaped their channels of entry and settlement in relation to higher education. This is because channels are highly regulated by governments and have barriers to entry. Entering student channels, for instance, requires admission to tertiary education programs. Entering highly skilled channels requires respondents to have completed advanced tertiary education. The data pictured in Figure 52 reflect the highly controlled nature of channels and, hence, the high barriers to shape channels related to tertiary education. Thirty out of the 34 respondents who never enrolled in tertiary education exhibited none of the channel patterns. 
Figure 51: Channel Patterns of Respondents who Never Enrolled in Higher Education

\begin{tabular}{lr}
\hline \multicolumn{1}{c}{ Higher Education Channel Pattern } & $\begin{array}{c}\text { Respondents who Never Enrolled in } \\
\text { Higher Education (N=34)* }\end{array}$ \\
\hline Adoption to Access Higher Education & 3 \\
Avoidance because of Higher Education & 0 \\
Transition to Access and because of Higher Education & 0 \\
Exhibited 0 Patterns (Non-Exhibitors) & 30 \\
*Although 34 respondents never enrolled in tertiary education, the table represents 33 cases, as one respondent did not \\
provide sufficient data about his/her movement channel.
\end{tabular}

Notwithstanding, three respondents who never enrolled cited a channel pattern to access higher education. The narratives on the movement and educational trajectories of these "never-enrolled exhibitors" reveal several insights as to why and how they shaped their channels in relation to higher education. All three had higher education aspirations, but had failed to execute their plans for enrollment. One respondent entered Kenya by entering a student channel and had planned to learn English and enroll in a higher education institution in Nairobi. His family had supported his move and had paid for his expenses. He expressed the timing pattern "movement as part of a life cycle transition" and the destination patterns "movement to an anglophone study destination" and "movement to a higher education institution or sector." Upon settling in Nairobi, however, he became involved in the political affairs of some Congolese refugees and experienced threats to his safety and the safety of his family if he returned to the DRC. This ordeal prevented the respondent from enrolling in higher education, strained his contact with his family, and prompted him to enter an asylum channel.

The remaining two never-enrolled exhibitors had expressly described the access they would have to higher education in their destination countries, South Africa and Uganda, through entering asylum (and later refugee) channels. However, at the time of their interviews in 2015 and 2016, respectively, their plans for enrollment had so far failed. In their narrations of their movement and higher education trajectories, both expressed destination patterns related to higher education. The respondent who moved to South Africa cited "movement to a higher education institution or sector," while the respondent who moved to Uganda cited "movement to an anglophone study destination" and "movement to a labor market." Both respondents had been unable to enroll in tertiary education owing to financial reasons, and had been unsuccessful in finding steady employment or tertiary education scholarships. The challenging socio-economic conditions that these respondents faced had not impeded their expression of "entering 
channels to access tertiary education," as they had opted into humanitarian channels, rather than "voluntary" migration channels with higher barriers to entry.

These three cases, which span the three destination countries and different entry and settlement channels, reveal that higher education aspirations were a crucial component of shaping channel patterns. Respondents' more practical considerations featured in determining which channels they adopted. Humanitarian channels require few resources and capabilities, over and above the journey to the destination country. (Although for opting in to take place, respondents must be well-informed of the asylum and refugee policies related to higher education in the destination country.) Student channels require considerably more resources and, in the case of the Congolese respondent mentioned above, family support. In sum, it is possible for migrants and refugees who ultimately do not enroll in tertiary education to enter channels to allow for the possibility of accessing higher education. This same logic may extend to switching channels, so far as access is considered, but not avoiding channels, as that occurs because higher education is being actively pursued or because it was obtained.

\subsection{Implications and Conclusions}

By analyzing the narrative data on the entry and settlement channels of Congolese and Somali respondents, this chapter identified and examined three patterns related to higher education. They are:

1. Entering student or humanitarian channels to access tertiary education,

2. Avoiding humanitarian channels to access tertiary education, and

3. Switching channels to access tertiary education and employment.

These patterns showed that for refugees and migrants who pursued tertiary education in destination countries, and even for some who never enrolled, the prospect of tertiary studies had an impact on the legal or irregular channels that they used to enter and settle in their destinations. Moreover, the third pattern revealed that the attainment of tertiary education also expanded the variety of channels that respondents used to settle in destination countries over the longer-term. In this way, this chapter demonstrated how tertiary education shaped the way in which refugees and migrants accessed protection and other rights in contexts of asylum. These broad findings help to fill a gap within the refugee higher education literature, which focuses much of its attention on tertiary education in resettlement contexts and on the socio-economic impact of higher education. 
Turning to look at the more fine-grained findings of this chapter, the first pattern highlighted that certain channels increased migrants' and refugees' access to tertiary education, by granting the right to study, providing more favorable fee structures and pathways to employment, and opening up scholarship opportunities. It showed that imbalances among channels in relation to tertiary education rights and entitlements prompted channel displacement (or substitution) for some and risked impeding the educational attainment of others too constrained to enter or switch between channels. In so doing, this chapter showed the applicability of Czaika and de Haas' (2013) concept of substitution effects to micro-level and qualitative examinations of mobility patterns in contexts of conflict and crisis.

The second and third patterns revealed cases of migrants and refugees who avoided or opted out of asylum and refugee channels. At times, this occurred in conjunction with entering student channels; it also occurred independently when respondents chose to remain undocumented. In the case of switching channels, this took place when respondents left behind their refugee status in favor of, for instance, a student or highlyskilled status. In all of these cases, respondents perceived refugee status as undesirable, as in conflict with their identities and how they wanted others to identify them, and as providing few prospects for their futures and for so-called durable solutions. Instead, these respondents found alternative and emic forms of protection through "voluntary" and irregular migration channels. Although these alternative channels did not protect respondents from being forcibly returned to their origin countries, respondents nevertheless sought them out. While agencies like UNHCR recognize and seek to support the complementary protection pathways that tertiary education opens up for refugees, little is understood about these emic forms of protection and how they might be fostered.

Additionally, the third pattern on channel switching aligned with Long's (2013) study on the identity documents and citizenship of refugees in Uganda. While this study identified a limited number of cases in which respondents' had obtained multiple identity documents linked to different legal statuses and channels, it reinforced Long's (2013) earlier finding on the strategic status decisions that refugees make to enhance their movement, opportunities, and livelihoods in displacement. More generally, all of the respondents who exhibited a channel pattern related to tertiary education extended the applicability of Long's (2013) findings to international student statuses and channels.

Examining the narrative data to understand how these channel patterns emerged revealed that tertiary education and employment aspirations were key to respondents' entering and switching channels. The avoidance of humanitarian channels, on the other hand, was strongly influenced by respondents' norms and values surrounding what it 
meant to be an asylum seeker and refugee. More practical considerations were central to all three channel patterns and shaped whether respondents could fulfill their aspirations in entering and transitioning and abide by their norms in avoiding. Practical considerations comprised respondents individual and household socio-economic backgrounds, but also respondents' interaction with structural constraints and opportunities in destination countries. Crucially, the asylum and migration regimes within a destination country are the principal determinants of migration channels and, hence, were the principal determinants of respondents' practical considerations. It follows that practical considerations dominated respondents' expressions of agency to shape their channel patterns, more so than with the other dimensions of the displacement process, namely the timing of exit and destination.

Lastly, data on the profiles of respondents revealed two notable insights related to gender and type of tertiary education. Male and female respondents shaped their entry and settlement channels in relation to higher education in similar ways, as men and women had relatively balanced distributions in the entering, avoiding, and switching patterns. That being said, the data revealed a slight tendency towards female respondents enrolling in higher education but not exhibiting any of the channel patterns. It also revealed that female respondents shaped their movement channels mainly in terms of moving within student channels, and not highly-skilled or undocumented channels, whereas their male counterparts moved within a greater variety of channels. This suggests that while both male and female respondents shaped their channels in relation to higher education, access to particular channels was unequal.

In terms of the type of higher education, the rate of expressing all three patterns increased with respondents' level of academic achievement, irrespective of the type of channel. As mentioned previously, this may stem from the fact that respondents who pursued technical and vocational certificates tended to come from more constrained socioeconomic backgrounds and to have more acute displacement experiences. Their tertiary education attainment was less often planned in advance or a part of their educational aspirations and was more a function of their desire to expand their livelihood opportunities in asylum countries. A greater share of channel pattern exhibitors at the university level is likely linked to the fact that these respondents tended to have higher capabilities and their education qualified them for more "voluntary" channels, so they were more able to shape their channels. Additionally, university degree programs take more time to complete than certificate or diploma programs, and such time spent in the destination country provided respondents with a greater opportunity to change their settlement channels. Thus, higher levels of tertiary education created the conditions for expressing channel patterns, as did the (self-selected) respondents who gained these higher levels of tertiary education, as they were more adept at shaping channel patterns. 
CHAPTER 9

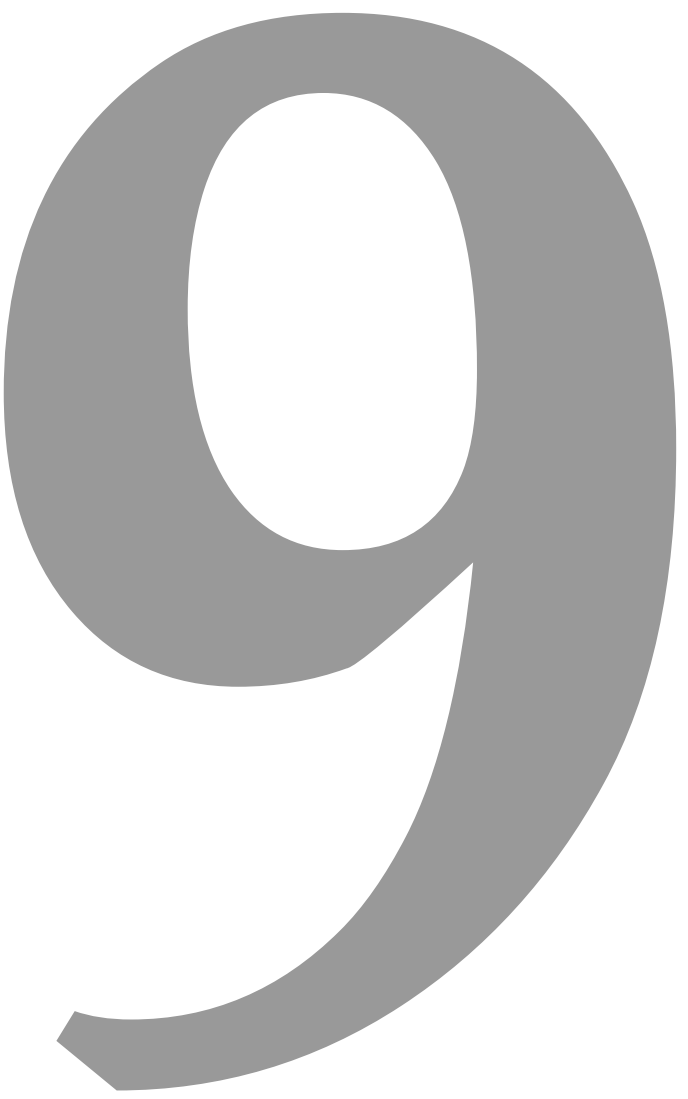




\section{Conclusion}


This study was born out of two notions. First, that violence and conflict alone do not explain the dynamics of forced displacement patterns; rather these factors overlay, contravene, and interact with a range of other political, social, economic, and environmental drivers of mobility at the micro and macro levels (Bakewell and Bonfiglio 2013; Zolberg, Suhrke and Aguayo 1986). Second, that many refugees perceive education, particularly tertiary education, as being key to rebuilding their lives in displacement.

While research and policy highlight the positive impact of tertiary education on refugee livelihoods and their socio-economic integration into countries of asylum and resettlement, little is understood about the impact of tertiary education on the process of forced displacement, particularly the patterns of movement of refugees. Therefore, this study set out to understand: How does refugees' pursuit of tertiary education impact their forced displacement patterns to asylum countries? For instance, if a person's higher education was interrupted, prevented, or not possible in his or her home country because of conflict or persecution, how might the prospect of tertiary education elsewhere play a role in that person's decision-making about where and how to seek asylum?

Underpinning this research question was an implicit focus on the strategic decisionmaking of refugees and migrants coming from areas afflicted by conflict and crisis and their abilities to negotiate the structural environments within and across their countries of origin and asylum. This study employed a framework on agency, conceptualized as aspirations, norms, and practical considerations, to examine precisely how respondents shaped their movements in relation to tertiary education. By focusing on these components of their agency, and not the "reasons" why they moved, this study was able to uncover a rich picture of mobility, tertiary education, and protection strategies.

This final chapter reflects on the methodological design of this study; synthesizes the key findings related to timing, destination, and channels of entry and settlement; and examines their implications for how we conceptualize forced displacement and complementary protection pathways for refugees through higher education. While not a separate section, this chapter also explores potential avenues for further research as part of its reflections on this study's methodology, findings, and implications.

\subsection{Reflections on the Methodology}

The following is a brief reflection on this study's multi-sited, qualitative and interpretive research design. Particular attention is paid to the elements which strengthened this study's understanding of how refugees shaped their forced displacement patterns in relation to tertiary education as well as to the persisting limitations which must be acknowledged. 
This study was set in Sub-Saharan Africa because it is one of the largest refugee hosting regions in the world, where most countries are subject to the same international and regional norms and where many of the same refugee populations can be studied in multiple countries. Moreover, Sub-Saharan Africa has relatively porous borders, which means that the movements of migrants and refugees are not fully constrained by highly enforced visa regimes that structure and pre-determine movements. For these reasons, the region was an apt place to study processes of forced displacement and to observe how people move based on their aspirations, norms, and practical considerations, as well as structural factors like levels of development, geography, migration and refugee regimes, and higher education policies.

This study selected Kenya, South Africa, and Uganda as research sites because they are among the top hosts for refugees and migrants in Africa and, as detailed in Chapter Four, they have some of the most developed higher education sectors, are often invoked as architypes of their respective refugee-hosting policies, and have different proximities to conflict and levels of development. Moreover, as discussed in Chapter Five, these countries appear to be engaged in a migration system and, indeed, a number of respondents journeyed to two or all three countries and others recounted their consideration of two or more of these countries in planning their destination outcomes.

By constructing a multi-sited research design, this study responded to a noted gap within studies on forced displacement with respect to comparative research across different hosting environments. Indeed, it was because of this design that this study identified a greater diversity of movement patterns related to tertiary education and, more importantly, identified links between movement patterns and the different structural environments in destination countries. Thus, respondents in South Africa revealed the greatest capacity to express their agency related to higher agency while those in Kenya exhibited a highly constrained capacity.

In terms of its target population, as explained in Chapter One, this study included asylum seekers, refugees, irregular migrants, student migrants, and other categories of migrants, as many other scholars and researchers within the field of refugee studies have done. A primary reason for this being that many refugees experience significant challenges in registering their status. The criterion for inclusion within this study was that research participants came from communities impacted by conflict and crisis within the DRC or Somalia. While not the intention at the outset, this decision allowed for the observation of strategic decision-making in relation to channels of entry and settlement. Not including migration status within exclusion criteria also allowed for migration status and the channels they represent to be studied and considered as dynamic features of movement processes. As a result, this research observed student migrants who had entered 
destination countries as refugees and vice versa as well as a shift overtime across the entire sample of respondents towards non-humanitarian statuses.

As outlined in Chapter Three, the sampling criteria, which included origin country, relationship to tertiary education, tertiary education level, and gender, were another element that strengthened this study's methodology by creating a fuller picture of movement patterns. In terms of origin country, the DRC and Somalia were selected because they were experiencing protracted conflict, had different migration histories and cultures, and had refugees and migrants in each of the research sites. Initially, protracted conflict was an important feature because it was assumed that for higher education to feature in displacement processes, conflict and crisis would have to be longer-term conditions. This study found that not only did protracted conflict appear to create the space for movement patterns related to tertiary education to emerge, but also it appeared to impact preexisting movement patterns and lead to an overlapping of processes of forced displacement and migration.

The criterion on different relationships to tertiary education (graduate, enrolled, dropout, and never enrolled) was perhaps the most important because it helped to isolate factors that were unique to refugee and migrant students. It did this by comparing graduates and currently enrolled students to students who had dropped out or never enrolled, to construct a quasi-counterfactual using qualitative methods. This methodological step allowed this study to find that higher education aspirations, norms, and more practical considerations featured in the movement processes of those who did not go on to enroll in higher education. In other words, this study found that certain timing, destination, and channel patterns related to tertiary education were not unique to those who went on to enroll. This speaks to the strength of the aspirations and norms tied to tertiary education and it being perceived as key to rebuilding the lives of respondents in displacement. Taking this notion forward, this highlights that the effects of higher education are felt beyond the privileged few who enroll, as it provides potential learners with something to which they can aspire. This strengthens the case for a systems view of education and, hence, for greater investment in tertiary education for refugees to be seen as positively impacting the broader tertiary education pipeline.

Further, in terms of sampling criteria, level of tertiary education deserves some reflection. At the start of this study, university, college, and vocational levels were included because they afforded different opportunities, fee structures, and acceptance criteria more likely to accommodate the diverse needs and capabilities of refugee and migrant students. Not only was this confirmed over the course of this research, but also their inclusion revealed divergent purposes and educational pathways underpinning each of these levels. This was particularly the case for vocational and technical education. This study observed that vocational education was often pursued by respondents well after their arrival to 
destination countries as an alternative livelihood strategy when other strategies had failed. Vocational and technical education was not something that shaped the process of movement. This was likely because of the protected nature of countries' vocational education sectors and their integration with national industries. Moreover, the destination countries had vocational sectors which were constrained and underdeveloped as compared to their university sectors.

The last methodological element that warrants positive reflection is this study's use of biographical interviews centered on respondents' mobility and educational trajectories. The use of biographical data collection methods allowed this research to identify and analyze the movement patterns of refugees and migrants in a way that would otherwise not have been possible. Asking about their movements immediately preceding their arrival to destination countries or solely asking why respondents left their origin countries would have yielded overly simplistic responses about avoiding conflict and seeking out education. By using biographical interviews, this study observed the chronic internal displacement or immobility that respondents had faced or the evolution of their personal timelines. This methodological step allowed for the process of exit to be unpacked and distinguished from the process of entry, and for the timing of movement to become a meaningful dimension.

Turning to consider the limits of this study's methodological approach and the aspects that were not as successful, the remainder of this section shall discuss external validity, gaps in the sampling frame, and the tension between capturing breadth versus depth with the data. In total, the author conducted 149 biographical interviews with refugees and migrants who were purposively selected based on the aforementioned criteria. As such, this research does not amass a representative sample of refugees and migrants within each research country and cannot claim generalizability to any larger population of refugees or migrants. While external validity was never the intention of this study, only generalizability to a theoretical level, it must be emphasized that the findings related to timing, destination, and channels of entry and settlement are confined to the respondents within this study. Further, while saturation was reached with the patterns of movement identified within each of the three dimensions, they should not be interpreted as an exhaustive list. It is possible an expanded sample would reveal new insights.

Relatedly, it was challenging to find respondents who fit certain combinations of the purposive sampling criteria. For instance, Somali women in South Africa and Congolese women in Uganda proved difficult to identify. For this reason, women are underrepresented - 68 women as compared to 81 men. Following diminished representation in the sample, women are underrepresented in the analysis. In Chapters Six through Eight, case studies from the narrative data of male respondents outnumber 
female respondents. While for certain patterns it was important to represent the voices of male respondents because they were the primary exhibitors of such patterns, in other instances in which men and women both expressed movement patterns, a more balanced set of case studies would have been preferred. Future research using this data should include a more nuanced analysis sensitive to gender to examine whether there was something about the nature of their experiences - or the positionality of the author - that made them seemingly more relevant to highlight and how this may have influenced the interpretation of findings.

In terms of other notable gaps in the sample, as mentioned in Chapter Three, the author was unable to identify many students who dropped out of higher education programs. Several respondents and key gatekeepers explained that this likely stemmed from the stigma attached to leaving school and from such individuals moving onward to other countries or returning to their origin countries after not fulfilling their educational plans. This is an acknowledged limitation of the study, as it may overlook the existence of returns within movement processes. Also, this gap may exclude refugees from lower socioeconomic backgrounds or with lower education aspirations. This study therefore had to rely on the category of "never enrolled" to serve as a comparison group.

Lastly, given the comparative nature of this study, and its objective to map out a comprehensive range of movement patterns by amassing a breadth of experiences of refugee tertiary education mobility, there was an inherent tension with its aim of collecting in-depth qualitative data on the reflections of refugees and migrants on their movements. For this reason, this study would have benefited from greater time for repeated interactions with respondents to discuss, for instance, their norms and values related to mobility and education. These aspects of agency are multi-layered based on respondents' experiences, those of their family, and their broader society. In retrospect, this research would have been strengthened by providing respondents with additional space to reflect on these different layers. In the same vein, this study would have benefited from more time to examine the different ways respondents expressed their socio-economic backgrounds. Given the multi-sited design of this research, no standard or objective measure of socio-economic background, whether quantitative or qualitative, seemed appropriate. Asking respondents how they assessed their socio-economic backgrounds relative to other members of their community yielded responses that could not be meaningfully compared. As a result, this study relied on more conventional indicators, such as the level of education and occupations of parents, the level of education obtained by siblings, whether respondents studied at public or private schools, and whether they had to contribute to the income of their households, to name a few. 


\subsection{Synthesis of Key Findings on Timing, Destination and Channel}

This study has argued that respondents expressed their agency in relation to tertiary education to shape their movement patterns along three main dimensions: the timing of exit from origin countries, the destination of movements, and the legal or irregular channels of entry and settlement into destination countries. Regarding the timing of movement, examined in Chapter Six, 70 out of 149 respondents (47 percent) cited at least one timing pattern related to tertiary education. For this select group of refugees and migrants who pursued tertiary education in destination countries and even for some who did not, the prospect of higher education had an impact even at the "early" stages of the displacement process, when such individuals were planning and executing their exit from origin countries. In this way, higher education played a role in initiating the search for safety and security and/or becoming a refugee. This is important because, as outlined in Chapter Two, the literature on refugee tertiary education highlights the impact that tertiary education has on refugees' displacement patterns and experiences after their arrival in asylum and resettlement countries. It is mainly in the historical literature on higher education and forced displacement where we find evidence of tertiary education impacting the timing of exit, either because it is connected to why refugees face persecution or because it provides refugees with the capabilities to anticipate danger and move proactively (Kunz 1973). By analyzing the different components of respondents' agency, this study uncovered a wider and more complex range of higher education impacts related to respondents' capabilities and experiences with persecution, life cycle transitions and norms, perceptions of constraints and opportunities, and education aspirations and strategies.

These findings aligned with studies by Cantor (2014) and Lindley (2011) which argued that refugees express their agency in shaping whether and when to leave and in avoiding, delaying, and planning the timing of their movements. Also, in line with Cantor (2014) and Lindley (2011), this study's timing patterns demonstrated the way in which forced displacement patterns can overlap with mobility patterns, in this case educational mobility patterns. The transition to adulthood and to tertiary studies, the pursuit of cultural rites of passage, and the experience of educational constraints were aspects of timing expressed by respondents and found within the international student migration literature (Punch 2007a; Black et al. 2006; Black, Hilker and Pooley 2004).

In terms of the destination of movement, examined in Chapter Seven, 69 out of 149 refugees and migrants (46 percent) cited at least one destination pattern related to tertiary education. For such respondents, tertiary education considerations played multiple and multidimensional roles in how they negotiated their destination outcomes. This is 
important because it underscores that educational and employment opportunities factor into the choice of destination alongside or as part of safety and security concerns. The findings from this chapter aligned with many of the destination drivers identified by the international student migration literature, suggesting an overlap between drivers of student migration and forced displacement. Similarly, this chapter showed that so-called utility-maximizing dynamics related to the destination of movement can extend to refugees and migrants coming from areas of conflict and crisis. For instance, "movement to a labor market" and "movement to a higher education regime" reflected what Tati (2010) and Rafi and Lewis (2013) observed regarding the impact of labor market opportunities and student visa policies for the destination decisions of student migrants. "Movement to an anglophone study destination" aligned with Baláž and Williams's (2004) finding that anglophone countries are especially attractive to international students as learning English and obtaining English degrees are perceived as being beneficial to tapping into international labor markets. Further, "movement to a higher education institution or sector" supported studies by King and Raghuram (2013) and Tati (2009), which highlighted the recruitment function of tertiary institutions and the role they play in structuring migration processes.

Regarding channels of entry and settlement in destination countries, examined in Chapter Eight, 60 out of 147 respondents (41 percent) cited at least one channel pattern related to tertiary education. For these respondents, both the prospect and pursuit of tertiary studies had an impact on their legal or irregular statuses, their entitlements, and the bureaucratic procedures they had to follow. Moreover, the attainment of tertiary education expanded the variety of channels that respondents used to settle in destinations over the longer-term. Hence, this chapter demonstrated how tertiary education shaped the way in which refugees and migrants accessed protection and other rights in contexts of asylum. These broad findings help to fill a gap within the refugee higher education literature, which focuses much of its attention on resettlement contexts and on the socio-economic impacts of tertiary education.

In particular, the findings of this chapter highlighted that certain channels increased the access of respondents to tertiary education, and showed that imbalances among channels in relation to tertiary education rights and entitlements prompted channel displacement for some and risked impeding the educational attainment of others too constrained to enter or switch between channels. In so doing, this chapter showed the applicability of Czaika and de Haas' (2013) concept of substitution effects to micro-level and qualitative examinations of mobility patterns in contexts of conflict and crisis. Additionally, this chapter revealed cases in which respondents found alternative and emic forms of protection through "voluntary" and irregular migration channels. While agencies like UNHCR recognize and seek to support the complementary protection pathways that 
tertiary education opens up for refugees, little is understood about these emic forms of protection and how they might be fostered. Furthermore, the third channel pattern on "channel switching" aligned with Long's (2013) finding on the strategic status decisions that refugees make to enhance their movement, opportunities, and livelihoods in displacement. More generally, all of the respondents who exhibited a channel pattern related to tertiary education extended the applicability of Long's (2013) findings to international student statuses and channels.

As mentioned at the start of Part Three, the dimensions of timing, destination, and channel arose from an inductive analysis of biographical interview data. This does not mean that these are the only dimensions describing the process of movement. A potential avenue for future research relates to how refugees and migrants shape their journeys between the time they exit origin countries and enter destinations through one of the aforementioned migration and asylum channels. Discussions with respondents on their movement trajectories revealed information on their modes of transportation, whether they moved alone or with others, how direct their movements were, and the time it took to make their journeys, to name a few. However, respondents did not reflect further on these aspects to understand their possible connections to tertiary education. Also, this aspect of movement appeared more relevant to movements to South Africa and less relevant for single border crossings to Uganda and Kenya. Therefore, future research should include additional destinations farther afield and focus exclusively on the journeys of refugees and migrants.

Similarly, while respondents in this study readily discussed their irregular movements and crossings into destination countries, none reported interactions with smugglers. This is likely because repeated interactions with respondents were not possible and more trust needed to be built to discuss sensitive topics such as irregular border crossings, protection risks, and possibly the use of smugglers. In this vein, an additional avenue for further research is to examine the role that smugglers play in enabling or constraining the abilities of refugees and migrants to shape their movements in relation to tertiary education or in determining which routes are used. The role of smugglers should be examined alongside other key actors in the process of movement, such as tertiary education institutions and social networks.

Stepping back to examine the findings on timing, destination, and channels altogether and to assess their relative importance and interactions within the overall process of movement, we may observe that a little less than half of respondents shaped each dimension in relation to tertiary education. Moreover, it appears that no single dimension is more readily impacted by tertiary education than another for the respondents sampled. This is somewhat surprising as one might have assumed the choice of destination to be 
more often linked to tertiary education considerations. This prompts the question of whether these shares are comprised of the same respondents. Indeed, 43 out of 147 respondents, or nearly one-third of the sample, cited at least one pattern within each of the three dimensions. Hence, the majority of respondents who shaped their movements in relation to tertiary education, did so in negotiating the timing of their exits, their destinations, as well as their channels of entry and settlement. By contrast, 61 out of 147 (41 percent) respondents were non-exhibitors for all three dimensions of movement. Hence, most of the non-exhibitors of timing patterns were also the non-exhibitors for the patterns on destination and channels of entry and settlement.

Going beyond the surface of each dimension reveals that within each dimension sits a movement pattern with a far higher incidence rate than the other patterns. For timing, it is "movement with life cycle transition;" for destination, it is "movement to a higher education institution or sector;" and for channels of entry and settlement, it is "entering student or humanitarian channels to access tertiary education." A separate multivariate analysis would be needed to determine significant associations between these and other movement patterns across the dimensions, and would be an important avenue for future research. The data reveal that 28 respondents, or just under 20 percent of the sample, cited all three of these patterns. Thus, they account for most of the cases in which respondents shaped all three dimensions of the process of movement in relation to tertiary education. Based on the narrative data of respondents, these three patterns appear to be related because "movement with life cycle transition" largely describes cases in which respondents are more able to express their agency and their movement closely resembles tertiary education mobility. In this way, there appears to be a higher incidence of these respondents exhibiting "movement to a higher education institution or sector" and "entering student channels to access tertiary education."

Based purely on the conceptualization of the different movement patterns and the indepth examination of respondent cases, another pattern with a clear relationship to other dimensions is "movement upon securing an educational opportunity in the destination." This timing pattern is not only connected to a specific destination, but also a migration channel, as respondents entered destination countries as international students. Future quantitative research using the data collected from this study should explore these intra and inter-dimensional associations between movement patterns, particularly to aid in uncovering less apparent connections, as well as the existence of well-trodden movement trajectories related to tertiary education and whether certain respondent profiles are associated with certain patterns. Indeed, understanding potential links between the background characteristics and movement patterns could provide insight into which groups of refugees and migrants are less able to express their agency in relation to tertiary education and might therefore be targeted for educational interventions. 


\subsection{Implications for Forced Displacement}

The review of the forced displacement literature in Chapter Two revealed that the more historical literature on forced displacement patterns sought to theorize and create typologies of how refugees move. Such studies played a crucial role in prompting researchers to examine what is unique about forced displacement and what shapes the timing and destination of forced movements. While refugee agency occupied a space within these frameworks, underscoring its importance, its conceptualization and the conceptualization of refugee mobility remained thin. By contrast, more contemporary studies on forced displacement patterns have highlighted the numerous ways in which refugees express their agency to shape their movements. Moreover, they have argued that refugees might have moved without the presence of persecution or conflict, as people often have mobility-related norms, aspirations, and practices that pre-exist or co-exist with conflict (Bakewell and Bonfiglio 2013). Indeed, Kibreab (1996) argued that preexisting mobility strategies linked to economic deprivation and political oppression shape forced displacement patterns.

By examining pre-existing mobility strategies linked to tertiary education attainment, this study has shown that a more dynamic relationship exists between forced displacement and pre-existing mobility patterns. This relationship sees forced displacement determinants and patterns constraining or impeding movement that would have otherwise taken place as well as pre-existing mobility patterns impacting forced displacement by providing a well-trodden path, built-in networks, and more aspirational and social connections to a destination. This relationship also sees forced displacement and mobility patterns combining to yield new or transformed patterns of (forced) movement, for instance: with the internationalization of previously internal educational mobility patterns; with the initiation of longer-distance, international forced displacements to destinations offering greater opportunities for tertiary education; or with the delaying of forced displacement and, at times, engaging in internal displacement, to gain an opportunity for international student mobility.

This more dynamic relationship underscores the fact that we must re-think how we answer the question: "What is forced displacement?" and reconsider the tools and methodological approaches that accompany studies of such a question. Conceptualizations of forced migration should encompass a notion of (refugee) mobility in order to understand, explain, and ultimately accommodate through policy and practice the diversity and complexity of movement originating from countries afflicted by conflict and crisis, particularly countries like the DRC and Somalia where conflict and crisis are protracted conditions. Failing to do so risks denying or constraining attempts by people 
to use mobility as part of their livelihood and protection strategies, displacing people to other legal or irregular channels, and being out of touch with the livelihoods and protection needs of vulnerable people.

A concept of refugee mobility would allow for forced displacement to be recognized, as migration is recognized, as part of a broader process of socio-economic and political transformation and as encompassing a rich variety of expressions of agency. Just one example of how a more nuanced concept of refugee mobility would enhance our understanding - and hence, responses to - forced displacement comes from Chapter Six on the timing of movement. In this chapter, we observed how the timing of exit was as much a part of respondents' personal timelines and life cycles as it was about external events and forces, such as outbreaks in violence. Hence, the movement of some respondents took place outside known periods of violence and instability and occurred when they felt most able to make the journey and the decision to become a refugee in another country and to provide for their livelihoods in displacement. Contemporary policy and practice trends might mean that these people would be classified as irregular and moving within "mixed migration flows," whereas they see themselves as asylum seekers and/or in need of international protection.

From a research perspective, adapting concepts from migration studies to understand refugee mobility does not detract from the unique experiences that refugees and other forced migrants face linked to persecution, violence, and conflict, nor does it detract from their legal claim to international protection. This fact, while crystalized within this study through the examination of refugee tertiary education mobility, is relatively well known in refugee studies, particularly within the field of anthropology. Applying methodological and theoretical concepts from migration studies:

"[S]tems from the concern that refugees are not mere victims but people adapting to the world system, using their social and cultural resource [sic]. Refugees and other types of migrants share a number of social features, and individuals may belong to several categories at a time or successively" (Monsutti 2008: 65).

The narratives of refugees and migrants pursuing tertiary education in this study serve as a striking example of such adaptation to the world system and to using their socioeconomic, political, and human capital to do so. In most other contexts, the pursuit of tertiary education across an international border would be a process of enhancing one's human capital and entering a privileged highly skilled and highly mobile channel. For Congolese and Somali respondents, it is such a process at the same time as it is a means of avoiding persecution and violence and (re)building their livelihoods. 


\subsection{Implications for Complementary Protection Pathways through Higher Education}

As defined at the start of this study, complementary protection pathways are "safe and regulated avenues by which refugees may live in a country and have their international protection needs met, while also being able to support themselves and reach sustainable and lasting solutions" (UNHCR 2018a). In the context of tertiary education, such pathways can take shape through international student channels or exceptional skills channels. For instance, the "Japanese initiative for the future of Syrian refugees" provides 100 Syrian refugee students the opportunity to pursue MA degrees and remain in Japan for at least five years (UNHCR 2018). The World University Service of Canada (WUSC) provides refugees living in asylum countries with scholarships to pursue university education in Canada and gain resettlement. Such programs underscore the value of higher education in providing complementary protection options.

In the current framing of tertiary education and complementary protection by UNHCR, international non-governmental organizations supporting refugee education, and member states, refugees from countries of asylum move to "third" countries to pursue higher education and gain protection. This research has shown that such a concept may also extend to the rights and protection that refugees seek out in asylum countries, albeit in different ways. This study observed respondents who entered student channels and, hence, who obtained an international student migrant status in lieu of a refugee status. For instance, Francis, whose case was detailed in Chapters Six and Eight, delayed his departure from the DRC and remained in a community afflicted by violence and insecurity until he secured admission to a South African university and a student visa. He perceived that entering South Africa through a student channel offered him a better opportunity to rebuild his life and the lives of his family members. Complementary protection in this sense takes on a different meaning and level of protection than it does in third countries. For Francis, the rights provided by his student visa were not complementary to refugee status, as he did not hold such a status. Consequently, this form of protection through higher education can more accurately be described as an alternative form of protection. Such an alternative brings with it great risk - perhaps the greatest risk - as it does not protect against refoulement.

On the other hand, this form of protection recognizes and overcomes the challenge that many refugees, and people who would qualify as refugees, perceive refugee status as highly undesirable both because it is a politicized status that marks them as in opposition to the governments in their origin countries and because it carries a heavy social stigma. This aspect is also recognized by the protection mechanism established by the International Cities of Refuge Network (ICORN) which provides temporary protection 
without granting refugee status to journalists, writers, and artists from abroad until the threat they face reduces. Protection through tertiary education in an "asylum" context should be seen within this innovative range of temporary protection measures. Those who are able, take steps to find alternative ways to access rights and protection outside of their origin countries and in place of seeking asylum.

Additionally, this study showed that international student channels can open up exceptional skills or highly-skilled channels, which are privileged channels of settlement in many countries and ones that lead to permanent residence and/or citizenship. Indeed, we learned that Francis switched into an exceptional skills channel in South Africa and was in the process of obtaining permanent residency at the time of the interview for this study. This type of protection pathway through higher education therefore opens the door to high-skilled mobility and a durable solution through local integration.

The protection identified and examined in this study is something conceptually different from the notion of complementary protection through higher education defined by UNHCR. It is also distinct from the notion of complementary protection used by many European countries as a humanitarian status provided to people who cannot be safely returned to their origin countries but who also do not qualify as refugees. The findings from this study both challenge and extend notions of complementary protection by critiquing the desirability of refugee status, understanding the links between different legal categories and their different implications for durable solutions, and exploring how complementary protection might function in an asylum context. Perhaps more importantly, this study brought attention to forms of protection created by refugees and migrants themselves, based on their practical considerations, aspirations, and norms. More research is needed on the quality of protection that complementary or alternative protection pathways create; the differences between individual and state-provided protection, including across countries; whether and how these protection pathways through tertiary education might be facilitated; and in what situations they are appropriate or desirable. There is a clear need for research on these non-traditional forms of protection for refugees, whether through international student or labor mobility, as possibilities for durable solutions become ever more elusive and international NGOs and United Nations agencies must look for alternative means for sustainable protection. 
WORKS CITED 
Abdi, Ali A. 1998. "Education in Somalia: History, destruction, and calls for reconstruction." Comparative Education 34(3):327-40.

Adepoju, Aderanti. 2000. "Issues and Recent Trends in International Migration in Sub-Saharan Africa." International Social Science Journal 52(165):383-94.

African_Union. 2017. "List of Countries which have Signed, Ratified/Acceded to the African Union Convention for the Protection and Assistance of Internally Displaced Persons in Africa (Kampala Convention)." edited by African Union. Addis Ababa: African Union.

Åkesson, Lisa. 2004. "Making a life. Meanings of migration in Cape Verde."

Ali, Syed. 2007. "'Go west young man': The culture of migration among Muslims in Hyderabad, India." Journal of Ethnic and Migration Studies 33(1):37-58.

Alzaroo, Salah, and Gillian Lewando Hunt. 2003. "Education in the Context of Conflict and Instability: The Palestinian Case." Social Policy \& Administration 37(2):165-80.

AMISOM. 2017. "Uganda - UPDF." African Union Mission in Somalia (AMISOM).

-. 2018. "AMISOM Background." African Union Mission in Somalia.

Amit, Roni, Darshan Vigneswaran, T Monson, and GM Wachira. 2009. "National survey of the refugee reception and status determination system in South Africa." Migrant Rights Monitoring Project (MRMP) Research Report. Johannesburg: Forced Migration Studies Programme, University of the Witwatersrand.

Amnesty_International. 2017. "South Africa: Promote social cohesion to end xenophobic attacks against African refugees and migrants." edited by Amnesty International.

Asis, Maruja Milagros B, Shirlena Huang, and Brenda SA Yeoh. 2004. "When the light of the home is abroad: Unskilled female migration and the Filipino family." Singapore Journal of Tropical Geography 25(2):198-215.

Atkinson, Rowland, and John Flint. 2001. "Accessing hidden and hard-to-reach populations: Snowball research strategies." Social research update 33(1):1-4.

Ayiemba, EO, and J Oucho. 2007. "Migration and Regional Development in Kenya." in IFSP workshop. South Africa.

Bagenda, Emmanuel, Angela Naggaga, and Elliott Smith. 2003. "Land problems in Nakivale settlement and the implications for refugee protection in Uganda." Refugee Law Project Working Paper Series 8.

Bailey, Sarah. 2004. "Is Legal Status Enough? Legal status and livelihood obstacles for urban refugees." The Fletcher School, MALD Thesis.

Bakewell, Oliver. 2009. "South-South migration and human development." IMI Working Paper (15).

-. 2010. "Some reflections on structure and agency in migration theory." Journal of Ethnic and Migration Studies 36(10):1689-708.

-. 2014. "Relaunching migration systems." Migration Studies 2(3):300-18.

Bakewell, Oliver, and Ayla Bonfiglio. 2013. "Moving Beyond Conflict: Re-framing mobility in the African Great Lakes region." IMI Working Paper No 71:34.

Bakewell, Oliver, Hein de Haas, and Agnieszka Kubal. 2011. "Migration systems, pioneers and the role of agency." International Migration Institute Working Papers Series. University of Oxford: Oxford. 
Baláž, Vladimír, and Allan M Williams. 2004. "'Been there, done that': international student migration and human capital transfers from the UK to Slovakia." Population, Space and Place 10(3):217-37.

BBC. 2017. "South Africa Clashes at Anti-Foreigner Protest in Pretoria." in BBC News.

Ben-Moshe, Danny, Ethnicity Victoria University. Institute for Community, Policy Alternatives, Santina Bertone, and Michele Grossman. 2008. "Refugee access and participation in tertiary education and training." Melbourne: Victoria University, Institute for Community, Ethnicity and Policy Alternatives.

Benezer, Gadi, and Roger Zetter. 2014. "Searching for Directions: Conceptual and Methodological Challenges in Researching Refugee Journeys." Journal of Refugee Studies 28(3):297-318.

Bennouna, Cyril, Elburg van Boetzelaer, Lina Rojas, Kinyera Richard, Gang Karume, Marius Nshombo, Leslie Roberts, and Neil Boothby. 2018. "Monitoring and reporting attacks on education in the Democratic Republic of the Congo and Somalia." Disasters 42(2):314-35.

Bevir, Mark, and Rod AW Rhodes. 2002. "Interpretive theory." Theory and methods in political science 1.

Black, Richard, JS Crush, Sally Peberdy, and Savina Ammassari. 2006. Migration and Development in africa: an Overview: Inst for Democracy in South Africa.

Black, Richard, Lyndsay M Hilker, and Claire Pooley. 2004. "Migration and Pro-Poor Policy in East Africa." Brighton: Development Research Centre on Migration, Globalisation and Poverty, University of Sussex.

Black, Richard, and Khalid Koser. 1999. The end of the refugee cycle?: Refugee repatriation and reconstruction: Berghahn Books.

Bloch, Alice. 2007. "Methodological challenges for national and multi-sited comparative survey research." Journal of Refugee Studies 20(2):230-47.

Blunch, Niels-Hugo. 2009. "Multidimensional human capital, wages, and endogenous employment status in Ghana." Labour Markets and Economic Development 73:367.

Bonfiglio, Ayla. 2009. "The Self-Reliance of Self-Settled versus Settlement Refugees in Uganda." Pp. 101 in Department of Political Science. New York: Columbia University.

-. 2010. "Learning outside the classroom: non-formal refugee education in Uganda." New Issues in Refugee Research 193.

Boyatzis, Richard E. 1998. Transforming qualitative information: Thematic analysis and code development: sage.

Boyle, Patrick M. 1995. "School wars: church, state, and the death of the Congo." The Journal of Modern African Studies 33(3):451-68.

Boyle, Paul, and Keith Halfacree. 1998. Migration into rural areas: theories and issues: John Wiley and Sons Ltd.

Bradley, Megan. 2019. "Unresolved and Unresolvable? Tensions in the Refugee Regime." Ethics \& International Affairs 33(1):45-56.

Buckland, P. 2005. Reshaping the Future: Education and Postconflict Reconstruction: World Bank.

Byrnes, R. M. 1992. "Uganda: A Country Study." Library Of Congress. Federal Research Division \& Thomas Leiper Kane Collection. 
Campbell, Elizabeth, Jeff Crisp, and Esther Kiragu. 2011. "Navigating Nairobi: A review of the implementation of UNHCR's urban refugee policy in Kenya's capital city." Geneva: UNHCR.

Cantor, David James. 2014. "The New Wave: Forced Displacement Caused by Organized Crime in Central America and Mexico." Refugee Survey Quarterly 33(3):34-68.

Carling, JØ rgen. 2002. "Migration in the age of involuntary immobility: theoretical reflections and Cape Verdean experiences." Journal of Ethnic and Migration Studies 28(1):5-42.

Carling, Jørgen. 2014. "The role of aspirations in migration." Determinants of International Migration, International Migration Institute, University of Oxford, Oxford 2325.

Carlson, Sören. 2013. "Becoming a mobile student-a processual perspective on German degree student mobility." Population, Space and Place 19(2):168-80.

Castles, Stephen. 2010. "Understanding global migration: A social transformation perspective." Journal of Ethnic and Migration Studies 36(10):1565-86.

Castles, Stephen, Hein De Haas, and Mark J Miller. 2013. The age of migration: International population movements in the modern world: Macmillan International Higher Education.

Castles, Stephen, Maja Korac, Ellie Vasta, and Steven Vertovec. 2002. "Integration: Mapping the field." Home Office online report 29(03):115-18.

CEI. 2014. "United for Tertiary Refugee Students." Washington, D.C.: Center for Education Innovations, Results for Development Institute.

Cernea, Michael M. 2003. "For a new economics of resettlement: a sociological critique of the compensation principle." International Social Science Journal 55(175):37-45.

Chapman, David W., and Samira Lindner. 2016. "Degrees of integrity: the threat of corruption in higher education." Studies in Higher Education 41(2):247-68.

Chatty, Dawn. 2007. "Researching Refugee Youth in the Middle East: Reflections on the Importance of Comparative Research." Journal of Refugee Studies 20(2):265-80.

Chelpi-den Hamer, Magali. 2009. "Educational attainments of Liberian refugees in Côte d'Ivoire (1992-2007): reflections on certification, equivalence and informal schooling for refugees." Certification Counts: Recognizing the Learning Attainments of Displaced and Refugee Students. Paris: IIEP-UNESCO.

Chiteng Kot, Felly. 2014. "Stakeholder participation in international higher education partnerships: results of a survey of two sub-Saharan African universities." Tertiary Education and Management 20(3):252-72.

Clark-Kazak, Christina. 2009. "Power and politics in migration narrative methodology: Research with young Congolese migrants in Uganda." Migration Letters 6(2):131.

-. 2010. "The Politics of Formal Schooling in Refugee Contexts: Education, Class, and Decision Making among Congolese in Uganda." Refuge 27(2).

Clark, Christina. 2006. "Livelihood networks and decision-making among Congolese young people in formal and informal refugee contexts in Uganda." Households in Conflict Network.

Clark, John F. 1998. "Foreign intervention in the civil war of the Congo Republic." African Issues 26(1):31-36.

Connected_Learning_Consortium. 2017. "About us." Connected Learning Consortium. 
Conner, Kerry. 1987. "An analysis of residential choice among self-settled Afghan refugees in Peshawar, Pakistan."

Connor, Kerry M. 1987. "Rationales for the movement of Afghan refugees to Peshawar." Afghan Resistance: the Politics of Survival:151-90.

Court, Alex. 2017. "“Growing hopelessness' grips 'forgotten' Somali refugees, warns UNHCR." Geneva: UNHCR.

Crea, Thomas M. 2016. "Refugee higher education: Contextual challenges and implications for program design, delivery, and accompaniment." International Journal of Educational Development 46:12-22.

Crush, Jonathan, Caroline Skinner, and Manal Stulgaitis. 2017. "Benign neglect or active destruction? A critical analysis of refugee and informal sector policy and practice in South Africa." African Human Mobility Review 3:751-82.

Czaika, Mathias. 2015. "Migration and economic prospects." Journal of Ethnic and Migration Studies 41(1):58-82.

Czaika, Mathias, and Hein De Haas. 2013. "The effectiveness of immigration policies." Population and Development Review 39(3):487-508.

Czaika, Mathias, and Krisztina Kis-Katos. 2007. "Civil conflict and displacement."

de Haas, Hein. 2010. "Migration transitions: a theoretical and empirical inquiry into the developmental drivers of international migration." in IMI Working Paper No. 24. Oxford: International Migration Institute, University of Oxford.

-. 2011. "The determinants of international migration: Conceptualizing policy, origin and destination effects." in IMI Working Paper. Oxford: International Migration Institute, University of Oxford.

-. 2014. Migration theory: Quo vadis?: International Migration Institute, University of Oxford.

Derry, Min. 2017. "Research Writing: What's Your Positionality?" in Weingarten Learning Resources. Philadelphia: Weingarten Learning Resources Center, University of Pennsylvania.

DHASA. 2017. "Refugee Status \& Asylum." Pretoria: Department of Home Affairs Republic of South Africa.

DHET. 2012. "Green Paper for Post-School Education and Training." Pretoria: Department of Higher Education and Training (DHET), Republic of South Africa.

-. 2015. "Annual Report 2014/2015." Pretoria: Department of Higher Education and Training, Republic of South Africa.

Dippo, D, A Orgocka, and W Giles. 2012. "Feasibility study report: Reaching Higher: The Provision of Higher Education for Long-Term Refugees in the Dadaab Camps, Kenya." The Borderless Higher Education for Refugees Partnership/York University, Toronto, Canada.

Dodds, Tony, and Solomon Inquai. 1983. Education in Exile: The Educational Needs of Refugees. IEC Broadsheets on Distance Learning No. 20: ERIC.

Donald, Heather Anne. 2014. "Preparing for Uncertainty: Exploring Access to Higher Education in Dzaleka Refugee Camp, Malawi."

Dryden-Peterson, S, and L Hovil. 2003. "Local integration as a durable solution: refugees, host populations and education in Uganda (New Issues in Refugee Research Working Paper No. 93)." Geneva: Evaluation and Policy Analysis Unit, UNHCR. 
Dryden-Peterson, Sarah. 2003. "Education of refugees in Uganda: Relationships between setting and access." Kampala, Uganda: Refugee Law Project.

-. 2010. "The Politics of Higher Education for Refugees in a Global Movement for Primary Education." Refuge 27(2).

-. 2011. "Refugee Education: A Global Review." Geneva: Policy Development and Evaluation Service, UNHCR.

Duval, David Timothy. 2004. "Linking return visits and return migration among Commonwealth Eastern Caribbean migrants in Toronto." Global Networks 4(1):51-67.

Earnest, Jaya, Andrew Joyce, Gabriella de Mori, and Genevieve Silvagni. 2010. "Are universities responding to the needs of students from refugee backgrounds?" Pp. pp.155-74. Camberwell: ACER.

Easthope, Hazel, and Michelle Gabriel. 2008. "Turbulent lives: Exploring the cultural meaning of regional youth migration." Geographical research 46(2):172-82.

Eastmond, Marita. 2007. "Stories as Lived Experience: Narratives in Forced Migration Research." Journal of Refugee Studies 20(2):248-64.

El Jack, Amani. 2010. "“Education Is My Mother and Father": The "Invisible” Women of Sudan." Refuge 27(2).

Emirbayer, Mustafa, and Ann Mische. 1998. "What is agency?" American journal of sociology 103(4):962-1023.

Engel, Stefanie, and Ana María Ibáñez. 2007. "Displacement due to violence in Colombia: A household-level analysis." Economic Development and Cultural Change 55(2):335-65.

Farah, Randa. 2010. "“Knowledge in the Service of the Cause": Education and the Sahrawi Struggle for Self-Determination." Refuge 27(2).

Ferro, Anna. 2006. "Desired mobility or satisfied immobility? Migratory aspirations among knowledge workers." Journal of Education and Work 19(2):171-200.

Fetterman, David M. 1998. Ethnography: Step by Step, Second Edition. Thousand Oaks: Sage Publications, Inc.

Fiddian-Qasmiyeh, Elena. 2009. "Representing Sahrawi Refugees' ‘Educational Displacement' to Cuba: Self-sufficient Agents or Manipulated Victims in Conflict?" Journal of Refugee Studies 22(3):323-50.

-. 2010. "Education, migration and internationalism: situating Muslim Middle Eastern and North African students in Cuba." The Journal of North African Studies 15(2):137-55.

-. 2011. "Paradoxes of Sahrawi refugees' educational migration: promoting self-sufficiency or renewing dependency?" Comparative Education 47(4):433-47.

Findlay, Allan M, Russell King, Fiona M Smith, Alistair Geddes, and Ronald Skeldon. 2012. "World class? An investigation of globalisation, difference and international student mobility." Transactions of the Institute of British Geographers 37(1):118-31.

Frye, Margaret. 2012. "Bright futures in Malawi's new dawn: Educational aspirations as assertions of identity." American Journal of Sociology 117(6):1565-624.

Galasińska, Aleksandra, and Olga Kozlowska. 2009. "Either'and 'Both'-the changing concept of living space among Polish post-communist migrants to the United Kingdom." Globalization and language in contact: Scale, migration and communicative practices:170-89. 
GCPEA. 2018. Education Under Attack 2018. New York: Global Coalition to Protect Education from Attack.

Geertz, Clifford. 1994. "Thick description: Toward an interpretive theory of culture." Readings in the philosophy of social science:213-31.

Giddens, Anthony. 1991. "Structuration theory." Past, Present and Future. In: Bryant, C. and Jary, D.(eds.). Giddens' Theory of Structuration. A Critical Appreciation. London: Routledge.

Goitom, Hanibal. 2016. "Refugee Law and Policy: Kenya." in Legal Reports, edited by Library of Congress. Washington, D.C.: Library of Congress.

Hampshire, Kate, and Sara Randall. 1999. "Seasonal labour migration strategies in the Sahel: coping with poverty or optimising security?" International Journal of Population Geography 5(5):367-85.

Handmaker, Jeff, Lee Anne De la Hunt, and Jonathan Klaaren (Eds.). 2001. Perspectives on Refugee Protection in South Africa. Pretoria: Lawyers for Human Rights.

Hannah, Janet. 2000. "Education, training and adult refugees in the UK and Australia." Pp. pp.26375 in Lifelong learning: education across the lifespan. London: RoutledgeFalmer.

Hansen, Art. 1981. "Refugee Dynamics: Angolans in Zambia 1966 to 1972." International Migration Review 15(1/2):175-94.

Harris, Thomas. 2018. "The importance of administrative justice rights in international refugee law: a case study of South Africa." University of Cape Town.

Hashim, Iman. 2007. "Independent child migration and education in Ghana." Development and Change 38(5):911-31.

Haug, Ruth. 2002. "Forced migration, processes of return and livelihood construction among pastoralists in Northern Sudan." Disasters 26(1):70-84.

Hazen, Helen D., and Heike C. Alberts. 2006. "Visitors or immigrants? International students in the United States." Population, Space and Place 12(3):201-16.

Heering, Liesbeth, Rob Van Der Erf, and Leo Van Wissen. 2004. "The role of family networks and migration culture in the continuation of Moroccan emigration: A gender perspective." Journal of Ethnic and Migration Studies 30(2):323-37.

Helgesson, Linda. 2006. "Getting ready for life: Life strategies of town youth in Mozambique and Tanzania." in Department of Social and Economic Geography. Umea: Umea University.

Hinchman, Lewis P, and Sandra Hinchman. 1997. Memory, identity, community: The idea of narrative in the human sciences: Suny Press.

HIPS. 2013. "The State of Higher Education in Somalia: Privatization, rapid growth, and the need for regulation." Heritage Institute for Policy Studies.

Hitchen, Jamie. 2016. "Steady progress? 30 years of Museveni and the NRM in Uganda."

Hitlin, Steven, and Glen H. Elder. 2007. "Time, Self, and the Curiously Abstract Concept of Agency*." Sociological Theory 25(2):170-91.

Hogg, Richard. 1986. "The new pastoralism: poverty and dependency in northern Kenya." Africa 56(3):319-33.

Horváth, István. 2008. "The culture of migration of rural Romanian youth." Journal of Ethnic and Migration Studies 34(5):771-86.

Hovil, Lucy. 2007. "Self-settled refugees in Uganda: An alternative approach to displacement?" Journal of Refugee Studies 20(4):599-620. 
Hynes, Tricia. 2003. "The issue of 'trust' or 'mistrust'in research with refugees: choices, caveats and considerations for researchers." in New Issues in Refugee Research. Geneva: Evaluation and Policy Analysis Unit, UNHCR.

ICEF. 2016. "Kenyan students staying home in greater numbers but quality concerns persist." in ICEF Monitor. Nairobi: International Consultants for Education and Fairs (ICEF).

-. 2017. "Kenya cracks down in sweeping review of higher education quality." in ICEF Monitor. Nairobi: International Consultants for Education and Fairs (ICEF).

IRIN. 2018. "Armed Groups in Eastern DRC." in IRIN.

Jacobsen, Karen. 2006. "Refugees and asylum seekers in urban areas: a livelihoods perspective." Journal of Refugee Studies 19(3):273-86.

Jacobsen, Karen, and Loren Brett Landau. 2003. Researching refugees: some methodological and ethical considerations in social science and forced migration: UNHCR Geneva.

Jewsiewicki, Bogumil. 2008. "Residing in Kinshasa: between colonial modernization and globalization." Research in African Literatures:105-19.

Jones, Huw, and Sirinan Kittisuksathit. 2003. "International labour migration and quality of life: Findings from rural Thailand." International Journal of Population Geography 9(6):517-30.

Kandel, William, and Douglas S Massey. 2002. "The culture of Mexican migration: A theoretical and empirical analysis." Social Forces 80(3):981-1004.

Kasara, Kimuli. 2017. "Does Local Ethnic Segregation Lead to Violence?: Evidence from Kenya." Quarterly Journal of Political Science 11(4):441-70.

Keatley, P. 2003. "Idi Amin." in The Guardian.

Keller, Stephen L. 1975. Uprooting and social change: The role of refugees in development: Manohar Book Service.

Kelly, Robert L. 1983. "Hunter-gatherer mobility strategies." Journal of anthropological research 39(3):277-306.

Kibreab, Gaim. 1996. "Eritrean and Ethiopian urban refugees in Khartoum: What the eye refuses to see." African Studies Review 39(3):131-78.

Kimani, M. 2008. "East Africa Feels Blows of Kenyan Crisis." Africa Renewal.

King, Russell, and Parvati Raghuram. 2013. "International Student Migration: Mapping the Field and New Research Agendas." Population, Space and Place 19(2):127-37.

Kinyanjui, Kabiru. 2007. "The transformation of higher education in Kenya: challenges and opportunities." Mijadala on social policy, governance and development in Kenya 9.

Kivati, Gladys. 2017. "The Role of Kenya's formal higher education in sustainable development within the context of globalization." Pp. 17-33 in Handbook of theory and practice of sustainable development in higher education: Springer.

Knudsen, Are John. 2018. "The Great Escape? Converging Refugee Crises in Tyre, Lebanon." Refugee Survey Quarterly 37(1):96-115.

Koser, Khalid. 1996. "INFORMATION AND REFUGEE MIGRATION: THE CASE OF MOZAMBICANS IN MALAWI." Tijdschrift voor economische en sociale geografie 87(5):40718.

-. 1997. "Social Networks and the Asylum Cycle: The Case of Iranians in the Netherlands." The International Migration Review 31(3):591-611. 
Koti, Francis T. 2010. "Confronting sociospatial exclusion on the fringe of Africa's cities using participatory GIS: Lessons from Athi River Town, Kenya." Africa Today 56(3):62-82.

Kpandji, Simplice. 2013. "UNHCR urges protection for civilians amid fresh fighting in DR Congo." Geneva: UNHCR.

Kritz, Mary M. 2015. "International student mobility and tertiary education capacity in Africa." International Migration 53(1):29-49.

Kunz, Egon F. 1981. "Exile and resettlement: refugee theory." International Migration Review:42-51.

-. 1973. "The Refugee in Flight: Kinetic Models and Forms of Displacement." International Migration Review 7(2):125-46.

Kureková, Lucia. 2011. "The role of welfare systems in affecting out-migration: the case of Central and Eastern Europe."

Landau, Loren B. 2006. "Protection and Dignity in Johannesburg: Shortcomings of South Africa's Urban Refugee Policy." Journal of Refugee Studies 19(3):308-27.

Lanzi Mazzocchini, EM. 2008. "Policy implications learned from the analysis of the integration of refugees and asylum-seekers at tertiary education in Cape Town." Unpublished Master's thesis. Dublin: University College Dublin. http://siteresources. worldbank. org/INTLM/Resources/3900411244141510600/Nyenti_Plessis_Apon-South_Africa-2007. pdf [20 October 2011].

Lee, Everett S. 1966. "A Theory of Migration." Demography 3(1):47-57.

Lee, Stacey. 1997. "The Road to College: Hmong American Women's Pursuit of Higher Education." Harvard Educational Review 67(4):803-28.

Liang, Xiaoyang. 2004. Uganda tertiary education sector report: The World Bank.

Lindley, Anna. 2009. "The Early-Morning Phonecall: Remittances from a Refugee Diaspora Perspective." Journal of Ethnic and Migration Studies 35(8):1315-34.

-. 2010. "Leaving Mogadishu: Towards a Sociology of Conflict-Related Mobility." Journal of Refugee Studies 23(1):2-22.

-. 2011. "Between a Protracted and a Crisis Situation: Policy Responses to Somali Refugees in Kenya." Refugee Survey Quarterly 30(4):14-49.

Lindley, Anna, and Nicholas Van Hear. 2007. "New Europeans on the Move: A preliminary review of the onward migration of refugees within the European Union." Oxford: Centre on Migration, Policy and Society (COMPAS), University of Oxford.

Lomo, Zachary, Angela Naggaga, and Lucy Hovil. 2001. "The phenomenon of forced migration in Uganda: an overview of policy and practice in an historical context." Refugee Law Project, Working Paper 1.

Long, Katy. 2009. "Extending protection?: labour migration and durable solutions for refugees." New Issues in Refugee Research.

-. 2013. "When refugees stopped being migrants: Movement, labour and humanitarian protection." Migration Studies 1(1):4-26.

-. n.d. Free to Move Not Forced to Move: Refugees, Identity Documents and Citizenship.

Lopez Rodriguez, Magdalena. 2010. "Migration and a quest for 'normalcy'. Polish migrant mothers and the capitalization of meritocratic opportunities in the UK." Social identities 16(3):339-58. 
Lubkemann, Stephen C. 2000. "The Transformation of Transnationality among Mozambican Migrants in South Africa." Canadian Journal of African Studies / Revue Canadienne des Etudes Africaines 34(1):41-63.

-. 2008. "Involuntary Immobility: On a Theoretical Invisibility in Forced Migration Studies." Journal of Refugee Studies 21(4):454-75.

Lyytinen, Eveliina. 2015. "Refugees' Conceptualizations of "Protection Space": Geographical Scales of Urban Protection and Host-Refugee Relations." Refugee Survey Quarterly 34(2):45-77.

Mabogunje, Akin L. 1970. "Systems Approach to a Theory of Rural-Urban Migration." Geographical Analysis 2(1):1-18.

Macchiavello, Michela. 2003. Forced migrants as an under-utilized asset: refugee skills, livelihoods, and achievements in Kampala, Uganda: UNHCR Policy and Evaluation Unit.

Mackinnon, Hayley. 2014. Education in emergencies: The case of the Dadaab refugee camps: CIGI.

MacLaren, Duncan. 2010. "Tertiary Education for Refugees: A Case Study from the Thai-Burma Border." Refuge 27(2).

Madikane, Miranda, and Kimberly Brennan. 2016. "Scalabrini Centre of Cape Town." edited by Ayla Bonfiglio. Cape Town, South Africa.

Malkki, Liisa H. 1995. "Refugees and exile: From "refugee studies" to the national order of things." Annual review of anthropology:495-523.

Martin, Gayle H, and Obert Pimhidzai. 2013. "Service delivery indicators: Kenya." in Service Delivery Indicators: Education and Health. Kenya.

Mason, Elisa. 2000. "Forced migration studies: surveying the reference landscape." Libri 50(4):24151.

Massey, Douglas S, Joaquin Arango, Graeme Hugo, Ali Kouaouci, Adela Pellegrino, and J Edward Taylor. 1993. "Theories of international migration: A review and appraisal." Population and Development Review 19(3):431-66.

Massey, Douglas S. 1990. "Social Structure, Household Strategies, and the Cumulative Causation of Migration." Population Index 56(1):3-26.

Maxwell, Joseph A. 2004. "Qualitative Research Design: An Interactive Approach Author: Joseph A. Maxwell, Publisher: Sage Publications, Inc Pages."

McGrath, Simon, and Salim Akoojee. 2007. "Education and skills for development in South Africa: Reflections on the accelerated and shared growth initiative for South Africa." International Journal of Educational Development 27(4):421-34.

McKnight, Janet. 2008. "Through the fear: a study of xenophobia in South Africa's refugee system." Journal of Identity and Migration Studies 2(2):18-42.

Meny-Gibert, Sarah, and Sintha Chiumia. 2016. "FACTSHEET: Where do South Africa's international migrants come from?", edited by Nechama Brodie: Africa Check.

Miles, Matthew B, and A Michael Huberman. 1994. Qualitative data analysis: An expanded sourcebook: Sage.

Misago, Jean Pierre, Iriann Freemantle, and LB Landau. 2015. "Protection from xenophobia: An evaluation of UNHCR's regional office for Southern Africa's xenophobia related programmes." University of Witwatersrand, ACMS. 
Mohamedbhai, Goolam. 2014. "Massification in higher education institutions in Africa: Causes, consequences and responses." International Journal of African Higher Education 1(1).

Monsutti, Alessandro. 2008. "Afghan migratory strategies and the three solutions to the refugee problem." Refugee Survey Quarterly 27(1):58-73.

Mooney, Erin. 2005. "The concept of internal displacement and the case for internally displaced persons as a category of concern." Refugee Survey Quarterly 24(3):9-26.

Moore, K. 2001. "Frameworks for Understanding the Intergenerational Transmission of Poverty and Well-being in Developing Countries." in CPRC Working Paper No. 8. Manchester: Chronic Poverty Research Centre.

Moretti, Enrico. 2004. "Estimating the social return to higher education: evidence from longitudinal and repeated cross-sectional data." Journal of Econometrics 121(1):175-212.

Morlang, Claas, and Carolina Stolte. 2008. "Tertiary Refugee Education in Afghanistan: Vital for Reconstruction." Forced Migration Review 30(April).

Morlang, Claas, and Sheri Watson. 2007. Tertiary Refugee Education Impact and Achievements: 15 Years of DAFI;[Albert Einstein Academic Refugee Initiative (DAFI) Programme]: UNHCR.

Morris, Alan, and Antoine Bouillon. 2001. "African Immigration to South Africa: francophone migrants of the 1990s."

Mulumba, Deborah, and Wendo Mlahagwa Olema. 2009. "Policy analysis report: Mapping migration in Uganda." Makerere University and Mbarara University of Science and Technology.

Nations, United. 2016. "New York Declaration for Migrants and Refugees." in A/RES/71/1, edited by United Nations General Assembly. New York: United Nations.

NCHE. 2013a. "The State of Higher Education and Training in Uganda 2011." Kampala: National Council for Higher Education.

-. 2013b. "The state of higher education and training in Uganda 2011: A Report on higher education delivery and institutions." Kyambogo, Kampala: National Council for Higher Education.

Ngolovoi, Mary, and Pamela Marcucci. 2006. "Higher education finance and cost-sharing in Uganda."

Ní Laoire, Caitríona. 2000. "Conceptualising Irish rural youth migration: a biographical approach." International Journal of Population Geography 6(3):229-43.

Nussbaum, Martha C. 2001. Women and Human Development: The Capabilities Approach: Cambridge University Press.

Oh, Su-Ann, and Marc van der Stouwe. 2008. "Education, Diversity, and Inclusion in Burmese Refugee Camps in Thailand." Comparative Education Review 52(4).

Okello, J O Moses. 2014a. "The 1969 OAU Convention and the continuing challenge for the African Union." Forced Migration Review 48(November):70-73.

-. 2014b. "The 1969 OAU Convention and the continuing challenge for the African Union." Forced Migration Review (48).

Okumu, Maurice J. 2013. "Financial Devolution under the Constitution of Kenya 2010: The Question of Equitable Distribution of Resources." in School of Law. Nairobi: University of Nairobi. 
Oldenburg, Silke. 2016. "' I am an Intellectual". War, Youth and Higher Education in Goma (Eastern Congo)." AnthropoChildren 2016(6).

Otunnu, Ogenga. 1994. "Refugee movements from the Sudan: an overview analysis." Refuge: Canada's Journal on Refugees 13(8).

Owino, Kwame, Noah Wamalwa, and Ivory Ndekei. 2017. "How Kenya is Failing to Create Decent Jobs." in CounterPoints: Africa Research Institute.

Oyugi, Walter O. 2002. "Politicized Ethnic Conflict in Kenya: A Periodic Phenomenon." in African Conflicts: Their Management, Resolution, and Post-Conflict Reconstruction, edited by Abadalla Bujra and Abdel Ahmed. Addis Ababa DPMF/OSSREA.

Parker, John. 2000. Structuration: Open University Press.

Pavanello, Sara, Samir Elhawary, and Sara Pantuliano. 2010. Hidden and exposed: Urban refugees in Nairobi, Kenya: Overseas Development Institute London.

Peberdy, Sally. 2013. "GCRO Data Brief: No. 5." Johannesburg: Gauteng City-Region Observatory (GCRO), University of Johannesburg, University of the Witwatersrand, Gautend Provincial Government (GPG).

Peberdy, Sally, and Jonathan Crush. 1998. "Rooted in racism: The origins of the Aliens Control Act." Beyond control: Immigration and human rights in a democratic South Africa:18-36.

Petersen, William. 1958. "A general typology of migration." American Sociological Review:256-66.

Porter, Gina, Kate Hampshire, Mac Mashiri, Sipho Dube, and Goodhope Maponya. 2010. "'Youthscapes' and escapes in rural Africa: Education, mobility and livelihood trajectories for young people in Eastern Cape, South Africa." Journal of International Development 22(8):1090-101.

Powles, Julia. 2004. Life History and Personal Narrative: Methodological Issues Relevant to Research and Evaluation in Refugee Contexts: UNHCR, Evaluation and Policy Analysis Unit.

Prokop, Pamela. 2013. "Strategies utilized by African refugee and immigrant students in order to persist in post-secondary career and technical education programs." [Minneapolis]: University of Minnesota.

Punch, Samantha. 2002. "Youth transitions and interdependent adult-child relations in rural Bolivia." Journal of Rural Studies 18(2):123-33.

-. 2007a. "Migration Projects: Children on the Move for Work and Education." in Workshop on Independent Child Migrants: Policy Debates and Dilemmas. Central Hall, Westminster, London: Development and Research Centre on Migration, Globalisation and Poverty, University of Sussex

UNICEF Innocenti Research Centre.

-. 2007b. "Migration Projects: Children on the Move for Work and Education." in Independent Child Migrants: Policy Debates and Dilemmas: Development Research Centre on Migration, Globalisation and Poverty, University of Sussex and UNICEF Innocenti Research Centre.

Rabikowska, Marta. 2010. "The ritualisation of food, home and national identity among Polish migrants in London." Social identities 16(3):377-98.

Rafi, Bilal, and Phil Lewis. 2013. "Indian higher education students in Australia: Their patterns and motivations." Australian Journal of Education 57(2):157-73. 
Reyntjens, Filip. 2005. "The privatisation and criminalisation of public space in the geopolitics of the Great Lakes region." The Journal of Modern African Studies 43(4):587-607.

Richmond, A.H. 1993. "Reactive Migration: Sociological Perspectives On Refugee Movements." Journal of Refugee Studies 6(1):7-24.

Richmond, Anthony H. 1988. "Sociological theories of international migration: the case of refugees." Current Sociology 36(2):7-25.

Rubbers, Benjamin. 2009. "The story of a tragedy: how people in Haut-Katanga interpret the postcolonial history of Congo." The Journal of Modern African Studies 47(2):267-89.

Rutinwa, Bonaventure. 2017. "The end of asylum? The changing nature of refugee policies in Africa." Pp. 35-64 in International Refugee Law: Routledge.

Sabot, R. H. 1972. "Education, Income Distribution and URban Migration in Tanzania." Dar es Salaam: Economic Research Bureau, University of Dar es Salaam.

SADC. 2012. "Immigration." Gabarone: Southern African Development Community.

Scalabrini. 2019. "Teach Yourself: The Refugees Amendment Act Explained ". Cape Town: Scalabrini Centre.

Schapendonk, Joris. 2009. "Staying put in moving sands: The stepwise migration process of subSaharan African migrants heading north." Pp. 113-38 in Respacing Africa: Brill.

Schewel, Kerilyn. 2015. Understanding the aspiration to stay: a case study of young adults in Senegal: International Migration Institute, University of Oxford.

Sen, Amartya. 1999. "Commodities and capabilities." OUP Catalogue.

Sennett, Justin, Gillian Finchilescu, Kerry Gibson, and Rosanna Strauss. 2003. "Adjustment of black students at a historically white South African university." Educational Psychology 23(1):107-16.

Shakya, Yogendra B. , Sepali Guruge, Michaela Hynie, Arzo Akbari, Mohamed Malik, Sheila Htoo, Azza Khogali, Stella Abiyo Mona, Rabea Murtaza, and Sarah Alley. 2010. "Aspirations for Higher Education among Newcomer Refugee Youth in Toronto: Expectations, Challenges, and Strategies." Refuge 27(2).

Shum, Terence C. T. 2014. "Refugees' Transnational Mobility: A Study of Asylum Seeking in Hong Kong and Urban Thailand." Refugee Survey Quarterly 33(4):50-80.

Skeldon, Ronald. 2014. Migration and development: A global perspective: Routledge.

Smith, James H. 2011. "Tantalus in the Digital Age: Coltan ore, temporal dispossession, and "movement" in the Eastern Democratic Republic of the Congo." American Ethnologist 38(1):17-35.

Sommers, Marc. 2003. "Education in Emergencies: Critical Questions and Challenges." Washington, D.C.: Creative Associates International.

Spindler, William. 2014. "UNHCR: Return of displaced people in Eastern DR Congo should be voluntary." Geneva: UNHCR.

Stark, Oded, and David Levhari. 1982. "On Migration and Risk in LDCs." Economic Development and Cultural Change 31(1):191-96.

Steele, Abbey. 2009. "Seeking Safety: Avoiding Displacement and Choosing Destinations in Civil Wars." Journal of Peace Research 46(3):419-29.

Stein, Barry N. 1981. "Part VI: Resources: The Refugee Experience: Defining the Parameters of a Field of Study." International Migration Review 15(1-2):320-30. 
Sterley, C., and K. Hiebert. 2016. "The Politics of Using Refugees as Election Fodder: The Case of Kenya's Government." in IOA Position Paper: In One Africa (IOA).

Stevenson, Jacqueline, and John Willott. 2007. "The aspiration and access to higher education of teenage refugees in the UK." Compare: A Journal of Comparative and International Education 37(5):671-87.

Stupart, Richard. 2016. "Is South Africa home to more than a million asylum seekers? The numbers don't add up." Africa Check.

Summers, Hannah. 2017. "Tensions rise as Uganda neighbourly refugee policy starts to feel the strain." in The Guardian. United Kingdom.

Tambe Endoh, Fabrice. 2015. "Democratic constitutionalism in post-apartheid South Africa: the interim constitution revisited." Africa Review 7(1):67-79.

Tati, Gabriel. 2008. "Working on South African Mines in a changing regional labour market: a reference to cross-border migrants from Swaziland." in Migrants' Experiences within the South African Labour Market, edited by Simona Gallo-Mosala. Cape Town: Scalabrini Centre of Cape Town.

-. 2009. "Some emerging theoretical perspectives on youth migration in the global migratory systems: the African experience." in New Frontiers of Child and Youth Research in Africa. Douala, Cameroon: Council for the Development of Social Science Research in Africa.

-. 2010. "Student Migration in South Africa: A Special reference to the Youth from Francophone Africa." Espace populations sociétés. Space populations societies (2010/2-3):281-96.

Taylor, Sandra, and Ravinder Kaur Sidhu. 2012. "Supporting refugee students in schools: What constitutes inclusive education?" International Journal of Inclusive Education 16(1):39-56.

Todaro, Michael P. 1976. Internal migration in developing countries: International Labour Office.

UNDESA. 2003. "Population, Education and Development: The Concise Report." Pp. 41-45. New York: United Nations Department of Economic and Social Affairs.

-. 2015. "Documentation." in Trends in International Migrant Stock: The 2015 Revision. New York: United Nations Department of Economic and Social Affairs, Population Division.

-. 2017a. "2017 Revision of World Population Prospects." edited by UNDESA/Population Division. New York.

-. 2017b. "Documentation." in Trends in International Migrant Stock: The 2017 Revision. New York: United Nations Department of Economic and Social Affairs, Population Division.

UNDP. 2016. "Human Development Report: Human Development for Everyone." in Human Development Reports. New York: United Nations Development Program.

UNECA. 2017. "African Migration: Drivers of Migration in Africa." in Background document for the Africa Regional Consultative Meeting on the Global Compact on Safe, Orderly and Regular Migration: United Nations Economic Commision for Africa.

UNHCR. 2003. "World Refugee Day 2003: Information Kit." Geneva: UNHCR.

-. 2009. "UNHCR Global Appea 2009 (update) - South Africa." in Global Appeal, edited by UNHCR. Geneva: UNHCR.

-. 2012. "Education Strategy: 2010-2012." Geneva: UNHCR.

-. 2014a. "Kenya: UNHCR disturbed by arrests and deportations of Somali refugees." Geneva and Nairobi: UNHCR.

-. 2014b. "Somalia Fact Sheet." edited by UNHCR. Geneva: UNHCR. 
-. 2014c. "UNHCR Statistical Yearbook 2014." Geneva: UNHCR.

-. 2015. "Global Trends in Forced Displacement." Geneva: UNHCR.

-. 2016a. "Global Trends in Forced Displacement 2015 Data Annex." in Global Trends, edited by UNHCR. Geneva: UNHCR.

-. 2016b. "Missing Out: Refugee Education in Crisis." Geneva: UNHCR.

-. 2017a. "DAFI Programme." UNHCR.

—. 2017b. "UNHCR's Strategic Directions 2017-2021." Geneva: UNHCR.

-. 2018a. "Complementary pathways through education." in Education: UNHCR.

-. 2018b. "Kalobeyei Settlement." edited by UNHCR. GVA: UNHCR.

-. 2018c. "Population Statistics." Geneva: UNHCR.

-. 2018d. "Uganda Comprehensive Refugee Response Portal: Refugee Settlements." in Refugees Operational Data Portal, edited by UNHCR.

UNICEF. 2016. "Somalia: The impact of language policy and practice on children's learning." in Country Review. Geneva: UNICEF.

UNOCHA. 2009. "Human Security in Theory and Practice: Application of the Human Security Concept and the United Nations Trust Fund for Human Security." Pp. 79. Geneva: Human Security Unit, United Nations Office for the Coordination of Humanitarian Affairs (UNOCHA).

Van Hear, N. 1998. New Diasporas: Taylor \& Francis.

Van Hear, Nicholas, Rebecca Brubaker, and Thais Bessa. 2009. "Managing mobility for human development: The growing salience of mixed migration."

Wacquant, Loïc JD. 1997. "Three pernicious premises in the study of the American ghetto." International Journal of Urban and Regional Research 21(2):341-53.

Wagenaar, Hendrik. 2014. Meaning in action: Interpretation and dialogue in policy analysis: Routledge.

Wellman, Elizabeth, and Loren B Landau. 2015. "South Africa's tough lessons on Migrant Policy." Foreign Policy.

Werker, E. 2002. "Refugees in Kyangwali Settlement: Constraints on Economic

Freedom." edited by Refugee Law Project. Kampala: Refugee Law Project.

Whittaker, Hannah. 2012. "Forced villagization during the shifta conflict in Kenya, ca. 1963-1968." The International Journal of African Historical Studies 45(3):343-64.

World_Bank. 2009. Accelerating Catch-Up: Tertiary Education for Growth in Sub-Saharan Africa. Washington, D.C.: World Bank.

Wright, Laura-Ashley, and Robyn Plasterer. 2010. "Beyond Basic Education: Exploring Opportunities for Higher Learning in Kenyan Refugee Camps." Refuge 27(2).

Yin, R. 2003. "Case study methodology." Sage: Thousand Oaks, CA, USA.

Zetter, Roger. 2018. "Conceptualising forced migration: Praxis, scholarship and empirics." Pp. 1943 in Forced Migration: Routledge.

Zeus, Barbara. 2010. "Exploring Paradoxes Around Higher Education in Protracted Refugee Situations." in Borderless Education Conference Toronto: Borderless Higher Education for Refugees. 
-. 2011. "Exploring Barriers to Higher Education in Protracted Refugee Situations: The Case of Burmese Refugees in Thailand." Journal of Refugee Studies 24(2):256.

Zolberg, Aristide R, Astri Suhrke, and Sergio Aguayo. 1986. "International factors in the formation of refugee movements." International Migration Review 20(2):151-69. 
ANNEX 


\section{A. Respondent Data}

\section{a. Total Sample Breakdown}

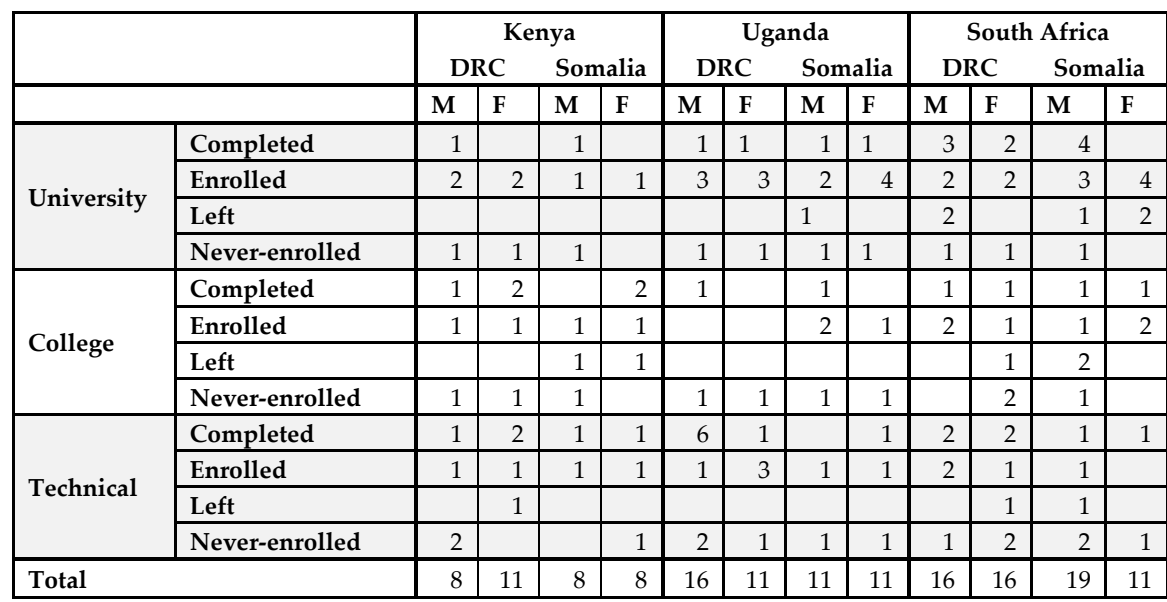

\section{b. Cross Tabulation: Timing Pattern by Destination Country}

\begin{tabular}{|l|r|r|r|r|}
\hline & $\begin{array}{c}\text { Kenya } \\
\mathbf{( 3 8 )}\end{array}$ & $\begin{array}{c}\text { Uganda } \\
\mathbf{( 4 9 )}\end{array}$ & $\begin{array}{c}\text { South } \\
\text { Africa } \\
\mathbf{( 6 2 )}\end{array}$ & $\begin{array}{c}\text { Total } \\
\mathbf{( 1 4 9 )}\end{array}$ \\
\hline Move follow tertiary education persecution & 1 & 3 & 4 & 8 \\
\hline Move follow achievement of educational milestone & 2 & 3 & 7 & 12 \\
\hline Move in response to educational constraint in origin & 1 & 5 & 14 & 20 \\
\hline Move upon educational opportunity in destination & 1 & 3 & 3 & 7 \\
\hline Move with life cycle transition & 5 & 21 & 17 & 43 \\
\hline Non Exhibitors timing & 30 & 21 & 28 & 79 \\
\hline Total (unique) & 38 & 49 & 62 & 149 \\
\hline
\end{tabular}


c. Cross Tabulation: Timing Pattern by Origin Country

\begin{tabular}{|l|r|r|r|}
\hline & \multicolumn{1}{|c|}{ DRC } & \multicolumn{1}{|c|}{ Somalia } & \multicolumn{1}{|c|}{ Total } \\
\hline Move follow tertiary education persecution & 7 & 1 & 8 \\
\hline Move follow achievement of educational milestone & 7 & 5 & 12 \\
\hline Move in response to educational constraint in origin & 13 & 7 & 20 \\
\hline Move upon educational opportunity in destination & 3 & 4 & 7 \\
\hline Move with life cycle transition & 21 & 22 & 43 \\
\hline Non Exhibitors timing & 42 & 37 & 79 \\
\hline Total (unique) & 81 & 68 & 149 \\
\hline
\end{tabular}

\section{d. Cross Tabulation: Timing Pattern by Gender}

\begin{tabular}{|l|r|r|r|}
\hline & \multicolumn{1}{|c|}{ Male } & \multicolumn{1}{|c|}{ Female } & \multicolumn{1}{|c|}{ Total } \\
\hline Move follow tertiary education persecution & 6 & 2 & 8 \\
\hline Move follow achievement of educational milestone & 9 & 3 & 12 \\
\hline Move in response to educational constraint in origin & 17 & 3 & 20 \\
\hline Move upon educational opportunity in destination & 4 & 3 & 7 \\
\hline Move with life cycle transition & 24 & 19 & 43 \\
\hline Non Exhibitors timing & 37 & 42 & 79 \\
\hline Total (unique) & 81 & 68 & 149 \\
\hline
\end{tabular}

\section{e. Cross Tabulation: Timing Pattern by Migration Status at Entry}

\begin{tabular}{|l|r|r|r|r|r|}
\hline & $\begin{array}{c}\text { Student } \\
\text { migrant }\end{array}$ & $\begin{array}{c}\text { Asylum } \\
\text { seeker }\end{array}$ & $\begin{array}{c}\text { Undocu- } \\
\text { mented }\end{array}$ & Tourist & Total \\
\hline Move follow tertiary education persecution & 0 & 7 & 0 & 0 & 7 \\
\hline Move follow achievement of educational milestone & 2 & 10 & 0 & 0 & 12 \\
\hline Move in response to educational constraint in origin & 4 & 14 & 0 & 2 & 20 \\
\hline Move upon educational opportunity in destination & 4 & 2 & 0 & 1 & 7 \\
\hline Move with life cycle transition & 23 & 17 & 1 & 1 & 42 \\
\hline Non Exhibitors timing & 1 & 76 & 0 & 0 & 77 \\
\hline Total (unique) & 26 & 114 & 1 & 4 & 145 \\
\hline
\end{tabular}




\section{f. Cross Tabulation: Timing Pattern by Tertiary Education Level}

\begin{tabular}{|l|r|r|r|r|}
\hline & Technical & College & University & Total \\
\hline Move follow tertiary education persecution & 1 & 2 & 2 & 5 \\
\hline Move follow achievement of educational milestone & 2 & 4 & 5 & 11 \\
\hline Move in response to educational constraint in origin & 4 & 4 & 11 & 19 \\
\hline Move upon educational opportunity in destination & 1 & 0 & 6 & 7 \\
\hline Move with life cycle transition & 3 & 11 & 23 & 37 \\
\hline Non Exhibitors timing & 26 & 12 & 16 & 54 \\
\hline Total (unique) & 37 & 28 & 50 & 115 \\
\hline
\end{tabular}

\section{g. Cross Tabulation: Timing Pattern by Relationship to Tertiary Education}

\begin{tabular}{|l|r|r|r|r|r|}
\hline & $\begin{array}{c}\text { Never } \\
\text { enrolled }\end{array}$ & $\begin{array}{c}\text { Dropped } \\
\text { out }\end{array}$ & Graduated & Enrolled & Total \\
\hline Move follow tertiary education persecution & 3 & 2 & 2 & 1 & 8 \\
\hline Move follow achievement of educational milestone & 1 & 1 & 6 & 4 & 12 \\
\hline Move in response to educational constraint in origin & 1 & 1 & 12 & 6 & 20 \\
\hline Move upon educational opportunity in destination & 0 & 0 & 4 & 3 & 7 \\
\hline Move with life cycle transition & 6 & 4 & 10 & 23 & 43 \\
\hline Non Exhibitors timing & 25 & 8 & 22 & 24 & 79 \\
\hline Total (unique) & 34 & 14 & 45 & 56 & 149 \\
\hline
\end{tabular}

\section{h. Cross Tabulation: Destination Pattern by Destination Country}

\begin{tabular}{|l|r|r|r|r|}
\hline & Kenya & Uganda & South Africa & \multicolumn{1}{|c|}{ Total } \\
\hline Movement to anglophone study destination & 3 & 18 & 5 & 26 \\
\hline Movement to tertiary institution or sector & 3 & 22 & 29 & 54 \\
\hline Movement to tertiary education regime & 0 & 2 & 7 & 9 \\
\hline Movement to labor market & 1 & 2 & 14 & 17 \\
\hline Non Exhibitors destination & 33 & 23 & 24 & 80 \\
\hline Total (unique) & 38 & 49 & 62 & 149 \\
\hline
\end{tabular}




\section{i. Cross Tabulation: Destination Pattern by Origin Country}

\begin{tabular}{|l|r|r|r|}
\hline & DRC & Somalia & Total \\
\hline Movement to anglophone study destination & 13 & 13 & 26 \\
\hline Movement to tertiary institution or sector & 28 & 26 & 54 \\
\hline Movement to tertiary education regime & 1 & 8 & 9 \\
\hline Movement to labor market & 6 & 11 & 17 \\
\hline Non Exhibitors destination & 49 & 31 & 80 \\
\hline Total (unique) & 81 & 68 & 149 \\
\hline
\end{tabular}

\section{j. Cross Tabulation: Destination Pattern by Gender}

\begin{tabular}{|l|r|r|r|}
\hline & Male & \multicolumn{1}{|c|}{ Female } & \multicolumn{1}{c|}{ Total } \\
\hline Movement to anglophone study destination & 15 & 11 & 26 \\
\hline Movement to tertiary institution or sector & 32 & 22 & 54 \\
\hline Movement to tertiary education regime & 6 & 3 & 9 \\
\hline Movement to labor market & 16 & 1 & 17 \\
\hline Non Exhibitors destination & 37 & 43 & 80 \\
\hline Total (unique) & 81 & 68 & 149 \\
\hline
\end{tabular}

\section{k. Cross Tabulation: Destination Pattern by Migration Status at Entry}

\begin{tabular}{|l|r|r|r|r|r|}
\hline & $\begin{array}{c}\text { Student } \\
\text { migrant }\end{array}$ & $\begin{array}{c}\text { Asylum } \\
\text { seeker }\end{array}$ & Undocumented & Tourist & Total \\
\hline Movement to anglophone study destination & 13 & 11 & 0 & 2 & 26 \\
\hline Movement to tertiary institution or sector & 23 & 27 & 0 & 4 & 54 \\
\hline Movement to tertiary education regime & 0 & 9 & 0 & 0 & 9 \\
\hline Movement to labor market & 0 & 14 & 1 & 1 & 16 \\
\hline Non Exhibitors destination & 1 & 76 & 0 & 0 & 77 \\
\hline Total (unique) & 26 & 114 & 1 & 4 & 145 \\
\hline
\end{tabular}




\section{Cross Tabulation: Destination Pattern by Tertiary Education Level}

\begin{tabular}{|l|r|r|r|r|}
\hline & Technical & College & University & Total \\
\hline Movement to anglophone study destination & 4 & 2 & 17 & 23 \\
\hline Movement to tertiary institution or sector & 7 & 12 & 30 & 49 \\
\hline Movement to tertiary education regime & 1 & 3 & 3 & 7 \\
\hline Movement to labor market & 3 & 5 & 6 & 14 \\
\hline Non Exhibitors destination & 27 & 13 & 14 & 54 \\
\hline Total (unique) & 37 & 28 & 50 & 115 \\
\hline
\end{tabular}

\section{m. Cross Tabulation: Destination Pattern by Relationship to Tertiary Education}

\begin{tabular}{|c|c|c|c|c|c|}
\hline & $\begin{array}{c}\text { Never } \\
\text { enrolled }\end{array}$ & $\begin{array}{c}\text { Dropped } \\
\text { out }\end{array}$ & Graduated & Enrolled & Total \\
\hline Movement to anglophone study destination & 3 & 2 & 6 & 15 & 26 \\
\hline Movement to tertiary institution or sector & 5 & 4 & 22 & 23 & 54 \\
\hline Movement to tertiary education regime & 2 & 0 & 3 & 4 & 9 \\
\hline Movement to labor market & 3 & 4 & 5 & 5 & 17 \\
\hline Non Exhibitors destination & 26 & 6 & 23 & 25 & 80 \\
\hline Total (unique) & 34 & 14 & 45 & 56 & 149 \\
\hline
\end{tabular}

\section{n. Cross Tabulation: Channel Pattern by Destination Country}

\begin{tabular}{|l|r|r|r|r|}
\hline & Kenya & Uganda & $\begin{array}{r}\text { South } \\
\text { Africa }\end{array}$ & Total \\
\hline Non Exhibitors channel & 33 & 26 & 30 & 89 \\
\hline Entering student or humanitarian channel to access tertiary education & 3 & 22 & 26 & 51 \\
\hline Avoiding humanitarian channel to access tertiary education & 2 & 4 & 1 & 7 \\
\hline Switching channel to access tertiary education and employment & 1 & 2 & 8 & 11 \\
\hline Total (unique) & 38 & 49 & 60 & 147 \\
\hline
\end{tabular}


o. Cross Tabulation: Channel Pattern by Origin Country

\begin{tabular}{|l|r|r|r|}
\hline & DRC & \multicolumn{1}{|c|}{ Somalia } & Total \\
\hline Non Exhibitors channel & 54 & 35 & 89 \\
\hline Entering student or humanitarian channels to access tertiary education & 25 & 26 & 51 \\
\hline Avoiding humanitarian channels to access tertiary education & 5 & 5 & 7 \\
\hline Switching channels to access tertiary education and employment & 5 & 6 & 11 \\
\hline Total (unique) & 81 & 66 & 147 \\
\hline
\end{tabular}

\section{p. Cross Tabulation: Channel Pattern by Gender}

\begin{tabular}{|l|r|r|r|}
\hline & Male & \multicolumn{1}{|c|}{ Female } & \multicolumn{1}{|c|}{ Total } \\
\hline Non Exhibitors channel & 45 & 44 & 89 \\
\hline Entering student or humanitarian channels to access tertiary education & 29 & 22 & 51 \\
\hline Avoiding humanitarian channels to access tertiary education & 5 & 2 & 7 \\
\hline Switching channels to access tertiary education and employment & 7 & 4 & 11 \\
\hline Total (unique) & 79 & 68 & 147 \\
\hline
\end{tabular}

\section{q. Cross Tabulation: Channel Pattern by Migration Status at Entry}

\begin{tabular}{|l|r|r|r|r|r|r|}
\hline & $\begin{array}{r}\text { Student } \\
\text { migrant }\end{array}$ & $\begin{array}{c}\text { Asylum } \\
\text { seeker }\end{array}$ & $\begin{array}{c}\text { Undocu- } \\
\text { mented }\end{array}$ & Tourist & Refugee & Total \\
\hline Non Exhibitors channel & 0 & 87 & 0 & 0 & 0 & 87 \\
\hline $\begin{array}{l}\text { Entering student or humanitarian } \\
\text { channel to access tertiary education }\end{array}$ & 26 & 22 & 0 & 3 & 0 & 51 \\
\hline $\begin{array}{l}\text { Avoiding humanitarian channel to } \\
\text { access tertiary education }\end{array}$ & 5 & 0 & 1 & 1 & 0 & 7 \\
\hline $\begin{array}{l}\text { Switching channel to access tertiary } \\
\text { education and employment }\end{array}$ & 2 & 8 & 0 & 1 & 0 & 11 \\
\hline Total (unique) & 26 & 114 & 1 & 4 & 0 & 145 \\
\hline
\end{tabular}




\section{r. Cross Tabulation: Channel Pattern by Migration Status at Interview}

\begin{tabular}{|l|r|r|r|r|r|r|r|r|}
\hline & $\begin{array}{c}\text { Student } \\
\text { migrant }\end{array}$ & Refugee & $\begin{array}{c}\text { Asylum } \\
\text { seeker }\end{array}$ & $\begin{array}{c}\text { Undocu- } \\
\text { mented }\end{array}$ & $\begin{array}{c}\text { Permanent } \\
\text { Resident }\end{array}$ & $\begin{array}{c}\text { High } \\
\text { Skilled }\end{array}$ & $\begin{array}{c}\text { Family } \\
\text { migrant }\end{array}$ & Total \\
\hline $\begin{array}{l}\text { Non Exhibitors } \\
\text { channel }\end{array}$ & 0 & 71 & 13 & 1 & 2 & 0 & 0 & 87 \\
\hline $\begin{array}{l}\text { Entering student/ } \\
\text { humanitarian channel } \\
\text { to access education }\end{array}$ & 24 & 18 & 6 & 1 & 0 & 2 & 0 & 51 \\
\hline $\begin{array}{l}\text { Avoiding } \\
\text { humanitarian channel } \\
\text { to access education }\end{array}$ & 4 & 0 & 0 & 2 & 0 & 1 & 0 & 7 \\
\hline $\begin{array}{l}\text { Switching channel to } \\
\text { access tertiary } \\
\text { education and } \\
\text { employment }\end{array}$ & 2 & 2 & 0 & 0 & 4 & 2 & 1 & 11 \\
\hline Total (unique) & 24 & 89 & 19 & 4 & 6 & 2 & 1 & 145 \\
\hline
\end{tabular}

\section{s. Cross Tabulation: Channel Pattern by Tertiary Education Level}

\begin{tabular}{|l|r|r|r|r|}
\hline & Technical & College & University & Total \\
\hline Non Exhibitors channel & 30 & 15 & 14 & 59 \\
\hline $\begin{array}{l}\text { Entering student or humanitarian channel to access tertiary } \\
\text { education }\end{array}$ & 5 & 11 & 32 & 48 \\
\hline Avoiding humanitarian channel to access tertiary education & 1 & 1 & 5 & 7 \\
\hline Switching channel to access tertiary education and employment & 1 & 2 & 8 & 11 \\
\hline Total (unique) & 37 & 28 & 49 & 114 \\
\hline
\end{tabular}

\section{t. Cross Tabulation: Channel Pattern by Relationship to Tertiary Education}

\begin{tabular}{|l|r|r|r|r|r|}
\hline & $\begin{array}{c}\text { Never } \\
\text { enrolled }\end{array}$ & $\begin{array}{c}\text { Dropped } \\
\text { out }\end{array}$ & Graduated & Enrolled & Total \\
\hline Non Exhibitors channel & 30 & 12 & 23 & 24 & 89 \\
\hline $\begin{array}{l}\text { Entering student or humanitarian channel to access } \\
\text { tertiary education }\end{array}$ & 3 & 1 & 17 & 30 & 51 \\
\hline $\begin{array}{l}\text { Avoiding humanitarian channel to access tertiary } \\
\text { education }\end{array}$ & 0 & 0 & 3 & 4 & 7 \\
\hline $\begin{array}{l}\text { Switching channel to access tertiary education and } \\
\text { employment }\end{array}$ & 0 & 2 & 7 & 2 & 11 \\
\hline Total (unique) & 33 & 14 & 44 & 56 & 147 \\
\hline
\end{tabular}




\section{B. Expert and Key Stakeholder Data}

\section{a. Kenya}

\begin{tabular}{lll}
\multicolumn{1}{c}{ Position } & \multicolumn{1}{c}{ Organization } & \multicolumn{1}{c}{ Date } \\
\hline $\begin{array}{l}\text { Head } \\
\text { Performance Lead }\end{array}$ & $\begin{array}{l}\text { Tamuka Hub, Xavier Project } \\
\text { Xavier Project }\end{array}$ & Aug 25, 2016 \\
& Danish Refugee Council & Oct 7, 2015 \\
University Registrar & Daystar University & Aug 26, 2016 \\
$\begin{array}{l}\text { Chief Operating } \\
\text { Officer }\end{array}$ & $\begin{array}{l}\text { Jesuit Commons: Higher Education at the } \\
\text { Margins (now known as Jesuit World Learning) }\end{array}$ & Sep 8, 2015 \\
Project Director & Jesuit Refugee Service & Sep 30, 2015 \\
\hline $\begin{array}{l}\text { Admissions Officer } \\
\text { Professor John Oucho }\end{array}$ & United Nations High Commissioner for Refugees & Sep 22, 2015 \\
$\begin{array}{l}\text { Senior Education } \\
\text { Counsellor }\end{array}$ & University of Nairobi & Aug 27, 2015 \\
Director of Research & Aindle Trust & Aug 31, 2015 \\
& African Migration and Development Policy & Aug 24, 2015 \\
& Centre & Aug 23, 2015
\end{tabular}

\section{b. South Africa}

\section{Position}

\begin{tabular}{|c|c|c|}
\hline Founder and Director & United Tertiary Refugee Students & Apr 1, 2016 \\
\hline Former President & $\begin{array}{l}\text { Congolese Students Society, University of the } \\
\text { Witwatersrand }\end{array}$ & Feb 29, 2016 \\
\hline President & $\begin{array}{l}\text { Congolese Students Society, University of the } \\
\text { Witwatersrand }\end{array}$ & Mar 8, 2016 \\
\hline Head of College & Sacred Heart College Three2Six & Mar 4, 2016 \\
\hline $\begin{array}{l}\text { Officer of Vocational } \\
\text { Skills Training }\end{array}$ & Livelihoods Unit, Jesuit Refugee Service & Mar 4, 2016 \\
\hline Advocacy Officer & $\begin{array}{l}\text { Coordinating Body for Refugee and Migrant } \\
\text { Communities }\end{array}$ & Mar 2, 2016 \\
\hline Manager & $\begin{array}{l}\text { International Students Office, University of the } \\
\text { Witwatersrand }\end{array}$ & Feb 29, 2016 \\
\hline Manager & $\begin{array}{l}\text { International Office, University of the Western } \\
\text { Cape }\end{array}$ & Apr 11, 2016 \\
\hline Pastor & Restoration Seed of Life Church & Mar 1, 2016 \\
\hline Director & Scalabrini Centre of Cape Town & Apr 5, 2016 \\
\hline $\begin{array}{l}\text { Employment Access } \\
\text { Programme manager }\end{array}$ & Scalabrini Centre of Cape Town & Apr 5, 2016 \\
\hline
\end{tabular}


Director

Head
Advisor to the
Minister of Education
of South Africa
Former President

Founder and Director
Consortium for Refugees and Migrants of South

Africa

International Affairs Office, University of

Stellenbosch Business School

Ministry of Education of South Africa

Muslim Students Association of South Africa

Africa Unite
Mar 3, 2016

Apr 6, 2016

Mar 18, 2016

Mar 4, 2016

Apr 1, 2016

\section{c. Uganda}

\begin{tabular}{lll}
\multicolumn{1}{c}{ Position } & \multicolumn{1}{c}{ Organization } & \multicolumn{1}{c}{ Date } \\
\hline Registrar & $\begin{array}{l}\text { Monaco Institute of Business and Computer } \\
\text { Science }\end{array}$ & May 19, 2015 \\
\hline $\begin{array}{l}\text { Registrar } \\
\text { Registrar }\end{array}$ & $\begin{array}{l}\text { Axial International College - Uganda } \\
\text { Cavendish University }\end{array}$ & May 22, 2015 \\
Vice Chancellor & Kampala International University & May 21, 2015 \\
Academic Registrar & Kyambogo University & May 27, 2015 \\
\hline Head & International Office, Makerere University & May 27, 2015 \\
\hline $\begin{array}{l}\text { Education Officer } \\
\text { Director }\end{array}$ & United Nations High Commissioner for Refugees & $\begin{array}{l}\text { May 12, 2015 \& } \\
\text { Administrator, no }\end{array}$ \\
$\begin{array}{l}\text { interview, only a } \\
\text { meeting to discuss } \\
\text { their data }\end{array}$ & Windle Trust & May 27, 2015 \\
\hline
\end{tabular}




\section{Data Collection Instruments}

\section{a. Semi-Structured Biographical Interviews}

The interviews with respondents were semi-structures and so the following questions served only as guides for the interviewer.

\section{Inclusion criteria}

\begin{tabular}{|l|l|}
\hline Relationship to tertiary education & $\square$ Graduate \\
& $\square$ Enrolled \\
& $\square$ Drop-out \\
& $\square$ Never enrolled* \\
\hline Type of tertiary education & $\square$ University \\
& $\square$ College (2-year degree) \\
& $\square \quad$ Technical school \\
\hline Research site & $\square$ Kampala \\
& $\square$ Nairobi \\
& $\square$ Johannesburg \\
& $\square$ Cape Town \\
\hline Sex & $\square$ Male \\
& $\square \quad$ Female \\
\hline Country of Origin & $\square$ Burundi \\
& $\square$ Democratic Republic of Congo \\
& $\square$ Somalia \\
& $\square$ South Sudan/Sudan \\
\hline
\end{tabular}

*If "Never enrolled," then respondent must hold academic and linguistic qualifications that would make him/her eligible for tertiary education.

\section{Exclusion criteria}

\begin{tabular}{|l|l|l|}
\hline Respondent is 18 years of age or older & $\begin{array}{l}\text { Yes } \\
\end{array}$ & No \\
\hline $\begin{array}{l}\text { Respondent has completed his/her O-levels } \\
\text { or equivalent }\end{array}$ & $\square \quad$ Yes \\
\hline $\begin{array}{l}\text { Respondent is not a National of [Uganda, } \\
\text { Kenya, South Africa] and does not have a } \\
\text { second nationality deemed a "safe }\end{array}$ & $\square \quad$ Yes \\
country" & & \\
\hline
\end{tabular}

Background characteristics (not asked, but filled in after the interview) 


\begin{tabular}{|c|c|}
\hline Community/city of origin & \\
\hline $\begin{array}{l}\text { Name of current higher education } \\
\text { institution }\end{array}$ & \\
\hline Age & \\
\hline Marital status & $\begin{array}{ll}\square & \text { Married } \\
\square & \text { Single } \\
\square & \text { Divorced } \\
\square & \text { Widowed }\end{array}$ \\
\hline Children & $\begin{array}{ll}\quad \text { Yes } \\
\square \quad \text { No }\end{array}$ \\
\hline Number of Children (if none, put 0) & \\
\hline Current job(s) / income generating activity & \\
\hline $\begin{array}{l}\text { Profession in origin country (if student, } \\
\text { write student) }\end{array}$ & \\
\hline $\begin{array}{l}\text { Highest level of education before moving } \\
\text { to [Uganda, Kenya, South Africa] }\end{array}$ & $\begin{array}{ll} & \text { No Education } \\
\square & \text { Primary education, incomplete } \\
\square & \text { Primary education, complete } \\
\square & \text { Secondary education, incomplete } \\
\square & \text { Secondary education, complete } \\
\square & \text { Undergraduate, incomplete } \\
\square & \text { Undergraduate, complete }\end{array}$ \\
\hline Year of arrival in [Uganda, Kenya, SA] & \\
\hline Year of arrival in [KLA, NBO, JNB, CPT] & \\
\hline $\begin{array}{l}\text { All degrees/trainings received and schools } \\
\text { attended, post secondary, incl. current }\end{array}$ & \\
\hline Professions of parents & $\begin{array}{l}\text { Mother: } \\
\text { Father: }\end{array}$ \\
\hline Number of siblings & \\
\hline Position (age) amongst siblings & \\
\hline $\begin{array}{l}\text { Migration Status (stress everything is } \\
\text { confidential) }\end{array}$ & $\begin{array}{ll}\square & \text { Refugee (skip next row) } \\
\square & \text { Asylum seeker (skip next row) } \\
\square & \text { Student migrant } \\
\square & \text { Family migrant } \\
\square & \text { No status } \\
\square & \text { No response }\end{array}$ \\
\hline Do you consider yourself a refugee? & $\begin{array}{ll}\square \quad \text { Yes } \\
\square \quad \text { No }\end{array}$ \\
\hline
\end{tabular}




\section{General higher education questions}

Q.1 How did you end up in [university/college/technical school]?

Sub questions: Why this school? Did you apply to other schools? How did you learn about this school? Did you know anyone who attended this school? Did this school advertise in your origin country?

Q.2 How did you plan for it?

Sub questions: Did you apply from your origin country or from Uganda? Did you know about this school before you arrived? How did you get your academic qualifications recognized? How did you learn English?

Q.3 What motivated you to enter higher education? Why higher education?

Q.4 What goals will this degree help you to achieve?

Sub questions: What is your ultimate professional vision?

\section{Education and migration norms}

Q.5 Growing up, did people around you (e.g. friends, friends of friends, neighbors, aunts, uncles) move often or shift to other places?

Q.6 Did any family members move/shift away (for one month, one year, or more than a year)?

Q.7 What were the different reasons or combinations of reasons why these people moved? (If necessary, prompt: how common is moving for work, education, marriage, or a change in lifestyle?)

Q.8 Why did they choose those particular places (why not Kampala or some place in Ethiopia or Tanzania)?

Q.9 Did such movement tend to be temporary or long-term?

Q.10 How were such movements perceived? Were people who moved away thought of as successes or failures?

Q.11 How does your family perceive your (or the) attainment of tertiary education (when you were growing up, did they encourage you to reach university)? 
Q.12 Is higher education celebrated or are other types of work valued more highly? (If people are given a choice between finishing Senior 6/high school and getting a job right away or going to university, which do you think most people would prefer?)

Q.13 Are you the first in your family to reach the tertiary level?

Q.14 What is the most common level of education people receive in your family?

Q.15 What is the most common level of education people receive in your community?

Q.16 Is it common for children to move away from their homes for primary and secondary education? Tertiary?

Education trajectory and agency fluctuations overtime data display

\begin{tabular}{|l|l|l|l|l|}
\hline & Primary & Secondary & Higher (start) & Present \\
\hline Capabilities & & & & \\
\hline $\begin{array}{l}\text { Family's/own economic } \\
\text { situation }\end{array}$ & & & & \\
\hline $\begin{array}{l}\text { Money for schools fees (all } \\
\text { children)? }\end{array}$ & & & & \\
\hline $\begin{array}{l}\text { Money for medical care (all } \\
\text { children)? }\end{array}$ & & & & \\
\hline $\begin{array}{l}\text { Age matched education } \\
\text { level?* (If yes, skip Q.17) } \\
\text { How old were you when you } \\
\text { graduated high school? }\end{array}$ & & & & \\
\hline $\begin{array}{l}\text { Support from extended family } \\
\text { or community? }\end{array}$ & & & & \\
\hline $\begin{array}{l}\text { Outside education or other } \\
\text { support (from an education } \\
\text { institution, NGO, } \\
\text { government) }\end{array}$ & & & & \\
\hline $\begin{array}{l}\text { Education opportunities } \\
\text { (presence of schools, quality, } \\
\text { public or private) }\end{array}$ & & & & \\
\hline $\begin{array}{l}\text { Other } \\
\text { constraints/opportunities (not } \\
\text { really asked) }\end{array}$ & & & & \\
\hline Aspirations & & & & \\
\hline
\end{tabular}




\begin{tabular}{|l|l|l|l|l|}
\hline $\begin{array}{l}\text { Desires regarding higher } \\
\text { education (level, subject } \\
\text { matter, school, etc.) When you } \\
\text { were growing up, did you } \\
\text { dream about going to } \\
\text { university? }\end{array}$ & & & & \\
\hline $\begin{array}{l}\text { Desires regarding } \\
\text { employment Why did you } \\
\text { dream about for your job } \\
\text { when you were growing up? }\end{array}$ & & & & \\
\hline Other key aspirations/goals & & & & \\
\hline
\end{tabular}

Q.17 Why was your education delayed?

Q.18 When you were growing up, did you ever experience any conflict or insecurity, and did it ever lead to your school closing for one day/one week/one month/longer? Did this ever lead you to repeat a year? Did you ever move to another place and have to repeat a year?

\section{Movement trajectories overtime data display}

At the same time, draw out maps of movements

\begin{tabular}{|l|l|l|l|}
\hline Movement / change of residence & 1 & 2 & 3 \\
\hline Age & & & \\
\hline Year & & & \\
\hline Travel group (single, family, etc.) & & & \\
\hline Resources (personal/household?) & & & \\
\hline Education level & & & \\
\hline $\begin{array}{l}\text { Location (A-to-B) (incl. movements } \\
\text { within cities) }\end{array}$ & & & \\
\hline Means of transport & & & \\
\hline Length of time in transport & & & \\
\hline Length of time in destination & & & \\
\hline Status claimed (if any) in destination & & & \\
\hline $\begin{array}{l}\text { Reasons for exit (think in terms of } \\
\text { norms, aspirations, } \\
\text { constraints/opportunities) }\end{array}$ & & & \\
\hline
\end{tabular}




\begin{tabular}{|l|l|l|l|}
\hline $\begin{array}{l}\text { Relationship to conflict (reactive, pre- } \\
\text { emptive) }\end{array}$ & & & \\
\hline $\begin{array}{l}\text { Reason for particular destination } \\
\text { (incl. internal/external forces) }\end{array}$ & Leave blank & Leave blank & Leave blank \\
\hline $\begin{array}{l}\text { Int: network, HH or indiv aspirations, } \\
\text { past experience, closest safe place, } \\
\text { knowledge of... }\end{array}$ & & & \\
\hline $\begin{array}{l}\text { Ext: brought by organization, } \\
\text { deported, recruited by institution, etc. }\end{array}$ & & & \\
\hline Extent of integration at destination? & & & \\
\hline $\begin{array}{l}\text { Interaction with assistance or legal } \\
\text { structures, host society }\end{array}$ & & & \\
\hline Other relevant info & & & \\
\hline
\end{tabular}

\section{Refugee Meaning}

Q.19: How would you define what it means to be a refugee, if someone asked you the definition?

Q:20: If you are comfortable telling me, can I ask what is your migration status?

Q21: Why do you or don't you consider yourself a refugee?

Sub questions: What does being a refugee mean to you? What is the definition of a refugee? Can someone be a refugee and international student? Why or why not? 


\section{b. Structured Expert Interviews: Tertiary Education Institution}

Job title of interviewee:

Name of organization/institution and section:

Type of organization/institute:

Date of interview:

\section{Background}

1. How long have you been in this role?

2. What are your main priorities as [title] of [office/institution]?

3. Describe the range of your work with international students (including students who are refugees and asylum seekers).

\section{International student programming}

4. How do you verify qualifications? Are there any challenges with regard to qualifications recognition (especially for different nationalities - DR Congolese, Somali, Sudanese, South Sudanese, and Burundian)?

5. Do you have any differing policies and services when it comes to refugee students versus other international students? For example:

a. Fee structures, scholarship programs?

b. Do you have any specific support mechanisms or resources for students who identify themselves as refugees, or for international students more generally?

6. Do you have any job market integration programs or career advising programs for graduates?

7. Outreach: do you do any cross-border or international outreach?

a. Do you hold specific information sessions or have information available for refugees interested in accessing higher education?

8. Coordination: Do you any work with any international organizations?

a. Particularly any development organizations that might fund refugee students? 


\section{Data}

9. What kind of information do you collect on international students?

a. Do you ask about migration status?

b. What else do you ask about?

c. Do you track performance? Any stats on drop-outs?

d. Do you track how they are able to find jobs?

e. What opportunities do refugees have to identify themselves to the administration?

10. How many international students are currently studying at [institution] and what proportion of the total student body do they represent?

a. How many of the international students are refugees? What are the main countries of origin?

b. Are the number of refugee and international students increasing or decreasing?

\section{Other}

11. What would be important for your institution to learn from this research? What questions would you want to ask about refugees in higher education or international students coming from areas of conflict?

12. In your experience, what are some of the biggest challenges refugees encounter in higher education? 


\section{c. Structured Expert Interviews: Refugee Education NGO}

Job title of interviewee:

Name of organization/institution and section:

Type of organization/institute:

Date of interview:

\section{Background}

1. Describe the range of your work with refugees.

2. How long have you been in this role?

\section{Higher education programming}

3. What are your short and long term goals for refugee higher education?

a. Do you have any specific support mechanisms, programs, or resources for refugees to enroll in higher education programs?

b. How do you verify qualifications? Are there any challenges with regard to qualifications recognition?

c. Do you track their performance? (Drop-out rates, integration into the labour market after graduation)

d. Do you hold information sessions or have information available for refugees interested in accessing higher education?

4. Which actors do you work with (including operational partners as well as higher education stakeholders)? For instance, do you interact with any academic institutions or branches of government / education ministries? Describe the work.

\section{On refugees in higher education}

5. What kind of data, if any, do you collect on refugee education and higher education in particular?

a. How many refugees are in higher education in [country]? Any further breakdowns? Enrolment and completion data?

b. Pre-displacement education data? How qualified are arriving refugees in [country]? 
6. What do you find are refugees' main aspirations in the arena of education?

7. What are different refugee communities' values and beliefs toward higher education?

8. What are some of the biggest constraints and opportunities refugees encounter in higher education in [country]? What are the greatest needs?

9. How aware are refugees of higher education opportunities in [country]?

\section{Other}

10. What would be important for your agency to learn from this research? What questions would you want to ask about refugees in higher education?

11. Outside of your organization, what resources are available to refugees looking to access higher education in [country]? 
ABSTRACT 
Tertiary education institutions in resettlement and asylum countries across the world are asking what role can and should they play in responding to today's forced displacement crises. Exploring and better understanding opportunities within higher education for complementary protection should be a priority. On September 19, 2016, the United Nations General Assembly adopted the New York Declaration for Refugees and Migrants, which not only referenced education as a crucial part of refugee protection and development throughout its 90 paragraphs, but also highlighted the importance of tertiary education for refugees. The positive impacts of tertiary education on refugees' wellbeing, their integration into host societies, and their contributions to home countries is relatively well-understood from a livelihoods or development perspective. What is less understood is the impact of tertiary education on forced displacement patterns, or the when, where, why, and how of refugees' forced movements.

We know from studies on education migration that education is a key driver of movement in most societies. We also know that refugees perceive higher education as crucial to rebuilding their lives in host countries. Further, interviews with organizations supporting refugee education, such as the Jesuit Refugee Service, Danish Refugee Council, and Windle Trust, reveal a considerable unmet demand amongst refugees for tertiary education. Therefore, this research set out to understand: How do refugees who pursue higher education in asylum countries, shape their forced displacement patterns in relation to tertiary education? For instance, if a person's higher education was interrupted, prevented, or simply not possible in his or her home country because of conflict, crisis, or persecution, how might the prospect of higher education elsewhere play a role in that person's decision-making about where and how to seek asylum?

Understanding how refugees' pursuit of tertiary education impacts their forced displacement patterns has important implications for complementary protection and refugee mobility. According to UNHCR, complementary protection pathways are "safe and regulated avenues by which refugees may live in a country and have their international protection needs met, while also being able to support themselves and reach sustainable and lasting solutions." In the context of tertiary education, such pathways might take shape through student migration channels to "third" countries. This research argues that protection may also extend to refugees' stay in asylum countries and be a strategy that certain individuals undertake to avoid contact or sever ties with the refugee regime. Organizations working with refugees should find ways to support this process and explore the full potential of tertiary education in facilitating these pathways.

In terms of implications for refugee mobility, understanding how refugee's pursuit of higher education impacts how they negotiate their movements invites us to re-examine the limited ways in which we think about forced displacement with respect to refugee agency. It compels us to challenge concepts like "secondary movement" and to recognize 
refugees' freedom of movement within asylum countries. Integrating a more nuanced concept of agency into the refugee movement discourse, particularly with respect to the pursuit of higher education and skills, and hence employment, has the potential to impact the way policy and practice conceptualize and seek to manage refugee mobility.

This study is multi-sited and employs a qualitative and interpretive methodological approach. It is set within Kenya, South Africa, and Uganda, as these are hubs for tertiary education and forced displacement in Africa and each country represents a unique refugee hosting policy (camp-based, self-settlement-based, or a hybrid policy). Further, these countries have different proximities to conflict and development contexts. This study collected and analyzed 149 narrative interviews with Congolese and Somali refugees and migrants on their displacement and higher education trajectories, in all three receiving countries. Research participants were sampled based on their level of tertiary education (university, college, technical/vocational school), gender, and relationship to tertiary education (graduated, enrolled, dropped-out, never enrolled). This study also analyzed the macro-level drivers and patterns of forced displacement between the DRC and Somalia and Kenya, South Africa and Uganda to understand the structural context framing respondents' micro-level decisions and actions. 


\section{About the Author}

Ayla E. Bonfiglio is the North Africa Regional Coordinator of the Mixed Migration Center at the Danish Refugee Council. For more than a decade, she has worked on issues of forced displacement and migration, with a focus on mobility patterns as well as educational attainment among refugees and migrants coming from countries afflicted by conflict and crisis. In 2016, she co-founded the Conflict and Education Learning Laboratory (CELL), which works towards the reduction of divisive stereotypes in educational materials and examines the impact of divisive educational content on conflict and crisis. In recognition of her work at CELL and research, she was awarded the 2019 Lion's Pride honor by Columbia University, as a young alumna working to have a meaningful and positive impact on the world.

Formerly, she was a Research Officer at the International Migration Institute, Oxford. She obtained an MSc in Forced Migration from the University of Oxford and her dissertation on refugee non-formal education was published by UNHCR. Ayla holds a BA (Hons) in Political Science from Columbia University where she won the Charles Beard Prize for her dissertation on refugee self-reliance. She has worked and carried out research in Kenya, Libya, Rwanda, South Africa, Sudan, Tunisia, and Uganda. She has contributed to projects for GIZ, ICMPD, Samuel Hall, IOM, and UNESCO. 



\section{UNU-MERIT/MGSoG Dissertation Series}

2020

\section{Ayla E. Bonfiglio}

Student migrant, refugee or both?

Exploring Refugee Agency and Mobility through Tertiary Education in Kenya, South Africa and Uganda UNU-MERIT/MGSoG Dissertation Series № 242

\section{Danilo Sartorello Spinola}

Cycles, Economic Structures and External Constraints.

A Structuralist study on the causes of economic volatility in Latin America UNU-MERIT/MGSoG Dissertation Series № 241

2019

\section{Jemal Adem}

Livelihood Vulnerability to Shocks,

Behaviour and Investment in

Education: Essays in Behavioural

Development Economics

UNU-MERIT/MGSoG Dissertation

Series № 240

\section{Davina Osei}

Corrupt or corrupted networks?

An empirical enquiry

UNU-MERIT/MGSoG Dissertation

Series № 239

\section{Patima Chongcharoentanawat}

Beyond Static Inequality

Public policies and economic mobility

in Thailand

UNU-MERIT/MGSoG Dissertation

Series № 238

\section{Charlotte Guillard}

Rethinking economic growth

and structural change.

The role of boundaries and linkages

between industries

UNU-MERIT/MGSoG Dissertation

Series № 237

\section{Nicolas Echarti}

Employment Effects or Vocational

Rehabilitation in Germany:

A quantitative analysis

UNU-MERIT/MGSoG Dissertation

Series № 236

\section{Shellie E. Solomon}

Neighborhoods Matter:

Crime, collective efficacy and

foreclosures in Miami

UNU-MERIT/MGSoG Dissertation Series № 235 


\section{Michał Kazimierczak}

Regional Innovation and

Entrepreneurship

Patents, trade marks, entry and

entrants' growth in European

manufacturing industries

UNU-MERIT/MGSoG Dissertation

Series № 234

\section{Fernanda Soares}

The Influence of Within School and

Across Schools' Collaborative Practices

on Student Learning and Teaching

Outcomes in West Africa

UNU-MERIT/MGSoG Dissertation

Series № 233

\section{Mira Bierbaum}

New Mindsets to Innovate Activation UNU-MERIT/MGSoG Dissertation

Series № 232

\section{Norman Dytianquin}

Technology in the Asian Miracle and

Crisis Debates: Applications of and

Insights from the Field of Influence

Approach to Input-Output Analysis

UNU-MERIT/MGSoG Dissertation

Series № 231

\section{Nga Le}

The implications of health insurance for the labour market and patient satisfaction with medical care in

Vietnam

UNU-MERIT/MGSoG Dissertation

Series № 230
Jinhyuck Park

Intellectual Property right protection and cross-border RED investments by multinational enterprises

UNU-MERIT/MGSoG Dissertation

Series № 229

\section{Richard de Groot}

Show me the Money:

Essays on the Impact of Cash Transfers on Child Nutrition and the Role of

Intra-Household Dynamics

UNU-MERIT/MGSoG Dissertation

Series № 228

\section{Catie Lott}

Diamonds are a Women's Best Friend Broadening Measures of Women's Access to Formal Political DecisionMaking

UNU-MERIT/MGSoG Dissertation Series № 227

\section{Ana Cristina Calderon Ramirez}

Public Management Reforms

Three stories about public procurement agencification in Latin America UNU-MERIT/MGSoG Dissertation Series № 226

\section{Camilo Nicanor Carrillo Purin}

Teachers' in-service training and

student achievement:

The effect of in-service training of

Peruvian teachers on student

achievement

UNU-MERIT/MGSoG Dissertation

Series № 225 


\section{Hugo Confraria}

Developing scientific capacity in the

Global South

UNU-MERIT/MGSoG Dissertation

Series № 224

\section{Alison Cathles}

Educational Pathways and Skills:

Past, Present, and Future

UNU-MERIT/MGSoG Dissertation

Series № 223

\section{Ibrahima Sory Kaba}

Aggregate Fluctuations and

Development: Essays on

Macroeconomic Volatility and

Economic Growth

UNU-MERIT/MGSoG Dissertation

Series № 222

\section{Charlotte Keijser}

Firm Participation, Learning and

Innovation in Heterogenous Value

Chains of IT-enabled Services

UNU-MERIT/MGSoG Dissertation

Series № 221

\section{Salih Çevikarslan}

Innovation Strategies and Their

Implications for Technological Change and Market Outcomes:

An Evolutionary Multi-Agent Based

Modelling Approach

UNU-MERIT/MGSoG Dissertation

Series № 220
Wondimagegn Mesfin Tesfaye

Essays on the Impacts of Climate-

Smart Agricultural Innovations on

Household Welfare

UNU-MERIT/MGSoG Dissertation

Series № 219

\section{Tatevik Poghosyan}

How Board Networks Affect Firm

Performance and Innovation Incentives in Transition Economies: The Case of Armenia

UNU-MERIT/MGSoG Dissertation

Series № 218

\section{Arip Muttaqien}

Essays on Inequality and Polarization:

Empirical Studies in Developing Asia

UNU-MERIT/MGSoG Dissertation

Series № 217

2018

\section{Katrin Marchand}

Essays on Forced Migration and

Labour Market Participation in

Developing Countries

UNU-MERIT/MGSoG Dissertation

Series № 216

\section{Ortrun Merkle}

The Myth of Gender Neutral Power:

Corruption and Gender Norms

UNU-MERIT/MGSoG Dissertation

Series № 215 


\section{Biljana Meshkovska}

Life after Trafficking:

(re)integration processes of women that have been trafficked for the purpose of sexual exploitation in Europe

UNU-MERIT/MGSoG Dissertation

Series № 214

\section{Vincenzo Vinci}

The Relevance of Institutions and

People's Preferences for Social

Protection

UNU-MERIT/MGSoG Dissertation

Series № 213

\section{Silke Heuser}

The Effectiveness of Environmental Policies on Reducing Deforestation in the Brazilian Amazon

UNU-MERIT/MGSoG Dissertation Series № 212

\section{Jennifer Waidler}

Social Assistance and Remittances and Their Role in the Fight Against

Poverty

UNU-MERIT/MGSoG Dissertation Series № 211

\section{Choolwe Muzyamba}

The role of community mobilization in the promotion of maternal health of women living with HIV in Zambia UNU-MERIT/MGSoG Dissertation Series № 210

\section{Juan Carlos A. Castillo Sánchez}

Assessing the Role of the Export Sector in Mexican Economic

Development,1965-2014

UNU-MERIT/MGSoG Dissertation

Series № 209

\section{Tareq Abuelhaj}

Food Security Policy Impact Analysis:

The Econometrics of Cash and Food

Assistance Cost Effectiveness

UNU-MERIT/MGSoG Dissertation

Series № 208

\section{Marta Férnandez de Arroyabe}

Arranz

Essays on MEAS and Innovation

UNU-MERIT/MGSoG Dissertation

Series № 207

\section{Clotilde Mahé}

Essays on Migration and Occupational Choice

UNU-MERIT/MGSoG Dissertation Series № 206

\section{Simone Sasso}

Talent on the move. Essays on Human Capital, Graduate Mobility and Economic Development

UNU-MERIT/MGSoG Dissertation Series № 205

\section{Khaled Walid Rajab}

Strategic Planning under Fragility UNU-MERIT/MGSoG Dissertation Series № 204 
Mutinta Hambayi Nseluke

A Tall Order: Improving Child Linear

Growth

UNU-MERIT/MGSoG Dissertation

Series № 203

Elvis Korku Avenyo

Innovations and Firm Performance

in sub-Saharan Africa: Empirical

Analyses

UNU-MERIT/MGSoG Dissertation

Series № 202

\section{Ni Zhen}

Employment Dynamics, Firm

Performance and Innovation

Persistence in the Context of

Differentiated Innovation Types:

Evidence from Luxembourg

UNU-MERIT/MGSoG Dissertation

Series № 201

\section{Caroline Wehner}

Too Scared to Achieve: The Relation

Between Neuroticism,

Conscientiousness

and Socioeconomic Outcomes

UNU-MERIT/MGSoG Dissertation

Series № 200

\section{Stefania Innocenti}

On Institutional Persistence

UNU-MERIT/MGSoG Dissertation

Series № 199

\section{Hassen Abda Wako}

Economic Globalization, Institutions

and Development: Essays on Aid,

Foreign Direct Investment and Trade

UNU-MERIT/MGSoG Dissertation

Series № 198
2017

\section{Hans-Erik Edsand}

Winds of Change

UNU-MERIT/MGSoG Dissertation

Series № 197

\author{
Ana Patricia Silva Vara \\ Redressing the Gender Gap \\ UNU-MERIT/MGSoG Dissertation \\ Series № 196
}

\section{Andrés Iván Mideros Mora}

Essays on the Economic Effects of Noncontributory Social Protection

UNU-MERIT/MGSoG Dissertation

Series № 195

\section{Tobias Broich}

New Actors in the Global Economy

UNU-MERIT/MGSoG Dissertation

Series № 194

\section{Bernard Nikaj}

From No-government to E-government UNU-MERIT/MGSoG Dissertation

Series № 193

\section{Ali Safarnejad}

Prioritizing the HIV Response

UNU-MERIT/MGSoG Dissertation

Series № 192

\section{Clovis Freire}

Diversification and Structural

Economic Dynamics

UNU-MERIT/MGSoG Dissertation

Series № 191 


\section{Michael Verba}

Innovation and Knowledge Dynamics:

Essays on the Knowledge Economy

UNU-MERIT/MGSoG Dissertation

Series № 190

\section{Pui Hang Wong}

The Hearts and Minds in Conflict and

Peace: The Economics of

Counterinsurgency and the Psychology of Reconstruction

UNU-MERIT/MGSoG Dissertation

Series № 189

\section{Brenda Yamba}

Schooling Despite All Odds: Evidence

from Lesotho on Female Child Carers who Stayed in School

UNU-MERIT/MGSoG Dissertation

Series № 188

\section{Sheng Zhong}

Moving towards An Energy Efficient

Future: Essays on Energy Efficiency,

Technology and Development

UNU-MERIT/MGSoG Dissertation

Series № 187

\section{Julieta Marotta}

Access to Justice and Legal

Empowerment of Victims of Domestic

Violence through Legal Organizations

in the City of Buenos Aires: A

Qualitative Empirical Legal Study

UNU-MERIT/MGSoG Dissertation

Series, № 186

\section{Andrea Franco-Correa}

On the Measurement of

Multidimensional Poverty as a Policy

Tool: Empirical Applications to Chile,

Colombia, Ecuador and Peru

UNU-MERIT/MGSoG Dissertation

Series, № 185

\section{6}

\section{Yesuf Awel}

Insurance for Growth: Empirical

Essays on Insurance Demand and

Impacts in Africa

UNU-MERIT Dissertation Series,

№ 108

\section{Tigist Mekonnen Melesse}

Grow More Food using Fewer

Resources: Agricultural Technology

Adoption and Innovation Practices for

Inclusive and Sustainable

Development

UNU-MERIT Dissertation Series,

№ 107

\section{Eleni Yitbarek}

Getting Ahead or left Behind? Essays on Poverty Dynamics and Social

Mobility in Africa

UNU-MERIT Dissertation Series, № 106

\section{Thuy Dieu Nguyen}

Firm-Level Theory and Evidence of

Corruption

UNU-MERIT Dissertation Series,

№ 105 


\section{Raquel Tsukada Lehman}

Essays on Household Production with

Labor-Saving Technology

UNU-MERIT Dissertation Series, № 104

\section{Eva Barteková}

Multi-Problem Challenges for a

Renewable Future: Empirical Studies

on Competitive Disadvantages from

Electricity Price Differentials and

Mineral Supply Risk in an Open

Economy

UNU-MERIT Dissertation Series,

№ 103

\section{Jocelyn Olivari}

Entrepreneurial Traits and Innovation:

Evidence from Chile

UNU-MERIT Dissertation Series,

№ 102

\section{Muhammad Shafique}

Essays on the role of knowledge, $R \mathcal{E} D$, and Technology-based Firms in the

Evolution of Socio-techno-economic

System

UNU-MERIT Dissertation Series, № 101

\section{Serdar Türkeli}

Governance of Innovation Policy:

Empirical Studies on Applied Political

Economy by Multi-Methods Analysis

UNU-MERIT Dissertation Series,

№ 100

\section{Ayokunu Adedokun}

Pathways to Sustainable Peace

building in Divided Societies: Lessons

and Experiences from Mozambique

MGSoG Dissertation Series, № 75

\section{Luiz Rothier Bautzer}

Organizing Concurrent Engineering through ICT Platforms

Blueprinting Product Lifecycle

Management Platforms across

Disciplinary Agencies

MGSoG Dissertation Series, № 74

\section{Natalia Popova}

Migration in the Periphery of the

European Union:

Determinants of Successful and

Sustainable Labour Market Integration of Return Migrants in Albania, Egypt, Moldova and Tunisia

MGSoG Dissertations Series, № 73

\section{Richard A. Martina}

Uncertainty and Resource Constraint in the Small Island Developing States: Essays in Entrepreneurial Cognition MGSoG Dissertations Series, № 72

\section{Cécile Cherrier}

The Expansion of Basic Social

Protection in Low-income Countries:

An Analysis of Foreign Aid Actors'

Role in the Emergence of Social

Transfers in Sub-Saharan Africa

MGSoG Dissertations series, № 71 


\section{Paul Caldron}

The Tacit Bargain in Short-Term

Medical Missions: Why U.S.

physicians go and what it costs

MGSoG Dissertation Series, № 70

\section{Mahmut Kobal}

Customs E Excellence: A Comparative Approach on Administrative and

Regulatory Compliance Perspectives of the EU-Turkey Customs Union

MGSoG Dissertation Series, № 69

\section{Craig Loschmann}

Essays on Conflict-related Migration and Development in the Case of

Afghanistan

MGSoG Dissertations Series, № 68

\section{Andrea Milan}

Rural Livelihoods, Location and Vulnerable Environments: Approaches to Migration in Mountain areas of Latin America

MGSoG Dissertation Series, № 67

\section{Farida Lada}

On Guarding the Welfare of Clinical

Trial Subjects While Promoting Novel

Drug Innovation

A Game Theoretical Approach

MGSoG Dissertation Series, № 66

\section{5}

\section{Hibret Belete Maemir}

Dissecting Aggregate Productivity:

International Integration and Growth

with Heterogeneous Firms

UNU-MERIT Dissertation Series, № 96

\section{Giorgio Triulzi}

Looking for the Right Path: Technology

Dynamics, Inventive Strategies and

Catching-up in the Semiconductor

Industry

UNU-MERIT Dissertation Series, № 95

\begin{abstract}
Abdul Baseer Qazi
Knowledge flows and networks in the ICT sector: The case of Pakistan

UNU-MERIT Dissertation Series, № 94
\end{abstract}

\section{Ajay Thutupalli}

Technology Paradigm Shifts in Agriculture: Drivers of Sustainability and Catch up

UNU-MERIT Dissertation Series, № 93

\section{Eduardo Urias}

Improving access to HIVIAIDS

treatment in Brazil: When are

Compulsory Licenses effective in Price Negotiations?

UNU-MERIT Dissertation Series, № 92

\section{Francesca Guadagno}

Why have so few Countries

Industrialised?

UNU-MERIT Dissertation Series, № 91

\section{Daniel Opolot}

The Evolution of Beliefs and Strategic Behaviour

UNU-MERIT Dissertation Series, № 90 
Alejandro Lavopa

Structural Transformation and

Economic Development: Can

Development Traps be Avoided

UNU-MERIT Dissertation Series, № 89

\section{Jinjin Zhao}

Urban water management reform: The

Case of China

UNU-MERIT Dissertation Series,

№ 88

\section{Simona Vezzoli}

Borders, Independence and Postcolonial Ties: the Role of the State in

Caribbean Migration

MGSoG Dissertation Series, № 65

\section{Silvia Consuelo Gómez Soler}

Civil Conflict and Education: How

Does Exposure to Civil Conflict Affect

Human Capital Accumulation?

Evidence from Standardized Exit

Exams in Colombia

MGSoG Dissertation Series, № 64

\section{Paula Nagler}

Occupational Choice in the Developing World

MGSoG Dissertation Series, № 63

\section{Jasmin Kientzel}

Determinants of Professional

Commitment to Environmental

Sustainability

MGSoG Dissertation Series, № 62

\section{Mehmet Güney Celbiş}

Regional Policies: Convergence, Trade, and the Allocation of Public Capital MGSoG Dissertation Series, № 61

\section{Florian Henning}

Living Up to Standard:

Interoperability Governance and

Standards Adoption in Government

Information Networks

MGSoG Dissertation Series, № 60

\section{Niels P. Groen}

The Never-Ending Project

Understanding E-Government Project

Escalation

MGSoG Dissertation Series, № 59

\section{Derek Copp}

Teacher-Based Reactivity to Provincial

Large-scale Assessment in Canada

MGSoG Dissertation Series, № 58

\section{Michaella Vanore}

Family-Member Migration and the

Psychosocial Health Outcomes of

Children in Moldova and Georgia

MGSoG Dissertation Series, № 57

\section{Sonja Fransen}

The Economic and Social Effects of

Remittances and Return Migration in

Conflict-Affected Areas: The Case of

Burundi

MGSoG Dissertation Series, № 56

\section{Ibrahim Khalil Conteh}

The Impact of Floods on Primary

School Education in Zambia

MGSoG Dissertation Series, № 55 


\section{Richard Bluhm}

Growth Dynamics and Development

Essays in Applied Econometrics and

Political Economy

MGSoG Dissertation Series, № 54

\section{Nevena P. Zhelyazkova}

Work-Family Reconciliation and Use of Parental Leave in Luxembourg:

Empirical Analysis of Administrative Records

MGSoG Dissertation Series, № 53

2014

\section{Dirk Crass}

The Impact of Brands on Innovation and Firm Performance: Empirical

Evidence from Germany

UNU-MERIT Dissertation Series, № 87

\section{Samyukta Bhupatiraju}

The Geographic Dimensions of Growth and Development

UNU-MERIT Dissertation Series, № 86

\section{François Lafond}

The Evolution of Knowledge Systems UNU-MERIT Dissertation Series, № 85

\section{Annalisa Primi}

Promoting Innovation in Latin

America: What Countries Have

Learned (and What They Have Not) in

Designing and Implementing

Innovation and Intellectual Property

Policies

UNU-MERIT Dissertation Series,

№ 84

\section{Fatoumata Lamarana Diallo}

Evaluation of Meal and Deworming

Programs for Primary Schools in Rural Senegal

UNU-MERIT Dissertation Series, № 83

\section{Sachin Kumar Badkas}

Metachoice and Metadata: Innovating with Environmental Policy Analysis in Europe

MGSoG Dissertation Series, № 52

\section{Irina S. Burlacu}

An Evaluation of Tax-Benefit Systems Impact on the Welfare of Frontier

Worker:

The Case of Luxembourg and Belgium MGSoG Dissertation Series, № 51

\section{Özge Bilgili}

Simultaneity in Transnational Migration Research: Links Between Migrants' Host and Home Country Orientation

MGSoG Dissertation Series, № 50 


\section{Yulia Privalova Krieger}

Reshaping the Big Agenda:

Transnational Politics and Domestic

Resistance Financial crisis and social

protection reform in Bosnia and

Herzegovina

MGSoG Dissertation Series, № 49

\section{Marieke van Houte}

Moving Back or Moving Forward?

Return migration after Conflict

MGSoG Dissertation Series, № 48

\section{Oxana Slobozhan}

Global Governance in the Management of Natural Resources: The Case of the

Extractive Industries Transparency

Initiative (EITI)

MGSoG Dissertation Series, № 47

\section{Luis Bernardo Mejia Guinand}

The Changing Role of the Central

Planning Offices in Latin America: A

Comparative Historical Analysis

Perspective (1950-2013)

MGSoG Dissertation Series, № 46

\section{Cheng Boon Ong}

Ethnic Segregation in Housing,

Schools and Neighbourhoods in the

Netherlands

MGSoG Dissertation Series, № 45

\section{Luciana V. Cingolani}

Bureaucracies for Development:

Oxymoron or Reality? Studies on State

Capacity in Challenging Governance

Contexts

MGSoG Dissertation Series, № 44

\section{Carlos Cadena Gaitán}

Green Politics in Latin American

Cities - Sustainable Transport Agendas

MGSoG Dissertation Series, № 43

\section{Katie Kuschminder}

Female Return Migration and

Reintegration Strategies in Ethiopia

MGSoG Dissertation Series, № 42

\section{Metka Hercog}

Highly-Skilled Migration and New

Destination Countries

MGSoG Dissertation Series, № 41

\section{Margaret Agaba Rugadya}

Can Remittances Influence the Tenure and Quality of Housing in Uganda?

MGSoG Dissertation Series, № 40

\section{Ilire Agimi}

New Governance Under Limited

Statehood: The Case of Local

Government Reform in Kosovo

MGSoG Dissertation Series, № 39

2013
Anant Kamath
Information Sharing through Informal Interaction in Low-Tech Clusters
UNU-MERIT Dissertation Series,
№ 82 
Flavia Pereira de Carvalho

What we talk about when we talk about

Brazilian Multinationals: An

Investigation on Brazilian FDI,

Economic Structure, Innovation and

the Relationship between them

UNU-MERIT Dissertation Series, № 81

\section{Jun Hou}

Complementarity in Innovation and

Development: A Cross-country

Comparison

UNU-MERIT Dissertation Series, № 80

\section{Rufin Baghana}

Impacts of Government Incentives to RED, Innovation and Productivity: A Microeconometric Analysis of the Québec Case

UNU-MERIT Dissertation Series, № 79

\section{Lilia I. Stubrin}

High-Tech Activities in Emerging Countries: A Network perspective on the Argentinean Biotech Activity UNU-MERIT/MGSoG Dissertation Series, № 78

\section{Kristine Farla}

Empirical Studies on Institutions, Policies and Economic Development MGSoG Dissertation Series, № 38

\section{Marina Petrovic}

Social Assistance and Activation in the Pursuit of Happiness: Shedding New Light on Old Policy Solutions to Social Exclusion

MGSoG Dissertation Series, № 37

\section{Laura Torvinen}

Assessing Governance Assessments:

The Case of Mozambique: Governance Assessments in the Context of Aid Effectiveness Discourse MGSoG Dissertation Series, № 36

\section{Biniam Egu Bedasso}

Institutional Change in the Long

Shadow of Elite: Essays on

Institutions, Human Capital and

Ethnicity in Developing Countries

MGSoG Dissertation Series, № 35

\section{Sepideh Yousefzadeh Faal}

Deghati

Childhoods Embargoed: Constructing and Reconstructing Multidimensional Child Poverty in Iran 1984-2009

MGSoG Dissertation Series, № 34

\section{Robert Bauchmüller}

Investing in Early Childhood Care and Education: The Impact of Quality on Inequality

MGSoG Dissertation Series, № 33

\section{Martin Rehm}

Unified Yet Separated: Empirical

Study on the Impact of Hierarchical

Positions within Communities of

Learning

MGSoG Dissertation Series, № 32 


\author{
Abdul Waheed \\ Innovation Determinants and \\ Innovation as a Determinant: Evidence \\ from Developing Countries \\ UNU-MERIT Dissertation Series, \\ № 77
}

\section{Bilal Mirza}

Energy Poverty and Rural Energy

Markets in Pakistan

UNU-MERIT Dissertation Series, № 76

\section{Benjamin Engelstätter}

Enterprise Software and Video Games:

An Empirical Analysis

UNU-MERIT Dissertation Series, № 75

\section{Fulvia Farinelli}

Natural Resources, Innovation and Export Growth: The Wine Industry in Chili and Argentina

UNU-MERIT Dissertation Series

\section{Rodolfo Lauterbach}

Innovation in Manufacturing: From

Product Variety and Labor

Productivity Growth to Economic

Development in Chile

UNU-MERIT Dissertation Series

\section{Kirsten Wiebe}

Quantitative Assessment of

Sustainable Development and Growth in Sub-Saharan Africa

UNU-MERIT Dissertation Series, № 74
Julio Miguel Rosa

Organizational Strategies, Firms'

Performance and Spatial Spillovers:

The Canadian Case in Research and

Development.

UNU-MERIT Dissertation Series, № 73

Johannes Wilhelmus Marie Boels Joseph Schumpeter, Honderd Jaar Economische Ontwikkeling: Een Historisch-theoretische Beschouwing. UNU-MERIT Dissertation Series

\section{Dorcas Mbuvi}

Utility Reforms and Performance of the Urban Water Sector in Africa

MGSoG Dissertation Series, № 31

\section{Lina Salanauskaite}

Distributional Impacts of Public

Policies: Essays in Ex-Ante and Ex-

Post Evaluation

MGSoG Dissertation Series, № 30

\section{Esther Schüring}

To Condition or not - is that the Question?

An Analysis of the Effectiveness of ExAnte and Ex-Post Conditionality in Social Cash Transfer Programs MGSoG Dissertation Series, № 29

\section{Joe Abah}

Strong Organisations in Weak States: Atypical Public Sector Performance in Dysfunctional Environments MGSoG Dissertation Series, № 28 


\section{Zina Samih Nimeh}

Social Citizenship Rights: Inequality and Exclusion

MGSoG Dissertation Series, № 27

2011

\section{Daniel Vertesy}

Interrupted Innovation: Emerging

Economies in the Structure of the

Global Aerospace Industry

UNU-MERIT Dissertation Series, № 72

\section{Tina Saebi}

Successfully Managing Alliance

Portfolios: An Alliance Capability

View

UNU-MERIT Dissertation Series, № 71

\section{Nora Engel}

Tuberculosis in India: A Case of Innovation and Control

UNU-MERIT/MGSoG Dissertation

Series, № 70

\section{Evans Mupela}

Connectivity and growth in Sub-

Saharan Africa: The Role of

Communication Satellites

UNU-MERIT Dissertation Series, № 69

\section{Nantawan Kwanjai}

Cross Cultural Intelligence amid

Intricate Cultural Webs: A Tale of the

UnDutchables in the Land of 1002

Smiles

UNU-MERIT Dissertation Series, № 68

\section{Lina Sonne}

Innovation in Finance to Finance Innovation: Supporting Pro-poor Entrepreneur-based Innovation UNU-MERIT Dissertation Series, № 67

\section{Lenka Eisenhamerová}

Legitimacy of 'Humanitarian Military Intervention'

MGSoG Dissertation Series, № 26

\section{Sonila Tomini}

Informal Payments for Health Care

Services in Albania

MGSoG Dissertation Series, № 25

\section{Jinjing Li}

Dynamic Microsimulation in Public Policy Evaluation

MGSoG Dissertation Series, № 24

\section{Aziz Atamanov}

Rural Nonfarm Employment and International Migration as Alternatives to Agricultural Employment: The Case of Kyrgyzstan MGSoG Dissertation Series, № 23

\section{Frieda Vandeninden}

Poverty Alleviation: Aid and Social Pensions

MGSoG Dissertation Series, № 22

\section{Juliana Nyasha Tirivayi}

The Welfare Effects of Integrating AIDS Treatment with Food Transfers: Evidence from Zambia

MGSoG Dissertation Series, № 21 
Agnieska Ewa Sowa

Who's Left Behind? Social Dimensions

of Health Transition and Utilization of

Medical Care in Poland

MGSoG Dissertation Series, № 20

\section{Emmanaouil Sfakianakis}

The Role of Private Actors in the

Provision of Public Goods with

Applications to Infrastructure and

Financial Stability

MGSoG Dissertation Series, № 19

\section{Siu Hing Lo}

White Collars Green Sleeves: An Inter-

organizational Comparison of

Determinants of Energy-Related

Behaviors among Office Workers

MGSoG Dissertation Series, № 18

\section{Treena $\mathbf{W u}$}

Constraints to Human Capital

Investment in Developing Countries:

Using the Asian Financial Crisis in

Indonesia as a Natural Experiment

MGSoG Dissertation Series, № 17

\section{Henry Espinoza Peña}

Impact Evaluation of a Job-Training

Programme for Disadvantaged Youths:

The Case of Projoven

MGSoG Dissertation Series, № 16
2010

\section{Fernando Santiago}

Human Resources Management

Practices and Learning for Innovation

in Developing Countries:

Pharmaceutical Firms in Mexico

UNU-MERIT Dissertation Series,

№ 66

\section{Zakaria Babutsidze}

Essays on Economies with

Heterogeneous Interacting Consumers

UNU-MERIT Dissertation Series,

№ 65

\section{Bertha Vallejo}

Learning and Innovation Under

Changing Market Conditions: The

Auto Parts Industry in Mexico

UNU-MERIT Dissertation Series,

№ 64

\section{Donatus Ayitey}

Technical Change, Competitiveness

and Poverty Reduction: A Study of the

Ghanaian Apparel Industry

UNU-MERIT Dissertation Series,

№ 63

\section{Sergey Filippov}

Multinational Subsidiary Evolution:

Corporate Change in New EU Member

States

UNU-MERIT Dissertation Series, № 62 


\section{Asel Doranova}

Technology Transfer and Learning

under the Kyoto Regime: Exploring the Technological Impact of CDM Projects in Developing Countries

UNU-MERIT Dissertation Series, № 61

\section{Florian Tomini}

Between Family and Friend:

Understanding the Interdependency of Private Transfers

MGSoG Dissertation Series, № 15

\section{Michał Polalowski}

The Institutional Transformation of

Social Policy in East Central Europe:

Poland and Hungary in Comparative and Historical Perspective

MGSoG Dissertation Series, № 14

\section{Maha Ahmed}

Defining, Measuring and Addressing Vulnerability: The Case of Post

Conflict Environments

MGSoG Dissertation Series, № 13

\section{Pascal Beckers}

Local Space and Economic Success:

The Role of Spatial Segregation of

Migrants in the Netherlands

MGSoG Dissertation Series, № 12

\section{Victor Cebotari}

Conflicting Demands in Ethnically

Diverse Societies: Ethno political

Contention and Identity Values in

Europe

MGSoG Dissertation Series, № 11

\section{Dennis Gyllensporre}

Competing and Complementary

Perspectives on the EU as a Crisis

Management Actor:

An Examination of the Common

Security and Defence Policy through

the Lenses of Idealism and Realism

MGSoG Dissertation Series, № 10

\section{Judit Vall Castello}

Business Cycle and Policy Effects on Labour Market Transitions of Older and Disabled Workers in Spain

MGSoG Dissertation Series, № 9

\section{Keetie Roelen}

False Positives or Hidden Dimensions:

The Definition and Measurement of

Child Poverty

MGSoG Dissertation Series, № 8

\section{Denisa Maria Sologon}

Earning Dynamics in Europe

MGSoG Dissertation Series, № 7

\section{Melissa Siegel}

Money and Mobility: Migration and

Remittances

MGSoG Dissertation Series, № 6

\section{Jessica S. Hagen-Zanker}

Modest Expectations: Causes and

Effects of Migration on Migrant

Households inSource Countries

MGSoG Dissertation Series, № 5 


\section{Alexis Habiyaremye}

From Primary Commodity Dependence to Diversification and Growth:

Absorptive Capacity and Technological Catch Up in Botswana and Mauritius. UNU-MERIT Dissertation Series, № 60

\section{Yoseph Getachew}

The Role of Public Capital in Economic Development

UNU-MERIT Dissertation Series, № 59

\section{Sandra Leitner}

Embodied Technological Change and Patterns of Investment in Austrian

Manufacturing

UNU-MERIT Dissertation Series, № 58

\section{Semih Akçomak}

The Impact of Social Capital on Economic and Social Outcomes UNU-MERIT Dissertation Series, № 57

\section{Abraham Garcia}

The Role of Demand in Technical Change

UNU-MERIT Dissertation Series, № 56

\section{Saurabh Arora}

Coherence in Socio-technical Systems: A Network Perspective on the Innovation Process UNU-MERIT Dissertation Series, № 55
Human Development and Autonomy in Project Aid: Experiences from four bilateral projects in Nicaragua and $E l$ Salvador

MGSoG Dissertation Series, № 4

\section{Christiane Arndt}

Governance Indicators

MGSoG Dissertation Series, № 3

\section{Britta Augsburg}

Microfinance: Greater Good or Lesser Evil?

MGSoG Dissertation Series, № 2

2008

\section{Rutger Daems}

Medicines for the Developing World UNU-MERIT Dissertation Series, № 54

\section{Johannes Hanel}

Assessing Induced Technology:

Sombart's Understanding of Technical

Change in the History of Economics

UNU-MERIT Dissertation Series, № 53

\section{Rifka Weehuizen}

Mental Capital: the Economic Significance of Mental Health UNU-MERIT Dissertation Series, № 52 


\section{Danielle Cloodt}

The Relationship between RED

Partnership Formation, Social

Embeddedness and Innovative

Performance

UNU-MERIT Dissertation Series, № 51

\section{Sabine Fuss}

Sustainable Energy Development

under Uncertainty

UNU-MERIT Dissertation Series,

№ 50

\section{Geranda Notten}

Measuring and Managing Poverty

Risks

MGSoG Dissertation Series, № 1

2007

\section{Tobias Kronenberg}

Reconciling Environmental

Conservation with Economic

Prosperity: The Feasibility of Double

Dividends in the Short and Long Run

UNU-MERIT Dissertation Series, № 49

\section{Viktoria Kravtsova}

Assessing the Impact of Foreign Direct Investment in Transition Economies UNU-MERIT Dissertation Series, № 48

\section{Suhail Sultan}

The Competitive Advantage of Small and Medium Sized Enterprises: The Case of Jordan's Natural Stone Industry UNU-MERIT Dissertation Series, № 47

2006

\section{Bulat Sanditov}

Essays on Social Learning and

Imitation

UNU-MERIT Dissertation Series, № 46

\section{Mamata Parhi}

Dynamics of New Technology Diffusion: A Study of the Indian Automotive Industry UNU-MERIT Dissertation Series, № 45

\section{Andreas Reinstaller}

Social Structures and the Innovation Process: Their Role in the Demand of Firms and Consumers

UNU-MERIT Dissertation Series, № 44

\section{Rose Kiggundu}

Innovation systems and Development: The Journey of a Beleaguered Nile Perch Fishery in Uganda UNU-MERIT Dissertation Series, № 43 


\section{Thomas Pogue}

The Evolution of Research

Collaboration in South African Gold

Mining: 1886-1933

UNU-MERIT Dissertation Series, № 42

\section{Geoffrey Gachino}

Foreign Direct Investment, Spillovers and Innovation: The Case of Kenyan

Manufacturing Industry

UNU-MERIT Dissertation Series, № 41

\section{Önder Nomaler}

Technological Change, International

Trade and Growth: An Evolutionary, Multi-Agents-Based Modeling

Approach

UNU-MERIT Dissertation Series, № 40

2005

Samia Satti Osman Mohamed-

Nour

Change and Skill Development in the Arab Gulf Countries

UNU-MERIT Dissertation Series, № 39

\section{Elad Harison}

Intellectual Property Rights:

Economics and Policy Analysis

UNU-MERIT Dissertation Series, № 38

\section{Daniel Dalohoun}

Learning to innovate: agricultural innovation and entrepreneurship: the case of Songhaï farmers in Benin UNU-MERIT Dissertation Series, № 37

\section{Müge Ozman}

Networks, Organizations and

Knowledge

UNU-MERIT Dissertation Series, № 36

\section{Bas Straathof}

Product Variety and Economic

Growth: The Counteracting Effects of

Scale and Idiosyncrasy

UNU-MERIT Dissertation Series, № 35

\section{Wilfred Schoenmakers}

Knowledge Flows between

Multinational Companies: A Patent

Data Analysis

UNU-MERIT Dissertation Series, № 34

\section{Myriam Cloodt}

Mergers and Acquisitions ( $M$ and As) in High-Tech Industries: Measuring the Post-M and A Innovative Performance of Companies UNU-MERIT Dissertation Series, № 33 
2004

\section{Paola Criscuolo}

$R \mathcal{E D}$ Internationalisation and

Knowledge Transfer: Impact on MNEs and their Home Countries

UNU-MERIT Dissertation Series, № 32

\section{Maarten Verkerk}

Trust and Power on the Shop Floor UNU-MERIT Dissertation Series, № 31

\section{Gottfried Leibbrandt}

Adoption, Harmonization and

Succession of Network Technologies across Countries

UNU-MERIT Dissertation Series, № 30

\section{Mark Sanders}

Skill Biased Technical change: Its Origins, the Interaction with the Labour Market and Policy Implications UNU-MERIT Dissertation Series, № 29

2003

\section{Nadine Roijakkers}

Inter-firm Cooperation in High-tech Industries: a Study of RED

Partnerships in Pharmaceutical

Biotechnology

UNU-MERIT Dissertation Series, № 28
Viki Sonntag

Speed, Scale and Sustainability

UNU-MERIT Dissertation Series, № 27

\section{Masaru Yarime}

From End-of-Pipe Technology to Clean Technology

UNU-MERIT Dissertation Series, № 26

\section{Stéphane Malo}

The Combinatorial Chemistry

Revolution: Sustaining a Superior

Performance Position through

Technological Learning

UNU-MERIT Dissertation Series, № 25

2002

\section{Annelies Hogenbirk}

Determinants of Inward Foreign

Direct Investment: the Case of the

Netherlands

UNU-MERIT Dissertation Series, № 24

\section{Bastiaan Johan terWeel}

The Computerization of the Labour Market

UNU-MERIT Dissertation Series 


\section{Marjolein Caniëls}

Regional Growth Differentials: The

\section{John Adeoti}

Technology Investment in Pollution Control in Sub-Saharan Africa: The

Case of the Nigerian Manufacturing Industry

UNU-MERIT Dissertation Series, № 23

\section{Edward Huizenga}

Innovation Management: How

Frontrunners Stay Ahead: An

Empirical Study on Key Success

Factors in the ICT sector

UNU-MERIT Dissertation Series, № 22

2000

\section{Machiel van Dijk}

Technological Change and the

Dynamics of Industries: Theoretical Issues and Empirical evidence from

Dutch Manufacturing

UNU-MERIT Dissertation Series, № 21

1999

\section{Jan Cobbenhagen}

Managing Innovation at the Company Level: A Study on Non-Sector-Specific Success Factors

UNU-MERIT Dissertation Series, № 20
Impact of Locally Bounded Knowledge

Spillovers

UNU-MERIT Dissertation Series, № 19

\section{8}

\author{
Aldo Geuna \\ Resource Allocation and Knowledge \\ production: Studies in the Economics \\ of University Research \\ UNU-MERIT Dissertation Series, \\ № 18
}

\section{6}

\section{Reinoud Joosten}

Dynamics, Equilibria, and Values UNU-MERIT Dissertation Series, № 17

\section{Hugo Kruiniger}

Investment, $R \mathcal{E} D$, and the Financing

Decisions of the Firm

UNU-MERIT Dissertation Series, № 16

\section{5}

\section{Hans van Meijl}

Endogenous Technological Change:

The Case of Information Technology, Theoretical Considerations and

Empirical Results

UNU-MERIT Dissertation Series, № 15 


\section{René Kemp}

Environmental Policy and Technical

Change: A Comparison of the

Technological Impact of Policy

Instruments

UNU-MERIT Dissertation Series, № 14

\section{Rohini Acharya}

The Impact of New Technologies on

Economic Growth and Trade: A Case

Study of Biotechnology

UNU-MERIT Dissertation Series,

№ 13

\section{Geert Duysters}

The Evolution of Complex Industrial Systems: The Dynamics of Major IT Sectors

UNU-MERIT Dissertation Series, № 12

\section{Marjan Groen}

Technology, Work and Organisation: A Study of the Nursing Process in Intensive Care Units

UNU-MERIT Dissertation Series, № 11

1994

\section{Huub Meijers}

On the Diffusion of Technologies in a Vintage Framework: Theoretical Considerations and Empirical Results UNU-MERIT Dissertation Series, № 10

\section{Theon van Dijk}

The Limits of Patent Protection: Essays on the Economics of Intellectual

Property Rights

UNU-MERIT Dissertation Series, № 9

\section{Hans Voordijk}

Naar Integrale Logistiek in

Bedrijfsketens: Ontwikkelingen in de Bouw

UNU-MERIT Dissertation Series, № 8

\section{3}

\section{Paul Diederen}

Technological Progress in Enterprises and Diffusion of Innovation:

Theoretical Reflections and Empirical Evidence

UNU-MERIT Dissertation Series, № 7

\section{Ben Dankbaar}

Economic Crisis and Institutional Change: The Crisis of Fordism from the Perspective of the Automobile Industry UNU-MERIT Dissertation Series, № 6

\section{Hanno Roberts}

Accountability and Responsibility: The Influence of Organisation Design on Management Accounting UNU-MERIT Dissertation Series, № 5 


\section{Bart Verspagen}

Uneven Growth between

Interdependent Economies: An

Evolutionary View on Technology

Gaps, Trade and Growth

UNU-MERIT Dissertation Series,

№ 4

\section{Sjoerd Romme}

A Self-organization Perspective on

Strategy Formation

UNU-MERIT Dissertation Series,

№ 3

1989

John Spangenberg

Economies of Scale, and Atmosphere in

Research Organisations

UNU-MERIT Dissertation Series,

№ 2

1988

John Hagedoorn

Evolutionary and Heterodox

Innovation Analysis: A Study of

Industrial and Technological

Development in Process Control and

Information Technology

UNU-MERIT Dissertation Series, № 1 




$$
\begin{aligned}
& \begin{array}{c}
\odot=\cdots \\
0, \cdots
\end{array} \\
& \begin{array}{l}
0=-\cdots \\
\ldots-\cdots
\end{array} \\
& \begin{array}{r}
-\infty \\
+\infty \\
+\infty
\end{array} \\
& +\infty<+\infty \\
& \text {. }
\end{aligned}
$$
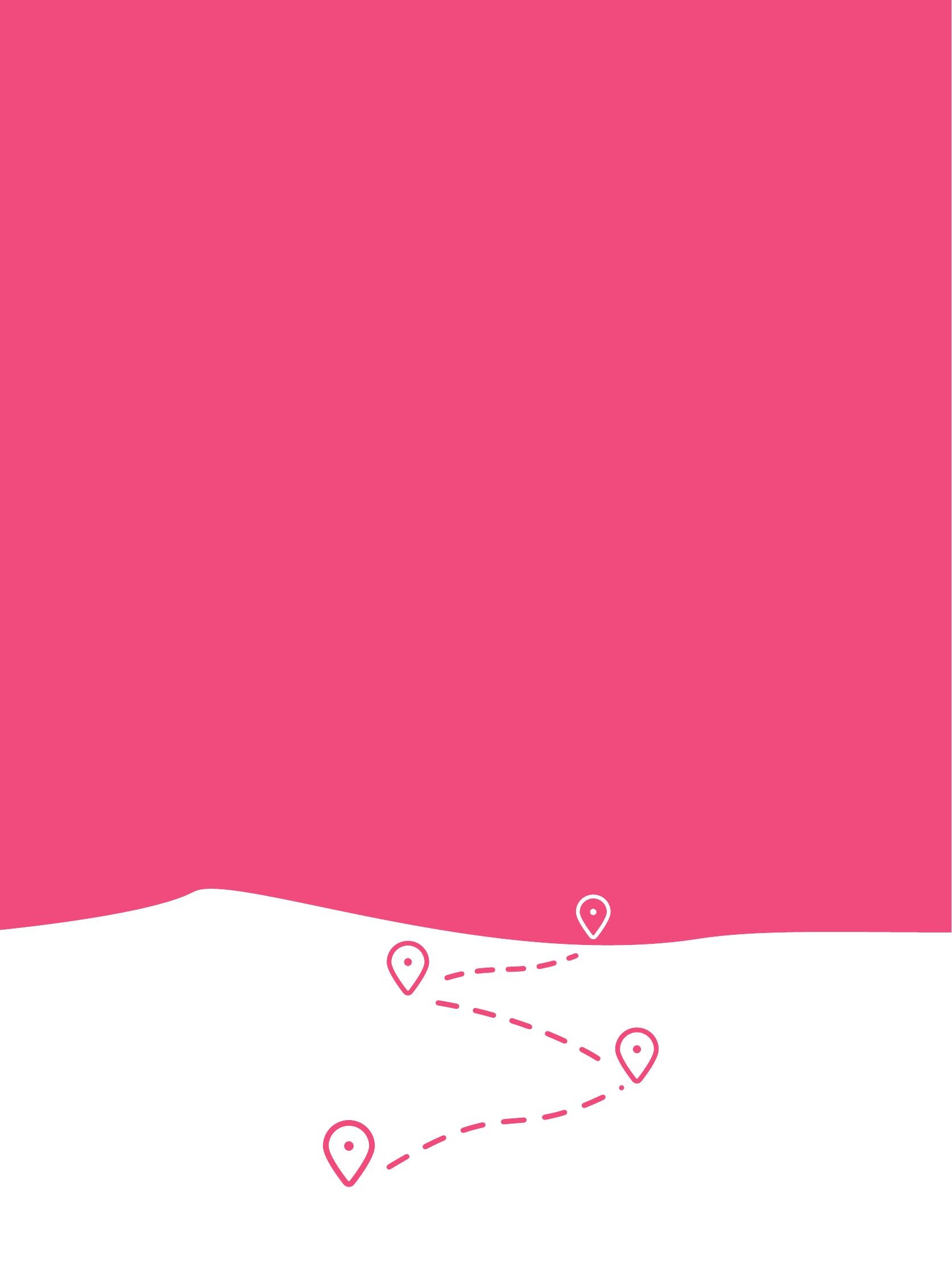